Portland State University

PDXScholar

\title{
Addressing Changing Demographics in Environmental Justice Analysis, State of Practice
}

\author{
Aaron Golub \\ Portland State University, agolub@pdx.edu \\ Les Brown \\ ICF International \\ Michael Grant \\ ICF International \\ Nathan McNeil \\ Portland State University, nmcneil@pdx.edu \\ Charles Ryerson \\ Portland State University
}

See next page for additional authors

Follow this and additional works at: https://pdxscholar.library.pdx.edu/trec_reports

Part of the Transportation Commons, Urban Studies Commons, and the Urban Studies and Planning Commons

Let us know how access to this document benefits you.

\section{Recommended Citation}

Golub, A., Brown, L., Grant, M., McNeil, N., Ryerson, C., Gray, M., Lonsdale, S., Levy, M., Addressing Changing Demographics in Environmental Justice Analysis, State of Practice. Report No. FHWAHEP-19-021. https://doi.org/10.15760/trec.216

This Report is brought to you for free and open access. It has been accepted for inclusion in TREC Final Reports by an authorized administrator of PDXScholar. Please contact us if we can make this document more accessible: pdxscholar@pdx.edu. 


\section{Authors}

Aaron Golub, Les Brown, Michael Grant, Nathan McNeil, Charles Ryerson, Matt Gray, Stephanie Lonsdale, and Madison Levy 


\section{Addressing Changing Demographics in Environmental Justice Analysis, State of Practice}

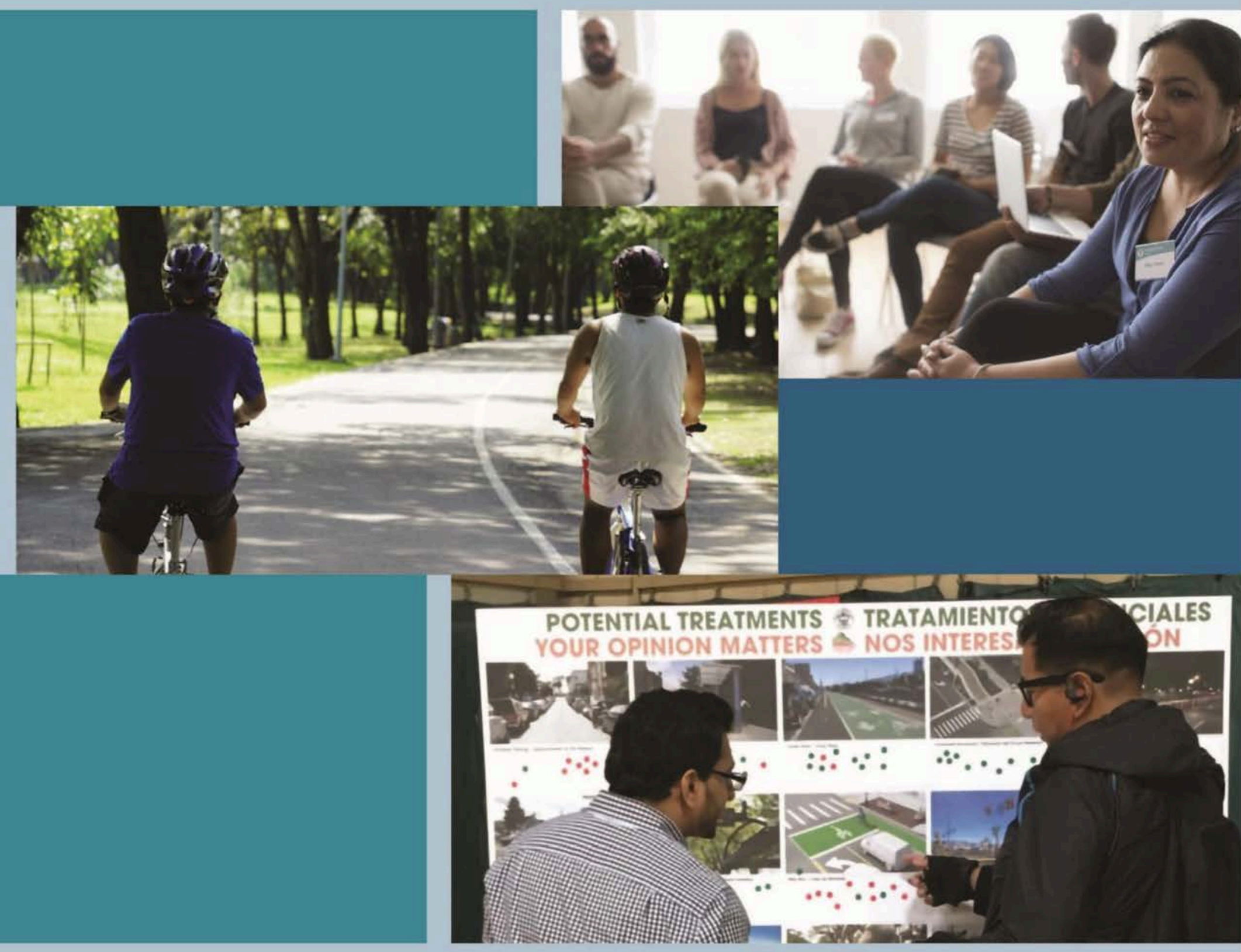

(2)

U.S.Department of Transportation

Federal Highway Administration 
Technical Report Documentation Page

\begin{tabular}{|c|c|c|c|c|c|}
\hline $\begin{array}{l}\text { 1. Report No. } \\
\text { FHWA-HEP-19-021 }\end{array}$ & \multicolumn{2}{|c|}{ 2. Government Accession No. } & \multicolumn{3}{|c|}{ 3. Recipient's Catalog No. } \\
\hline \multicolumn{3}{|l|}{ 4. Title and Subtitle } & \multicolumn{3}{|c|}{$\begin{array}{l}\text { 5. Report Date } \\
\text { February } 2019\end{array}$} \\
\hline \multicolumn{3}{|c|}{$\begin{array}{l}\text { Addressing Changing Demographics in Environmental Justice Analysis, State } \\
\text { of Practice }\end{array}$} & \multicolumn{3}{|c|}{ 6. Performing Organization Code } \\
\hline \multicolumn{3}{|c|}{$\begin{array}{l}\text { 7. Authors } \\
\text { Aaron Golub (Portland State University), Les Brown (ICF), Michael Grant } \\
\text { (ICF), Nathan McNeil (Portland State University), Charles Ryerson (Portland } \\
\text { State University), Matt Gray (Portland State University), Stephanie Lonsdale } \\
\text { (Portland State University), Madison Levy (Portland State University) }\end{array}$} & \multicolumn{3}{|c|}{$\begin{array}{l}\text { 8. Performing Organization Report } \\
\text { No. }\end{array}$} \\
\hline \multirow{2}{*}{\multicolumn{3}{|c|}{ 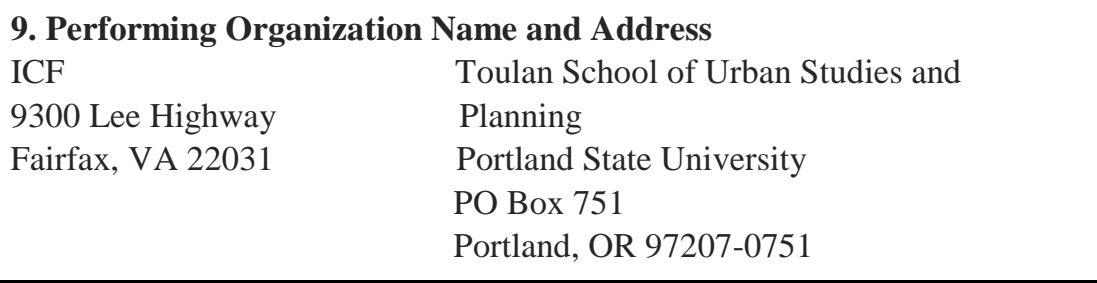 }} & \multicolumn{3}{|c|}{ 10. Work Unit No. (TRAIS) } \\
\hline & & & \multicolumn{3}{|c|}{$\begin{array}{l}\text { 11. Contract or Grant No. } \\
\text { DTFH61-17-D-00010 }\end{array}$} \\
\hline \multirow{2}{*}{\multicolumn{3}{|c|}{$\begin{array}{l}\text { 12. Sponsoring Agency Name and Address } \\
\text { United States Department of Transportation } \\
\text { Federal Highway Administration } \\
\text { 1200 New Jersey Ave. SE } \\
\text { Washington, DC } 20590\end{array}$}} & \multicolumn{3}{|c|}{$\begin{array}{l}\text { 13. Type of Report and Period } \\
\text { Covered } \\
\text { September 2017- December } 2018\end{array}$} \\
\hline & & & \multicolumn{3}{|c|}{$\begin{array}{l}\text { 14. Sponsoring Agency Code } \\
\text { HEPH }\end{array}$} \\
\hline \multicolumn{6}{|c|}{$\begin{array}{l}\text { 15. Supplementary Notes } \\
\text { Fleming A. El-Amin II, Federal Highway Administration, TOCOR }\end{array}$} \\
\hline \multicolumn{6}{|c|}{$\begin{array}{l}\text { 16. Abstract } \\
\text { This report documents how metropolitan planning organizations (MPO), State departments of transportation (DOT), and } \\
\text { other transportation agencies are adapting Environmental Justice (EJ) analysis techniques to understand transportation } \\
\text { impacts in communities undergoing rapid demographic change. The report also highlights national demographic trends, } \\
\text { showing significant change in the size and location of low-income and minority households. These changes are } \\
\text { documented in a series of State- and county-level maps demonstrating absolute and percent change in minority } \\
\text { populations, low-income populations and limited English proficiency populations between the } 1990 \text { - } 2010 \text { decennial } \\
\text { census periods. Based on the state of practice review, the report also highlights strategies for addressing changing } \\
\text { demographics in EJ analysis and provides five case studies that document best practices from State DOTs and MPOs in } \\
\text { areas undergoing rapid demographic change. Practices highlighted in this report offer practitioners improved methods for } \\
\text { understanding and responding to demographic change in EJ communities across the lifecycle of a transportation action. }\end{array}$} \\
\hline \multicolumn{2}{|c|}{$\begin{array}{l}\text { 17. Key Words } \\
\text { Demographics, changing demographics, environmental } \\
\text { justice, EJ, transportation decision-making, long-range } \\
\text { transportation planning, project development, demographic } \\
\text { forecasting }\end{array}$} & \multicolumn{4}{|c|}{$\begin{array}{l}\text { 18. Distribution Statement } \\
\text { No restrictions. This document is available to the public } \\
\text { from the National Technical Information Service, } \\
\text { Springfield, VA } 22161 .\end{array}$} \\
\hline $\begin{array}{l}\text { 19. Security Classif. (of this report) } \\
\text { Unclassified }\end{array}$ & $\begin{array}{l}\text { 20. Security } \\
\text { Unclassified }\end{array}$ & sssif. (of this pa & & $\begin{array}{l}\text { 21. No. of Pages } \\
170\end{array}$ & $\begin{array}{l}\text { 22. Price } \\
\text { N/A }\end{array}$ \\
\hline
\end{tabular}

Form DOT F 1700.7 (8-72) $\quad$ Reproduction of completed page authorize 


\section{NOTICE}

This document is disseminated under the sponsorship of the U.S. Department of

Transportation in the interest of information exchange. The U.S. Government assumes no liability for the use of the information contained in this document.

The U.S. Government does not endorse products or manufacturers. Trademarks or manufacturers' names appear in this report only because they are considered essential to the objective of this document. The contents of this report reflect the views of the authors, who are responsible for the facts and accuracy of the data presented herein.

The contents do not necessarily reflect the official policy of the U.S. Department of Transportation. This report does not constitute a standard, specification, or regulation.

Images in the report are intended to serve as examples of the range of real-world existing conditions; they are not limited to best practices or approved designs or behaviors and, in some cases, may reflect conditions that are not recommended.

Publication Number: FHWA-HEP-19-021 


\section{ACKNOWLEDGMENTS}

\section{FHWA PROJECT MANAGERS AND TECHNICAL LEADS}

Emily Biondi, Camille Bonham, Fleming El-Amin, James Esselman, Brian Gardner, Joseph Hausman, Erich Hines, Felicia James, Gary Jensen, Antonio Johnson, David Kuehn, Jody McCullough, Harlan Miller, Carolyn Nelson, Harold Peaks, Kenneth Petty, Jeremy Raw, Kevin Resler, Shari Schaftlein, Mary Ridgeway, Joi Singh, Valentin Vulov, Cheng Yan, and Robert Washington

\section{SUBJECT MATTER EXPERT PANEL}

Rusty Ennemoser, Florida Department of

Transportation

Nick Gill, Mid-Ohio Regional Planning

Commission (Columbus, $\mathrm{OH}$ )

Tanisha Hall, Tennessee Department of

Transportation

Daniel Holland, Metroplan (Little Rock, AR)

Susan Markman, Metroplan (Little Rock, AR)
Harrison Marshall, North Carolina Department of Transportation

Melissa Roberts, Atlanta Regional Commission

Vikrant Sood, Metropolitan Transportation Commission (San Francisco Bay Area)

Tammy Vrana, Vrana Consulting, Inc.

\section{OTHER CONTRIBUTORS}

In addition to agency staff who participated on the Subject Matter Expert panel, the project team would like to acknowledge contributions from Grace Cho at Metro (Portland, OR), Tyler Deke at Bend Metropolitan Planning Organization (Bend, OR), and Colby Lancelin at Atlanta Regional Commission.

\section{COVER PHOTOS}

Photo credits (top to bottom): woman at meeting (Shutterstock); bicyclists (Shutterstock); men in front of poster board (@Fitzgerald \& Halliday, Inc.). 


\section{TABLE OF CONTENTS}

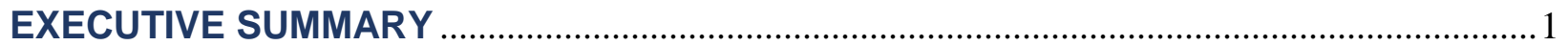

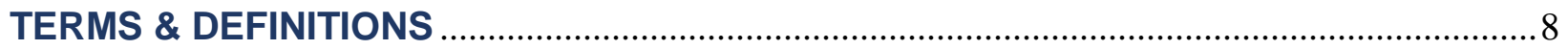

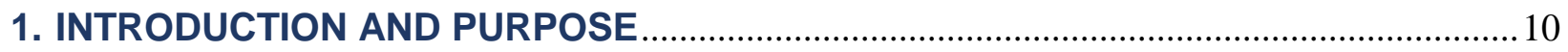

Context and Background.................................................................................................... 10

Purpose and Study Approach.............................................................................................. 12

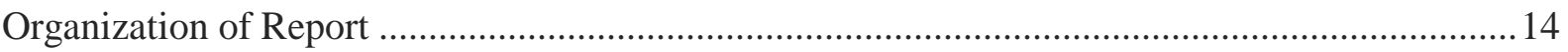

2. CHANGING DEMOGRAPHICS: TRENDS AND FORECASTS ........................................15

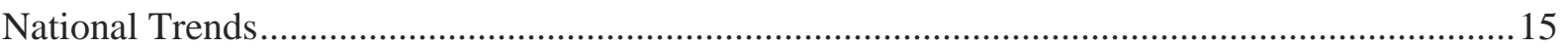

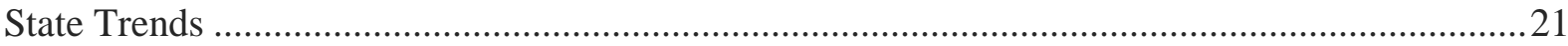

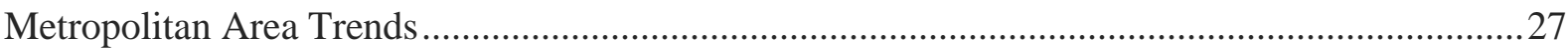

Small Urban and Rural Area Trends.................................................................................... 30

Key Takeaways .................................................................................................................. 32

3. CONSIDERATIONS OF CHANGING DEMOGRAPHICS:

STATE OF THE PRACTICE AND NOTABLE PRACTICES ……........................................

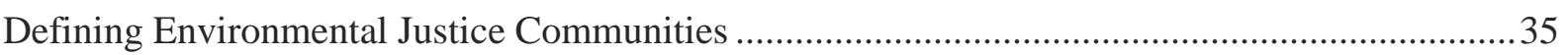

Identifying Geographic Locations of Environmental Justice Communities ....................................36

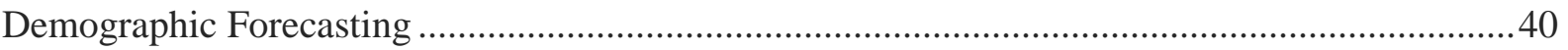

Environmental Justice Analysis Methods ................................................................................. 52

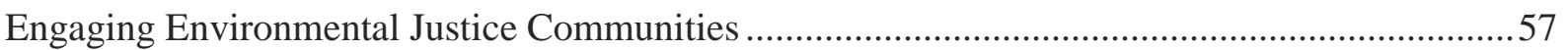

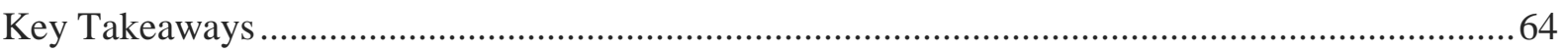

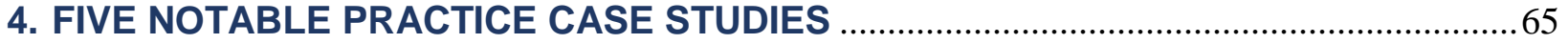

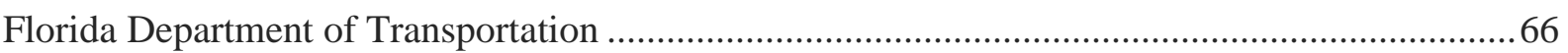

Mid-Ohio Regional Planning Commission............................................................................... 74

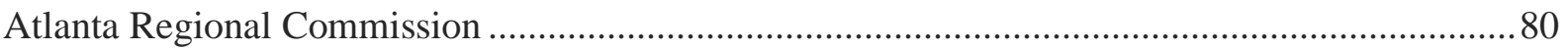

Metropolitan Transportation Commission ............................................................................... 88

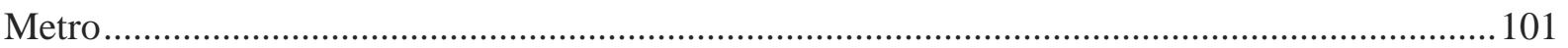

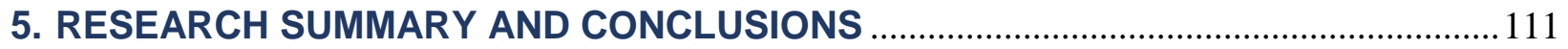

6. REFERENCES...............................................................................................................117

APPENDIX A: NATIONAL DEMOGRAPHIC CHANGE MAPS ………..............................

APPENDIX B: CASE STUDY MSA DEMOGRAPHIC CHANGE MAPS …………................ 


\section{EXECUTIVE SUMMARY}

Executive Order (EO) 12898: Federal Actions to Address Environmental Justice in Minority Populations and Low-Income Populations (59 FR 7629; 1994) directs each Federal agency to develop a strategy for identifying and addressing disproportionately high and adverse human health or environmental effects on low-income populations and minority populations. EO 12898 is informed by nondiscrimination principles found in Title VI of the Civil Rights Act of 1964, a Federal statute that prohibits discrimination based on race, color, and national origin in programs and activities receiving Federal financial assistance. Title VI provides that "No person in the United States shall, on the ground of race, color, or national origin, be excluded from participation in, be denied the benefits of, or be subjected to discrimination under any program or activity receiving Federal financial assistance."

The Federal Highway Administration (FHWA) advances Environmental Justice (EJ) through its numerous policies, programs, and activities. It is FHWA's policy to identify and prevent discriminatory effects by actively administering its programs, policies, and activities to ensure that social impacts to communities and people are recognized early and continually throughout the transportation decision-making process from early planning through implementation and operations.

FHWA supports the U.S. DOT EJ principles, which are as follows:

- To avoid, minimize, or mitigate disproportionately high and adverse human health or environmental effects, including social and economic effects, on minority populations and low-income populations.

- To ensure the full and fair participation by all potentially affected communities in the transportation decision-making process.

- To prevent the denial of, reduction in, or significant delay in the receipt of benefits by minority populations and low-income populations.

Implementation of these principles are supported by the U.S. DOT Environmental Justice Order 5610.2(a); U.S. DOT Environmental Justice Strategy; FHWA Order 6640.23A: Actions to Address on Environmental Justice in Minority Populations and Low-Income Populations; and FHWA's Guidance on Environmental Justice and NEPA Memorandum.

The purpose of this Study is to provide information on changing demographics in the U.S. and discuss implications for transportation practitioners as it relates to identifying low-income and minority populations and addressing adverse effects and disproportionately high and adverse effects on those population groups. The research highlights national demographic trends and notable practices for addressing the transportation needs of low-income and minority populations based on an understanding of the current pattern and rate of demographic change. This report does not establish any new requirements or replace any existing guidance.

For the purposes of this report, the analysis of low-income populations and minority populations (EJ analysis) involves identifying potential adverse and disproportionately high and adverse effects on 
these population groups, and undertaking efforts to avoid, minimize, or mitigate those potential effects. EJ analysis also involves efforts to ensure the full and fair participation of all potentially affected communities in the decision-making process. Further, EJ analysis seeks to prevent minority populations and low-income populations from being denied benefits, receiving reduced benefits, or experiencing delays in receiving benefits.

Effective EJ analysis relies on an accurate understanding of the demographics of impacted populations. An emerging issue across the United States at various jurisdictional scales is the rapid pace of demographic change, especially regarding minority populations and low-income populations — often referred to as "EJ populations." Overall, the percentage of the U.S. population that is non-Hispanic white dropped from 80 percent in 1980 to about 63 percent in 2018 and is projected to be less than 44 percent by 2060. Between 1990 and 2010, for instance, Fayetteville, Arkansas experienced a 10-fold increase in its minority population, while the New York City metropolitan area gained more than 3 million minority residents (and lost more than 1 million white residents). Such rapidly changing demographics could affect the ability to understand the impacts of transportation projects and actions on EJ populations and raises questions about how to assess the potential for disproportionately high and adverse effects on these populations.

To help improve the state of the practice for EJ analysis, this study addresses the overarching questions of: What is the state of the practice in conducting EJ analysis in communities undergoing rapid demographic change? and What are best practices for considering changing demographics when conducting an EJ analysis during various phases of transportation decision-making? The report addresses these questions in three stages:

1. An exploration of national demographic trends focused on changes in EJ populations, augmented by an analysis of 20 selected study areas (10 States and 10 metropolitan areas);

2. A broad review of existing planning and project development practices, case studies, and other related literature to identify the current state of the practice; and

3. An exploration of best practices associated with EJ analysis in the context of demographic change, accompanied by five detailed case studies.

National demographic trends and projected changes are provided in the report to 2060. Overall, growth in the U.S. population is expected to continue, most notably in the West and South, continuing recent patterns. Moreover, the United States is projected to continue to become more diverse, with substantial growth in the total number and share of minority populations ${ }^{1}$ over the coming decades. Immigration is expected to continue to be a major component of population growth

\footnotetext{
${ }^{1}$ The EJ Orders of the Federal Highway Administration (FHWA) and U.S. Department of Transportation (USDOT) define a "minority" individual as a person who is: (1) black: a person having origins in any of the black racial groups of Africa; (2) Hispanic or Latino: a person of Mexican, Puerto Rican, Cuban, Central or South American, or other Spanish culture or origin, regardless of race; (3) Asian American: a person having origins in any of the original peoples of the Far East, Southeast Asia, or the Indian subcontinent; (4) American Indian and Alaskan Native: a person having origins in any of the original people of North America, South America (including Central America) and who maintains cultural identification through Tribal affiliation or community recognition; or (5) Native Hawaiian and Other Pacific Islander: a person having origins in any of the original peoples of Hawaii, Guam, Samoa, or other Pacific Islands. Persons who identify as two or more races (mixed race) are considered minority for the purposes of this report so long as self-identification includes the ethnicity, national origin, or race as provided above.
} 
and residential location shifts in the United States, although Federal policy toward immigration may impact the expected growth trajectory. The number of foreign-born residents has increased substantially over the past two decades to more than 13 percent of the population and is projected to comprise nearly 19 percent of the population in 2060.

Overall, the Nation's poverty rate, or share of the population below the Federally-defined poverty income threshold, has fluctuated between 10 and 15 percent for the past several decades; an additional 4 to 5 percent of the population are near poverty, with annual household incomes between 100 and 125 percent of the Federal poverty threshold. ${ }^{2}$ The share of the population in poverty varies substantially across different geographic areas, and some communities have experienced substantial changes in income profiles. Moreover, shifts in preferences for housing type and location toward central, accessible locations has resulted in gentrification of neighborhoods in many urban areas of the country. Gentrification can displace EJ populations and put pressure on those low-income populations who struggle to afford increasing rents and housing prices. Transportation practitioners are beginning to understand how transportation investments can influence these phenomena and working with other agencies, such as housing or land use, to develop responses to these issues.

As noted above, this report first provides a review of national demographics literature and then presents an analysis of states and metro areas that have witnessed rapid demographic change. The review of existing EJ analysis practices did not make extensive findings on the approaches State DOTs, metropolitan planning organizations (MPOs), or other agencies apply to explicitly address the issue of changing demographics within EJ analysis. Although some States and MPOs are forecasting demographic changes as part of long-range planning, the uncertainties associated with demographic change makes explicitly accounting for these changes within EJ analysis challenging. The review found that demographic change is most likely to be explored during the transportation planning process, which involves long-range forecasting. The review also found that demographic change is not typically examined within programming, project development, or environmental review under the National Environmental Policy Act (NEPA), aside from describing historical context.

Despite the limited explicit consideration of demographic changes, the review highlighted several best practices that can help transportation agencies better understand and respond to rapid community change within the framework of transportation decision-making (Table 1). These practices combine both quantitative and qualitative approaches to understanding communities so that change can be recognized without having to rely solely on data sources that are updated only intermittently, such as the U.S. Census and American Community Survey (ACS). These practices include effective approaches for:

1. Identifying the geographic locations of EJ communities, based on different types of metrics or approaches;

2. Working with stakeholders, agencies, and relevant data from outside traditional transportation areas to augment understandings of community change;

${ }^{2}$ Census Bureau Table HSTPOV6 https://www2.census.gov/programs-surveys/cps/tables/time-series/historical-povertypeople/hstpov6.xls. 
3. Forecasting demographic and income changes, including predicting potential displacement and gentrification;

4. Analyzing potential disproportionate impacts to EJ populations; and

5. Engaging EJ communities in ways that can respond to community changes, including innovative partnerships and engagement techniques.

Five case studies were developed that exemplify some of these innovations and best practices. The case studies focus on four MPOs and one State DOT:

- Metro, Portland, Oregon metropolitan area.

- Metropolitan Transportation Commission (MTC), San Francisco Bay Area.

- Mid-Ohio Regional Planning Commission (MORPC), Columbus, Ohio metropolitan area).

- Atlanta Regional Commission (ARC).

- Florida Department of Transportation (FDOT).

The Metro and MTC cases demonstrate why improvements in long-range transportation plans and EJ population forecasts are especially important in assessing conditions of rapid community change. Both MPOs focus attention on displacement and gentrification using techniques that provide improved understanding of the shifting demographics of EJ populations. These techniques then inform policies and mitigation approaches for preventing unwanted economic displacement due to transportation projects. MORPC uses a unique "population-based” approach in its EJ analysis of potential transportation impacts from its long-range plan that measures aggregate impacts of transportation actions on different populations at the regional scale. ARC conducts an innovative stakeholder engagement process as part of its forecasting and modeling, while also helping those stakeholders understand the dynamics of change in their own communities. FDOT's Environmental Screening Tool, which is part of its Efficient Transportation Decision-Making framework, stands out as a practice with significant potential to improve EJ analysis and decision-making under conditions of rapid community change. These cases illustrate the broad range of practices that can influence how an agency understands its communities, how that agency can forecast community change, and how its EJ analyses can be improved to better anticipate and respond to demographic change.

Although many agencies have not explicitly considered the issue of changing demographics as it relates to EJ analysis, some are using public engagement practices to help understand and respond to such changes. Attention is needed to examine spatial and temporal dynamics of community change. Practices highlighted in this report offer practitioners improved methods for understanding and responding to change in EJ communities over time. In conditions of rapid change, this understanding is key to identifying potential disproportionately high and adverse effects of transportation actions on EJ populations and to undertaking efforts to avoid, minimize, or mitigate those potential impacts. 
Table 1. State and MPO notable practices for considering rapid demographic change in environmental justice analysis.

\begin{tabular}{|c|c|}
\hline State or MPO & Notable Practice \\
\hline $\begin{array}{l}\text { Atlanta Regional } \\
\text { Commission (ARC) }\end{array}$ & $\begin{array}{l}\text { - Measured the significance of a census tract’s demographic } \\
\text { characteristics by standard deviations above the regional } \\
\text { average for that demographic characteristic to avoid } \\
\text { diminishing analysis results of communities classified as EJ } \\
\text { (p. 38). } \\
\text { - Undertook a "small area outreach" approach with } \\
\text { stakeholders of local jurisdictions to provide feedback to } \\
\text { ARC about potentially missing critical data for their } \\
\text { forecasting tools (p. 46) } \\
\text { - Undertook an outcome based approach using surveys of non- } \\
\text { project-specific communities to obtain local perspectives of } \\
\text { how the agency is meeting equity goals concerning project } \\
\text { distribution, access, and benefits and burdens. (p. 59) } \\
\text { - Formed a Global Advisory Panel of } 150 \text { foreign-born } \\
\text { residents who helped ARC to gather notes and survey data } \\
\text { that informed the Atlanta Region's Long-Range } \\
\text { Transportation Plan (p. 59). }\end{array}$ \\
\hline Bend MPO & $\begin{array}{l}\text { Engaged in a joint funding and outreach effort with the City of Bend } \\
\text { to improve outreach to the area's growing Hispanic communities } \\
\text { (p. 32). }\end{array}$ \\
\hline Florida DOT (FDOT) & $\begin{array}{l}\text { Used the Efficient Transportation Decision-making (ETDM) } \\
\text { initiative to enhance stakeholder access to planning data and } \\
\text { documents and provided a forum for soliciting feedback (p. 60). }\end{array}$ \\
\hline Georgia DOT (GDOT) & $\begin{array}{l}\text { Convened a committee of citizens for input and feedback on } \\
\text { decisions for a timeframe longer than the duration of an individual } \\
\text { project review (p. 63). }\end{array}$ \\
\hline $\begin{array}{l}\text { Greater Dalton MPO } \\
\text { (GDMPO) - Whitfield } \\
\text { County and Murray } \\
\text { County in northwestern } \\
\text { Georgia }\end{array}$ & $\begin{array}{l}\text { Used Spanish-language media outreach and "four-factor analysis" to } \\
\text { understand the needs and resources necessary for language services } \\
\text { (p. 32). }\end{array}$ \\
\hline $\begin{array}{l}\text { Houston-Galveston Area } \\
\text { Council (H-GAC) }\end{array}$ & $\begin{array}{l}\text { Surveyed participants from minority, low-income, elderly } \\
\text { populations, limited educational attainment, and zero-automobile } \\
\text { households to better understand needs of underserved populations }\end{array}$ \\
\hline
\end{tabular}




\begin{tabular}{|c|c|}
\hline & $\begin{array}{l}\text { and help prioritize investments within the transportation system (p. } \\
\text { 58). }\end{array}$ \\
\hline $\begin{array}{l}\text { Kentucky } \\
\text { Transportation Cabinet }\end{array}$ & $\begin{array}{l}\text { Obtained information on housing needs and transportation concerns } \\
\text { identified through the community impact assessment process during } \\
\text { development of the Newtown Pike Extension. The process led to } \\
\text { acquisition of affordable rental units through a community land trust } \\
\text { (p. 56). }\end{array}$ \\
\hline Little Rock MPO & $\begin{array}{l}\text { Conducted targeted outreach with local Spanish-speaking } \\
\text { communities and documented feedback received which informed } \\
\text { their decision-making (p. 31). }\end{array}$ \\
\hline $\begin{array}{l}\text { Mid-Ohio Regional } \\
\text { Planning Commission } \\
\text { (MORPC) }\end{array}$ & $\begin{array}{l}\text { Used a population-weighted method to address underrepresentation } \\
\text { of EJ populations that can occur when using threshold-based traffic } \\
\text { analysis zones (TAZ) analyses to measure the impact of a } \\
\text { transportation action (p. 53). }\end{array}$ \\
\hline Memphis MPO & $\begin{array}{l}\text { - Encouraged public participation through ads for meetings on } \\
\text { buses and through YouTube videos featuring mayors from } \\
\text { the jurisdictions in the region (p. 60). } \\
\text { - Leveraged its partnership with local libraries to distribute } \\
\text { printed copies of planning documents throughout the region } \\
\text { to increase engagement with traditionally underserved } \\
\text { residents (p. 60). }\end{array}$ \\
\hline $\begin{array}{l}\text { Metro - Portland, } \\
\text { Oregon metropolitan } \\
\text { area }\end{array}$ & $\begin{array}{l}\text { - Utilized four county-level population growth scenarios by } \\
\text { future racial and ethnic dispersion that resulted in a rare } \\
\text { explicit modeling of the spatial dynamics of race and } \\
\text { ethnicity (p. 50). } \\
\text { - Developed equity analysis methodology models to assess } \\
\text { potential displacement and possible mitigation strategies (p. } \\
\text { 54). } \\
\text { Developed interim forecasts that recognized the rapid pace } \\
\text { of demographic change and emphasized existing } \\
\text { transportation needs and current disparities experienced by } \\
\text { communities (p. 104). }\end{array}$ \\
\hline $\begin{array}{l}\text { Metropolitan } \\
\text { Transportation } \\
\text { Commission (MTC) - } \\
\text { San Francisco Bay Area }\end{array}$ & $\begin{array}{l}\text { - Used an equity analysis that included a “population/use- } \\
\text { based” measure which compares how investments will } \\
\text { benefit EJ communities relative to the region’s total } \\
\text { population and their amount of travel (p. 53). } \\
\text { - Displacement analysis examined housing cost burdened } \\
\text { households with planned housing growth to determine }\end{array}$ \\
\hline
\end{tabular}




\begin{tabular}{|c|c|}
\hline & $\begin{array}{l}\text { vulnerability to future displacement and to inform } \\
\text { investment scenarios (p. 56). }\end{array}$ \\
\hline Nevada DOT (NDOT) & $\begin{array}{l}\text { - Identified stakeholder in various communities and attended } \\
\text { their meetings in lieu of asking them to attend separate } \\
\text { public meetings (p. 62). } \\
\text { Conducted intergovernmental consultation with tribal } \\
\text { governments regarding statewide planning, project } \\
\text { development, and construction impacts (p. 63). }\end{array}$ \\
\hline $\begin{array}{l}\text { New Hampshire DOT } \\
\text { (NHDOT) }\end{array}$ & $\begin{array}{l}\text { Collected extensive demographic data for participants and } \\
\text { beneficiaries of federally-assisted programs to conduct more } \\
\text { accurate analyses of potential project impacts (p. 38). }\end{array}$ \\
\hline $\begin{array}{l}\text { San Diego Association of } \\
\text { Government (SANDAG) }\end{array}$ & $\begin{array}{l}\text { Used a shift-share approach where historical rates of growth in the } \\
\text { subarea are assumed for each ethnic or racial group and then the } \\
\text { population growth in the geography is allocated to each group based } \\
\text { on its share of growth (p. 44). }\end{array}$ \\
\hline $\begin{array}{l}\text { Southern California } \\
\text { Association of } \\
\text { Governments (SCAG) }\end{array}$ & $\begin{array}{l}\text { Held public workshops featuring computer modeling to help the } \\
\text { public visualize possible land use impacts at the parcel level, which } \\
\text { provided higher sensitivity than TAZ-based models (p. 62). }\end{array}$ \\
\hline
\end{tabular}




\section{TERMS \& DEFINITIONS}

Adverse effect - The U.S. DOT and FHWA EJ Orders state that "adverse effects" means the totality of significant individual or cumulative human health or environmental effects, including interrelated social and economic effects, which may include, but are not limited to: bodily impairment, infirmity, illness, or death; air, noise, and water pollution and soil contamination; destruction or disruption of human-made or natural resources; destruction or diminution of aesthetic values; destruction or disruption of community cohesion or a community's economic vitality; destruction or disruption of the availability of public and private facilities and services; vibration; adverse employment effects; displacement of persons, businesses, farms, or nonprofit organizations; increased traffic congestion, isolation, exclusion, or separation of minority and/or low-income individuals within a given community or from the broader community; and, the denial of, reduction in, or significant delay in the receipt of benefits of FHWA/DOT programs, policies, or activities.

Advisory Committee - A group of representative stakeholders who meet regularly to discuss common concerns, such as transportation, land use, and environmental topics, and to advise agency officials. These groups interact and communicate with residents and government. Advisory committees are usually housed within MPOs and State DOTs.

Displacement - In this document, the term “displacement” refers to the economically induced movement of established residents and businesses due to rapid and prohibitive increases in local costs.

Disproportionately high and adverse - The U.S. DOT and FHWA EJ Orders state that “disproportionately high and adverse" refers to an adverse effect that (1) is predominately borne by a minority population and/or a low-income population; or (2) will be suffered by the minority population and/or low-income population and is appreciably more severe or greater in magnitude than the adverse effect that will be suffered by the nonminority population and/or non-low-income population. When considering whether an effect is "disproportionately high and adverse," practitioners should include the community that may be affected in that discussion.

Gentrification - In this document, the term "gentrification” is defined as the influx of capital and higher-income residents to working class neighborhoods, which might or might not cause or accompany displacement.

Low-income - The U.S. DOT and FHWA EJ Orders define a "low-income" individual as a person whose median household income is at or below the Department of Health and Human Services (HHS) poverty guidelines. However, The Council on Environmental Quality (CEQ) guidance on EJ uses of U.S. Census Bureau poverty guidelines to define low-income. The HHS website outlines key differences between HHS guidelines and Census guidelines.

Minority - The U.S. DOT and FHWA EJ Orders define a "minority” individual as a person who is: (1) Black: a person having origins in any of the black racial groups of Africa; (2) Hispanic or Latino: 
a person of Mexican, Puerto Rican, Cuban, Central or South American, or other Spanish culture or origin, regardless of race; (3) Asian American: a person having origins in any of the original peoples of the Far East, Southeast Asia, or the Indian subcontinent; (4) American Indian and Alaskan Native: a person having origins in any of the original people of North America, South America (including Central America), and who maintains cultural identification through Tribal affiliation or community recognition; or (5) Native Hawaiian and Other Pacific Islander: a person having origins in any of the original peoples of Hawaii, Guam, Samoa, or other Pacific Islands.

Mitigation - A means of avoiding, minimizing, rectifying, or reducing an impact, and, in some cases, compensating for an impact.

Metropolitan Statistical Area - A Core Based Statistical Area associated with at least one urbanized area that has a population of at least 50,000. The Metropolitan Statistical Area comprises the central county or counties containing the core, plus adjacent outlying counties having a high degree of social and economic integration with the central county or counties as measured through commuting. (Federal Register Vol. 75, No. 123 / Monday, June 28, 2010).

Populations - For the terms "minority" and "low-income," the U.S. DOT and FHWA EJ Orders define a "population” as any readily identifiable group of minority and/or low-income persons who live in geographic proximity, and, if circumstances warrant, geographically dispersed/transient persons of those groups (such as migrant workers, homeless persons, or Native Americans) who will be similarly affected by a proposed FHWA/DOT program, policy, or activity.

Practitioner - In this document, the term "practitioner” refers to the agency staff directly conducting an activity or project, which in most cases will be FHWA funding recipients, such as State departments of transportation and metropolitan planning organizations. FHWA primarily serves in an oversight and advisory role.

Underserved population - In this document, the term "underserved population” or "traditionally underserved population” refers to a broad category that includes minority populations and lowincome populations but may also include many other demographic categories that face challenges engaging with the transportation process and reaping equitable benefits, such as children, older adults, and persons with disabilities. 


\section{INTRODUCTION AND PURPOSE}

\section{CONTEXT AND BACKGROUND}

Executive Order (EO) 12898 on Environmental Justice (1994) directs Federal agencies to identify and address, as appropriate, disproportionately high and adverse human health or environmental effects of programs, policies, and activities on minority populations and low-income populations. The guiding Environmental Justice (EJ) principles of the U.S. Department of Transportation are as follows:

- Avoid, minimize, or mitigate disproportionately high and adverse human health and environment effects, including social and economic effects, on minority populations and lowincome populations;

- Ensure the full and fair participation by all potentially affected communities in the transportation decision-making process; and

- Prevent the denial of, reduction in, or significant delay in receipt of benefits by minority populations and low-income populations.

EO 12898 is supported by Title VI of the Civil Rights Act of 1964, which prohibits discrimination based on race, color, and national origin in programs and activities receiving Federal financial assistance. Although the nondiscrimination principles of EO 12898 and the Title VI statute intersect, they are two separate mandates, each with its own unique requirements. The EO intended to ensure minority and low-income populations do not experience disproportionately high and adverse effects from Federal projects, plans, and programs, while Title VI is focused on protecting individuals from discrimination (intentional discrimination and disparate impact discrimination) based on race, color, and national origin, including individuals with limited English proficiency (LEP). Title VI includes the Civil Rights Restoration Act of 1987, which provides that Title VI covers all agency or department programs and activities, whether federally funded or not. EJ, however, does not cover activities that are exclusively state-funded.

It is important to note that EO 12898 provides no authority for private parties to initiate a legal challenge. However, if a transportation project is advanced through the NEPA process, aggrieved parties can file a challenge to EJ findings and determinations under the Administrative Procedures Act. Under Title VI on the other hand, private parties can initiate a lawsuit claiming intentional discrimination but not for disparate impact. Individuals and groups may file administrative complaints through the disparate impact regulations for the Federal funding agency (e.g. FHWA or FTA) or such agencies may initiate a disparate impact investigation under their own initiative. 
In regards to implementation of EO 12898, the U.S. DOT Environmental Justice Order (5610.2) uses the following criteria to define a disproportionately high and adverse effect: "(l) is predominately borne by a minority population and/or a lowincome population, or (2) will be suffered by the minority population and/or low-income population and is appreciably more severe or greater in magnitude than the adverse effect that will be suffered by the non-minority population and/or non-lowincome population.” Consequently, understanding where these communities live and travel and how they will be affected by transportation investments and operations is essential to

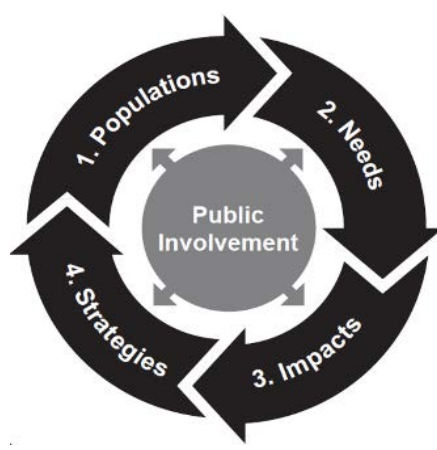

Figure 1. The four stages of the EJ analysis process. satisfying these analysis requirements. Demographic information forms a central part of the EJ analysis framework and is key to identifying the location of EJ populations and understanding the potential for disproportionately high and adverse impacts of a transportation action.

Within this context, recognizing and addressing broad demographic changes occurring now and projected to continue throughout the country in the EJ analysis process is of great importance. The composition of the U.S. population has changed significantly in recent decades due to a myriad of social and economic factors, with many areas of the country becoming "majority-minority" regions (i.e., a region in which one or more racial or ethnic minorities makes up a majority of the overall population). According to the 2014 U.S. Census Bureau Report Projections of the Size and Composition of the U.S. Population: 2014 to 2060, by the time the 2020 Census is completed, more than half the people under age 18 in the United States are expected to be part of a minority racial or ethnic group. This trend is expected to continue, so that by 2060, just 36 percent of all people under age 18 will be single-race non-Hispanic white. Moreover, the U.S. population as a whole is expected to become majority-minority in 2044. Minorities_black, Hispanic or Latino, Asian American, American Indian or Alaskan Native, and Native Hawaiian or Other Pacific Islander-represented about 38 percent of the U.S. population in 2014 and are projected to rise to 56 percent in 2060.

These broad demographic shifts are even more dramatic in certain States and metropolitan areas. For instance, California had an estimated 33.3 percent minority population in 1980 that increased to 59.7 percent in 2014; the population of California is projected to be 77.2 percent minority by 2060 . Economic characteristics of communities can also change dramatically over time. For example, the shale oil boom and the growth of new technology industries (e.g., Silicon Valley) in many urban regions have resulted in housing pressures that have displaced some existing residents. Similarly, rapid changes occur in areas experiencing deindustrialization and economic decline.

These demographic changes are important to consider when exploring EJ and fair and meaningful public involvement in all aspects of transportation decision-making. Specifically:

- Long-range transportation plans at the metropolitan and statewide levels have an outlook of 20 years or more. However, these plans often do not anticipate demographic changes when conducting EJ analyses. 
- Most demographic projections do not explicitly forecast race and ethnicity, especially at the finer spatial scales (e.g., traffic analysis zones), and often use existing race and ethnicity breakdowns as assumptions for long-range estimates. Under conditions of rapid change, a static approach to assessing project impacts on communities might not address impacts on EJ populations or the potential for disproportionate impacts.

- The demographics of a community can shift over time, especially between the time when transportation projects are planned and when they are implemented. Due to the time lags between project approval and funding, for example, the demographic composition of a community could change by the time a project moves to right-of-way acquisition, detailed design, or construction. These community changes might result in previously unforeseen impacts on EJ populations that could affect population groups who were not part of the original planning and decision-making process.

Accurate and complete demographic information is therefore needed at both regional and neighborhood scales at various decision-making points and timescales, ranging from immediate impacts to those decades in the future. However, core Federal resource data sets such as the decennial census and the American Community Survey (ACS), which works by grouping survey responses from successive annual surveys, may not be updated frequently enough or be sufficiently granular to capture this change. This challenge is of particular importance in areas undergoing rapid demographic change.

\section{PURPOSE AND STUDY APPROACH}

The purpose of this study is to improve the understanding of demographic change in EJ analysis. This study highlights best practices for understanding demographic change in transportation decisionmaking in order to help State and local agencies assess projected benefits and the potential for disproportionately high and adverse impacts resulting from transportation projects across different populations. This study also is designed to improve the understanding of metropolitan areas and States where the minority or low-income population is rapidly changing (sometimes becoming the majority) and how these changes affect EJ analyses at the various phases of transportation decision-making. It provides context on demographic changes occurring throughout the country, describes the current state of practice in EJ analyses in communities experiencing substantial demographic change, and identifies best practices for addressing these demographic changes through case study examples. Additionally, the study presents innovative approaches for understanding EJ impacts in geographies where most of the population is comprised of racial or ethnic minorities. 
This study was conducted in three phases using the series of steps outlined below:

\section{Literature Review and Study Design:}

- A broad literature review was conducted, including research on the analysis methods, tools, and resources used by State DOTs and MPOs to identify EJ populations and conduct EJ analyses.

- Ten MPOs and 10 State DOTs that have experienced significant demographic changes were then selected for further examination.

- A preliminary list of candidate State DOTs and MPOs were selected for further exploration using two steps. First, several key demographic variables for all 50 States and 366 major metropolitan areas from 1990 and 2010 were analyzed to understand the pace and magnitude of demographic change. Next an array of demographic information including income, housing tenure, age, and other variables was analyzed.

- Following a review of this data, the rate of change and magnitude of change of minority populations in these jurisdictions was selected for further study.

- Next, a sample of the jurisdictions that underwent rapid proportional or absolute change in the size of their minority populations was examined.

\section{Demographic Trends and State of the Practice Assessment:}

- Following the literature review, demographic indicators for EJ populations such as race, income, and English proficiency were reviewed between 1990 and 2010, and forecasts of demographic changes through 2060.

- This data was explored in the context of the nation as a whole, by State, and for selected metropolitan areas. Maps were then produced maps showing changes in demographics by State and county.

- In addition, specific analyses of historic and forecast data for the selected MPOs and State DOTs were conducted. Concurrent with the demographic trends assessment, the current practices used in the areas of EJ data analysis methods, metrics, and data sources were analyzed.

- Public involvement techniques and EJ engagement techniques from these agencies were also analyzed by reviewing existing documentation of recent projects, plans, and other related analyses.

\section{Notable EJ Analysis Practices Considering Changing Demographics:}

- Finally, notable practices were identified at the regional and State levels for EJ analysis relative to changing demographics.

- Although examples of agencies directly incorporating considerations of changing demographics into their analyses were limited, several notable and relevant practices were identified.

- Following the review of notable practices for consider changing demographics in EJ analysis, five case studies were selected to provide a more in-depth exploration of these practices. 
Throughout this process, a Technical Oversight Panel comprised of FHWA subject matter experts and EJ practitioners helped inform and advise the study approach, review the interim study findings and provide feedback on the draft study report.

\section{ORGANIZATION OF REPORT}

The report is organized to help the user understand key findings in the following areas:

- Section 2. Changing Demographics: Trends and Forecasts - Highlights historic information and projections about demographic changes within the United States as a whole, by State, and for specific areas that have experienced particularly rapid demographic change.

- Section 3. Considerations in Changing Demographics: State of the Practice and Notable Practices - Provides an overview of the current state of the practice relative to considerations of changing demographics in EJ analysis and describes effective practices identified through the study.

- Section 4. Five Notable Practice Case Studies - Presents case studies of the EJ practices of four MPOs and one State DOT experiencing significant demographic changes. The case studies provide more detailed information on the approaches used and helps elucidate practices that other agencies could apply or adapt.

- Section 5. Summary of Research Results and Conclusions - Provides a high-level summary of research results and takeaways following the analysis of trends and forecasts, the review of the state of practice and notable practices, and the in-depth study of notable practices from five case study agencies taking effective steps to address demographic change in the EJ analysis process.

- Section 6. References - Includes a bibliography of relevant research and studies.

- Appendices - Provides maps of the United States showing demographic changes by county and a set of maps depicting demographic change in metropolitan statistical areas for the five transportation agencies profiled in the case studies. Additionally, Federal resource data is analyzed as it pertains to addressing changing demographics in EJ analysis, and results of an MPO practitioner survey on the benefits and challenges of using Federal resource data sets and tools such as the American Community Survey are presented. 


\section{CHANGING DEMOGRAPHICS: TRENDS AND FORECASTS}

The demographics of the U.S. population have changed substantially over the past 20 years, with an increasingly racially and ethnically diverse population, including segments of the country that are majority-minority. These trends are projected to continue, with increasing minority populations in many States and regions of the country. This section of the report presents an overview of national demographic trends focusing on minority populations and low-income populations. The section also discusses trends for population groups not defined as EJ populations, but often considered transportation disadvantaged, such as the elderly and youth, persons with disabilities, and persons with limited English proficiency.

This analysis relies primarily on data and projections from the U.S. Census Bureau, existing reports, and original data analysis and mapping. Reports were scanned for important trends that affect EJ analysis, focusing on race, ethnicity, and income. Additional demographic trends that affect the core EJ demographics, such as migration, or are interrelated with transportation disadvantage, such as age or immigration status were highlighted. First national trends are presented, followed by State, and then regional trends.

\section{NATIONAL TRENDS}

To examine national trends, several documents were reviewed that chronicle national-scale demographic changes and key points relating to EJ communities were extracted. The documents illustrate recent trends and changes projected to the middle of this century. Notable trends are highlighted here.

\section{OVERALL POPULATION CHANGES}

The U.S. population has grown substantially in recent decades, driven heavily by international migration. Although this overall trend is projected to continue, population growth is projected to be uneven and to occur principally in the West and South, continuing recent trends. Key points drawn from existing studies include the following:

- According to the U.S. Census Bureau (2014), the national total population grew by over 50 percent from 1970 to 2009 and is projected to increase by another third by 2060 to more than 410 million.

- The South and West experienced more of the growth than the Northeast and Midwest.

- The South nearly doubled, assimilating nearly one-half of the Nation's entire population increase from 1970 to 2009.

- The West doubled (from a smaller initial population), absorbing about a third of the Nation's population increase.

- According to NCHRP Report 710, Practical Approaches for Involving Traditional Underserved Populations in Transportation Decision-making (2012), the Midwest and the Northeast combined, accounted for only 16 percent of the Nation's population increase and declined as a share of the national population. 


\section{MINORITY POPULATIONS}

Overall, the U.S. has experienced substantial growth in minority populations over the past few decades, which is likely to continue. Such trends will dramatically impact the number and location of majority-minority communities. Recent findings include:

- The Center for American Progress (2015) found that the population of the United States was 80 percent white in 1980. Today, that proportion is 63 percent, and by 2060, it is projected to be less than 44 percent.

- As of 2018, four States are majority-minority: California, Hawaii, New Mexico, and Texas. Over the next 10 years, 6 additional States are estimated to become majority-minority: Nevada, Maryland, Arizona, Georgia, Florida, and New Jersey (see Table 2 for other States projected to become majority-minority States by 2056).

- The U.S. Census Bureau (2014) projects the Nation to be majority-minority overall in 2044. In 2060, about 44 percent of the population will be non-Hispanic white, down from 62.2 percent in 2014 (See Figure 2 for more details on the growth of other groups). Immigration policy has an effect, however, and this date could be delayed as a result of policy initiatives to reduce immigration rates for immigrants of minority groups (Stein \& Van Dam, 2018).

- According to NCHRP Report 710 (2016), the principal cities of major metropolitan areas in the United States (e.g., Los Angeles) are already majority-minority.

- The top 15 most populous metropolitan areas contain 60 percent of the Nation's Hispanic population and more than 66 percent of the Nation's Asian population but less than half of the Nation's black population. The Southeast has increased in importance for the growth of Hispanic communities in recent decades. The black population has increased in the South and Southeast over the past two decades.

- Purvis (2001) notes a stronger sensitivity of EJ populations to macroeconomic and political forces, which could shape migration and economic dislocation (such as trade and immigration policies, deindustrialization, climate change, and housing markets).

Table 2. The dates when States became majority-minority or are projected to do so (Hawaii has been majorityminority since its founding ${ }^{3}$ ) (Source: Center for American Progress, 2015, p. 3).

\begin{tabular}{|llllll|}
\hline New Mexico & 1994 & New Jersey & 2028 & Oklahoma & 2046 \\
\hline California & 2000 & Alaska & 2030 & Virginia & 2046 \\
\hline Texas & 2004 & New York & 2031 & Connecticut & 2047 \\
\hline Nevada & 2019 & Louisiana & 2039 & Colorado & 2050 \\
\hline Maryland & 2020 & Illinois & 2043 & North Carolina & 2050 \\
\hline Arizona & 2023 & Mississippi & 2043 & Washington & 2056 \\
\hline Georgia & 2025 & US & 2044 & & \\
Florida & 2028 & Delaware & 2044 & & \\
\hline
\end{tabular}

${ }^{3}$ See http://www.ohadatabook.com/T01-03-11u.pdf for more details on Hawaii’s demographics since statehood. 


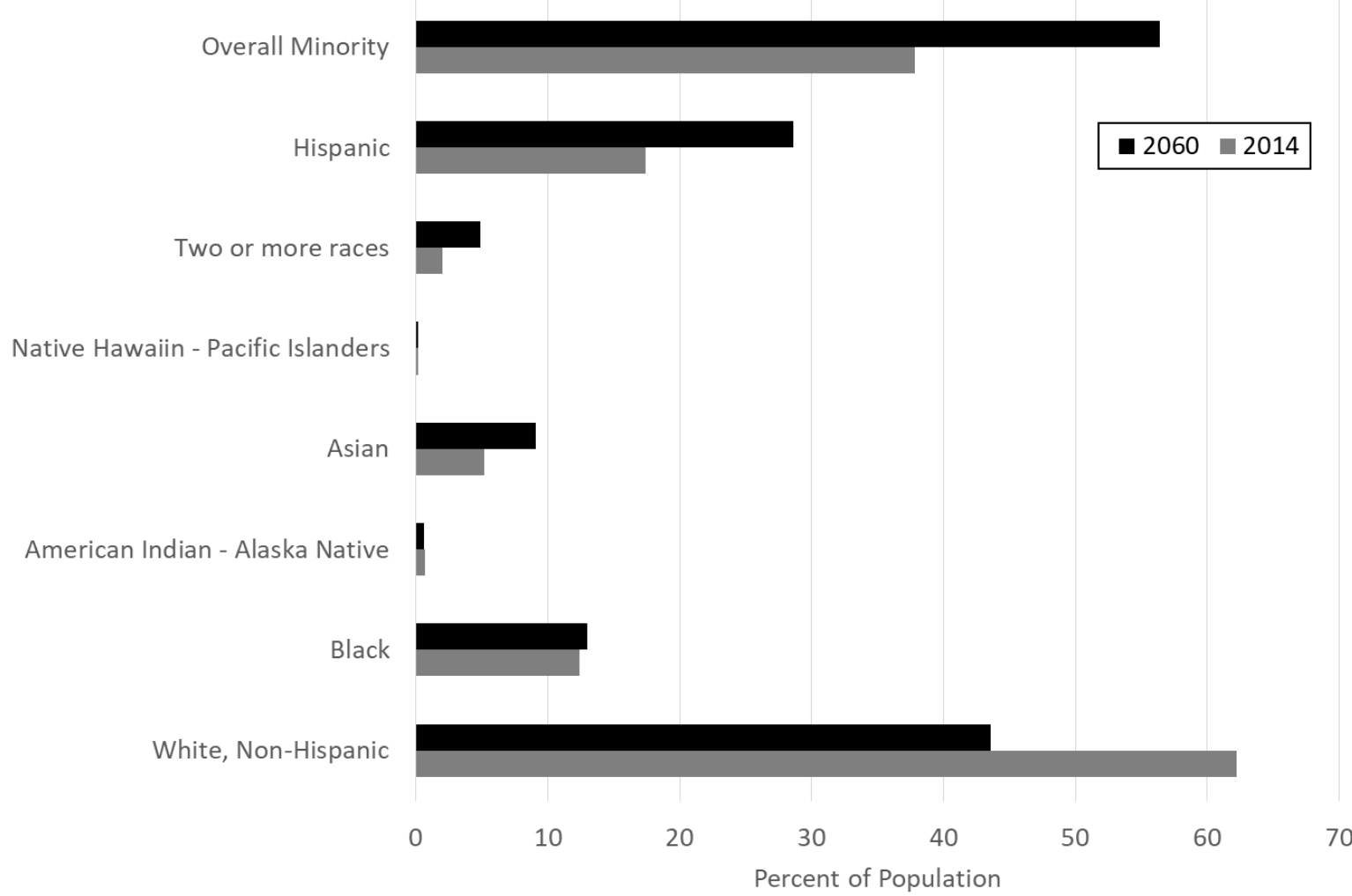

Figure 2. Distribution of the total population by race and Hispanic origin, 2014 (lighter bars) and 2060 (darker bars) (Source: US Census, 2015, p. 10).

Figure 3 and Figure 4 show the share of minority population by county in 1990 and 2010, based on U.S. Census data. The number of counties with large minority populations has been increasing around the country, with particularly large increases in States in the West and South, including California, Nevada, Colorado, Washington, Texas, Oklahoma, and Florida. Additionally, the number of counties with large minority populations has been increasing in many States in the Midwest, including Illinois and Michigan. Figure 5 shows PolicyLink (2017) projections of minority population by county, demonstrating significant nationwide growth from the 1990 and 2010 Census figures. 


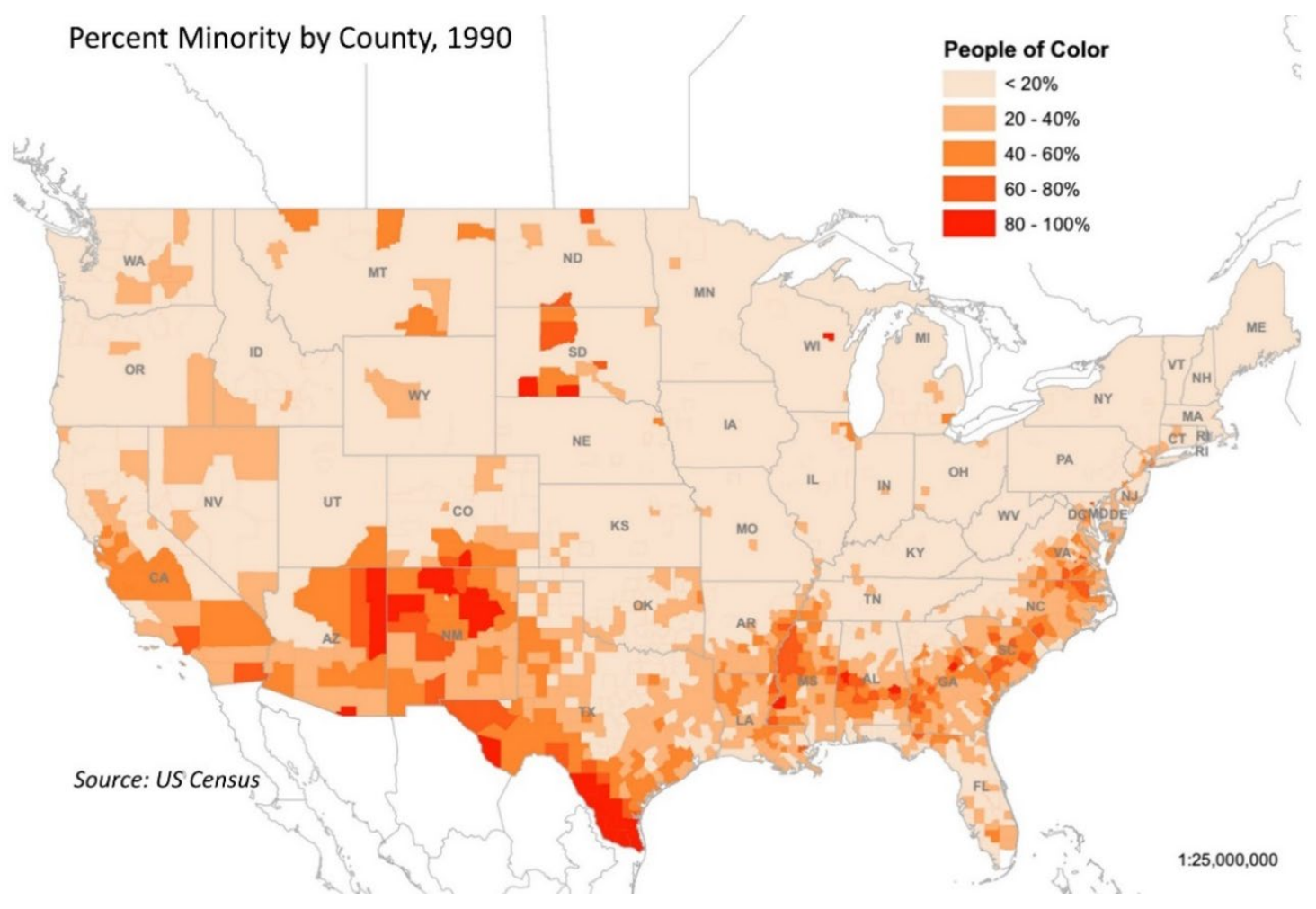

Figure 3. Percent Minority by county, 1990 (Data Source: US Census, 1990).

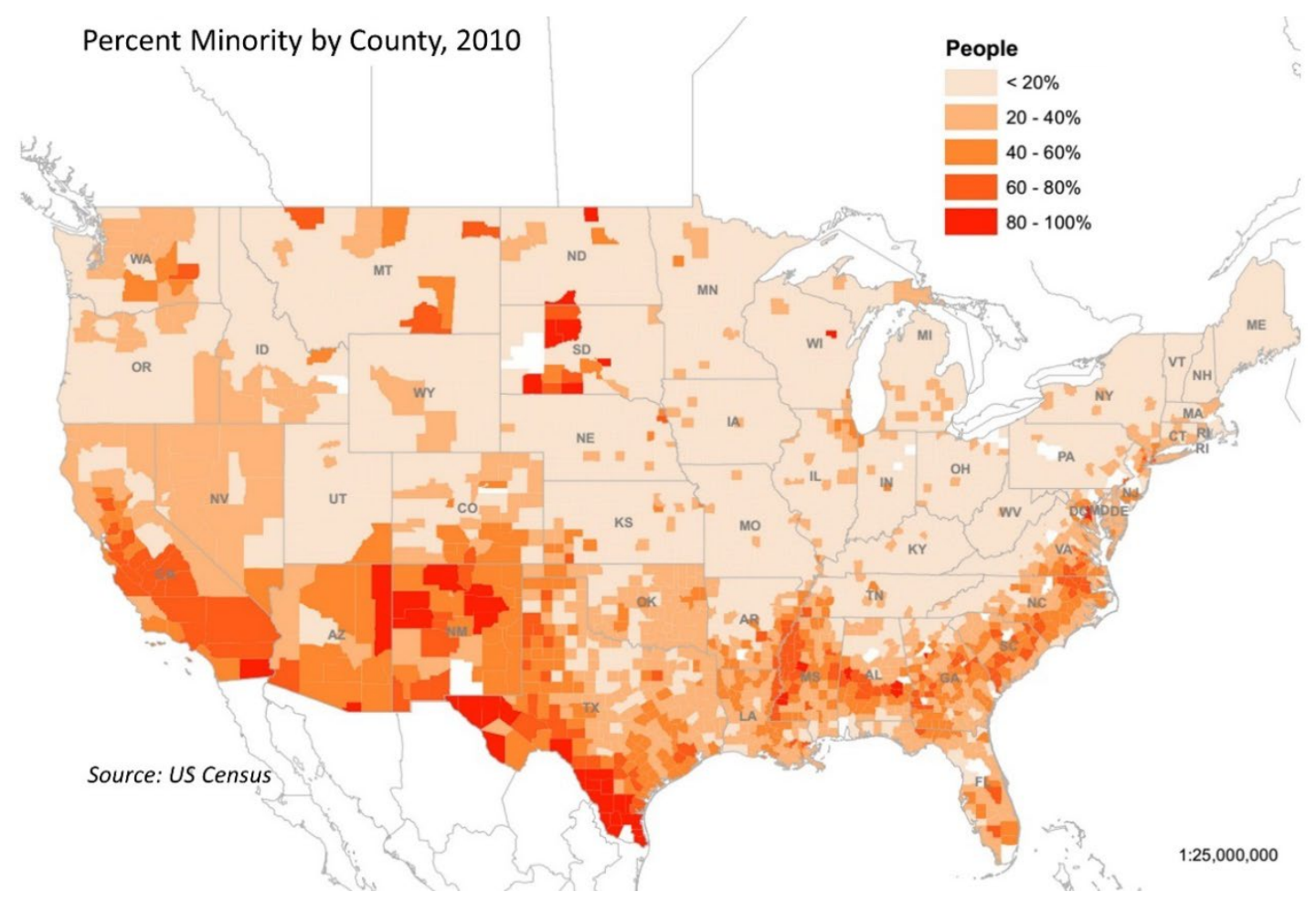

Figure 4. Percent minority by county, 2010 (Data Source: US Census, 2010). 


\section{Percent Minority by County, 2050 \\ $20 \% \quad 40 \% \quad 60 \% \quad 80 \%$}

Google

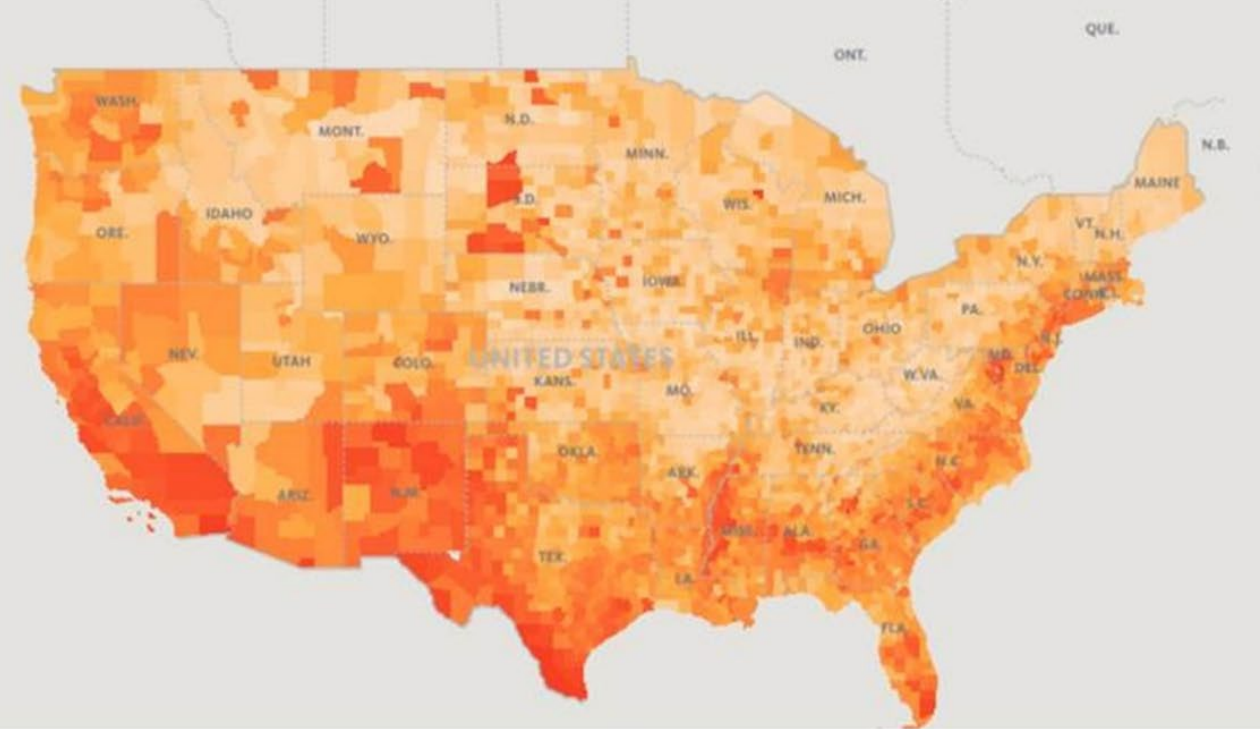

Source: PolicyLink

Figure 5. Percent minority by county, 2050 (@PolicyLink, 2017).

\section{MIGRATION}

International migration will likely continue to be a major component of population growth and spatial shifts in the United States, although that could be tempered by Federal policy changes toward immigration. Several salient points found in the literature include:

- $\quad$ U.S. Census (2014) data shows the number of foreign-born residents has increased dramatically over the past two decades and is now over 13 percent of the population. The number of foreign-born residents is projected to nearly double by 2060 and to grow to be nearly 19 percent of the population.

- The Center for American Progress (2015) reported that the Los Angeles and New York metropolitan areas remain the most important gateways for Hispanics, accounting for 22.1 percent of the Nation's Hispanic population in 2009. This share, however, is down from 30 percent in 1990.

- $\quad$ NCHRP Report 710 (2016) notes that the originating regions of foreign-born residents has changed significantly since 1970; Europe accounted for more than 60 percent in 1970, while in 2018 it accounts for just 13 percent of the origins of foreign-born residents.

- Recent immigrants have significantly increased in Southeastern metropolitan areas over the past decade.

- California, New York, Texas, and Florida remain traditionally important gateway States for migration. 


\section{INCOME, EMPLOYMENT AND POVERTY}

Household incomes vary substantially across the United States. Poverty rates for many minority groups have steadily declined, although they are still significantly higher than for white households. A few key trends taken from the Census Bureau report, Income and Poverty in the United States: 2015 (Proctor et al., 2016), based on census, labor statistics and other data include:

- The overall poverty rate in the United States is 13.5 percent (2015 data), with some variations across the country; the poverty rate in the Northeast is 12.4 percent, the Midwest 11.7 percent, the South 15.3 percent, and the West 13.3 percent. $^{4}$

- From 2009 to 2012, 34.5 percent of the national population had at least one period of poverty lasting 2 or more months. Chronic poverty over the same 4-year period was relatively uncommon, with 2.7 percent of the population living in poverty throughout the 48 months.

- Overall, the Nation's poverty rate has fluctuated between 10 and 15 percent for the past several decades (the poverty threshold income is updated annually to adjust for inflation in the cost of goods and services).

- The poverty rate for blacks and Hispanics has declined from above 30 percent to around 25 percent over the past two decades but remains significantly higher than the current overall U.S. rate.

- Female-headed families, especially amongst minority families, experience poverty at a significantly higher rate than families overall, although their poverty rates have declined over the past decade.

- The absolute number of persons in poverty living in central cities is similar to the number living within metro areas outside of central cities although poverty rates in central cities are much higher (18.7 percent vs. 11 percent).

AGE

The country's population will become much older over the coming decades (the so-called "Grey Tsunami”) with significant impacts on transportation demand.

- U.S. Census data (2014) shows the share of the population over 65 years old will increase from 15 percent currently to 24 percent of the overall population in 2060.

- $\quad$ The share of the population under 18 will decline from 23 to 20 percent in 2060.

- According to Coughlin (2017), aging Baby Boomers are expected to have greater transportation demand for nonessential services relative to preceding cohorts.

\section{FAMILY AND HOUSEHOLD STRUCTURE}

Changing family structures also shape housing and transportation preferences. According to Coughlin (2017), households are smaller and are forming later, contributing to a shift to smaller,

\footnotetext{
${ }^{4}$ The Northeast region includes Connecticut, Maine, Massachusetts, New Hampshire, New Jersey, New York, Pennsylvania, Rhode Island, and Vermont. The Midwest region includes Illinois, Indiana, Iowa, Kansas, Michigan, Minnesota, Missouri, Nebraska, North Dakota, Ohio, South Dakota, and Wisconsin. The South region includes Alabama, Arkansas, Delaware, Florida, Georgia, Kentucky, Louisiana, Maryland, Mississippi, North Carolina, Oklahoma, South Carolina, Tennessee, Texas, Virginia, West Virginia, and the District of Columbia, a state equivalent. The West region includes Alaska, Arizona, California, Colorado, Hawaii, Idaho, Montana, Nevada, New Mexico, Oregon, Utah, Washington, and Wyoming (Proctor, Semega, \& Kollar, 2016).
} 
more urban housing and location preferences and willingness to participate in shared mobility systems like car sharing. According to Coughlin:

- In 2018, one in five women have no children, a significant decrease from earlier generations.

- The average birthing age has risen by 5 years in the past two decades.

- The only group with a rising birthrate is those over 40 years of age.

- Thirty-two percent of young adults aged 18-34 years, live with parents.

- The fastest growing household demographic in the United States are persons living alone.

\section{STATE TRENDS}

In this section, national demographic trends are presented by state through a series of maps highlighting the fastest-growing states. Data for the change in minority populations, persons with incomes below the poverty line, and persons with limited English proficiency are mapped.

\section{CHANGES IN MINORITY POPULATIONS}

Some States saw a near quadrupling of minority populations over the past two decades. Nevada led States with the fastest growth as a percentage change, while California led States with total absolute change with nearly 10 million new minority residents. Figure 6 and Figure 7 show the national landscape of change in race/ethnicity, according to percentage changes and absolute changes. States with high percentage changes are found throughout the United States. The Intermountain West (especially Utah and Nevada), the Midwest (especially Iowa and Minnesota), and New England (New Hampshire, Vermont, and Maine) experienced high proportional changes. The largest States by population (e.g., Texas and California) had the highest absolute increases in minority populations during this period. Other populous states, such as New York, Florida, and Georgia, also experienced high increases in minority populations.

\section{CHANGES IN POVERTY}

Many States saw their populations with incomes below the poverty level increase alongside their general population increases. Figure 8 and Figure 9 show the national percent and absolute value changes of the population living in poverty by State. Nevada led all States, more than doubling its population below the poverty line. California added nearly 2 million people in poverty, experiencing the highest absolute change in population in poverty. Relative increases in poverty appeared to fall generally in the Southeast, West, and Midwest. North Dakota, Louisiana, and West Virginia saw declines in poverty, likely due to outmigration for the latter two states and improvements in the economy in North Dakota. Absolute increases in poverty fell most strongly in the most populous States, including California, Texas, and Florida. 


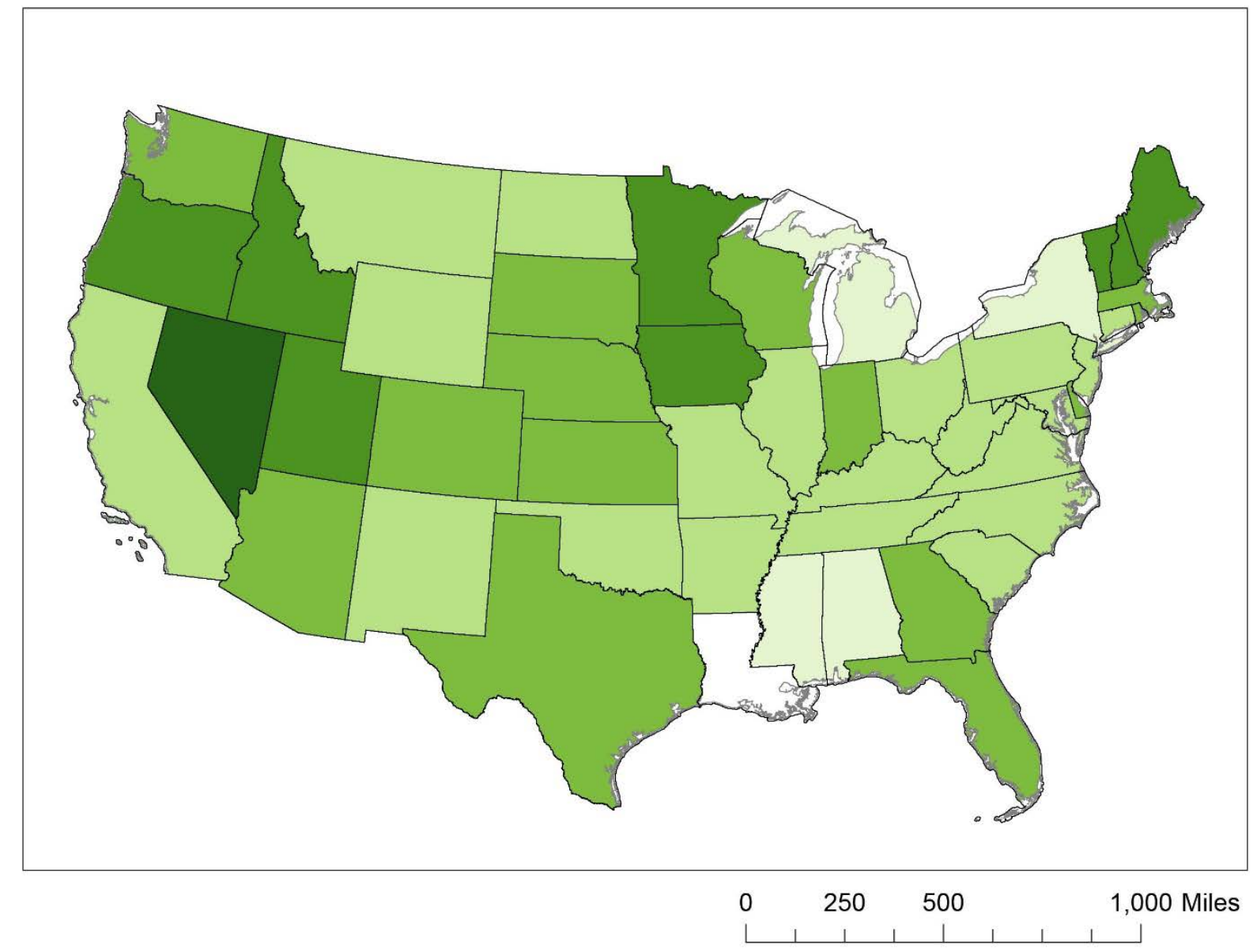

Minority Population Percent Change
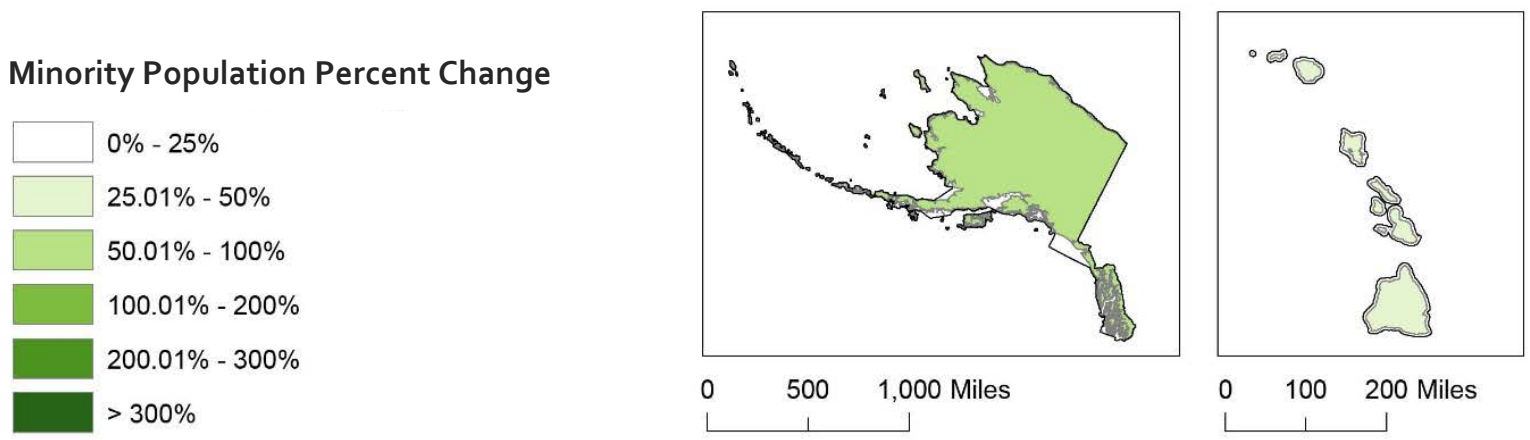

\section{NORTH}

Data Sources: IPUMS,

American FactFinder

Figure 6. National map of States: Minority population percentage change, 1990-2010. 


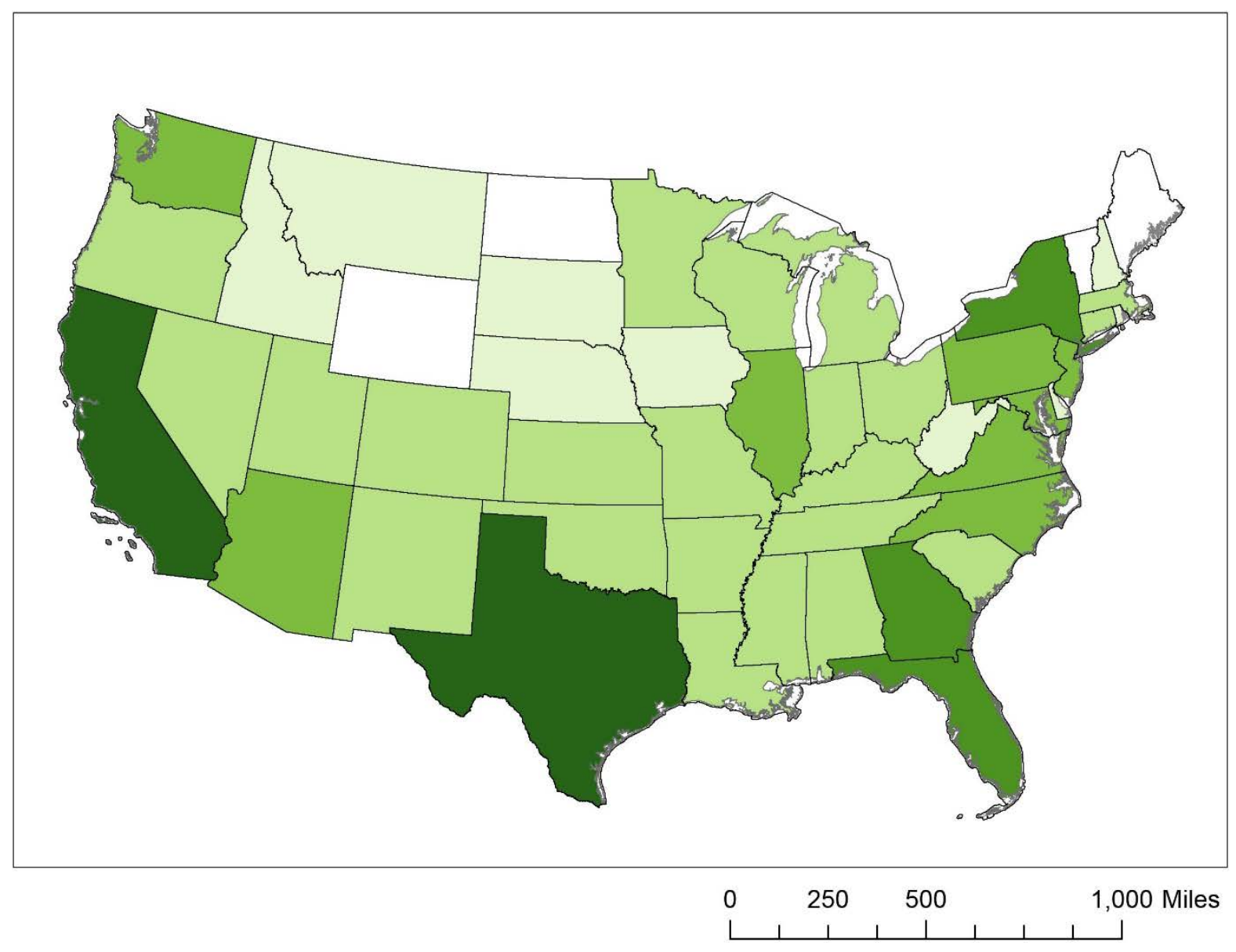

Minority Population Absolute Change
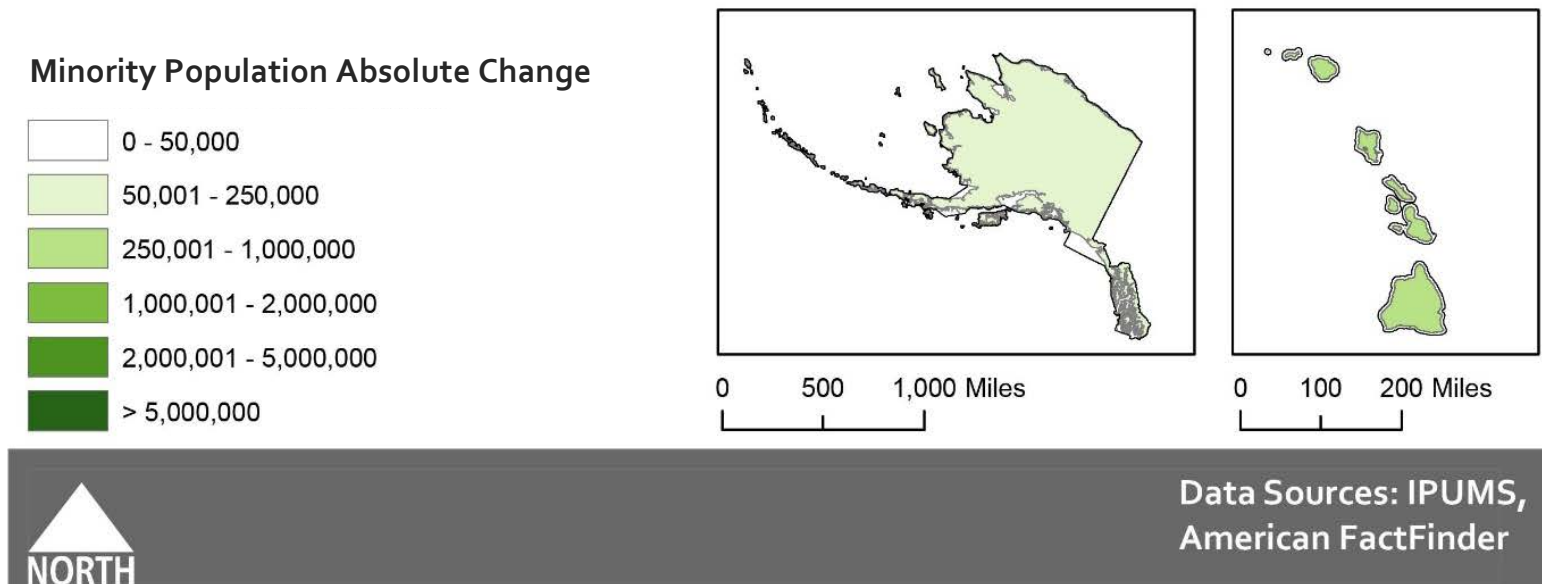

Data Sources: IPUMS,

American FactFinder

Figure 7. National map of States: Minority population absolute change, 1990-2010. 


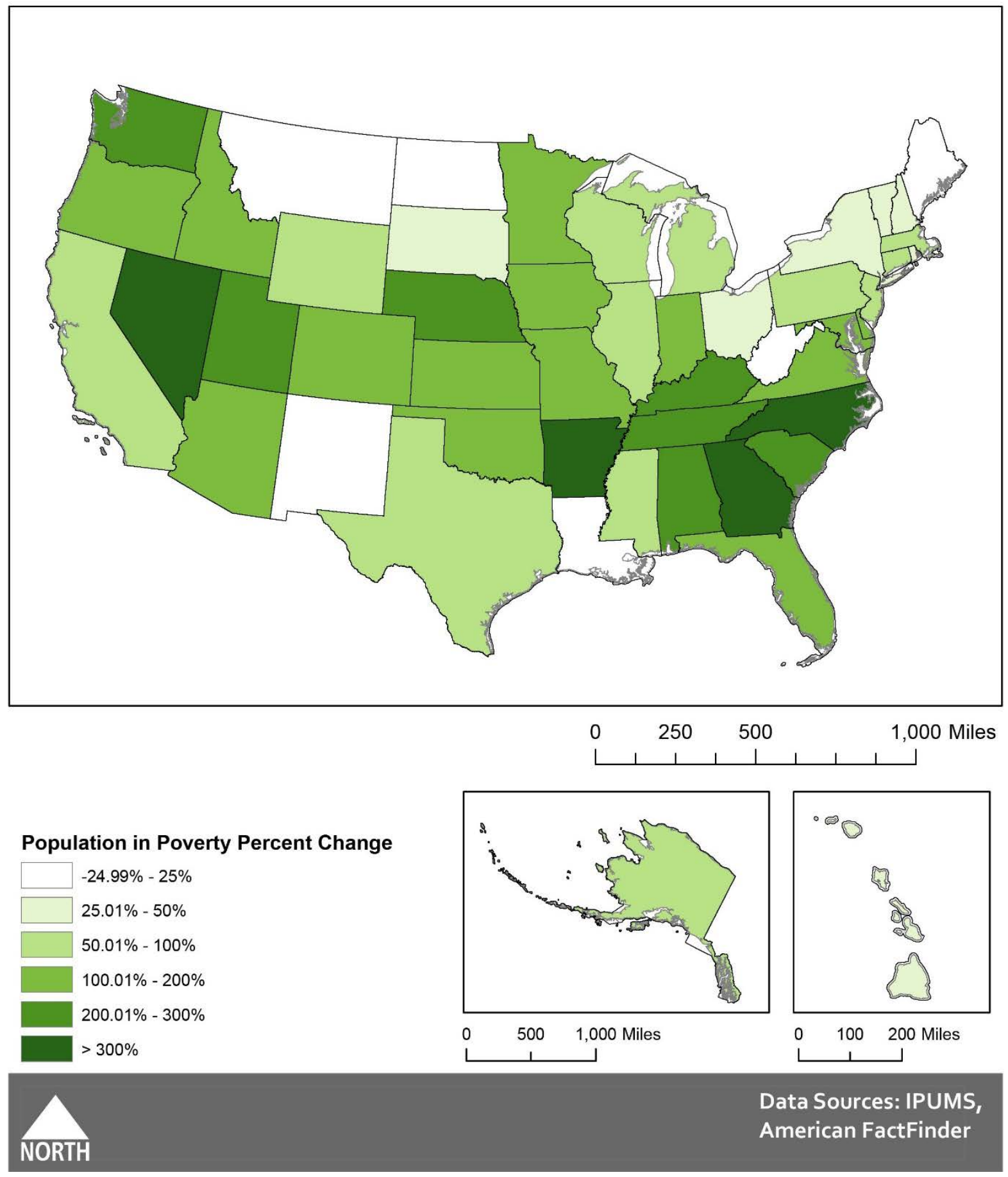

Figure 8. National map of States: Population in Poverty percentage change, 1990-2010. 


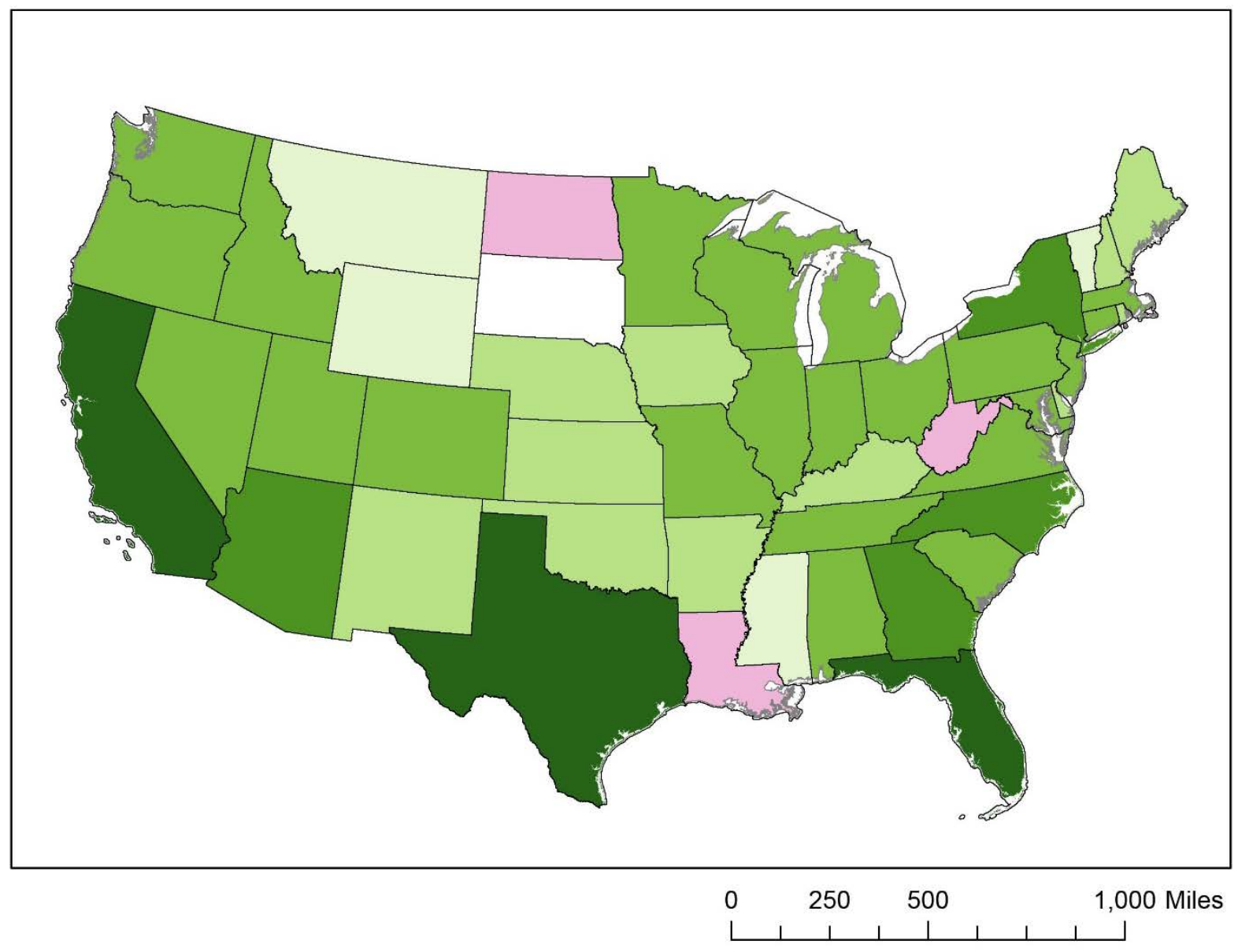

\section{Population in Poverty Absolute Change}
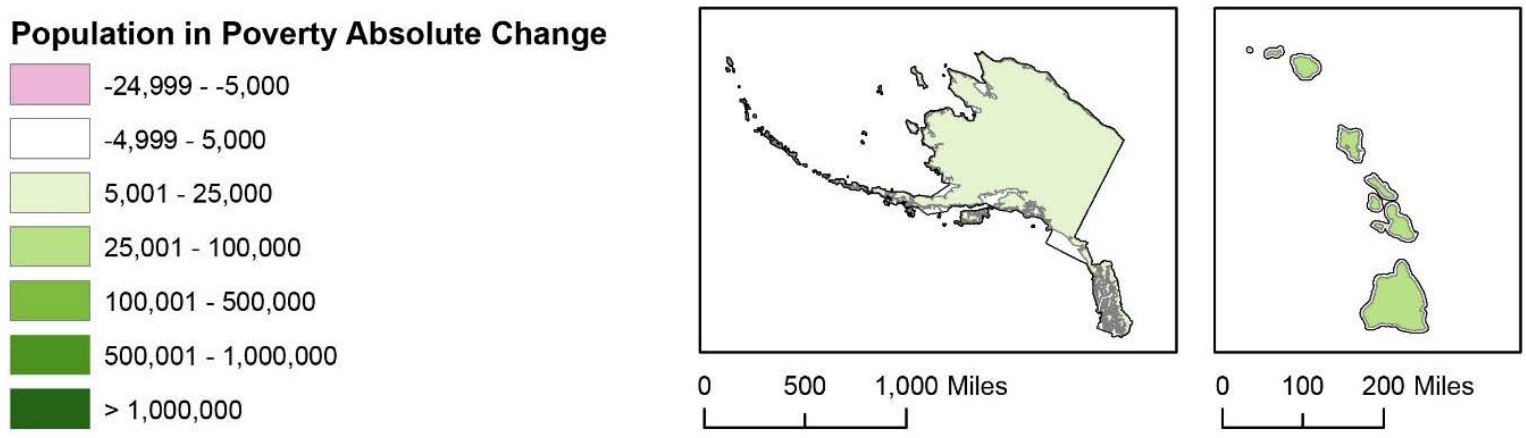

Data Sources: IPUMS, NORTH

American FactFinder

Figure 9. National map of States: Population in Poverty absolute change, 1990-2010.

\section{CHANGE IN LIMITED ENGLISH PROFICIENCY POPULATIONS}

States saw dramatic increases in their limited English proficiency (LEP) populations. Figure 10 and Figure 11 show the national percent and absolute value changes of LEP populations by State. North Carolina's LEP population increased more than five times, while California added nearly 2.5 million LEP residents. In terms of relative change, States with large increases in LEP populations clustered 
in the Southeast and West and generally from the Midwest to Nevada. Like the other trends for absolute growth, the largest States experienced the largest absolute changes in LEP populations. Some States experienced slight declines in LEP populations, although no State-specific pattern was apparent. Louisiana lost the most LEP populations, although the reasons are unclear.

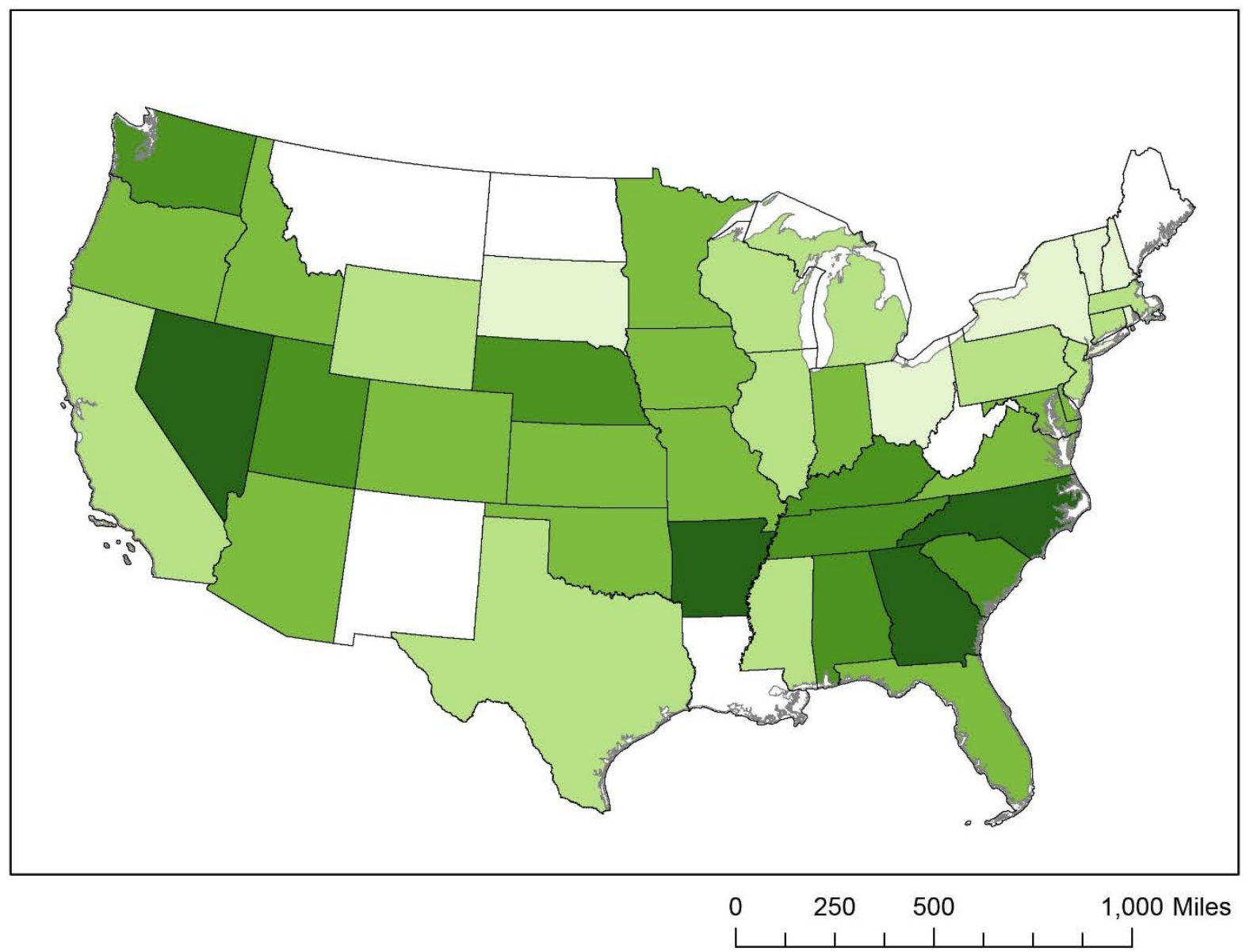

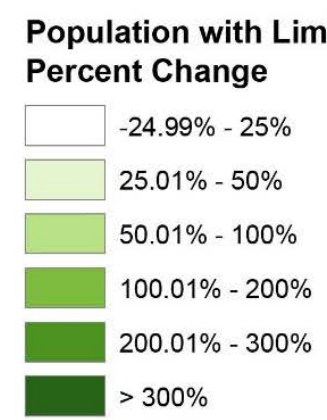

NORTH

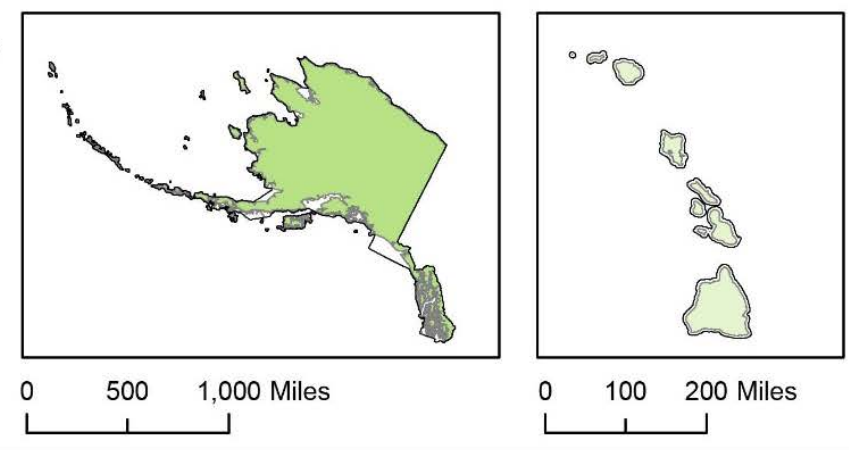

Data Sources: IPUMS, American FactFinder

Figure 10. National map of States: Limited English proficiency populations percentage change, 1990-2010. 


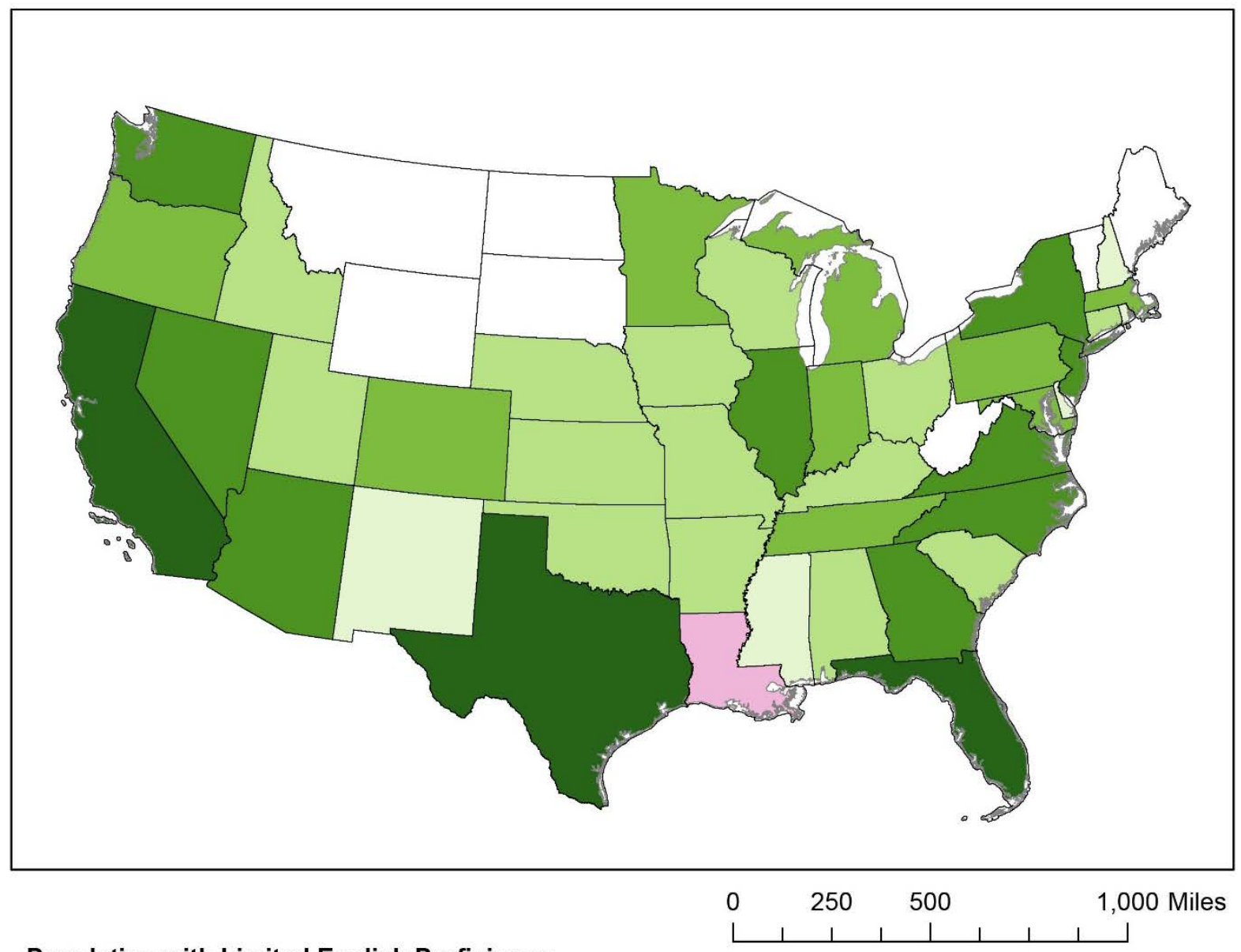

Population with Limited English Proficiency Absolute Change
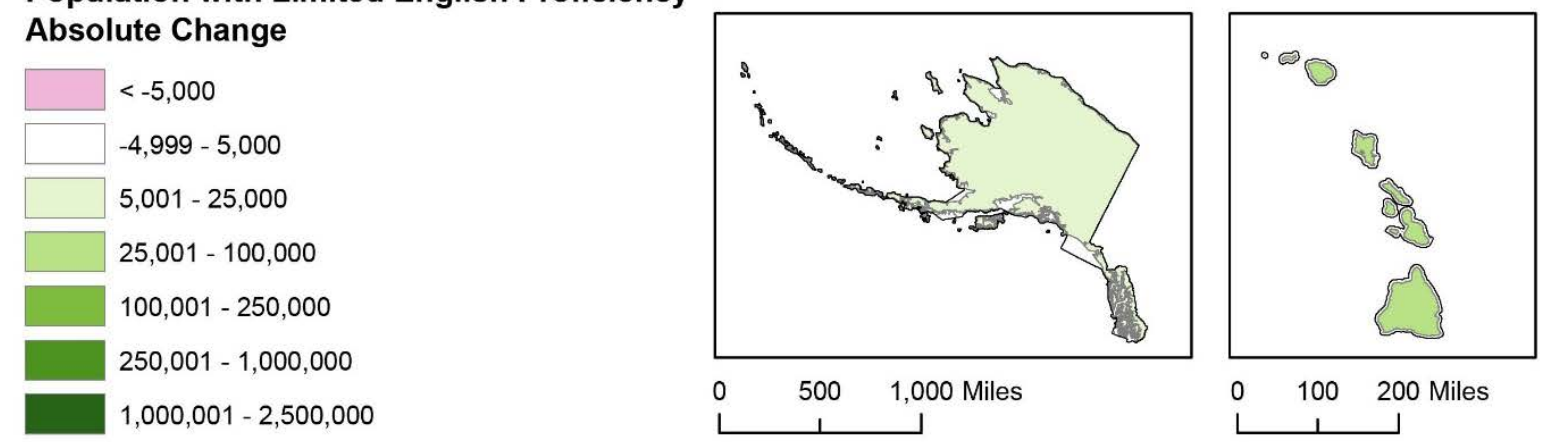

\section{NORTH}

Data Sources: IPUMS,

American FactFinder

Figure 11. National map of States: Limited English proficiency populations absolute change, 1990-2010.

\section{METROPOLITAN AREA TRENDS}

Significant growth in EJ populations is generally found in metropolitan areas in all areas of the country. Large absolute changes have occurred in the larger cities, while larger proportional changes 
occur in smaller and midsized regions across the country. To delve further into the spatial dynamics of demographic change, maps were developed at the county level to increase understanding of the detailed changes within States and near metropolitan areas. Maps were developed with the same three dimensions presented earlier — changes in minority populations, persons with incomes below the poverty line, and LEP persons. These maps are compiled as Appendix A and are presented as both percentage change and absolute change, similar to the maps of States presented earlier.

\section{CHANGE IN MINORITY POPULATIONS}

Following national trends, most metro areas experienced significant increases in their minority populations over the past two decades. Table 3 lists the metropolitan areas with the fastest growing minority populations. The Fayetteville, Arkansas area saw the fastest proportional growth in its minority populations with nearly ten-fold growth between 1990 and 2010. The New York metropolitan area experienced the largest absolute change and added more than three-million minority residents. Fast growing minority populations are found throughout the United States, with the largest absolute increases occurring in the largest metropolitan areas.

Table 3. Ten fastest-growing minority metropolitan statistical area (MSA) populations from 1990 to 2010, ranked by percentage change (left) and absolute change (right) (Data Source: IPUMS National Historical Geographic Information System).

\begin{tabular}{|lclc|}
\multicolumn{1}{c}{ MSA } & \% Change & \multicolumn{1}{c|}{ MSA } & $\begin{array}{c}\text { Absolute } \\
\text { Change }\end{array}$ \\
\hline $\begin{array}{l}\text { Fayetteville-Springdale- } \\
\text { Rogers, AR-MO }\end{array}$ & 999.2 & $\begin{array}{l}\text { New York-Northern New Jersey-Long } \\
\text { Island, NY-NJ-PA }\end{array}$ & $3,230,779$ \\
\hline St. George, UT & 946.6 & Los Angeles-Long Beach-Santa Ana, CA & $2,671,657$ \\
\hline Dalton, GA & 652.9 & Houston-Sugar Land-Baytown, TX & $2,011,592$ \\
\hline Bend, OR & 587.9 & Dallas-Fort Worth-Arlington, TX & $1,978,996$ \\
\hline St. Cloud, MN & 564.0 & Miami-Fort Lauderdale-Pompano Beach, & $1,779,951$ \\
\hline Sioux Falls, SD & & FL & $1,710,244$ \\
\hline Palm Coast, FL & 546.7 & Atlanta-Sandy Springs-Marietta, GA & $1,705,646$ \\
\hline Provo-Orem, UT & 491.6 & Riverside-San Bernardino-Ontario, CA & $1,562,311$ \\
\hline Las Vegas-Paradise, NV & 460.8 & Chicago-Joliet-Naperville, IL-IN-WI & $1,381,327$ \\
\hline Coeur d'Alene, ID & 456.1 & Washington-Arlington-Alexandria, DC- & \\
\hline
\end{tabular}

In Appendix A, Figure A-1 and Figure A-2 illustrate the changes in minority populations at the county scale. Figure A-1, in Appendix A, illustrates the absolute changes in minority populations. The figure shows the large metro areas in Florida, Texas, Arizona, and California and along the Northeast and New England experiencing the highest absolute changes in minority populations. However, these populations declined in parts of Texas and New Mexico, counties along the Mississippi River, and rural counties in the South. 
Figure A-2 in Appendix A shows a notable pattern of faster percentage growth in minority populations throughout the center of the country, extending from the Intermountain West up through the Dakotas and Minnesota and over to Pennsylvania, Virginia, and Georgia, likely reflecting the previous relative scarcity of minority individuals in some of those areas. Florida and Texas also have some faster growing counties. Interestingly, interspersed with fast growth are many counties in the center of the country losing minority populations, especially in New Mexico, Alabama, and Mississippi and large parts of Texas and West Virginia. These areas might coincide with population loss in general and could reflect prevailing migration patterns from rural to urban areas.

\section{CHANGE IN POVERTY POPULATION}

In terms of absolute numbers, the major metro areas are the locations of fastest growth in poverty (Figure A-3, Appendix A). Miami, Detroit, Los Angeles, Phoenix, and the large cities in Texas showed the largest absolute increases in populations with incomes below the poverty line. The middle of the country, extending from western Pennsylvania and West Virginia to Louisiana, and Texas and up through the Dakotas and Montana, showed a general pattern of no change or slight declines in numbers of persons in poverty. Whether this result is due to migration or to improvements in the economies is difficult to discern.

Figure A-4 in Appendix A, shows increases and decreases in poverty scattered throughout the country. Declines are most notable in Louisiana and up the Mississippi river, and in many Midwestern States (Montana, North Dakota, South Dakota, Nebraska, Kansas, and Texas). Knowing whether declines are due to improvements in the economy in these locations or to overall population exodus is difficult; the cause is likely due to both. Areas of increases in poverty are notableespecially in California, Georgia, and Florida and throughout the Southwest and Midwest (especially in Indiana, Illinois, and Michigan). Suburbs around Washington DC, New York, Atlanta, Las Vegas, and Denver showed significant percentage increases in poverty. These households could have been displaced from central cities or might have moved from other parts of the metro areas, rural areas, and small towns. Increases in suburban poverty are concerns for transportation providers, as these households often need improved public transportation services.

\section{CHANGE IN LIMITED ENGLISH PROFICIENCY POPULATION}

Figure A-5 illustrates absolute changes in LEP populations. This map shows concentrated areas of large absolute changes. The nation's largest metropolitan areas and their suburbs experienced substantial growth in LEP populations, while outside those areas experience little change. A pattern of growth is evident across the Northeast into New England, throughout Florida and the large cities of Texas, and across the more urban parts of California (the Bay Area and through the central and southern parts of the State). Washington State, North Carolina, and parts of Georgia also experienced some areas of growth. The less populated areas of the country saw little change in LEP populations in absolute numbers, with slight declines in Louisiana, parts of Texas, New Mexico and Arizona and scattered counties in Appalachia. It is likely these declines are due to population loss, though specific research was not found to support this theory. 
Figure A- 6 shows an interesting picture of percentage growth in LEP populations alongside declines in certain areas. In some cases, counties that have experienced substantial growth in LEP populations are bordered by counties that have seen losses in LEP populations. Percentage growth of LEP populations is evident across the South and Southeast with strong growth in the northwest Georgia and central North Carolina and throughout Florida, Virginia, and East Texas. The West also shows consistent and widespread growth with strong growth in some counties of Colorado, Utah, Wyoming, and Nevada. The entire West Coast shows growth with few areas of decline.

\section{SMALL URBAN AND RURAL AREA TRENDS}

Although the largest metro areas account for much of the absolute change in EJ populations, relative change was greatest and occurred most rapidly in some of the Nation's smaller metro areas. Table 4 lists the fastest-growing minority populations from 1990 to 2010 for metropolitan statistical areas with under one million residents. These fast-changing small metro areas merit special attention given potential resource and planning capacity constraints in these areas to adequately address rapid change in EJ populations. Planning documents from metro areas with less than a million residents with the top five percentage changes were reviewed for their EJ practices, including approaches to public participation and EJ analysis. Surveys by email were performed with the Bend, Oregon and Little Rock, Arkansas MPOs.

Table 4. Fastest-growing minority MSA populations for regions under 1 million.

\begin{tabular}{|lcc|}
\hline \multicolumn{1}{c}{ MSA } & MSA Population (2010) & $\begin{array}{c}\text { Minority \% Change } \\
(\mathbf{1 9 9 0 - 2 0 1 0 )}\end{array}$ \\
\hline Fayetteville-Springdale-Rogers, AR-MO & 463,204 & 999.2 \\
\hline St. George, UT & 138,115 & 946.6 \\
\hline Dalton, GA & 142,227 & 652.9 \\
\hline Bend, OR & 157,733 & 587.9 \\
\hline St. Cloud, MN & 189,093 & 564.0 \\
\hline Sioux Falls, SD & 228,261 & 546.7 \\
\hline Palm Coast, FL & 95,696 & 491.6 \\
\hline Provo-Orem, UT & 526,810 & 460.8 \\
\hline Coeur d'Alene, ID & 138,494 & 431.3 \\
\hline
\end{tabular}

Generally, the public participation, outreach approaches, and EJ analyses used by the smaller MPOs surveyed mirrored the approaches used by larger MPOs. For example, Figure 12 shows a mapping analysis comparing the locations of roadway expansions to EJ communities. None of these small metros noted the rate at which their communities were changing. Although many presented maps and data documenting changes in community composition, the pace of change was never highlighted as a factor demanding special attention in project planning and delivery. Furthermore, the Bend MPO noted their State-provided long-range population forecasts did not include race and ethnicity and that they were interested primarily in forecasts that could help them understand where EJ populations might grow and reside in the future. Little Rock similarly lamented their lack of access to forecasts that could specifically address change in the EJ communities. 


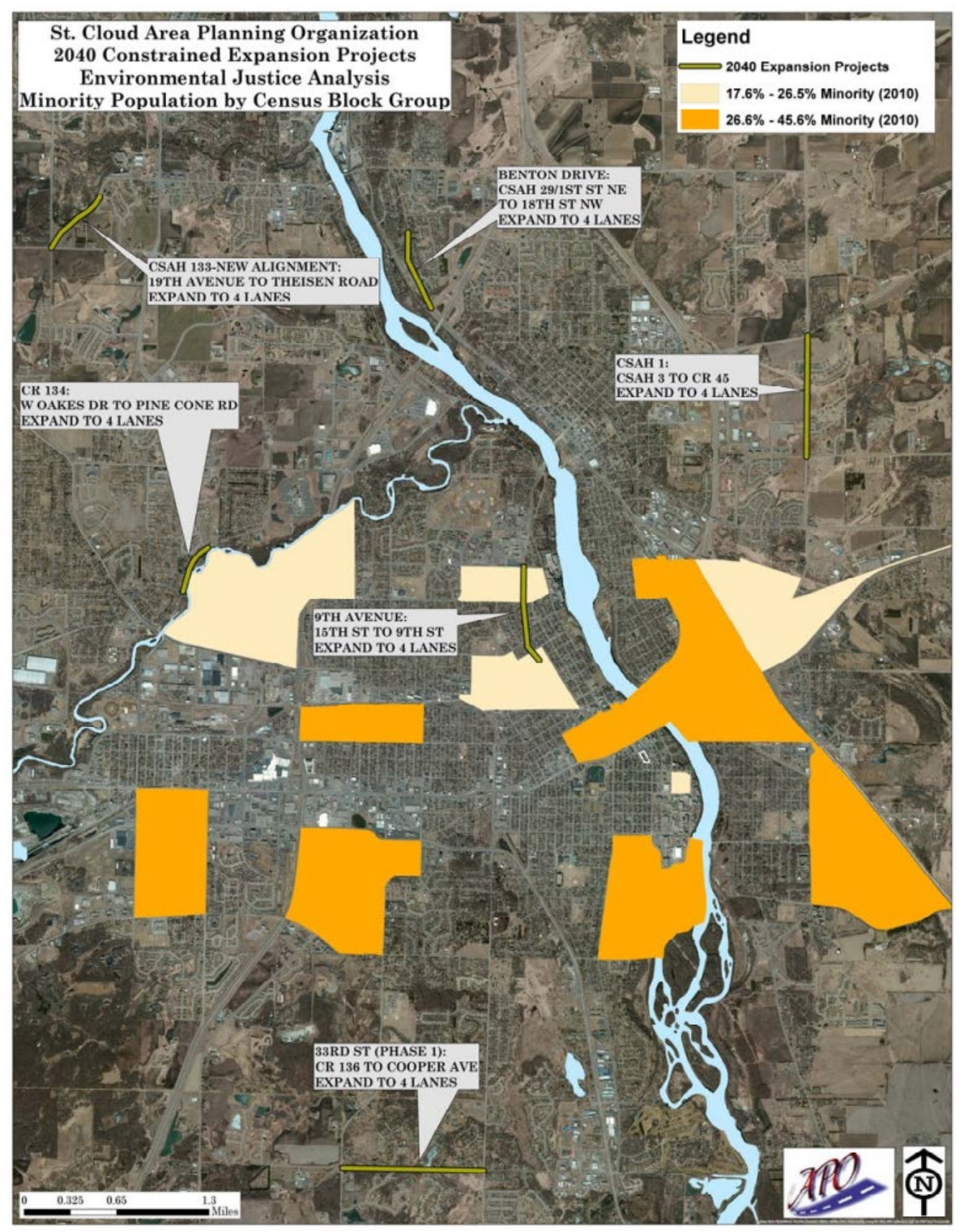

Figure 12. Roadway expansion project EJ analysis based on visual assessment of location of projects. Source: St. Cloud Area Planning Organization

Both Bend MPO and Little Rock MPO highlighted their approaches to reaching community members through community-based organizations and events. Special efforts are made by both to connect to Spanish-speaking communities. These efforts reflect the best practice techniques used by the larger MPOs and DOTs presented earlier in this document. Little Rock tries to document the feedback it receives and account for how that feedback is used in their decision-making. 
Bend MPO and Greater Dalton MPO (GDMPO) highlighted their annual updates of demographic profiles for EJ communities. GDMPO (2015) listed Spanish-language media as an avenue for their outreach and clarified how they use "four-factor analysis" to understand the need and resources to dedicate to language services as part of their outreach. Notably, GDMPO received no requests for language translation in the previous 6 years, even while their minority population (mostly Hispanic) grew by six times between 1990 and 2010. Bend and Little Rock are dedicating new efforts and funding (Bend in a joint effort with its city government) to improve outreach to their growing Hispanic communities.

To augment the information found in these planning documents and surveys, a nationally recognized expert on public involvement in transportation decision-making was interviewed regarding challenges facing MPOs in smaller but rapidly changing regions. This expert noted that smaller metros may be more challenged to develop robust outreach and collect good data because of budgetary and staff limitations. Other issues highlighted include:

- Immigration status can influence the level of participation in public forums like urban planning processes, where some might be wary of engaging with public officials.

- Many planners are simply unaware or unconnected to many minority communities in their regions due to spatial segregation patterns and the speed of community change.

- Many smaller metros have had relatively few minority residents until recently, so many of these issues are quite new.

Transportation practitioners in small metro areas undergoing rapid demographic change can look to the community outreach and engagement strategies employed by Bend MPO, Little Rock MPO and Greater Dalton MPO to begin actively facilitating healthy dialogue with growing EJ communities. Additionally, practitioners in small metro areas are encouraged to employ some of the techniques highlighted in the Engaging Environmental Justice Communities section of Chapter 3 of this report. While the engagement techniques highlighted in this section are typically employed by larger MPOs, many of them can be scaled to meet the unique needs and constraints of small metro areas.

Overall, addressing rapid community change in smaller metros that might have fewer resources and more limited technical capacities demands special considerations from a policy, planning, and guidance standpoint.

\section{KEY TAKEAWAYS}

A significant finding from the literature review is that the United States will become more diverse, with growing minority and older populations over the coming decades. Potential changes to immigration policy could alter some of these trends toward diversity, although only slightly, according to most estimates; the overall trends will likely prevail even if they are slowed. According to Chapman (2014), immigrants tend to rely on public transportation and carpooling significantly more than U.S.-born residents (even controlling for income), and future growth in the immigrant population will have important impacts on transportation demand and planning. 
Another significant trend with implications for transportation behavior is delayed family formation and smaller families. These trends are likely to alter housing type and location preferences and, consequently, mobility demands. Such demand could place pressure on certain areas of regions with better accessibility or more and better multifamily housing with smaller units. This may place new pressures on EJ communities residing in such areas, as already witnessed through the waves of gentrification and displacement in metro areas throughout the country such as Seattle and the San Francisco Bay Area. Indeed, the effort is increasing to understand how transportation investments are changing community demographics so that significant displacement of existing EJ communities can be avoided.

Superimposing these macro national trends with the growth and movement of EJ communities creates even more uncertainties. Such pressures will have profound impacts on the size and location of EJ communities and on how EJ issues will be identified and addressed in transportation decisionmaking. The rate of change of EJ communities in some locations as shown on the maps and in the tables above, is quite high. More vigilance on the part of planners and decision makers will be necessary to understand and address those changes. As more regions become majority-minority, the methods planners used to identify EJ communities and to gauge disproportionality of impacts from a transportation action on EJ communities and non-EJ communities also might need to be reconsidered. EJ analysis practices in majority-minority regions, however, tend to remain similar to other regions (this phenomenon is revisited in later sections of this report). 


\section{CONSIDERATIONS OF CHANGING DEMOGRAPHICS: STATE OF THE PRACTICE AND NOTABLE PRACTICES}

This section of the report presents the results of a two-staged review of practice. The review looked at how the transportation decision-making process understands and responds to rapid demographic change, especially with respect to EJ analyses. In particular, the review focused on identifying methodologies and tools used to identify EJ populations in transportation planning and project analysis. The review explores the literature on demographic projections and emerging issues in demographic forecasting. However, it does not focus on the impacts, burdens and benefits analyzed as part of the environmental justice analysis process, unless this was used in some way to define environmental justice communities.

The first stage of review began by compiling a list of relevant documents spanning a wide range of literature, including the following types of products:

- Peer-reviewed academic literature.

- Practice-oriented reports.

- Existing environmental justice analyses created as part of long-range plans, NEPA environmental impact statements, projects, design and right-of-way development, and construction and operations management.

- Case study materials, trainings, and webinars produced for peer learning and technical assistance through FHWA, other transportation agencies, and university transportation centers.

- Regulations and guidance from relevant DOT modal agencies.

The second stage took a more detailed look at the practice of 20 fast-changing jurisdictions (10 States and 10 metropolitan areas) that underwent rapid proportional or absolute change in the size of their minority populations over the past 25 years. Table 5 presents the states and metropolitan areas selected for more detailed study.

All metropolitan areas studied had significant increases in minority residents between 1990 and 2010. The Los Angeles area had the least proportional growth (44 percent) but had the secondhighest absolute increase of more than 2.6 million new minority residents. The metropolitan area on the list with the fastest growing minority populations proportionally was the Portland, Oregon area, which more than doubled its minority population between 1990 and 2010. Although some regions experienced greater proportional growth, those regions tended to be much smaller. Regions of varying sizes were selected, the smallest of which were Grand Rapids, Michigan; Omaha, Nebraska; and Fresno, California. Major metros including Atlanta, San Francisco, and Los Angeles were also chosen for their sophisticated EJ analysis practices. Other metros (e.g., Houston and Tampa) selected also had noteworthy practices. 
Table 5. States and metropolitan areas chosen for more detailed review.

\begin{tabular}{|cc|}
\hline MSA & State \\
\hline Atlanta-Sandy Springs-Marietta, GA & California \\
\hline Columbus, OH & Florida \\
\hline Fresno, CA & Georgia \\
\hline Grand Rapids-Wyoming, MI & Michigan \\
\hline Houston-Sugar Land-Baytown, TX & Nevada \\
\hline Los Angeles-Long Beach-Santa Ana, CA & New Hampshire \\
\hline Omaha-Council Bluffs, NE-IA & North Carolina \\
\hline Portland-Vancouver-Hillsboro, OR-WA & Ohio \\
\hline San Francisco-Oakland-Fremont, CA & Oregon \\
\hline Tampa-St. Petersburg-Clearwater, FL & Texas \\
\hline
\end{tabular}

\section{DEFINING ENVIRONMENTAL JUSTICE COMMUNITIES}

This section focuses on understanding the variety of measures used to identify and locate EJ communities. The state-of-practice review uncovered a range of approaches used around the country. EJ communities are defined through the context of Federal regulations and related guidance such as U.S. DOT Order 5610.2(a), as containing significant numbers of racial minorities, Hispanic populations, and/or low-income households. U.S. DOT Order 5610.2(a) defines minority populations as people who identify as black, Hispanic or Latino, Asian American, American Indian or Alaskan Native, or Native Hawaiian, or other Pacific Islander. According to the Federal Highway Administration's (2015) Environmental Justice Reference Guide and the Federal Transit Administration's (2012) Environmental Justice Policy Guidance for Federal Transit Administration Recipients, the designation of low income refers to "a person whose household income is at or below the Department of Health and Human Services [DHHS] poverty guidelines.” Some regions use higher income thresholds to define low income, such as a fraction of area median income (this is designated annually by HUD for each region).

Transportation planning documents were reviewed for majority-minority regions. This revealed that these jurisdictions employed similar threshold approaches based on prevailing regional averages of minority household shares. For example, in the San Francisco Bay Area, where almost 60 percent of households are minority, a threshold of 70 percent is used to classify a neighborhood as an EJ community. Similarly, Houston uses its regional average of 52 percent as a threshold above which a neighborhood would receive points toward its composite EJ score. Likewise, the Greater Los Angeles area uses the 67-percent regional share of minority households as the threshold for EJ communities. These examples demonstrate that, even under conditions of high prevailing shares of minority households, similar techniques are used to locate and quantify EJ communities. 
Beyond analysis of low-income and minority populations (the demographic variables required in an EJ analysis), this review uncovered several supplementary demographic variables used by jurisdictions to define communities experiencing transportation disadvantage. A list of the most common indicators is provided in Table 6.

Table 6. Dimensions of social and/or economic disadvantage (other than race/ethnicity and low-income) used by MPOs and State DOTs in their EJ analyses.

\begin{tabular}{|c|c|}
\hline $\begin{array}{l}\text { Demographic } \\
\text { Characteristics }\end{array}$ & $\begin{array}{l}\text { Jurisdictions Using Indicators Beyond the Required Race and Income } \\
\text { Variables }\end{array}$ \\
\hline Seniors & $\begin{array}{l}\text { Mid-Ohio RPC, FHWA, Michigan DOT, MTC (Bay Area), Houston GAC, SCAG } \\
\text { (Los Angeles), MAG (Phoenix), North Jersey TPA, Metro (Portland), Delaware } \\
\text { Valley RPC, HRTPO (Hampton Roads), Polk TPO (Florida), SANDAG (San } \\
\text { Diego), ARC (Atlanta) }\end{array}$ \\
\hline Young persons & Michigan DOT, Metro (Portland), Polk TPO, MTC (Bay Area) \\
\hline $\begin{array}{l}\text { Persons with a } \\
\text { disability }\end{array}$ & $\begin{array}{l}\text { Mid-Ohio RPC, Michigan DOT, MTC (Bay Area), MAG (Phoenix), North Jersey } \\
\text { TPA, DVRPC, HRTPO (Hampton Roads), Polk TPO (Florida), SANDAG (San } \\
\text { Diego), MTC (Bay Area) }\end{array}$ \\
\hline $\begin{array}{l}\text { Female head of } \\
\text { households }\end{array}$ & Houston GAC, Delaware Valley RPC, HRTPO (Hampton Roads) \\
\hline $\begin{array}{l}\text { Single-parent } \\
\text { households }\end{array}$ & MTC (Bay Area) \\
\hline $\begin{array}{l}\text { Rent burdened } \\
\text { households }\end{array}$ & MTC (Bay Area) \\
\hline $\begin{array}{l}\text { Low-educational } \\
\text { attainment* }\end{array}$ & Houston GAC, SCAG (Los Angeles), SANDAG, ARC \\
\hline $\begin{array}{l}\text { Zero-vehicle } \\
\text { households }\end{array}$ & $\begin{array}{l}\text { Mid-Ohio RPC, FHWA (2015e), Michigan DOT, Houston GAC, SCAG (Los } \\
\text { Angeles), Delaware Valley RPC, HRTPO (Hampton Roads), Polk TPO (Florida), } \\
\text { SANDAG (San Diego), MTC (Bay Area) }\end{array}$ \\
\hline $\begin{array}{l}\text { Limited English } \\
\text { proficiency }\end{array}$ & $\begin{array}{l}\text { Washington DOT, Houston GAC, SCAG (Los Angeles), MAG (Phoenix), Metro } \\
\text { (Portland), Delaware Valley RPC, HRTPO (Hampton Roads), SANDAG (San } \\
\text { Diego), MTC (Bay Area) }\end{array}$ \\
\hline Foreign-born & SCAG (Los Angeles) \\
\hline $\begin{array}{l}\text { Receiving some } \\
\text { form of } \\
\text { public assistance }\end{array}$ & HRTPO (Hampton Roads) \\
\hline
\end{tabular}

\section{IDENTIFYING GEOGRAPHIC LOCATIONS OF ENVIRONMENTAL JUSTICE COMMUNITIES}

An essential element of determining whether a community receives benefits or bears the burden from transportation investments is the ability to locate those communities by geography. The literature reviewed showed that a wide range of methodologies are used to designate a neighborhood or location as containing EJ households. Many used the regional averages of minority and low-income area composition to determine the minimum thresholds above which the percentage of persons or households in a given area were considered significant, thus designating that area to be an EJ 
community. Various terminologies were used to designate a neighborhood as containing an EJ population including “communities of concern” (Metropolitan Transportation Commission), "equitable target areas” (Atlanta Regional Commission), “disadvantaged communities” (Southern California Association of Governments), and "historically marginalized communities" (Metro).

Central to the legal definition of EJ populations is race/ethnicity and income. Age and automobile ownership are also sometimes used to define transportation disadvantage in broader "equity analyses” done to supplement EJ analyses (e.g., Metro 2017). Although lack of automobile ownership inherently is not an indicator of transportation disadvantage, the presence of zero-vehicle households in areas underserved by transit—especially in suburban and rural contexts-is a significant dimension of transportation disadvantage, especially where this coincides with other indicators of concern. Many other approaches and thresholds were identified, with considerable variation between jurisdictions. Table 7 lists various types of thresholds used to define EJ communities. One interesting example is San Diego Association of Governments' (SANDAG) Healthy Community Atlas that specifies the following population concentrations per Census tract to define a community of concern:

- Low-income: greater than 33 percent earn less than \$30,000.

- Minority: greater than 65 percent minority.

- Low mobility: greater than 25 percent do not own a car.

- Disability: 25 percent of the population has a disability, or 20 percent of the population is over 65 years old.

- Low community engagement: more than 20 percent have a disability, 20 percent of households are limited English speakers, or more than 20 percent of the population does not have a high school diploma

Table 7. Example thresholds used to define EJ communities.

\begin{tabular}{|ll|}
\hline \multicolumn{1}{|c|}{ Threshold Definition } & \multicolumn{1}{c|}{ Jurisdiction Using this Threshold } \\
\hline Regional average & $\begin{array}{l}\text { MWCOG, North Texas Tolling Authority, Mid-Ohio RPC, New York } \\
\text { Metropolitan Transportation Council, Houston GAC, SCAG (Los Angeles), } \\
\text { Metro (Portland) }\end{array}$ \\
\hline Standard deviations & Omaha-Council Bluffs MAPA, ARC (Atlanta) \\
\hline $\begin{array}{l}\text { Location quotient by } \\
\text { block based on State } \\
\text { averages }\end{array}$ & Michigan DOT \\
\hline $\begin{array}{ll}\text { Percentile groupings } \\
\text { Complex indices }\end{array}$ & Houston GAC \\
\hline
\end{tabular}


The Rhode Island Division of Statewide Planning (2017) uses a "location quotient” formula (below), where a number greater than 1 indicates a given area meets the threshold for designation as an EJ area.

EJ population in the study area / total population in the study area (U.S. Census, 2000 or 2010) EJ population in the reference area / total population in the reference area

The Atlanta Regional Commission (ARC) (2017) found that a large number of Census tracts with concentrations of EJ communities clustered near the regional average concentration. This clustering diminished the significance of their "equitable target area” methodology, as many communities were classified as EJ. To remedy this, they measured the significance of a census tract's demographic characteristics by the number of standard deviations higher than the regional average for that demographic characteristic, thereby creating levels representing different concentrations of EJ communities. Like ARC, some jurisdictions create a composite index combining different measures of demographics into an overall "score.” An equity profile by Houston-Galveston Area Council (2013) uses a "Diversity Score” measurement to compare racial and ethnic diversity in the region to the 150 largest metropolitan areas in the country.

Using binary thresholds or even indices to locate EJ communities has limitations. Most importantly, it creates a situation where many EJ households are left out of analyses because they are located outside of areas designated by such threshold or indices. The Council on Environmental Quality (CEQ) guidance provides that minority populations be identified where either "(a) the minority population of the affected area exceeds 50 percent or (b) the minority population percentage of the affected area is meaningfully greater than the minority population percentage in the general population or other appropriate unit of geographic analysis.” Such measures could provide some benefit for broad census data assessment at the planning level but should not be a sole determinant at the more detailed project-level analysis. For this reason, FHWA discourages the use of bright-line thresholds to define minority populations. An alternative method is to estimate the number of EJ households or the population within all geographies and to perform analyses that can be weighted by each geography's EJ population, no matter its size or proportion. Karner (2016) has shown this "population-based" approach, as distinguished from the neighborhood-based approach discussed above, to measure transportation impacts on the overall EJ population more accurately.

New Hampshire Department of Transportation (NHDOT) (2016) staff collect and maintain race, color, national origin, poverty status, and age data for participants and beneficiaries of federallyassisted programs where reasonably available. Examples are those relocated, impacted citizens, and communities affected by transportation projects. This data is included in annual reports to the Title VI Coordinator. NHDOT also gathers data to ensure appropriate outreach is conducted to encourage the participation of EJ populations, including LEP populations. Project managers use a Title VI Project Tracking Sheet to record and maintain attendance data of all public meetings and hearings NHDOT holds. An NHDOT project manager or program administrator may request an EJ population analysis for a project, service, or activity. The Title VI Coordinator conducts these analyses for affected areas during odd years. A more targeted analysis is conducted for all projects during the 
preliminary design phase, in which low-income, minority, and LEP populations are identified to target outreach efforts and develop context-sensitive solutions. Special considerations and recommendations for outreach are provided with each analysis.

Some jurisdictions examine the interactions between EJ communities and other issues such as segregation, housing availability, housing and transportation costs, or gentrification risk as shown in Table 8. For example, some entities measure jobs-housing imbalance as a contributor to transportation disadvantage for EJ communities. ARC (2017) calculated the change in jobs-housing balance from 2010 to 2040 for equitable target areas and all other areas, using their own population and employment forecasts at the traffic analysis zone (TAZ) level. SCAG (2012) measures vulnerable populations living in "High Quality Transit Areas" surrounding rail transit stations as indicators of displacement and gentrification risk using the 2000 U.S. Census and 2005-2009 American Community Survey (ACS) data. MTC (2013) uses a "Potential for Displacement" measure, which overlays concentrations of households spending more than half their incomes on housing with locations of more intensive, planned housing growth by 2040 .

Table 8. Additional measures used to analyze EJ communities.

\begin{tabular}{|ll|}
\hline \multicolumn{1}{|c|}{ Additional Measure } & \multicolumn{1}{c|}{ Jurisdiction Using this Measure } \\
\hline Community of concern population density & MTC (Bay Area) \\
\hline Racial/ethnic segregation & $\begin{array}{l}\text { Together North Jersey, Mid-Ohio RPC, PolicyLink } \\
\text { (non-MPO) }\end{array}$ \\
\hline $\begin{array}{l}\text { Concentrations of poverty, and racially } \\
\text { concentrated areas of poverty }\end{array}$ & New Jersey TPA, Together North Jersey \\
\hline Jobs-Housing Imbalance & ARC (Atlanta), SCAG (Los Angeles) \\
\hline Fair Housing Landscape & Together North Jersey \\
\hline Housing and Transportation (H \& T) Index & ARC (Atlanta) \\
\hline Displacement / Gentrification risk & MTC (Bay Area), SCAG \\
\hline
\end{tabular}

Much of the literature emphasizes the importance of qualitative approaches to understanding communities and their changes. The Mid-Ohio Regional Planning Commission (MORPC 2016) uses three types of qualitative data measures for identifying target populations: population, geographic, and visual. Population measures can be used to identify "small pockets" of target populations within nontarget neighborhoods. Geographic data provides information and details beyond what typical census data can indicate. Visual data is applicable when information cannot be readily quantified. Another example is the analysis the Colorado Department of Transportation performed that focused on businesses and community facilities EJ communities own and frequent (Federal Highway Administration, 2017a).

Finally, the Tax Cuts and Jobs Act of 2017 created an additional approach to understanding EJ communities through its implementation of Opportunity Zones. These zones are census tracts qualifying as low-income under the New Markets Tax Credit Program with tract poverty rate at least 
$20 \%$ or median family income below $80 \%$ of statewide (for non-metro) or metro area median income. Investments in these zones receive preferential tax considerations, with the goal of spurring investments in areas with historically low capital resources ${ }^{5}$. This could be a valuable additional dataset for transportation planners and demographers to consider as they are trying to understand the geography of EJ communities.

\section{DEMOGRAPHIC FORECASTING}

Population forecasting uses techniques and data that differ significantly from the typical modeling used in transportation planning and project development in many regions throughout the United States. In many instances, staff performing population forecasting may provide input early on, but different staff are involved in the actual transportation planning decision-making process. This section covers some components of population forecasting. Key issues affecting the ability for State DOTs and regional and local agencies to predict the location and size of EJ populations or the key dimensions of transportation disadvantage, such as automobile ownership, are highlighted. In addition to the review of population forecasting, this section provides information on the practice of projecting key variables for EJ analysis, including race, ethnicity, and income, along with other nonEJ markers of social, economic, and transportation disadvantage, such as age, sex, employment, income, and automobile ownership.

State and regional agencies commonly use several types of population forecasting methods to project the location and quantity of populations and households in the future. According to Smith, Tayman, and Swanson (2001), models fall into types based on trend extrapolation, cohort-component, or more detailed urban structural models. These models are typically then modified using subjective judgment from experts and other kinds of information.

Trend extrapolation models are the simplest and extrapolate past trends into the future. These can be simple linear models or more complex relationships and also can be used for population subgroups (e.g., race/ethnicity or income). Cohort-component methods divide populations into age and sex cohorts, which are then followed over time as they age, give birth (generating new cohorts), and pass away. Estimates of in- and out-migration by sex and age cohort are then added (or subtracted) to create total population estimates. More complex structural models seek to predict the geography of population and household growth according to variables such as changes to the economy and wages, housing production and costs, commuting time and costs, and a host of additional variables. These models are often employed in tandem, where migration by age-sex cohorts might be a function of urban structural trends such as changes in industry mix or housing costs, while birth rates might be based on simple trend extrapolation. Generally, forecasts are made at larger geographies, such as States or counties. Transportation models and EJ analyses rely on understanding community demographics at a smaller geographic scale, such as census tracts or traffic analysis zones. Therefore, different techniques are used to extrapolate from larger geographic scales to smaller scales.

\footnotetext{
${ }^{5}$ https://www.urban.org/policy-centers/metropolitan-housing-and-communities-policy-center/projects/opportunityzones-maximizing-return-public-investment
} 
Of importance for this review is how these methods are applied to projecting transportation disadvantage populations and the location and quantity of EJ populations. This section focuses on the practice of projecting these variables.

\section{RACE AND ETHNICITY}

\section{Statewide Forecasts}

Efforts have been made to create state-by-state demographic projections for the entire United States, like those found in the Center for American Progress's 2015 States of Change report. The most accurate long-range forecasts, however, are from the individual State population research centers. Like the national overview presented above, all States reviewed showed significant positive population growth over the 30- to 50-year time horizons typically used. Some, however, did not produce long-range projections of racial and ethnic breakdowns.

In the first phase of this study, 10 States were chosen for more detailed investigation following a more general review of recent trends. These States experienced significant growth in minority populations, and a preliminary review of their transportation decision-making revealed potentially interesting practices for further review. The States also were chosen to represent a variety of populations and locations throughout the country. For the 10 States chosen for further investigation, the long-range demographic projections from State population research offices were examined. Table 9 presents an overview of the projections, focusing on overall population growth and changes in the Hispanic, black, and Asian population shares along with the over-65-year-old shares. Consistent with national trends, most of the States included in this study experienced significant growth in their Hispanic population shares relative to the population as whole. Generally, the shares for AfricanAmericans remained stable or slightly decreased in Texas and California, while the Asian-American population share grew moderately (for areas where projections were available). The over 65 population share also grew significantly in all projections available.

Table 9. State demographic projections.

\begin{tabular}{|c|c|c|c|c|c|c|c|c|c|c|c|c|}
\hline State & 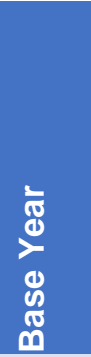 & 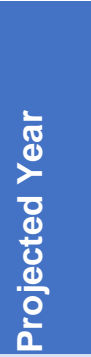 & 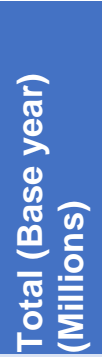 & 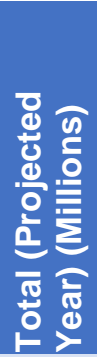 & 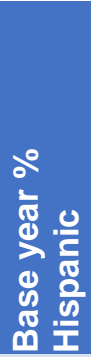 & 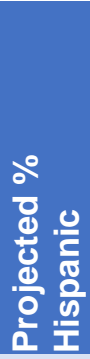 & 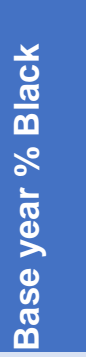 & 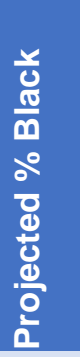 & 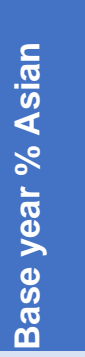 & 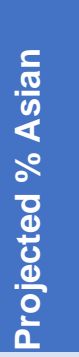 & 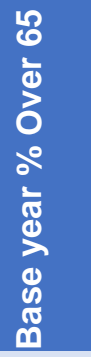 & 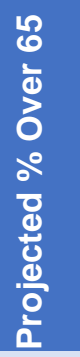 \\
\hline California & 2010 & 2060 & 37.3 & 51.0 & 37.7 & 45.2 & 5.9 & 5.4 & 13.0 & 14.1 & 11.5 & 26.4 \\
\hline Florida & 2010 & 2045 & 18.8 & 27.4 & 22.5 & 32.5 & 15.7 & -- & 2.4 & -- & 17.3 & 25.3 \\
\hline Georgia & 2015 & 2050 & 10.3 & 14.7 & 9.3 & 12.8 & 30.7 & 32.2 & 3.8 & -- & 12.8 & 22.3 \\
\hline Michigan & 2015 & 2045 & 9.9 & 10.7 & 4.9 & -- & 13.7 & -- & 3.0 & -- & -- & -- \\
\hline Nevada & 2017 & 2036 & 3.0 & 3.3 & 29.0 & 35.2 & 8.7 & 9.4 & 9.5 & 9.8 & 14.2 & 18.8 \\
\hline $\begin{array}{l}\text { New } \\
\text { Hampshire }\end{array}$ & 2015 & 2040 & 1.3 & 1.4 & 3.3 & -- & 1.4 & -- & 2.5 & -- & 16.4 & -- \\
\hline
\end{tabular}




\begin{tabular}{|lcccccccccccc|}
\hline $\begin{array}{l}\text { North } \\
\text { Carolina }\end{array}$ & 2015 & 2037 & 10.0 & 12.6 & 10.0 & 13.7 & 22.1 & 22.2 & 2.8 & 3.9 & 15.0 & 21.0 \\
\hline Ohio & 2015 & 2040 & 11.5 & 11.7 & -- & -- & 12.1 & -- & 2.0 & -- & 15.5 & 19.9 \\
\hline Oregon & 2015 & 2050 & 4.0 & 5.6 & 3.5 & -- & 1.8 & -- & 4.0 & -- & 16.4 & -- \\
\hline Texas & 2010 & 2050 & 25.1 & 40.5 & 37.6 & 53.1 & 11.5 & 10.0 & 3.8 & -- & 10.4 & 19.5 \\
\hline
\end{tabular}

\section{Metropolitan Area Forecasts}

This section explores the long-range demographic projections for the metropolitan areas chosen for further study. All experienced significant growth in minority populations, and a preliminary review of their transportation decision-making revealed potentially interesting practices for further review. The regions were also chosen to represent a variety of sizes and locations throughout the country.

Table 10 presents an overview of the projections, focusing on overall population growth and changes in the Hispanic, black, and Asian populations along with the over 65-year-old breakdown. Like the State projections, some metropolitan areas did not produce long-range projections by race and ethnicity. Following national trends, all metro areas showed significant overall population growth and a significant growth in the share of the population over 65 years old. Of those that projected race and ethnicity, significant growth in the Hispanic population share was shown, while the black population shares were expected to decline slightly in most of the areas (only Omaha and Portland showed no decline). 
Table 10. Metro area demographic projections (blank cells indicate unavailable data).

\begin{tabular}{|c|c|c|c|c|c|c|c|c|c|c|c|c|}
\hline Metro Area & 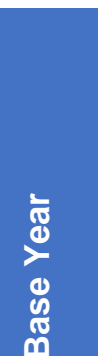 & 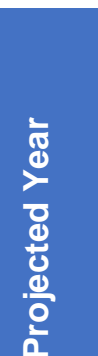 & 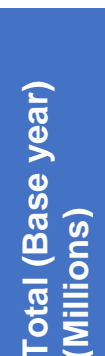 & 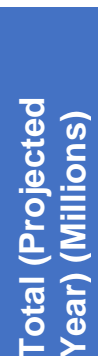 & 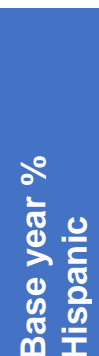 & 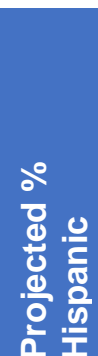 & 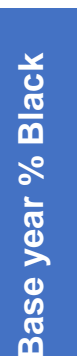 & 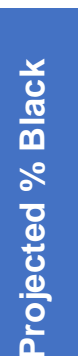 & 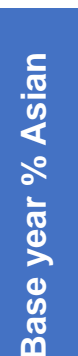 & 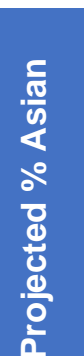 & 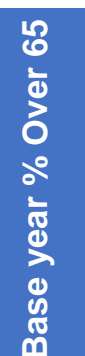 & 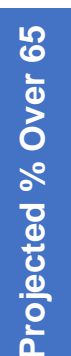 \\
\hline $\begin{array}{l}\text { Atlanta-Sandy Springs- } \\
\text { Marietta, GA }\end{array}$ & 2015 & 2040 & 5.6 & 8.1 & 10.6 & 22.9 & 52.7 & 45.1 & -- & -- & 11.2 & 19.4 \\
\hline Columbus, $\mathbf{O H}$ & 2010 & 2050 & 1.8 & 2.3 & 0.0 & 0.0 & -- & -- & -- & -- & 10.6 & -- \\
\hline Fresno, CA & 2015 & 2050 & 1.0 & 1.4 & 52.1 & 63.5 & 4.8 & 4.1 & 9.5 & 9.3 & 11.5 & 17.7 \\
\hline $\begin{array}{l}\text { Grand Rapids-Wyoming, } \\
\text { MI }\end{array}$ & 2010 & 2040 & 0.7 & 0.8 & 8.7 & -- & 8.4 & -- & 2.1 & -- & 11.7 & -- \\
\hline $\begin{array}{l}\text { Houston-Sugar Land- } \\
\text { Baytown, TX }\end{array}$ & 2011 & 2050 & 6.1 & 10.0 & 35.0 & 52.0 & 16.8 & 13.8 & -- & -- & 8.6 & 20.0 \\
\hline $\begin{array}{l}\text { Los Angeles-Long Beach- } \\
\text { Santa Ana, CA }\end{array}$ & 2015 & 2040 & 18.8 & 22.1 & 47.0 & 53.0 & 6.3 & 5.4 & 15.6 & 19.1 & 12.3 & 18.2 \\
\hline $\begin{array}{l}\text { Omaha-Council Bluffs, } \\
\text { NE-IA }\end{array}$ & 2017 & 2040 & 0.9 & 1.2 & 5.0 & 23.0 & 8.0 & 8.0 & 1.0 & 4.0 & 12.3 & -- \\
\hline $\begin{array}{l}\text { Portland-Vancouver- } \\
\text { Hillsboro, OR-WA }\end{array}$ & 2015 & 2060 & 2.3 & 3.5 & 12.1 & 25.7 & 3.2 & 3.4 & 6.8 & 11.1 & 13.7 & -- \\
\hline $\begin{array}{l}\text { San Francisco-Oakland- } \\
\text { Fremont, CA }\end{array}$ & 2010 & 2040 & 7.2 & 9.5 & 23.0 & 35.0 & 6.0 & 5.0 & 21.0 & 24.0 & 12.4 & 22.2 \\
\hline $\begin{array}{l}\text { Tampa-St. Petersburg- } \\
\text { Clearwater, FL }\end{array}$ & 2010 & 2045 & 1.1 & 1.8 & 16.3 & -- & 11.2 & -- & 2.9 & -- & 17.3 & -- \\
\hline
\end{tabular}

Because not all jurisdictions forecast race and ethnicity as part of their population projections, demographers were informally surveyed through a demography listserv to help narrow down the search. Table 11 lists the jurisdictions that do some form of population projections by race or ethnicity. Note that most of these are at the county or regional level, with only two producing projections for smaller geographical scales. 
Table 11. Jurisdictions forecasting population by race and ethnicity.

\begin{tabular}{|c|c|c|}
\hline Jurisdiction & Geographies Available & Additional Notes \\
\hline $\begin{array}{l}\text { San Diego Association of } \\
\text { Governments }\end{array}$ & $\begin{array}{l}\text { County and sub-county, including } \\
\text { community planning areas and } \\
\text { census tracts }\end{array}$ & \\
\hline Stanislaus County, California & $\begin{array}{l}\text { County, sub-county and Census } \\
\text { designated places }\end{array}$ & \\
\hline $\begin{array}{l}\text { Southern California } \\
\text { Association of Governments }\end{array}$ & Traffic analysis zones & \\
\hline State of Virginia & Counties & \\
\hline State of Delaware & Counties & \\
\hline $\begin{array}{l}\text { Houston-Galveston Area } \\
\text { Council }\end{array}$ & Region & \\
\hline State of Nevada & Counties & \\
\hline Minneapolis-St. Paul Region & Region & \\
\hline State of Florida & Counties & $\begin{array}{l}\text { Race and ethnicity by gender and } \\
20 \text { age groups }\end{array}$ \\
\hline State of California & Counties & $\begin{array}{l}\text { Five-year increments by single } \\
\text { year of age cohorts }\end{array}$ \\
\hline $\begin{array}{l}\text { Fresno Council of } \\
\text { Governments }\end{array}$ & $\begin{array}{l}\text { Eight Counties in San Joaquin } \\
\text { Valley }\end{array}$ & Totals only, no age breakdown \\
\hline State of Maryland & Counties & $\begin{array}{l}\text { Totals for two groups: non- } \\
\text { Hispanic white and other }\end{array}$ \\
\hline State of Colorado & Counties & $\begin{array}{l}\text { Three age groups by five } \\
\text { race/ethnic categories }\end{array}$ \\
\hline State of Arizona & Counties & $\begin{array}{l}\text { Totals for six race/ethnic } \\
\text { categories }\end{array}$ \\
\hline
\end{tabular}

\section{Notable Practices}

As each State and metropolitan area has its own distinct forecasting approaches, a review of all projections was not attempted. The examples below, however, afford some insight into the challenges of predicting change, especially rapid change, in EJ populations.

San Diego Association of Government's (SANDAG) (2010) demographic forecasting approach combines several models to forecast the number and location of different kinds of households at different points in time. The models incorporate industry mix and job type and wage, housing production and prices, and a wider-scale regional model of commuting. The model also separates the population into military and civilian households. Race and ethnicity are considered regarding the different rates of fertility, life expectancy, labor participation, and migration. These factors can differ quite significantly among population groups. SANDAG's larger-scale demographic forecasting (at the county scale) is translated into subareas and then census tracts, using a shift-share approach 
where historical rates of growth in the subarea are assumed for each ethnic or racial group and then the population growth in the geography is allocated to each group based on its share of growth.

While SANDAG's use of historic data to calibrate population composition at the tract level provides a more detailed picture than county or statewide forecasts, this method is nonetheless subject to some of the same shortcomings of other trend-based forecast models. Because of the smaller number of households, translating to a smaller geography can amplify changes in a small area and can point forecasts in complex directions. For example, the projections for the Mission Valley community planning area showed projections that reflect prevailing demographic trends, while census tract 20.01 within the planning area (containing around 3000 people) was forecast to lose its entire white population by 2050. The assumptions around extending historical trends many decades into the future can result in projections like these that are statistically unlikely and subject to the influence of any number of exogenous variables. Such difficulties are common and are a reason some jurisdictions are hesitant to produce long-range forecasts by race and ethnicity at small geographies.

Florida's Bureau of Economic and Business Research (BEBR) produces its long-range population projections in 5-year intervals to 2045 for each county (Rayer \& Wang, 2017). To accomplish this, BEBR uses a cohort component method to forecast population growth for three broad racial/ethnic categories: non-Hispanic whites, non-Hispanic nonwhites, and Hispanics. Each group has a separate model for fertility, death rates, and migration rates.

Given Hurricane Maria’s devastating impacts and likely effects on migration, the State of Florida's attempts to understand and measure this rapid demographic change are worth considering. How BEBR's cohort component model can respond to the migration impacts of Hurricane Maria will be important for projecting the accompanying transportation impacts.

BEBR's analysis shows that almost a third of the total migration from Puerto Rico is destined for Florida. One estimate places migration stemming from Hurricane Maria at around 50,000 people. The estimate was based on triangulating various kinds of data, including numbers of people seeking migration assistance at airports, flight arrival, and school enrollment data, among other factors. According to BEBR (2018), an overwhelming majority of these migrants will arrive without private vehicles. With many bearing significant economic hardships, the impacts on transportation demand in the locations where they reside also will likely be significant.

Stanislaus County, California employs a standard cohort component model to develop its population forecasts (Center for Business and Policy Research, 2016). The cohort components are grouped by sex, age, and race/ethnicity. Each group has its own natality, death, and migration rates. The county uses seven race/ethnicity categories. Once the projections are made at the county scale, subarea allocations are made using a shift-share approach (i.e., allocating households to subareas based on its share of growth in previous time periods); the total remains the same, but the population is shifted among subareas. Substantial calibration occurs using local information from cities and neighboring counties and knowledge not available in historical numerical data. This includes adjusting for planned housing construction or growth control policies along with other subjective judgments. 
Atlanta Regional Commission (ARC) works directly with stakeholders to augment survey data and census-type data. ARC planners and demographers have a process of local government engagement called "small area outreach." ARC works with local jurisdictions to discuss their current forecasting, get feedback on local developments, and see if the jurisdictions are aware of forecast changes. These partnerships also help ARC perform a reality check to determine if the agency is missing critical data at the local level. The demographer highlighted this approach as one of the most important practices ARC has in creating better forecasting and understanding community change. ARC highlighted the need to better understand data types and future needs to better understand trends and changes, especially with respect to migration. ARC uses new data sets such as tax data from entities like Equifax to extract demographic data on households to understand migration patterns at the county and MPO geographies. ARC planners also work with local jurisdictions to improve their data collection, which can trickle up into better regional planning. ARC makes a concerted effort to disseminate these forecasts to their member jurisdictions and hosts open data portals through which anyone can access that information.

\section{Forecasting Race and Ethnicity at the Census Tract Scale}

Agencies produce forecasts at different spatial and temporal scales for different purposes. For example, State agencies might make long-range forecasts for the entire State or counties, while regional governments produce different forecasts for use in regional planning processes. Differences between the forecasts can arise due to the spatial scales of the different planning processes and the timing of the forecasts. State and county projections might not be useful for regional-scale planning and programming processes, especially those needing census tract-scale information such as in environmental justice impact analyses. Furthermore, regional planning exercises that happen every few years might require forecasts updated on a different schedule than those produced by State agencies. Underlying data and assumptions used in forecasting are often shared among State, regional, and local jurisdictions producing forecasts, so the forecasting process among the jurisdictions can significantly overlap.

Many States produce population forecasts broken down by race and ethnicity. Although this finding warrants further investigation, the review of regional planning documents found only scant evidence that regions make explicit forecasts of population change by race and ethnicity at the census tract level (the scale required for long-range regional travel modeling). Instead, these documents provided information that implied that racial and ethnic distributions were created by applying present-day distributions to future population profiles and that no widely adopted method of projecting race and ethnicity at smaller spatial scales is available. Typically, population growth models are performed and new census tract populations are forecast; following this, present-day race and ethnicity profiles are applied to those projected populations. Alternatively, as in the case of San Diego, projections are made at larger geographies by race and ethnicity (e.g., county or county subareas) and then prorated to the census tracts based on recent growth rates. This method also avoids making explicit judgments around the neighborhood-scale movement of racial and ethnic groups.

A demographer at ARC was interviewed for this study. This interview revealed that ARC also based racial and ethnic projections at the census tract scale on present-day distributions. In this case, no 
explicit assumptions or estimates were made about the movement of communities between census tracts. The research found that most agencies do not explicitly predict movement patterns of communities by race and ethnicity at small scales within a region.

Even when considering forecasting at larger scales, which might be simpler than projections at a census tract scale, a demographer consulted for the project continuously noted the large uncertainties at play in long-range forecasting owing to the large number of exogenous variables. When considering methods to improve EJ analysis that could rely on long-range forecasts, one should consider these potential pitfalls. For instance, looking back at forecasts made in 1994 by the Census Bureau for 2020 (Campbell, 1994), significant errors were made by projecting past trends forward. In 1970, for example, about 80 percent of the population in South Los Angeles was African-American. But by 2010 the demographic makeup of South LA changed radically, with a 64 percent Latino population (Romero, 2017). That any forecasts from the earlier years predicted such large changes is unlikely.

Some of the key challenges to making long-range forecasting by race and ethnicity include the following:

- Race categories can change over time (although in many instances conversion between categories can be handled through post-hoc analysis of the data). For example, changes to the spread for persons of Asian descent in the 2015 estimates based on "alone” vs. "alone or in combination" resulted from changes to Census definitions that were not incorporated in earlier projections. Additionally, adding a "Middle East or North Africa (MENA)” category to the Census was considered; in this case, persons of Arabic ethnicity would suddenly become "minorities" instead of "white.” Further, the manner by which people self-identify can also change.

- Migration flows to the United States depend on social and macroeconomic events, and the recent past is often a poor indicator of the future. The 1994 Census projections would have incorporated 1980-1990 trends, when Asian projections were influenced by the flow of refugees from Southeast Asia that continued well into the 1980s. The Hispanic projections, however, might not have foreseen the Mexican Currency Crisis and the expansion of the U.S. economy in the 1990s that resulted in huge flows of laborers from Mexico to the United States.

- Migration flows between States, and to specific States from abroad, depend on the strength of State and local economies. The Center for American Progress's 2015 States of Change study uses 2007-2012 migration rates - a period of relative immobility, where growth of the Sun Belt slowed due to the housing crisis and high unemployment.

In addition to challenges with forecasting migration flows, fertility rates are notoriously difficult to predict. They have fallen much faster than predicted, resulting in the projected year that the United States becomes majority-minority being pushed out slightly. In 2007, 4,316,000 births occurred in the United States. In 2008, the Census Bureau projected that births would increase to 4,484,000 in 2016. In reality, they fell to 3,946,000 — by more than half a million fewer than projected. Some of 
that decline was amplified during the recession, although the trend has continued since the recovery. ${ }^{6}$ That magnitude of difference adds up over time. Instead of 439 million in 2050 (2008 Census projections), the Bureau now projects 398 million (2014). In that 2008 projection series, the Census Bureau assumed that the total fertility rates (TFRs) for Hispanic women would fall from 2.73 in 2001 to 2.53 by 2025. The observed TFR for Hispanic women in 2016 was already down to 2.09 .

\section{Overcoming Problems of Forecasting Race and Ethnicity}

At the heart of EJ analysis is understanding the composition of current and future communities and how transportation plans and investments will affect them. Unfortunately, current models used to forecast populations do not appear equipped to forecast race and ethnicity at a scale and precision needed to perform detailed EJ analyses far into the future. This poses problems for analyses required for long-range planning. Indeed, Metro (the MPO for the Portland, Oregon region), in the current planning process for their 2018 long-range plan has decided to model an interim year, only 10 years into the future, where they are more confident that the race and ethnicity composition and geography of the region is similar to present day. Like most jurisdictions, their current forecasting model cannot project the location of EJ communities with geographical precision. One compromise typically used is to assume that the geography of race and ethnicity remains the same from the present to the 20+ year planning horizon. This assumption would be problematic in geographies undergoing rapid demographic change such as Portland. Later sections of this report address in greater detail the challenges and opportunities to improve demographic projections to make long-range EJ analyses more robust, especially in areas with fast-changing demographics.

\section{UNDERSTANDING THE UNIFORM ACT, DISPLACEMENT, AND GENTRIFICATION}

Federally-funded programs or projects which are designed to benefit the public often need to acquire private property to be developed, which sometimes results in the displacement of individuals from their homes, businesses, or farms. To ensure property owners and tenants are treated fairly, equitably and receive relocation assistance, the "Uniform Relocation Assistance and Real Property Acquisition Policies Act" (Uniform Act) was enacted by Congress in 1970.

The "Uniform Act" provides important protections and assistance for people affected by federallyfunded projects government-wide. To provide guidance and assistance to Federal government agencies, the U.S. Department of Transportation (DOT) was named as the Federal lead agency for the Uniform Act, a role filled by FHWA's Office of Real Estate Services.

The DOT’s Uniform Act regulations at 49 CFR 24.205(c)(2)(ii)(D) provide: Whenever possible, minority persons shall be given reasonable opportunities to relocate to decent, safe, and sanitary replacement dwellings, not located in an area of minority concentration, that are within their financial

\footnotetext{
${ }^{6}$ http://www.pewsocialtrends.org/2011/10/12/in-a-down-economy-fewer-births/ and more specifically on Hispanic birth rate trends: http://www.pewhispanic.org/2016/09/08/latino-population-growth-and-dispersion-has-slowedsince-the-onset-of-the-great-recession/
} 
means. This policy, however, does not require an Agency to provide a person a larger payment than is necessary to enable a person to relocate to a comparable replacement dwelling.

Pursuant to this provision, a displaced person is entitled to decent, safe, and sanitary replacement housing when displaced incident is due to a public transportation project. While the Uniform Act (UA) does ensure fair compensation and assistance for those whose property was compulsorily acquired for public use, it does not contemplate the long-term impact of displacement or potential for gentrification. The UA provides replacement housing benefits for a period of 42 months for tenants. However, once these benefits are exhausted, the income of the family or person having low or fixed income may not have increased proportionately with the cost of the replacement housing. As such, advisory services are an important element of the relocation process and the agency involved in this process should advise the relocated person(s) of the resources that may address these future needs or to consider this when selecting replacement housing. The UA encourages homeownership, and allows tenant replacement housing to be utilized for a down payment on a dwelling. The relocation agent can be instrumental in providing advisory services for these purchases. Under 49 CFR 24.205(b) project funds can be used for loans to cover planning and other preliminary expenses for the development of additional housing. These advisory services could potentially help to address potential adverse impacts on the displaced person(s).

When displaced persons can no longer afford to remain in a community and property taxes increase due to various public and private investments, this may lead to gentrification. A low-income displaced person may be unable to afford replacement housing in his/her community, resulting in that individual or family relocating away from the community where they may have social, economic, and/or familial ties. As such, displacement can separate a person or group of persons from a support system. In regard to a public infrastructure project, property owners whose properties are not subject to acquisition and who are not legally entitled to advisory services could suffer profound impacts through inability to pay the higher property taxes. Gentrification can have also a profound impact on businesses in an EJ community. Businesses that are not affected physically by the footprint of the project may find it difficult to remain in the area due to increased costs and changing demographics. The service or goods they provide may have less of a market in the newly changed area. Providing assistance through mitigation for these affected businesses may be appropriate.

While Title VI provides protections to all persons in the US (including those who are not citizens) from discrimination based on race, color, or national origin, the UA prohibits payment of relocation benefits or provision of advisory services if the displaced person is not lawfully present in the United States, unless the displacement of the undocumented person would cause extreme hardship for the person's spouse, parent, or child who is a United States citizen or an alien lawfully admitted for permanent residence in the United States (49 CFR 24.208(g)). The UA also does not allow payments or services for undocumented citizens operating an unincorporated business, even if the business will be forced to close or will become inaccessible because of a [transportation] project. This could have a profound adverse effect on disadvantaged communities and populations who may struggle to reestablish themselves without financial assistance or advisory support. In the case of gentrification, 
it could cause the community to lose businesses and community members which could negatively affect community cohesion.

\section{MONITORING DISPLACEMENT AND GENTRIFICATION}

This review found that no regions actively attempt to model displacement of groups by race or ethnicity as part of their main regional planning exercises. Such predictions can be politically sensitive. Even general assumptions about the location of new housing, jobs, and population, without being specific to race or ethnicity, can be politically charged (e.g., USDA Forest Service, 2003, p. 32). Interestingly, Metro does model some population change scenarios using race and ethnicity movements, although they are not used as their official population forecasting scenarios. Still, two regions in this review were found to monitor a potential or risk for displacement and gentrificationthe Metropolitan Transportation Commission (MTC) of the San Francisco Bay Area and Metro. ${ }^{7}$ MTC evaluates its regional plan for its potential for inducing displacement of low-income and minority communities. It evaluates how development pressures induced by the plan and by wider economic development and investment scenarios are superimposed on existing low income and minority communities. When the plan and growth scenarios are projected to invest significantly in these communities, those investments are flagged for their potential to induce displacement. Metro's measure is not modeled into the future. Rather, the evaluations are updated annually based on understanding recent changes in housing prices, spending on housing and other real estate dynamics such as numbers of sales. This annual "monitoring" is designed to define and locate areas under higher risk for displacement and gentrification and to develop mitigation measures where possible.

Metro incorporates race and ethnicity breakdowns in its standard long-range population projections at the regional scale. Additionally, Metro has developed alternative scenarios to understand the gross implications of different shifts in the location of minority populations. Metro's four county-level population growth scenarios by future racial and ethnic dispersion are as follows:

1. "Status quo county trend” assumes steady increase in minority share between counties by race while adjusting for the rising percentage of minorities in the MSA.

2. Faster share of minorities shifting outward to live in suburban and exurban counties (i.e., urban area fringes).

3. Minority shift to urban fringe and white "flight" into central city (same as \#2 and at the same time increasing the share of whites living in Portland city).

4. Metro [urban growth boundary] (2016) “captures” proportionally higher share of minority population growth of the MSA (p. 2).

This explicit modeling of the spatial dynamics of race and ethnicity is rare and should be noted as a practice of interest. Most models that explicitly incorporate race and ethnicity do not incorporate mechanisms that reflect the social processes of displacement and gentrification. Metro's models, which attempt to explicitly understand these dynamics, could help in understanding the future locations of minorities, especially as they pertain to transportation project impacts.

\footnotetext{
${ }^{7}$ Other MPOs, such as Puget Sound Regional Council in the Seattle area, conduct similar analyses of displacement
} and gentrification risk, but they were not included in this review. 
In early 2016, Metro began work on its 2018 Regional Transportation Plan (RTP). At this stage, Metro convened a series of working groups to help design RTP evaluation methods, one of which was focused on equity and included members of transportation disadvantaged communities in the region. The equity working group helped define the EJ communities to consider various metrics to use for evaluation. Metro initially intended to evaluate the full 2040 RTP to the plan's horizon year. However, working group members recommended a shorter-term evaluation. Agency staff and stakeholders agreed that demographic projections were more certain in the shorter term than in 2040, especially with respect to the location of EJ communities. According to Metro (2016), "the emphasis on the near-term analysis years are to: 1 ) recognize that over the long-term, it is unrealistic to assume a community will not have turn over and change; [and] 2) emphasize the existing transportation needs and current disparities experienced by these communities” (p. 15).

Metro (2017) therefore developed an "interim” evaluation point at 2027 that would include 10 years of investments following the 2017 modeling date. The 10-year time point included about one-third of the total regional plan investments, or about $\$ 6.2$ billion (p. 5).

Table 12 describes the forecasting used to develop the community profiles used for the model for the various time points. Notice that the horizon year includes only a forecast of income and not a forecast for race/ethnicity or limited English proficiency (Metro 2016B, pp. 17-18). (Note that Metro also used an expanded definition of Historically Marginalized Communities or HMC, which included age categories.)

Table 12. Methods for forecasting historically underrepresented communities (Adapted from Metro 2016B).

\begin{tabular}{|c|c|c|c|}
\hline Community & Base Year (2015) & Interim Year (2027) & Horizon Year (2040) \\
\hline People of Color & \multicolumn{2}{|c|}{$\begin{array}{l}\text { Identifying the transportation analysis zones (TAZ) } \\
\text { which have greater than the regional rate of people } \\
\text { of color (at Base year). }\end{array}$} & $\begin{array}{l}\text { Will not produce results } \\
\text { for the horizon year. }\end{array}$ \\
\hline Low-Income & $\begin{array}{l}\text { Identifying the TAZs } \\
\text { which have greater than } \\
\text { the regional rate for low- } \\
\text { income households } \\
\text { (under } \$ 50 \mathrm{k} \text { annual } \\
\text { income) }\end{array}$ & \multicolumn{2}{|c|}{$\begin{array}{l}\text { Forecast spatial distribution of households with } \\
\text { incomes under } \$ 50 \mathrm{~K} \text {. }\end{array}$} \\
\hline $\begin{array}{l}\text { Limited English } \\
\text { Proficiency }\end{array}$ & \multicolumn{2}{|c|}{$\begin{array}{l}\text { Identifying the TAZs which have greater than the } \\
\text { regional rate of limited English proficiency (at } \\
\text { Base year). }\end{array}$} & $\begin{array}{l}\text { Will not produce results } \\
\text { for the horizon year. }\end{array}$ \\
\hline
\end{tabular}

\section{EMPLOYMENT AND INCOME}

Complex economic models are used to forecast employment and wages that could affect the location and quantity of low-income households of relevance for EJ demographic analysis. Local, regional, and even State economies are connected to and dependent on the dynamics of the larger national and international economies. States and regions therefore may wish to consider connecting their own modeling to the large macrostructural economic forecasts produced at the scale of the entire 
economy. A State economic forecast typically relies on an external forecast produced by a third-party such as IHS Global Insight (2018). These models provide estimates of the external drivers of the local economy such as the national and international demand for locally produced exports, national trends in wages, and shifts in industrial mix. For a local or State economy, these impact employment, wages, and spending into the local economy and tax base (State of Oregon, Office of Economic Analysis , 2010). State or county estimates are then scaled to smaller areas using similar "shift-share" methods described earlier. These estimates of employment and wages then become important elements for EJ analysis dimensions including wages, poverty rates, housing affordability, and commuting. For instance, SANDAG's (2010) urban growth model uses income distribution and employment to allocate growth among different areas within the region according to housing affordability and transportation commute times. This means that such forecasting might place lowincome households at the peripheries of regions where housing is more affordable.

\section{AUTOMOBILE OWNERSHIP}

Automobile ownership can be a significant dimension of transportation access, and lack of ownership and resulting public transit dependence is an important dimension of transportation disadvantage in many suburban and rural settings. Predicting automobile ownership could be an important part of understanding EJ impacts of transportation plans and investments, as investments in public transit will have more utility and impact in communities that own fewer vehicles and are transit dependent. Demographic forecasting does not typically extend to predicting automobile ownership. As part of long-range transportation modeling, however, some MPOs make this additional estimation based on the forecasts of household composition found in demographic forecasts. For example, Metro (2015) uses a typical regression model that predicts car ownership based on household composition, including variables for household size, number of workers, income and housing unit and neighborhood land use type.

As new mobility technologies and services, such as ridesourcing (e.g., Uber and Lyft) and car sharing (e.g., Car2go) grow the impacts of being car-less likely will change. Recent research in Portland, Oregon showed that lower-income residents used ridesourcing services at higher rates than higherincome residents, in part because of their lower car ownership (Golub, Serritella, \& Satterfield, Community-Based Assessment of Smart Transportation Needs in the City of Portland, 2018). However, other studies found that rideshare users with a college education and affluent background adopted ridesourcing services at double the rate of less educated and lower income populations (Clewlow \& Mishra, 2017).

\section{ENVIRONMENTAL JUSTICE ANALYSIS METHODS}

The approach an agency takes to EJ analysis can shape how that analysis might reflect community dynamics and change. This section highlights important notable practices from the document review. Approaches like population-based analyses, which can capture changes more accurately than traditional binary methods, help improve the sensitivity of analyses to changes in the location or number of EJ communities. Some of these techniques can also be used to forecast community change or warn against displacement or other unwanted changes. 


\section{POPULATION-WEIGHTED APPROACH}

Nearly all agencies surveyed were found to use a traffic analysis zone (TAZ) -based "binary" method of accounting for the location of EJ communities. With this approach, an entire TAZ is considered an EJ area if it surpasses some threshold for demographic characteristics (e.g., a higher than average concentration of low-income households). Once a TAZ is considered EJ, various measures of transportation performance like travel times, delay, and accessibility to different land uses can be tallied and averaged for EJ and non-EJ TAZs. This approach makes accounting for the precise impacts on EJ populations challenging, as they are sometimes a small share of the full TAZ population and therefore would be lost in the binary approach.

A better approach would be to perform analyses that can be weighted by each geography’s EJ population, no matter its size or proportion. In calculations of an overall regional average for the EJ community, this means that even small numbers of households count. This "population-weighted" approach, as opposed to the prevailing TAZ-based approach, was shown by Karner (2016) to measure transportation impacts on the overall EJ population more accurately. For instance, if one is calculating the overall average quality of transit service for the EJ community region wide, the population-weighted approach includes service for every household in the calculation of the average, even if they are in a TAZ with few EJ households. A binary method would account only for quality of service for TAZs that qualify as EJ TAZs based on a threshold approach.

Mid-Ohio Regional Planning Commission (MORPC) employed this population-weighted method in the EJ analysis of its 2016 metropolitan transportation plan. This method also helps overcome the difficulties that arise when EJ populations grow but might be in TAZs further from project impacts (the population-weighted method still counts these populations, but the impacts would be reduced by the distance to the project).

\section{POPULATION/USE-BASED ANALYSIS}

Metropolitan Transportation Commission's (MTC) 2040 Plan Bay Area (PBA) is the San Francisco Bay Area region's long-range transportation plan. PBA guides decisions of transportation, housing, financial, and environmental responsibility, while managing future population growth. Included in the equity analysis for the PBA planning process was a "Population/Use-Based" analysis that measures and compares how investments will benefit the EJ community relative to the region's total population and relative to their amount of travel (Table 13).

Table 13. Proportional population and investment analysis (Adapted from MTC, 2017).

\begin{tabular}{|c|c|c|c|}
\hline & $\%$ of Population & $\%$ of Plan Funding & $\begin{array}{l}\% \text { of Average Daily } \\
\text { Regional Trips }\end{array}$ \\
\hline Minority & $59 \%$ & $58 \%$ & $54 \%$ \\
\hline Low Income & $25 \%$ & $40 \%$ & $2818 \%$ \\
\hline
\end{tabular}

Using this "Population/Use-based analysis," funding is divided into transit and roads. Funding benefits are then assigned to the different EJ population groups (i.e., minority and low-income) based on these groups' amount of travel by transit and automobile. All investments by subgroup are totaled 
to determine the regional percentages in the table above. This methodology is followed to develop a Disparate Impact Analysis that examines the actual dollar amount of each project, totals it by the subgroup break down, and then determines the per capita benefit. Table 14 shows the results for the comparison between minority and non-minority communities. The numbers generated through the population/use-based analysis are then paired with a project mapping analysis. This process overlays infrastructure investments on census tracts with concentrations of minority populations or lowincome populations that are above the regional average. Stakeholder groups advocated for using the mapping analysis to balance the overreliance on quantitative analysis (MTC, 2017).

Table 14. Comparison of per capita benefits from Federal and State transit investments (Adapted from MTC, 2017).

\begin{tabular}{|c|c|c|c|c|c|}
\hline & $\begin{array}{c}\text { Total } \\
\text { Funding (in } \\
\text { Millions) }\end{array}$ & $\begin{array}{l}\text { Regional } \\
\text { Population } \\
(2010)\end{array}$ & $\begin{array}{l}\text { Per-Capita } \\
\text { Benefit }\end{array}$ & $\begin{array}{l}\text { Avg. Daily } \\
\text { Transit } \\
\text { Ridership }\end{array}$ & $\begin{array}{l}\text { Per Trip } \\
\text { Benefit }\end{array}$ \\
\hline Minority (M) & $\$ 25,797$ & $4,305,728$ & $\$ 5,991$ & 998,992 & $\$ 25.82$ \\
\hline Non-minority (NM) & $\$ 17,850$ & 3,033,324 & $\$ 5,885$ & 616,075 & $\$ 28.97$ \\
\hline
\end{tabular}

Whether per-capita spending accurately reflects transportation benefits such as improvement in accessibility and safety is debatable. Yet, these measures can be of some utility when combined with other kinds of analyses of other transportation benefits. This approach presents some additional complexities. For example, the population/use-based analysis does not assign value to benefits or burdens of improved access or mobility. Further, the measures are developed using current population conditions and do not reflect long-term impacts of investments into the future. Lastly, this approach measures only capital investments and does not account for service changes.

\section{ANALYZING DISPLACEMENT POTENTIAL}

Metro, the MPO for the Portland, Oregon region, convened a working group of representatives of various communities, advocacy groups, and nonprofits to develop its equity analysis methodology as part of its 2018 Regional Transportation Plan (RTP) evaluation. A central issue to stakeholders was the potential for displacement due to transportation plan investments. Displacement refers to the economically induced movement of established residents and businesses due to rapid and prohibitive increases in local costs. In recent decades, housing and location preferences have shifted toward central, accessible locations, resulting in higher costs of living in historically EJ urban neighborhoods. Such economic pressures have led to growing intra-metropolitan shifts in the location of racial/ethnic minorities and low-income individuals, a trend that is contributing to the growing "suburbanization of poverty." Relocation of displaced individuals to suburban and exurban areas with lower housing costs often results in fewer transit options and less access to necessary good and services. Further, displacement can break up established social bonds and community networks that could help individuals through these transitions, while further diminishing economic opportunities for displaced individuals. Concerns like these shaped discussions about the current contents of the 2018 plan, for example, where priorities may lie for addressing road safety or adding transit service.

In the long-range modeling conducted for the plan evaluation, questions about the ability to model displacement arose. Similar to the MTC approach, Metro assumed that investments that shape 
accessibility would cause increased development pressure and accelerate displacement potential, especially in areas currently experiencing housing vulnerability. Metro felt, however, that modeling long-term housing costs was not robust enough to understand long-term impacts of planned investments on housing costs and therefore displacement. Given this, Metro instituted a policy to monitor displacement risk and regularly update these measures to keep the community aware of potential displacement. The measure reflects housing cost burden, rapid increases in prices, and the share of residents who rent, among other things. Metro's displacement monitoring measure will be developed using a study by the City of Portland on gentrification and displacement (Figure 13).

Metro's aim with this measure emphasized the need not just to monitor gentrification and displacement passively, but also to understand how policies could be implemented to mitigate displacement. Metro (2018B) has since released a draft review of best practices to reduce the rate of displacement and is working to place a measure on the 2018 ballot to fund a regional bond for 500 million dollars for affordable housing and other anti-displacement investments. As the 2018 RTP is due for approval in the latter half of 2018, the extent to which displacement concerns will shape the final plan at the time of writing is difficult to know.

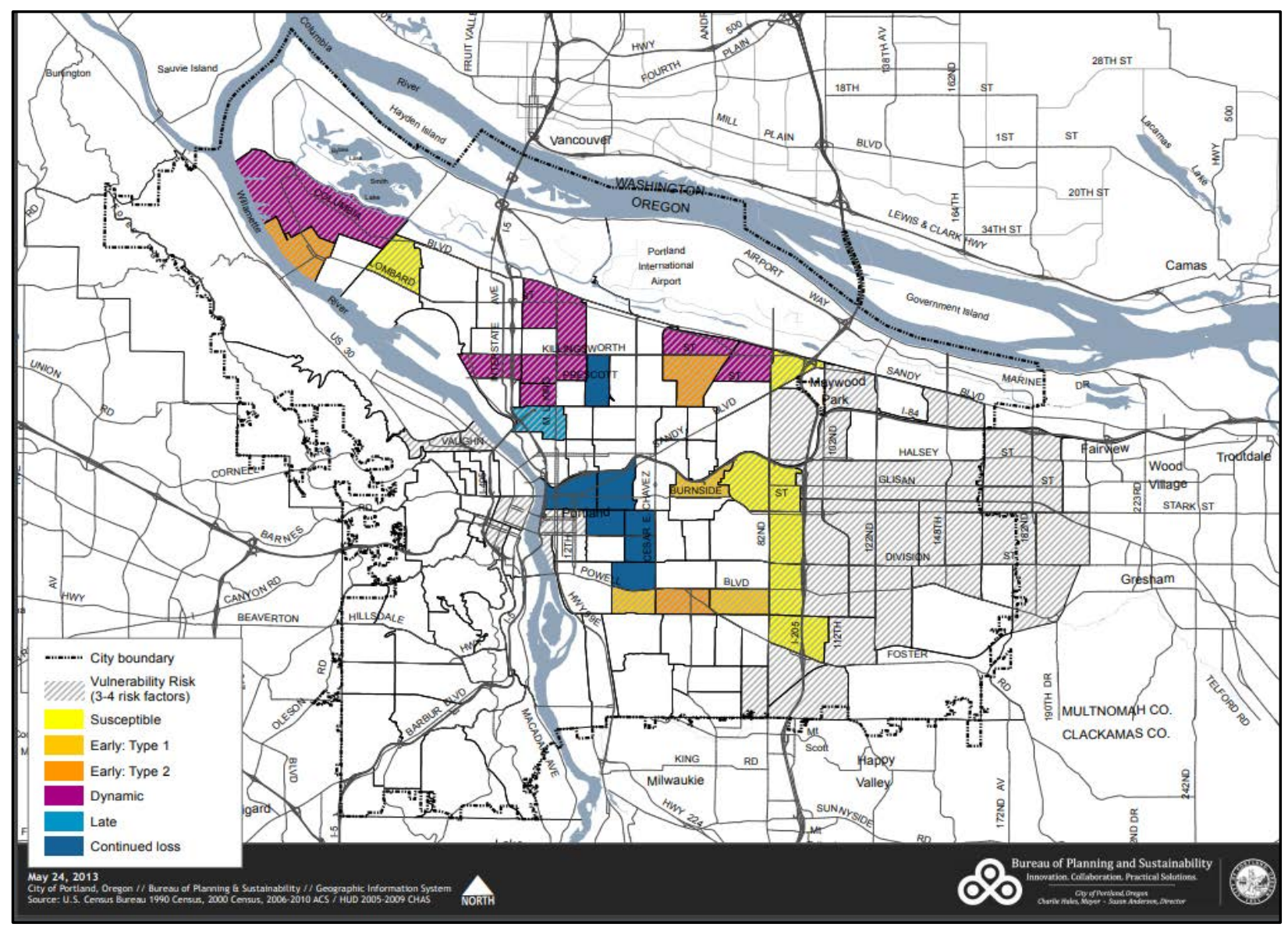

Figure 13. City of Portland gentrification and displacement study (Source: City of Portland, Bureau of Planning and Sustainability). 
Metropolitan Transportation Commission conducted a Potential for Displacement analysis for its 2013 Plan Bay Area (PBA). This analysis overlays housing cost burden with intensive planned housing growth (defined as more than 30 percent growth) to reveal neighborhoods that are vulnerable to future displacement. The potential for displacement measure was used to identify where clusters of vulnerable renters live relative to places anticipated to experience market pressure due to planned growth patterns. This measure was one part of a 2013 PBA rubric used to compare regional investment scenarios.

Compared to a no-build scenario, the measure showed that the regional plan would increase displacement potential by about 2/3 in both communities of concern and communities that were not of concern. This led the EJ evaluation to conclude that the plan did not create disproportionately high effects on communities of concern, even though the effects were adverse. Whether this adverse effect motivated any changes to the plan is unclear. However, MTC did address steps it was taking to reduce displacement pressures, including implementing grant programs and plans geared to addressing displacement pressures. Two of these grants included affordable housing construction, and the other examined both low- and middle-income jobs relative to the locations of affordable housing. Puget Sound Regional Council (2018) also uses measures of displacement risk in its planning and system monitoring of the Seattle region.

The Newtown Pike Extension in Lexington, Kentucky would link the existing Newtown Pike roadway with areas of downtown Lexington, including the University of Kentucky and surrounding environs. The Newtown Pike Extension project, a partnership between FHWA, State, and local partners, would cross the low-income neighborhood of Davistown, potentially displacing residents and disrupting the neighborhood by increasing the area's accessibility. This increased accessibility was anticipated to result in land value appreciation and development pressure. Additionally, it was expected to result in increased rent and housing costs for area residents.

A community impact assessment for the project noted the Davistown community had already been subject to decades of housing loss. In fact, the final environmental impact statement for the project stated that "the No Action alternative has already imposed an unfair burden on this neighborhood" (Federal Highway Administration and Kentucky Transportation Cabinet , 2007a). The Newtown Pike Extension involved acquisition of an additional 37 housing units. Because these impacts were deemed disproportionately high and adverse to the area's low-income residents, both directly through property acquisition and indirectly through induced market forces, planners determined that mitigation was required (FHWA and Kentucky transportation Cabinet, 2007B). The Southend Urban Park Village was conceived as a solution. The Village would be on adjacent land south of the Newtown Pike Extension and would offer affordable rental units and homeownership opportunities (with land held by a community trust), along with community spaces.

The Newtown Pike Extension was notable for several reasons. First, the crossover from transportation to housing concerns was very important for recognizing the non-transportation impacts of the project. The conviction of planners that the economic and neighborhood impacts were as important as traditional transportation impacts such as noise or traffic congestion is an important 
aspect of this case. Second, the project was notable for its ability to integrate a complete solution approach into the record of decision. The sophisticated housing relocation and mitigation plan, which included the institutional aspects of the community land trusts, compensation, and affordability planning provides a forward-thinking example in its consideration of both primary and secondary effects of transportation investments on EJ communities.

\section{ENGAGING ENVIRONMENTAL JUSTICE COMMUNITIES}

The documents reviewed focused heavily on State and regional agencies' methods of engagement with communities throughout various stages of transportation decision-making. Because DOTs rarely conduct the kind of technical analysis and modeling performed at the regional level, this emphasis on engagement was appropriate. The engagement activities varied but included a wide range of best practices that the next section focuses on. Engagement with communities can also help with gathering information and data not readily available through normal publicly available data sets such as the U.S. Census and American Community Survey. This section focuses on how decision-making practices at the State and regional level incorporate public engagement and the incorporation of practices that can respond more quickly to community changes.

This section also closely explores the practices of public engagement and engagement with LEP populations more specifically, as these demand more tailored responses to changing demographics. These practices are reviewed by sampling work plans and planning products from a national scan of documents and the 20 study jurisdictions proposed in earlier sections of this report. The major mechanisms and tools used to help decision-makers respond quickly to demographic changes are presented in the following sections.

\section{INNOVATIVE PUBLIC ENGAGEMENT AND DATA GATHERING}

Relying solely on large longitudinal or decennial data sets such as the U.S. Census or American Community Survey could result in delays in understanding communities undergoing rapid change. Improved engagement techniques and data gathering directly from communities is a powerful practice that improves understanding of community dynamics. This section highlights notable engagement and data gathering techniques that show promise in improving understanding of EJ communities.

Many agencies use online tools, such as websites and social media, to communicate with the public. That such engagement would be an important element of practice in a context of rapid demographic change was clear through the review. The ability to translate to new languages and redirect communications to new outlets because of the flexibility of web-based communications appears an important aspect of practice in fast-changing regions. These approaches to outreach are also important for low-literacy (although English-speaking) populations where reading texts and prints might be a challenge. Many of the jurisdictions reviewed used online communications not only as a core means of releasing information, but also for collecting feedback from the public on a variety of issues. 
Houston-Galveston Area Council (H-GAC) is the MPO for one of the most racially and ethnically diverse major metro areas in the United States, including a significant population of LEP residents (Mejia, 2017). In preparation for creating the 2035 Regional Transportation Plan, H-GAC began designing a public engagement strategy they called "Envision Houston Region." The initiative partnered with prominent stakeholder groups to answer questions of how and where future and existing residents would live and work in 2035. The first set of six meetings occurred in fall 2005 and was designed to map how the region could grow and depict alternative visions of livable scenarios for the participants. The largest event was a workshop that over 400 people attended, with over 50 Houston ZIP codes represented. In total, the fall series engaged 800 participants in designing three scenarios of the Houston-Galveston area in 2035. The first scenario (A) depicted the region's forecast growth. The second (B) depicted the workshop's ideal growth pattern with the region's forecast growth. The third scenario (C) depicted the same ideal growth patterns but showed the growth of each county individually. Scenario B portrayed growth along major road networks radiating from the city, while Scenario $C$ depicted growth in mixed-use clusters and along the highway networks.

The second phase followed in May 2006 and engaged 550 participants through four community forums. Each forum had a panel of experts, elected officials, land developers, lawyers, economists, and planners who could discuss the implications of each scenario on a multitude of factors with emphasis on mobility, environment, and quality of life. With the three scenarios, local government and citizens could understand how their preference for density and growth would play out once the population grew by 4 million people, nearly doubling in 35 years. When completed, Envision Houston Region provided a set of community values that could guide the planning process. The values informed the 2035 Regional Transportation Plan and the prioritization of projects in the 20082011 Transportation Improvement Program (HGAC 2011A, 2011B, 2011C). While the project had no clear emphasis on EJ other than translation of materials into Spanish and Vietnamese, future engagement efforts could build on the successes of the Envision Houston effort to create an approach tailored to improve engagement with these communities.

Houston planners continued their emphasis on outreach for their 2040 Regional Transportation Plan, Houston-Galveston Area Council (2016), and they set about designing a public engagement strategy to better understand what EJ populations prioritized within the transportation system. Survey results were collected for 170 participants from minority, low-income, elderly populations, limited educational attainment, and zero-automobile households. Results were analyzed separately for EJ groups and transportation disadvantaged groups and compared to the overall results for the entire region. These populations were asked to identify their priorities concerning public transportation; fixing existing roads and highways; building new roads and highways; improving design and safety, sidewalks, and bikeways; and planning and coordination. Public transportation was ranked the highest priority by each category of EJ and transportation disadvantaged respondent. "Fix existing roads and highways" was the second highest priority for minorities, low-income and elderly populations, and was of equal importance as "build new roads and highways" for limited educational attainment residents. H-GAC found that proposed public transportation expenditures did not reflect 
the high priority that the populations placed on public transportation. Proposed expenditure on highways and roads exceeded that of public transportation.

Atlanta Regional Commission's (ARC) (2018) uses a variety of methods to bolster stakeholder input, including partnerships with community and advocacy organizations; various media outlets, surveys, and web-based communications; and pop-up meetings along key transportation corridors to solicit feedback on projects underway. ARC measures outcomes by surveying non-projectspecific communities on their perspective of how the agency is meeting its equity goals concerning access and distribution of project impacts. Public input is gathered by representatives from groups representing social equity, seniors, youth, disability, LEP, ethnic, minority, and lowincome residents of the region. Input is also gathered about preferences for engagement methods and level of satisfaction with how ARC conducts community engagement in general (Atlanta Regional Commission, 2016b). This customer feedback could be important for understanding growing or changing communities and issues like the need for translation or new locations or events in which ARC should participate.

This kind of direct information gathering could serve as an important method to understand community and demographic change, especially if community comments highlight qualitative issues not easily recognizable through typical census-type data. For example, ARC conducted an online survey after the completion of the Atlanta Region's Plan to inform future regional planning efforts. The survey was sent to 4,147 unique participants of various outreach activities that took place throughout the planning process, over 450 of whom answered it in full or partially during the 13 days the survey was available. Survey questions asked about respondent experiences with various outreach activities to inform future process improvements.

ARC also creates innovative engagement venues such as the "New Voices Initiative" (2018), which seeks engagement with new perspectives in regional planning efforts. The initiative formed a Millennial Advisory Panel, recognizing that the millennial generation represented 25 percent of Metro Atlanta and will shape and lead the region in the future. In January 2015, 135 metro Atlanta residents between the ages of 18 and 34 years were selected as Millennial Advisory Panel members. Although white residents were overrepresented compared to the regional demographic makeup, equity was a major theme of the group discussions. The Panel participated in ARC-sponsored "mixers" in which they brainstormed challenges and solutions and formed eight task forces based on interest areas. The Panel was also challenged to expand outreach to neighbors and peers by hosting their own informal civic dinners and gathering input. Input from the civic dinners ultimately informed the Atlanta Region's Plan.

In addition to the Millennial Advisory Panel, ARC formed a Global Advisory Panel in January 2017 to engage the growing immigrant population, which had increased from roughly 100,000 in 1990 to 700,000 in 2015. This group now represents over 15 percent of the region's population. More than 150 foreign-born residents were selected as panel members who hosted civic dinners in their own homes or at restaurants, using a host guide ARC developed. The purpose of these dinners was to gather notes and survey data to be compiled into a report for ARC to share with their board and 
regional leaders. Through its successful engagement of populations MPOs have often struggled to reach - immigrants and youth, for example-ARC offers a fresh approach to public engagement that could be adapted to better understand rapid community change.

Memphis MPO’s demographic make-up is largely split between African American and white populations, with a growing Hispanic population. To better address their equity challenges, the Memphis Urban Area MPO developed public involvement strategies to ensure the needs and concerns of EJ communities are considered in the equity analyses. For the development of the current long-range plan, LIVABILITY 2040 Regional Transportation Plan, the MPO marketed public meetings through ads on Memphis Area Transit Authority buses and developed a series of YouTube videos featuring mayors from jurisdictions around the region in order to encourage broad public participation.

To foster a more inclusive public involvement process, public meetings were held throughout the region, including rural communities in neighboring Mississippi. When possible, meeting locations were accessible by public transit. The meeting notifications were circulated through email and postcards mailed to businesses and residents within a half-mile radius around the meeting location. Also, the Memphis MPO leveraged its partnership with local libraries, where printed copies of planning documents were made available at 17 library locations across the region.

\section{CONTINUOUS MONITORING AND EVALUATION OF ENGAGEMENT PROCESSES}

Many jurisdictions engaged in regular evaluations and adjustments of their engagement processes. For example, Ohio DOT, in its 2015 public involvement process claimed: "Reviewing public involvement opportunities is becoming particularly important as the technological options for public involvement are rapidly evolving."

Florida Department of Transportation's (FDOT) Efficient Transportation Decision-making (ETDM) initiative is designed to improve transportation planning and decision making by enhancing stakeholders' access to planning data and documents and providing a forum for soliciting their feedback. As this initiative creates the capacity to update key data between transportation decision-making points—especially pertaining to community demographics — this initiative offers a potential solution to the central challenge addressed in this report (i.e., how to improve decision making and EJ analysis in communities undergoing rapid demographic change).

The initiative centers on involving stakeholders early in the project development process.

Stakeholder groups specifically targeted for engagement are government entities including MPOs, county, municipal, State, and Federal governing bodies; Native American tribes; and the public. Partnering with the University of Florida's GeoPlan Center, the ETDM initiative created an online tool called the Environmental Screening Tool (EST). The EST serves as a web portal for project plans, analyses, updates, mapping and visualization tools, and feedback. The tool and process have proven effective at simplifying the environmental review process. As FDOT explains:

For over five years of operation with a user community of 1200 practitioners representing staff from 8 DOT Districts, 26 Metropolitan Planning Organizations (MPOs), 24 federal and 
state resource agencies, two Tribal Governments and the countless representatives from the public, the EST has proved successful in supporting the ETDM process. Over 1500 projects have been entered in the EST database and over 350 of them have completed the environmental review process (Florida Department of Transportation, 2016).

The EST provides a platform through which all stakeholders can access the same information about transportation projects. The EST provides the public and partner agencies opportunities to connect to transportation projects through the entire review process, as documents are updated, analyses are performed, comments are collected, and decisions are made. The tool folds in analytical and visualization tools with application documents. The platform operates with a search function that can query by project number, name, organization, county, or FDOT district. FDOT provides computerbased trainings and recorded webinars for the EST's public access site. Their online trainings include an overview of general navigation and tools and how to subscribe to project notifications.

The Sociocultural Data Report (SDR) is perhaps the most relevant EST resource for understanding demographic change in EJ areas. The SDR allows users to estimate "sociocultural effects" from projects and helps analyze project alternatives. The data representing community demographics are loaded from the U.S. Census and the most recent American Community Survey (ACS) data. The SDR report compiles a variety of demographic and community information into a single report. The user can define the impact area geography and other parameters. The report includes overall population, race and ethnicity, age, income, disability status, educational attainment, language, housing tenure, and land use. The report also lists important community facilities such as religious centers, parks, community centers, and schools. The SDR serves as an excellent compilation of relevant community information and resources. Although not currently configured to generate EJ analyses, the tool could be expanded to focus on EJ community definitions and impacts.

Atlanta Regional Council (ARC), in its 2016 stakeholder engagement plan stated: "To ensure the success of the stakeholder engagement program, ARC will continually monitor the effectiveness of various engagement techniques. In addition to qualitative assessment of each individual event or technique, ARC staff will evaluate the program in terms of how well it meets five goals...” These goals are to:

- Maximize the number of participants by reaching new audiences, with a focus on ensuring geographic and demographic diversity reflective of the region.

- Increase the return on investment-less cost per participant.

- Gain insight into public opinion with quality input.

- Increase consensus for plan priorities.

- Produce actionable information from quantifiable data.

The monitoring process, for example, analyzed the Transportation Equity Advisory Group membership to see how it could be even more inclusive and open with its membership. Other agencies had similar adjustment processes, sometimes including public comment periods when their participation planning resulted in significant changes to their practices. Such feedback and adjustment should be especially important in times of rapid demographic change. If the location or 
quantity of EJ communities change, this engagement process should also adjust accordingly. Furthermore, in meeting the needs to engage with LEP or low literacy (English-speaking) populations, this monitoring can help plan for translation or other outreach techniques. Several agencies remarked about the need for regular evaluation because of changing technologies used for outreach.

\section{POLLING AND SURVEYING}

Rather than relying solely on larger data sets from the Census, other agencies, or private data providers, many agencies actively survey their communities through either online tools, in-person methods, or both. This approach should allow agencies to understand community change significantly faster than Census data or other data sets can provide. Furthermore, using communitygenerated data can mean more nuanced questions can be asked and more precise understandings of community challenges and EJ issues can be gathered. Some agencies used more in-depth methods such as focus groups and interviews to obtain even richer information than larger sample surveys can provide.

Southern California Association of Governments (SCAG) hosts public workshops to disseminate information with the help of computer modeling. California Senate Bill 375 requires California MPOs to develop a Sustainable Communities Strategy (SCS) to reduce greenhouse gas emissions when creating a regional transportation plan. The bill stipulates that MPOs provide the public with tools and information necessary to understand and influence policy choices reflected in the SCS. To this end, SCAG created the Local Sustainability Planning Tool (LSPT). LSPT can model land use scenarios based on vehicle ownership, vehicle-miles traveled, and mode-use and their combined impact on greenhouse gas emissions. LSPT operates at the parcel level and can provide a higher level of sensitivity of analysis than the TAZ-based model. The model operates from an ArcGIS platform and is available for remote access at workshops. It is also available to individual community members via email inquiry to a staff member listed on the LSPT website (SCAG n.d., 2012, 2018).

\section{PARTNERSHIPS WITH COMMUNITY LEADERS AND STAKEHOLDER GROUPS}

Many agencies rely directly on partnerships with community organizations to obtain a better sense of community needs, communicate decision making issues to the community, and gather information from the community. For example, ARC, in its 2040 regional plan stated: "community partnerships provide opportunities for EJ organizations to convene listening sessions in their neighborhoods and provide resources to help low-income individuals participate in the planning process." Some agencies relied on these partnerships to gather feedback and information from communities that were more difficult to engage. Partnerships with community-based organizations can help speed the flow of information from communities to agencies, especially under fast-changing conditions.

Nevada Department of Transportation (NDOT) (2009) staff planned and hosted eight public involvement meetings while creating its 2008 long-range transportation plan. Afterward, staff were disappointed with the low turnout. Consequently, NDOT turned their engagement practice on its head and began intentionally engaging with specific stakeholder communities. Once identified as such, staff began attending their community meetings. This focused approach made sure specific 
voices were heard, rather than holding general meetings where the public had to make a special effort to attend. NDOT began piggybacking its information onto the meetings of these other stakeholder groups by presenting at their meetings and workshops. For example, staff began a regular practice of creating annual county and tribal tours where they presented the statewide transportation improvement program. Being out in the community allowed staff to better understand each community's needs and desires.

For NDOT's One Nevada Transportation Plan (2018A), staff facilitated a series of focus groups with subject matter experts from the public and private sectors to address issues of aging infrastructure, tourism and attractions, urbanization, diversified economy, transportation behavior, and new technologies. This included involvement of "multi-cultural community groups," comprised of representatives from minority communities. These focus groups were convened to identify strategies to prepare the State for changes over the next 20 years considering uncertainties surrounding contemporary transportation systems. Eight focus groups met for 4 hours each and used the Robust Decisions-Making framework, a scenario planning tool for decision making and strategic analysis.

NDOT's study team thoroughly examined all strategies developed throughout the focus groups processes. Similar strategies were combined, and ultimately, the proposals that best supported the One NV Plan goals were selected. Thirty potential strategies were produced spanning the goals of safety, resiliency, investment, livability, and quality of life for all modes.

\section{ADVISORY COMMITTEES}

In this review, standing advisory committees, especially regarding EJ, are a common tool that agencies use. For instance, the Georgia DOT (GDOT), in their report on the impact of EJ analysis on transportation planning (2018), stated the department uses a (p. 21): “committee of citizens for input and feedback on decisions for a specified term longer than the duration of an individual project or review. This committee may provide feedback on a variety of issues, including but not limited to EJ.” GDOT also maintains a stakeholder database of interested parties to contact for comments on their annual State Transportation Improvement Program (TIP), with parties organized by EJ categories. Outreach and events are organized by the location and number of EJ populations according to this database. Like community partnerships, advisory committees can give agency staff greater insight into community needs without relying on intermittent data sets. Furthermore, as community needs or locations change, this information can come directly to the agency through members of the committee.

Nevada Department of Transportation (NDOT) (2009) consistently seeks new and innovative approaches to maximize public participation in project and plan development. For example, NDOT's Advisory Committee for Transit (ACT) gathers representatives from numerous agencies and organizations to provide programmatic oversight and guide the development of its Statewide Transit Program. Diverse committee membership represents various communities with transportation disadvantage including the Nevada Department of Housing and Rehabilitation, Nevada State Health Division, Nevada Division of Aging Services, Retired Senior Volunteer Program, Ormsby Association of Retired Citizens, tribal councils, senior centers, transit providers, and employers. This 
type of advisory committee can be an important method for information gathering under conditions of rapid demographic and community change. NDOT, like many DOTs in States overlapping with tribal governments, also has direct intergovernmental consultation with tribal governments about project development, statewide planning, and construction impacts. Current planning for the statewide plan, “One Nevada” includes public meetings throughout the state (NDOT 2018B).

\section{KEY TAKEAWAYS}

The state of practice review found that most recognition of changing community demographics concerned the quality and process of long-range forecasting, which occurred primarily within the long-range regional transportation planning documents reviewed. Time plays a key role in this regard because community change is assumed when making long-term forecasts. Few references were found that addressed the issue of demographic changes between decision-making phases that could affect their quality, especially regarding understanding and addressing EJ impacts.

The FHWA Environmental Justice Reference Guide (2015) recommends that agencies follow an "iterative process to capture the demographic and socioeconomic changes that naturally occur in communities over time." The guide also primes practitioners to be ready to "repeat some or all of the steps as new information becomes available.” This would address any issues that arise if rapid community change renders analyses performed at the earlier decision-making stages obsolete. NCHRP Project 8-36 (11): Technical Methods to Support Analysis of Environmental Justice Issues (2002), also cautions that demographic projections and forecasts are often inaccurate. Similarly, the Federal Transit Administration's (FTA) Environmental Justice Policy Guidance for Federal Transit Administration Recipients (2012) circular recommends a "know your community" approach and emphasizes the need to track changes in the community over time using consistent data sources. These statements point to the need for more specificity and clarity on best practices. The five notable practice case studies in the following section seek to provide such examples. 


\section{FIVE NOTABLE PRACTICE CASE STUDIES}

This research identified several practices that best address the challenges associated with multimodal and multi-phased transportation decision making when affected communities are undergoing rapid change. Focusing particularly on EJ communities and EJ analyses, five case studies were chosen that exemplify some of these best practices. Five innovative and practical case studies highlight approaches to improve decision making under conditions of rapid community change.

The case studies cover a range of practices including demographic forecasting, EJ analysis for projects and plans, community and stakeholder engagement, and transportation decision-making support tools. Innovative practices from a range of jurisdictional sizes were identified. The case studies include the following four metropolitan planning organizations and one State DOT:

- Florida Department of Transportation (FDOT).

- Mid-Ohio Regional Planning Commission (MORPC) - the Columbus, Ohio metro area.

- Atlanta Regional Council (ARC).

- Metro - Portland, Oregon metropolitan area.

- Metropolitan Transportation Commission (MTC) - the San Francisco Bay Area.

Each case study includes background about the jurisdiction and the region or State where the organization is located. The case studies explain the core challenge the practice addresses, followed by a detailed exploration of the practice and outcomes for improved decision-making. Each case study closes with discussion of lessons learned and points the reader to additional resources to learn more.

The Florida Department of Transportation's Environmental Screening Tool, which is part of its Efficient Transportation Decision-Making initiative, stands out as a practice having significant potential to improve EJ analysis and decision making under conditions of rapid community change. The cases of Metro (Portland, Oregon) and Metropolitan Transportation Commission highlight innovative practices in EJ analysis for long-range transportation plans and forecasting, which are especially pertinent in conditions of rapid community change. Mid-Ohio Regional Planning Commission uses a unique "population-based” approach to its EJ analysis of transportation impacts from this long-range plan, and ARC conducts an innovative stakeholder engagement process to improve its forecasting and modeling while also assisting those stakeholders with understanding their own community dynamics. These cases illustrate the broad range of practices that influence how an agency understands its communities, how it can forecast community change, and how its EJ analyses can be improved to better anticipate and respond to demographic change. 


\section{FLORIDA DEPARTMENT OF TRANSPORTATION}

\section{INTRODUCTION AND OBJECTIVES}

To improve transportation decision-making, Florida Department of Transportation (FDOT) established the Efficient Transportation Decision-making (EDTM) multistage process for transportation projects. The review process is facilitated through the Environmental Screening Tool (EST), an interactive online database. This spatial analysis tool is used to generate a Sociocultural Data Report (SDR) that compiles historic demographic information for an area of interest (e.g., a project area) and inventories existing community-oriented facilities such as hospitals, schools, and parks. This report is generated during the first phase of the project review and is updated during each phase of the review process. The SDR serves as the starting point for the Sociocultural Effects Evaluation, which helps advance the EJ analysis process. This process is also unique in that it requires the demographic analysis conducted near the beginning of a project proposal phase to be updated at project milestones.

This process promotes early communication and improves public access to the decision-making process to streamline the review process. The collaborative approach links transportation, land use, and environmental resource planning with 26 MPOs, 6 FDOT districts, 2 tribal governments, and the public. With communication channels open early, potential human or environmental issues can be identified early rather than disrupting the process later, which can cause costly delays.

\section{COMMUNITY PROFILE}

Florida surpassed New York as the third most populous State in 2014. In 2017, it is estimated to have nearly 21 million residents. Florida is projected to become a majority-minority State in 2028. By 2060, the non-Hispanic white population is expected to comprise just 35 percent of the population (Center for American Progress, 2015).

Florida's population gains have historically come from an in-migration of retirees and Hispanic immigrants. Consequently, Florida's average age is 42 years, compared to the U.S. average of 38 years. Figure 14 shows that by 2030 nearly 65 percent of Florida’s population gain will come from people over the age of 60 years, and more than half of that from people over 70 years. Although age is not an EJ dimension, it is correlated with transportation disadvantage and the disproportional increase in the $60+$ age groups is worth considering. 


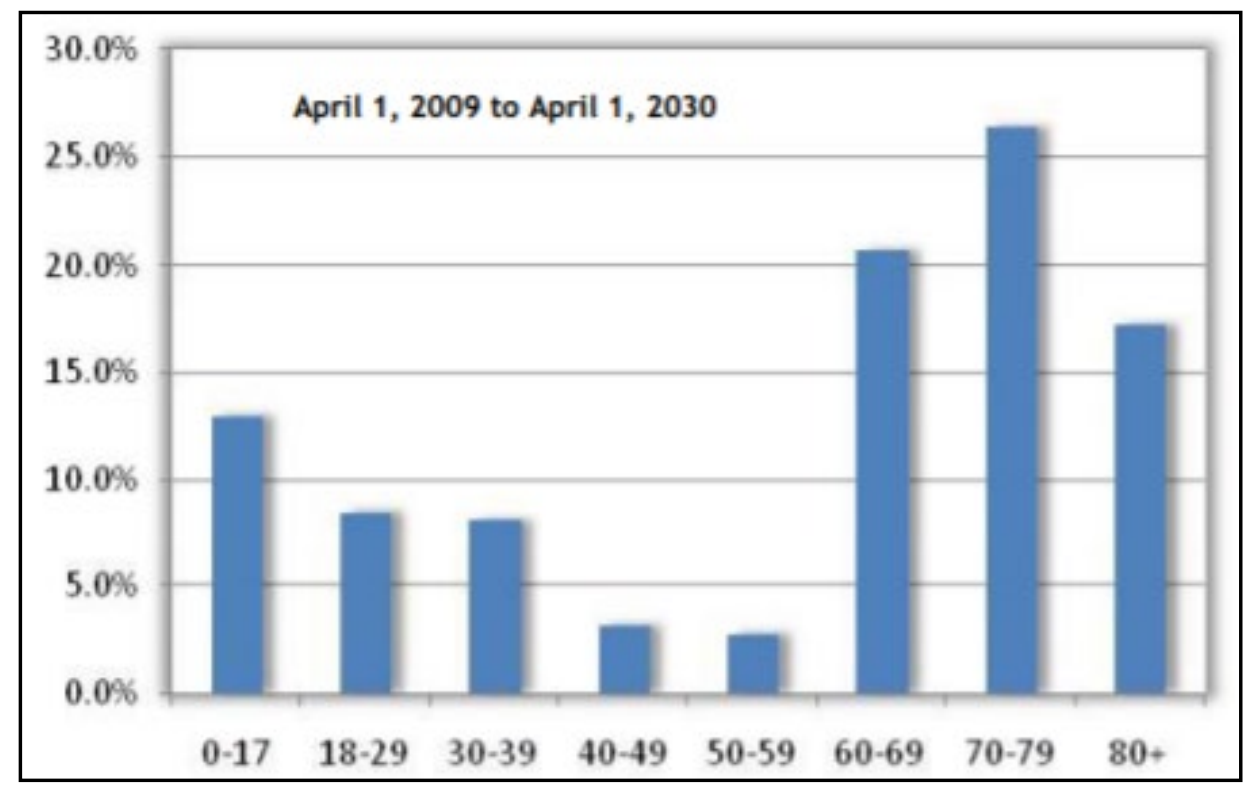

Figure 14. Projected population growth by age group, 2009-2030 (CFlorida Legislature Office of Economic Development and Demographic Research, n.d.).

Florida experienced a 129-percent increase in minority population between 1990 and 2010 and was the third-highest ranked State in terms of absolute growth of minority population. Table 15 shows the growth of minority populations in Florida from 2000 to 2010 and projected to 2045. Nearly all growth has occurred within the Hispanic population, which by 2045 is projected to be 32.5 percent of Florida's population (black and Asian populations were not projected). By comparison, Florida's Hispanic population in 1980 was 8 percent. Figure 15 shows the Hispanic population doubled to 16 percent in 2000 and grew to 22.5 percent by 2010. Much of that growth was concentrated in South Florida, in and around Miami-Dade County. The Hispanic population is projected to make-up more than 25 percent of the population in 2030, more than 30 percent by 2045, and more than 40 percent by 2060 (Florida Legislature Office of Economics and Demographic Research, 2011; Center for American Progress, 2015).

Table 15. Demographic Projections to 2045 (Source: Florida Bureau of Economic and Business Research, 2018).

\begin{tabular}{|l|l|l|}
\hline \multicolumn{1}{|l|}{} & Base Year (2010) & \multicolumn{2}{l|}{ Projected Year (2045) } \\
\hline Total (Millions) & 18.8 & 27.4 \\
\hline Percent Hispanic & 22.5 & 32.5 \\
\hline Percent Black & 15.7 & -- \\
\hline Percent Asian & 2.4 & -- \\
\hline
\end{tabular}




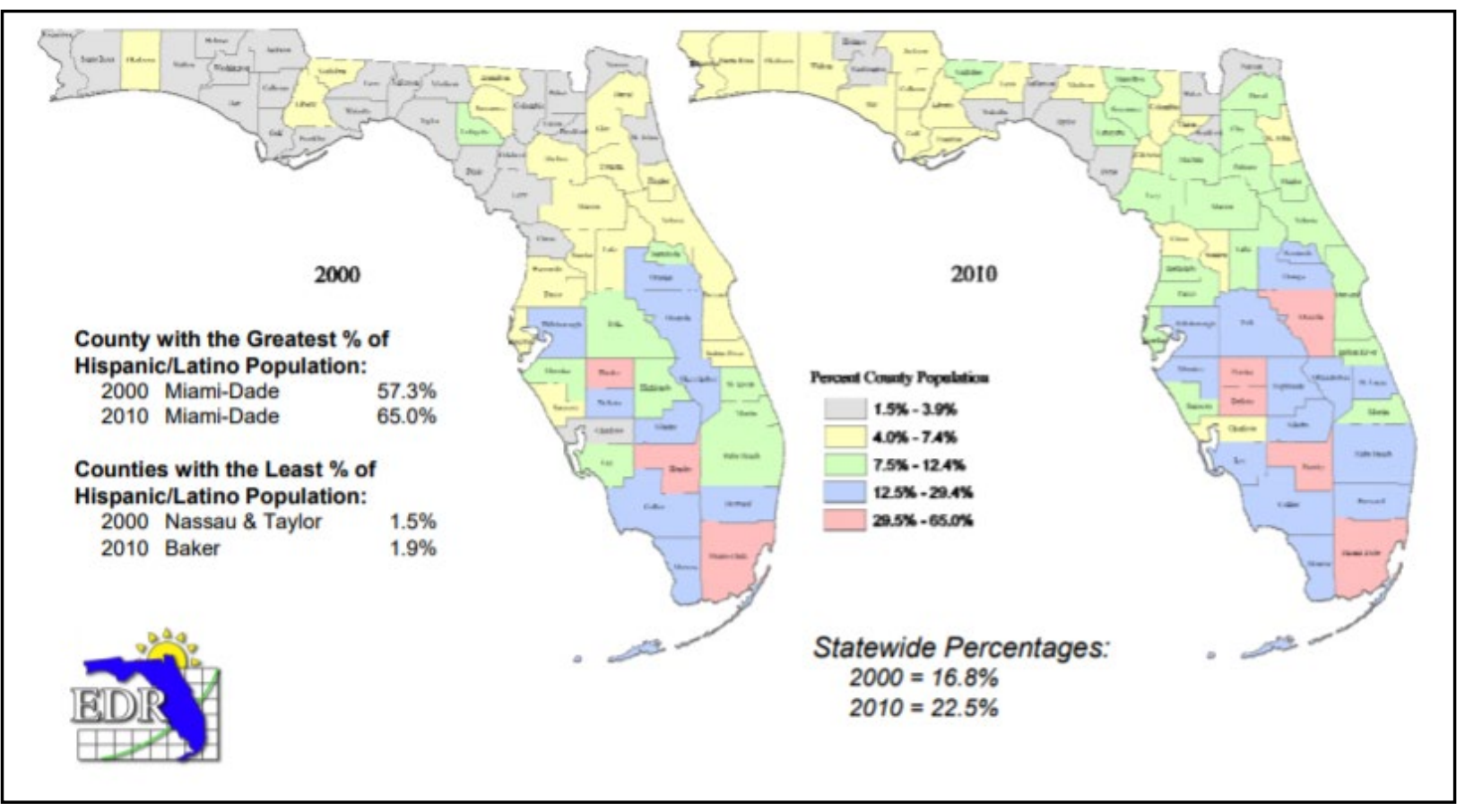

Figure 15. Hispanic/Latino population by county, 2000-2010 (@ Florida Legislature Office of Economic and Demographic Research, n.d.).

Due to time delays in demographic data collection, obtaining an accurate count of how many people have been displaced by Hurricane Harvey, Hurricane Irma, and Hurricane Maria is not yet possible. Puerto Rico, which is 1,100 miles off the southeastern tip of Florida, was hit hard by these hurricanes in 2017. Florida captures about 30 percent of all migrants from Puerto Rico bound for the continental United States. In 2000, 482,027 individuals born in Puerto Rico resided in Florida. By 2016, that number had grown by 121 percent to 1,067,474 people. By comparison, the national increase of individuals who were born in Puerto Rico from 2000 to 2016 was 60 percent. Although reliable data currently is not available, that migration from Puerto Rico following this series of 2017 hurricanes will have a powerful demographic impact on Florida, especially in the Orlando MPO, which has seen concentrated growth of these populations in recent decades (Bureau of Economic and Business Research, 2018a).

\section{PROBLEM STATEMENT}

Projects can lie dormant for years during complex review processes or delayed funding streams. The EDTM process was designed in part to reduce delays in transportation decision making. Prior to EDTM, projects could get delayed in the review process due to late agency involvement or uncovered environmental issues. The "fatal flaw" test is EDTM's adaptation to expand agency and public involvement (Florida Department of Transportation, 2017a). Early stakeholder involvement opens channels for localized community knowledge to inform the review process, saving time and money (Federal Highway Administration, 2012b). 
The Census Bureau performs a comprehensive census every 10 years. Between the decennial census, American Community Survey (ACS) data is compiled from 5 years of sample counts. Because this information is grouped across 5 years, the numbers do not always reflect current trends. FDOT's EST uses this available data to create demographic trends analysis in its Sociocultural Data Report. This report is updated at project milestones, shared with the public, and vetted by community members who can comment on the accuracy of the latest available data. FDOT's use of historic census data and community engagement to fine tune the accuracy of available data is an innovative approach to monitor change in the size or location of sensitive populations.

\section{METHOD OF ANALYSIS}

The ETDM process has three phases: Planning, Programming, and Project Development and Environment (PD\&E). The Planning phase consists of establishing a purpose and need for a project, reviewing preliminary documents, and providing the public and agency staff an opportunity to identify fatal flaws. The Programming phase involves a more refined analysis of the project and potential environmental impacts and identifies possible alternatives. Together, the Planning and Programming phases "allows planners to adjust project concepts to avoid or minimize impacts, develop alternatives, and produce accurate cost estimates by examining land use issues, ecosystem management, community insight, and mobility concerns (Federal Highway Administration, n.d.). In the Programming phase, project scoping including project alternatives is performed to guide the detailed analysis conducted in the PD\&E phase. Each phase runs through the six-step Sociocultural Effects Evaluation in greater detail and checks the accuracy and relevance of the existing documents from the prior phase. These six steps are as follows (Florida Department of Transportation, 2017c):

- Review Project Information: Review latest project documents, identify data gaps, conduct field review.

- Define Study Area: Review field notes and select appropriate study area buffers to evaluate project impacts.

- Prepare Community Information: Create or update the Sociocultural Data Report and collect additional community data.

- Evaluate Sociocultural Effects: Evaluate community data, assess potential effects and assign degrees of effect.

- Identify Solutions to Project Impacts: Identify possible solutions and document recommendations.

- Document results: Record potential effects in the EST and create a phase summary report (Planning and Programming phases) or prepare an environmental document (PD\&E phase).

Community data is revisited in each phase and updated in greater detail as the project moves forward. The EST operates as a virtual library where users can find project descriptions, purpose and need statements, GIS analysis results for each alternative, resource data and data maps for the project area, and previous public commentary. It also allows users to sign up to receive emails when project documents are changed or uploaded. The EST has two user profiles. A read-only site is available to anyone and equips users with GIS tools to conduct their own analyses around areas of concern. The 
site also allows read-only users to submit comments and to request a response from project staff. This tool empowers individuals who traditionally lack access to the review process and helps staff identify environmental and social issues early. The EST's second user profile is for partner agencies and allows them to share documents with one another, review public comments, and conduct preliminary project analyses. The EST's GIS tool is equipped with over 500 data layers and paired with 30 years of census data. Although the site is not designed for the public, much of the information is accessible by the public. No specific training or effort is needed to improve public access but contact information for agency staff is available in the project reports for members of the public who want more detailed information.

The project's environmental effects are first assessed using sociocultural information like community boundaries, focal points, histories, goals, and values. Figure 16 shows how the spatial and data analysis is timed with public input. This information is compiled into a Sociocultural Data Report (SDR). The SDR is first introduced in the third step of the Planning Screen and updated in step 3 of the later Programming and PD\&E phases.

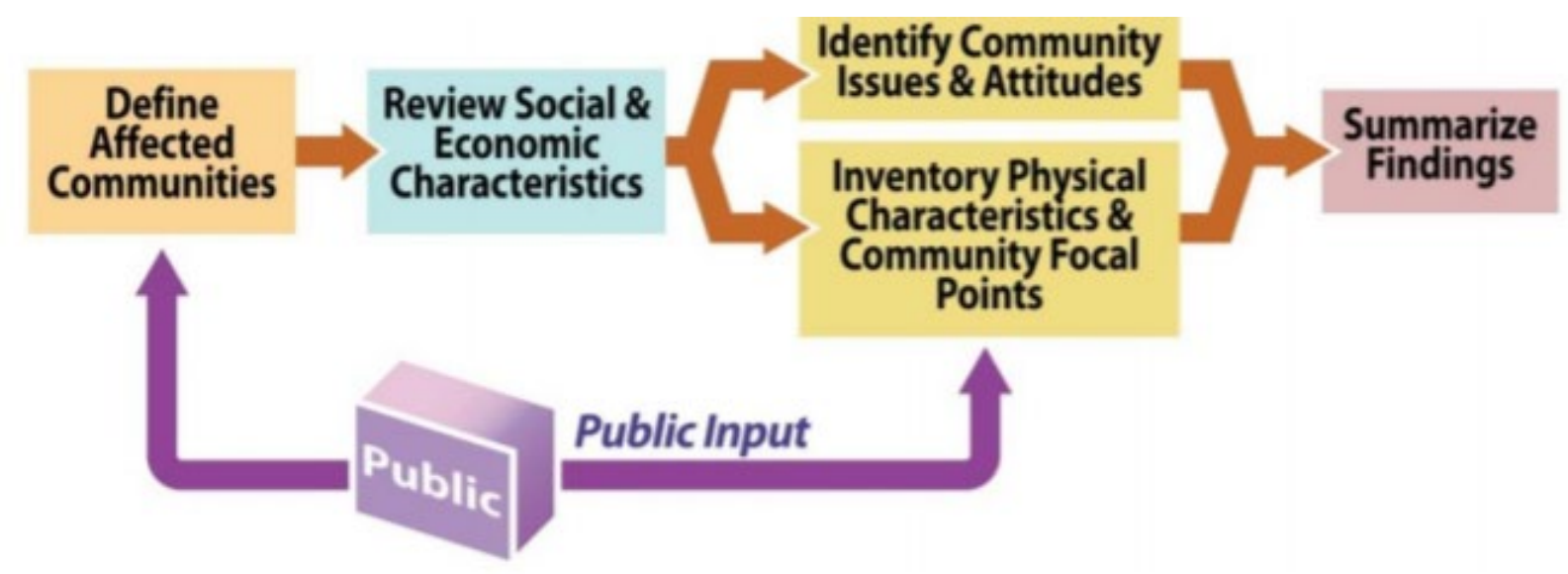

Figure 16. Process for developing community information (ㄷ Florida DOT, n.d.).

The SDR is the preliminary analysis that is later used to inform the Sociocultural Effects Evaluation, Florida's equivalent to a community impact assessment, which also satisfies the EJ analysis requirements (Florida Department of Transportation, 2017b). An SDR is generated for each project alternative and compiles decennial census data from 1990, 2000, 2010, and current American Community Survey data to aid in conducting a historic trends analysis. The SDR includes population demographics, land use and housing characteristics, and community focal points. Figure 17 shows the first page of the report, which provides data in tabular and graphic form. 


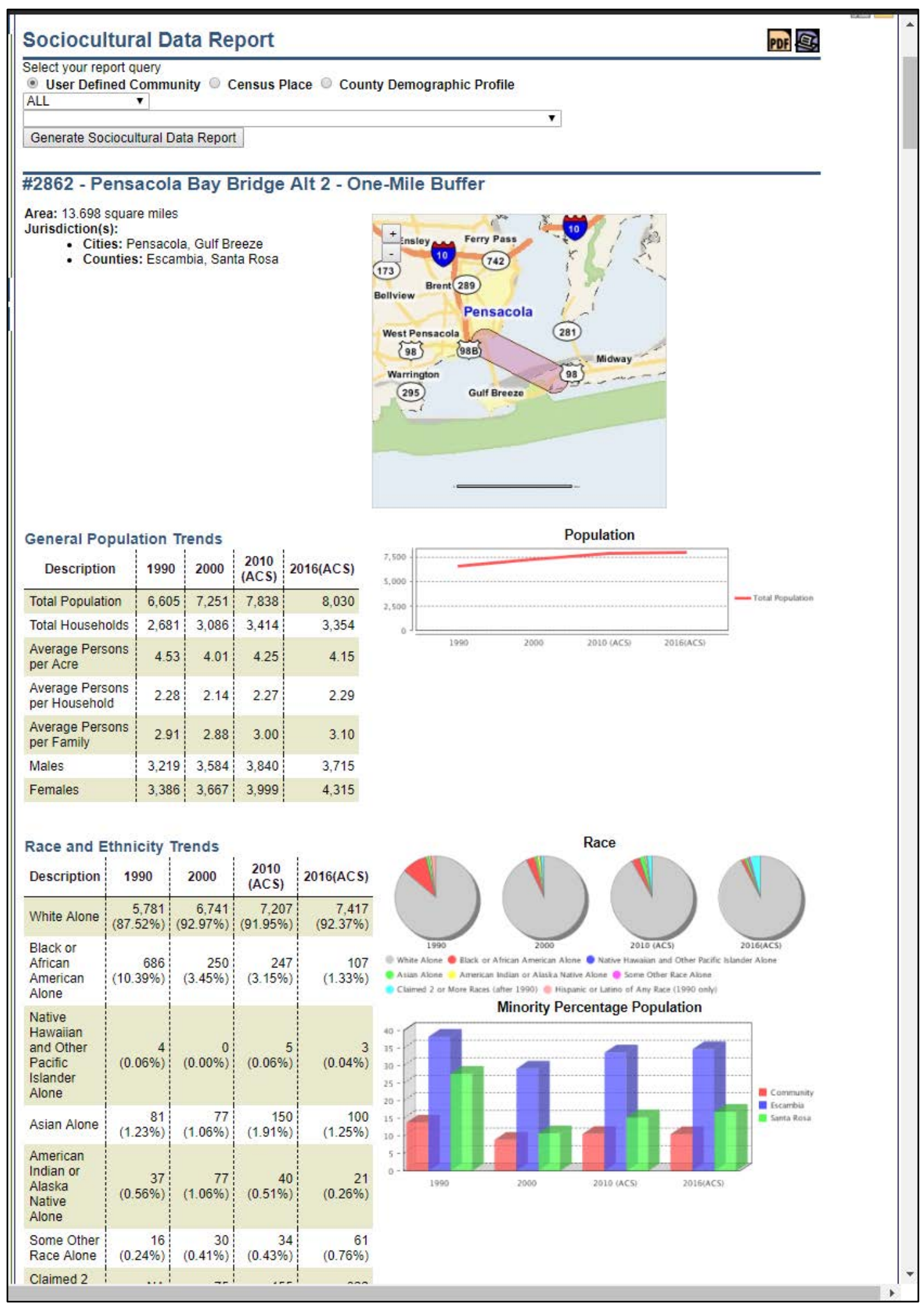

Figure 17. Florida DOT's Sociocultural Data Report: a tool within the Efficient Transportation Decision-making Portal (@Florida Department of Transportation. n.d.). 
The SDR can be accessed and downloaded through the EST. Informed community members can review the SDR and comment on inconsistencies between the tabular data and their community knowledge. FDOT's EST facilitates the first round of community impact assessments. FDOT's Project Development and Environment (PD\&E) Manual instructs planning staff on how to use this analysis to create the Sociocultural Effects Evaluation. The SDR is verified through local knowledge, windshield surveys, and staff expertise. GIS analysis is used to identify further trends and impacts. The Sociocultural Effects Evaluation expands on the SDR by delving into social, mobility, economic, and aesthetic effects; land use changes; and relocation potential (Florida Department of Transportation, 2012). Table 16 shows specific considerations that fall under each Sociocultural Effects Evaluation issue. Once each issue is evaluated, a degree of effect is assigned.

Table 16. Sociocultural effects issues and considerations (Adapted from Florida DOT Sociocultural Effects Evaluation Criteria).

\begin{tabular}{|c|c|c|c|c|c|}
\hline $\begin{array}{l}\text { Social } \\
\text { Effects }\end{array}$ & $\begin{array}{l}\text { Mobility } \\
\text { Effects }\end{array}$ & $\begin{array}{c}\text { Economic } \\
\text { Effects }\end{array}$ & $\begin{array}{c}\text { Aesthetic } \\
\text { Effects }\end{array}$ & $\begin{array}{l}\text { Land Use } \\
\text { Changes }\end{array}$ & $\begin{array}{l}\text { Relocation } \\
\text { Potential }\end{array}$ \\
\hline $\begin{array}{l}\text { - Demographics } \\
\text { - Community } \\
\text { Cohesion } \\
\text { - Safety/Emergency } \\
\text { Response } \\
\text { - Community Goals } \\
\text { - Quality of Life } \\
\text { - Special Community } \\
\text { Designations } \\
\text { - Community History } \\
\text { and Character }\end{array}$ & $\begin{array}{l}\text { - Modal Choices } \\
\text { - Pedestrian } \\
\text { - Bicycle } \\
\text { - Transit } \\
\text { - Motor Vehicles } \\
\text { - Transportation } \\
\text { Disadvantaged } \\
\text { - Connectivity } \\
\text { - Traffic } \\
\text { - Circulation } \\
\text { - Public Parking }\end{array}$ & $\begin{array}{l}\text { - Business } \\
\text { - Jobs } \\
\text { - Tax Base } \\
\text { - Travel } \\
\text { Patterns } \\
\text { - Business } \\
\text { Access } \\
\text { - Special Needs } \\
\text { - Patrons } \\
\text { - Freight } \\
\text { Movement }\end{array}$ & $\begin{array}{l}\text { - Noise } \\
\text { - Vibration } \\
\text { - Viewshed } \\
\text { Compatibility }\end{array}$ & $\begin{array}{l}\text { - Urban Form } \\
\text { - Local Plan } \\
\text { Consistency } \\
\text { - Open } \\
\text { - Space } \\
\text { - Sprawl } \\
\text { - Focal Points }\end{array}$ & $\begin{array}{l}\text { - Residential } \\
\text { - Non- } \\
\text { Residential } \\
\text { - Public } \\
\text { Facilities }\end{array}$ \\
\hline
\end{tabular}

\section{KEY TAKEAWAYS}

FDOT's EST is notable for two reasons. First, virtual public engagement techniques improve coordination and inclusion with communities and stakeholders. Second, FDOT requires that socioeconomic data be updated at project milestones. FDOT is the only governing body found to require that EJ data be updated at project milestones. Further, as data sources improve, the EST can be updated to provide more accurate demographic information.

The EST has been operating for more than 15 years. In that time, over 1,500 projects have been entered. However, FDOT does not require MPOs or counties to use the interface. In an interview with FDOT staff, they mentioned that the largest barrier to the EST's use is training. Once FDOT provides training to MPO staff about the EST and its resources, the MPO staff typically begin using it for their projects. Notably, while FDOT was developing the EST, Miami-Dade County created their own version of the EST, called InteracTIP. For this tool, Florida International University designed demographic reports for all census tracts and community background reports for each neighborhood. InteracTIP's interactive web-based application is most useful in preforming demographic analysis to inform public outreach strategies (AASHTO, 2016). 
Common across all States and MPOs is a general lack of comprehensive data between decennial census years. Florida is experiencing phenomenal growth-both in predictable, development-led growth and in surges caused by emergency relocation of large populations, like those displaced after Hurricane Maria. Significant population changes can occur between each comprehensive census. FDOT has designed a system to make best use of the available census data and supplements the less current 5-year sample sets with public engagement when updating the SDR and Sociocultural Effects Evaluation. Further, FDOT is exploring using more local data sources to inform housing or employment information. This data would complement census data to provide more current and accurate data to inform transportation planning and project development (Florida Department of Transportation, 2014). 


\section{MID-OHIO REGIONAL PLANNING COMMISSION}

\section{INTRODUCTION AND OBJECTIVES}

Mid-Ohio Regional Planning Commission (MORPC) is the designated metropolitan planning organization for the Columbus urbanized area and the principal public agency conducting regional planning in Central Ohio. Its jurisdiction consists of Franklin County (where Columbus is situated), Delaware County, and sections of Fairfield, Licking, and Union counties. MORPC produces the metropolitan transportation plan for the region along with the required equity analyses of the plan. Its equity analyses use a population-based weighting measure to calculate the impacts of transportation plan investments on EJ households throughout the region. This technique is used to improve the accuracy of EJ analysis and to better reflect the full extent of locations of EJ communities. This notable practice is unique and is the subject of this case study.

\section{COMMUNITY PROFILE}

Columbus is the capital of Ohio and the State's most populous city, having a 2010 population of 787,033. Centrally located at the junction of the major national thoroughfares Interstates 70 and 71 , Columbus is home to one of the largest university campuses in the Nation, The Ohio State University. Central Ohio is a part of the Great Lakes region, which accounts for 22 percent of industrial workers in the United States despite being home to only 15 percent of the Nation's population. Goods leaving Columbus are accessible to approximately 47 percent of the U.S. population within a day (Mid-Ohio Regional Planning Commission, 2016a).

The Columbus, OH, MSA is composed of eight Ohio counties and its population was 1.8 million in 2010 (Figure 18). The MSA population is projected to reach 2.3 million by 2040, a 25-percent increase, compared to a one-percent projected increase statewide. The MORPC region, which is part of the MSA, had a population of 1.45 million in 2015 and is expected to reach 1.78 million in 2040 (Mid-Ohio Regional Planning Commission, 2016a). Most of the MSA population resides in Franklin County. The Columbus MSA is State's second most populous after Cleveland-Elyria MSA and is narrowly more populous than the Cincinnati OH-KY-IN MSA.

Minority populations account for over 20-percent of the population in the MORPC MPO area, which is greater than the 16-percent share statewide and represented approximately 60 percent of MSA population growth from 2010 to 2014. Columbus, OH MSA experienced a 121-percent increase in minority households from 1990 to 2010, a total of 242,424. This increase was significantly higher than rates statewide; Ohio had a 55-percent increase, or a total growth of 774,748 minority households. Of the minority population added to the MORPC region from 2010 to 2014, roughly one-third was black/African American, a quarter was multiracial, 22 percent was Hispanic/Latino, and 18 percent was Asian Looking forward, approximately one-third of anticipated MSA population growth between 2010 and 2040 is attributed to seniors. During this same period, racial minorities are anticipated to account for nearly all population growth (Nelson, 2014).

The concentrations of other populations that might also face transportation challenges, such as the elderly, the disabled, households in poverty, and zero-car households, are lower in the region than the 
Ohio State average (ACS 2009-2013) (Mid-Ohio Regional Planning Commission, 2016b). The median age of the region is relatively low, in part due to the presence of The Ohio State University. The senior population is expected to grow considerably, by 25 percentage points, by 2040 as baby boomers age out of the workforce and as the life expectancy rate grows.

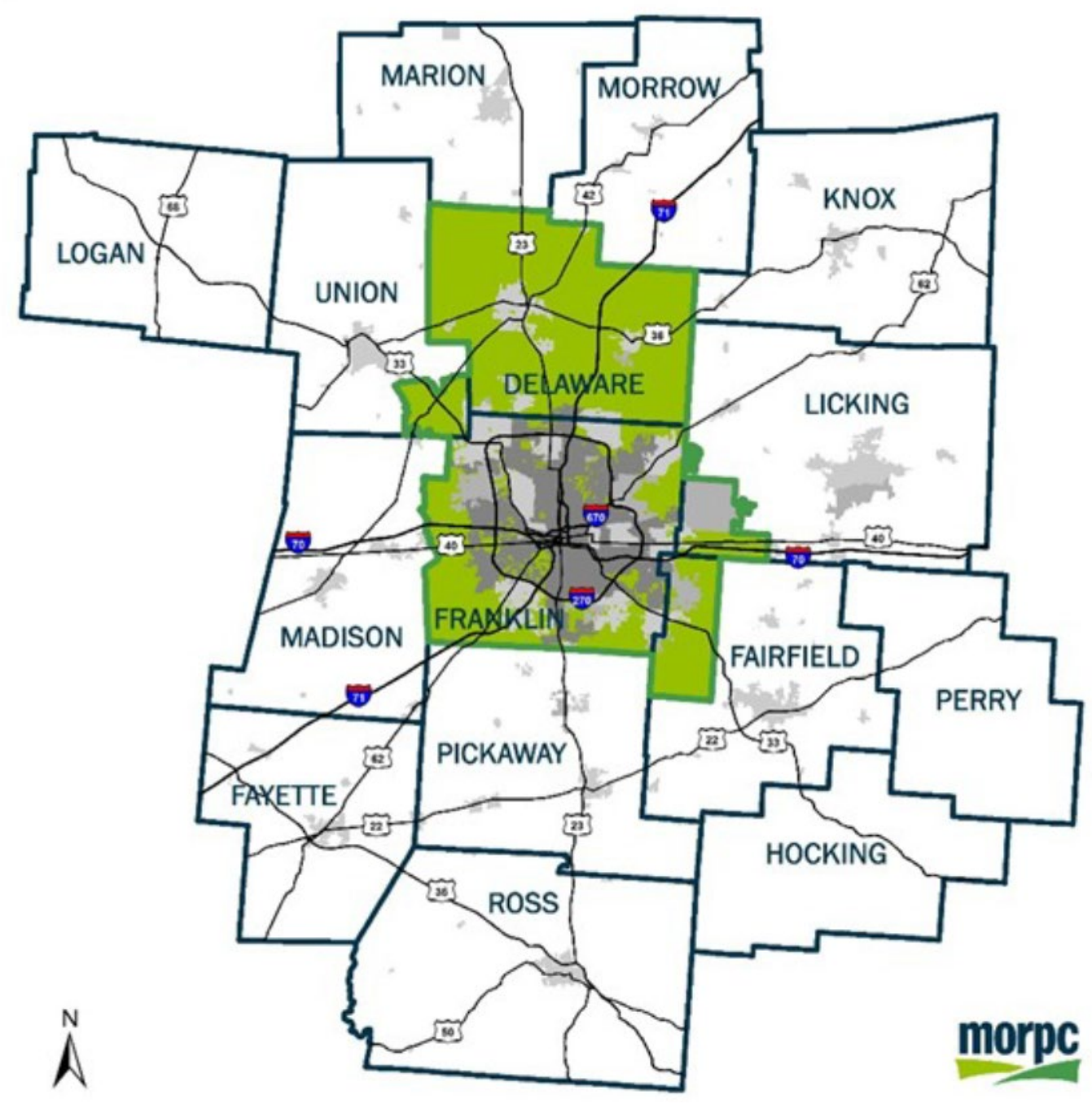

Figure 18. MORPC planning area and central Ohio region (CMid-Ohio Regional Planning Commission, 2016).

\section{PROBLEM STATEMENT}

Transportation investments create impacts on specific neighborhoods, such as improvements in travel time, or exposure to noise or other nuisances. Therefore, EJ analyses of individual projects or entire plans are built around an analysis of transportation impacts on populations located in space. EJ analyses traditionally locate EJ households in neighborhoods and then tabulate impacts, positive or negative, according to where transportation impacts occur. When the impacts are concentrated in neighborhoods with higher than typical numbers of EJ households, the project might create a disparate impact and warrant further investigation, mitigation, or reconfiguration. 
To analyze the EJ impacts from regional plans (an assembly of many different projects implemented over many years) or even a single project (perhaps through an environmental review process), agencies may wish to consider developing a method for identifying and locating EJ communities. Nearly all agencies surveyed for this report use a traffic analysis zone (TAZ)-based "threshold" method of accounting for the location of EJ communities. With this "binary" approach, an entire TAZ is considered an EJ community if it surpasses some threshold for demographic characteristics (for example, a higher than average concentration of low-income households). Once a TAZ is considered EJ, different measures of transportation performance (travel times, delay, and accessibility or environmental burdens) can be summed and averaged for EJ and non-EJ TAZs. Then, comparisons can be made to determine if a plan creates or reinforces a disparity in transportation impacts, be it positive or negative.

This binary approach makes accounting for precise impacts on EJ populations challenging, as they are sometimes a small share of a given TAZ population. Even if significant numbers of EJ households are in non-EJ TAZs, impacts on those households are not considered part of the EJ impacts. For example, say a threshold is used where 35 percent of households should have incomes below 150 percent of the Federal poverty line for a TAZ to be classified as an EJ community. A TAZ that falls just one percentage point below that rate is then not considered part of the EJ impact area, even if large transportation impacts occur there. This approach highlights impacts on TAZs with high concentrations of EJ communities but overlooks pockets of these populations not meeting the threshold. The methodological challenge is to find a more nuanced and graduated method that can reflect EJ impacts in neighborhoods with even small EJ populations. MORPC uses a different approach in their EJ analysis that better represents the full impacts of transportation investments on EJ households, wherever they are located (Mid-Ohio Regional Planning Commission, 2016b).

\section{METHOD OF ANALYSIS}

A more accurate, but more complicated, approach than the binary approach to EJ analysis explored above would be to perform analyses that can be weighted by each TAZ's EJ population, no matter its size or proportion. In calculating an overall regional average for the EJ community (for instance average delay per traveler), even small numbers of households count using this methodology. In contrast to the prevailing threshold-based approach, Karner (2016) showed this "population-based" approach measures transportation impacts on the overall EJ population more accurately. For instance, if one is calculating the overall average quality of transit service for the EJ community regionwide, the population-based approach includes service for every household in calculating the average, even if they are in a TAZ with few other EJ households. A binary method would only account for quality of service for TAZs that meet the given EJ thresholds.

MORPC used this population-based method in the EJ analysis of its 2016 metropolitan transportation plan (Mid-Ohio Regional Planning Commission, 2016b). The EJ or “Target” populations measured by MORPC are Minority Population, Hispanic Population, Elderly Population, Population in Poverty, Disabled Population, and Zero Car Households. Figure 19 shows the location of EJ households (Mid-Ohio Regional Planning Commission, 2016b). One can see in this example that while minority individuals (green dots) seem to correspond closely with TAZ's having high minority 
concentration (grey shaded areas), many green dots fall outside these high-concentration areas. In a traditional analysis approach, those individuals would not be included in the impact analysis.

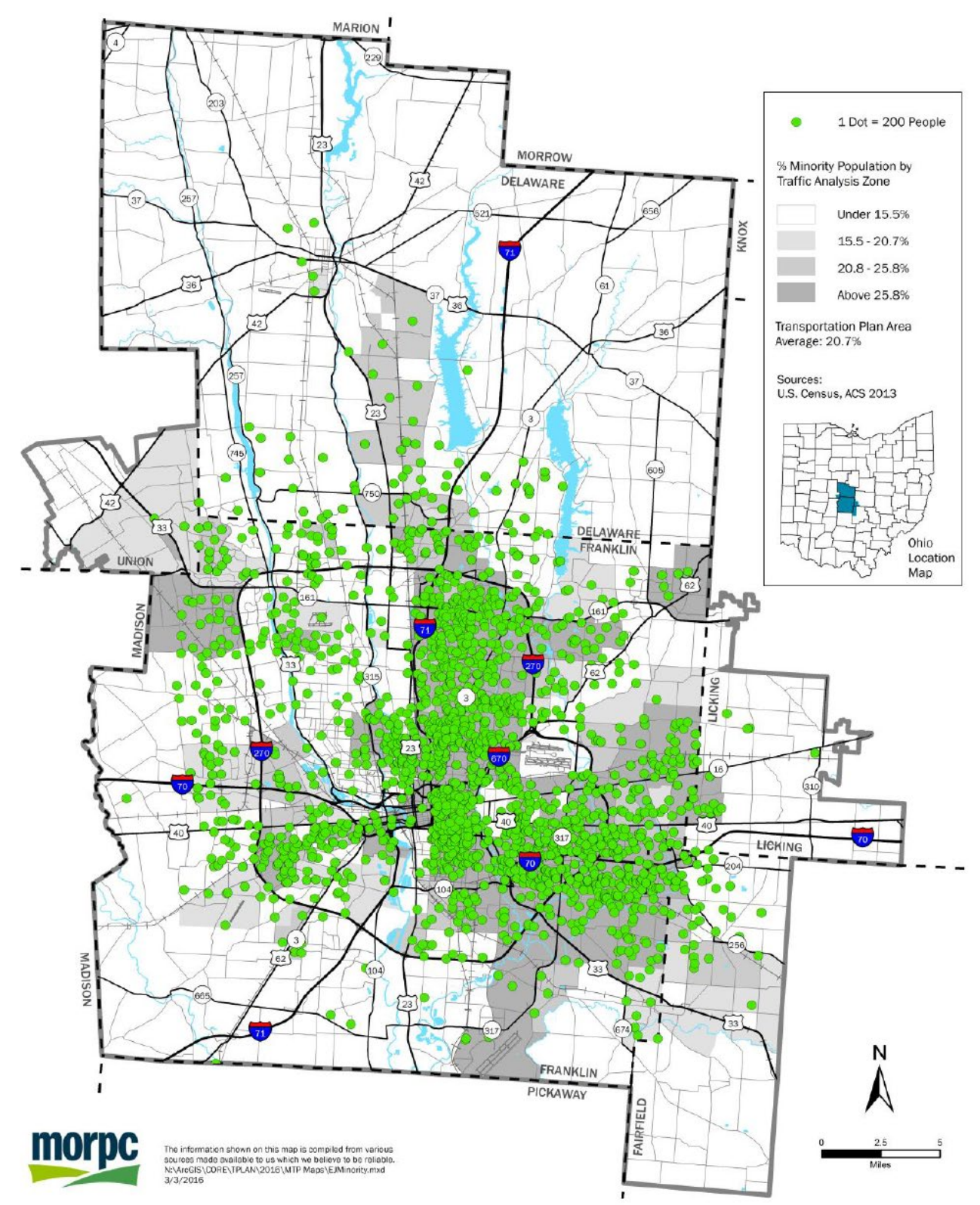

Sources: 2009-2013 American Community Survey

Figure 19. Minority household locations and concentrations (CMid-Ohio Regional Planning Commission, 2016).

MORPC measured the impact of transportation projects on these target populations through their travel demand forecast modeling. A no-build scenario and build scenario of RTP projects were forecast for 2040 and compared to 2015 levels. In projecting target populations to the outer plan year, the total regional percentage for each was assumed the same in 2040 as in 2015, and that each TAZ share of the total would also remain the same. For example, a region-wide percentage in poverty in 2015 of 13.9 percent is assumed for 2040, even though the total population might grow. The 
additional households in the target population are distributed proportionally over all TAZs according to their share in the base year. The overall growth is determined by the regional growth model developed by MORPC, which accounts for land use changes, housing development and preferences, and industrial and job growth (Mid-Ohio Regional Planning Commission, 2016b).

Using 2040 target and nontarget population estimates by TAZ, comparisons can be made for each outcome measure. Important outcome measures were identified during a preliminary EJ analysis completed in 2000 and narrowed down for application for this analysis. The outcome measurements used in 2016 include:

- Average number of jobs, shopping, and non-shopping opportunities within a given proximity.

- Percentage of population close to a college, hospital, and major retail destination.

- Average travel time for essential travel (employment and education), shopping, and other types of travel.

- Average travel time and transit accessibility to the Columbus central business district.

- Congested vehicle miles of travel during peak hours.

- Transportation investments.

- Displacements from highway projects.

These levels were calculated for each of the six target populations for the three plan scenarios, and results are found in the Environmental Justice Technical Analysis (Mid-Ohio Regional Planning Commission, 2016b). For example, the average number of jobs reachable within 20 minutes' travel time during the peak period was calculated for all target populations combined and for each target group individually. Figure 20 shows the result for 20 minutes of driving time, and Figure 21 shows the result for 40 minutes by public transit.

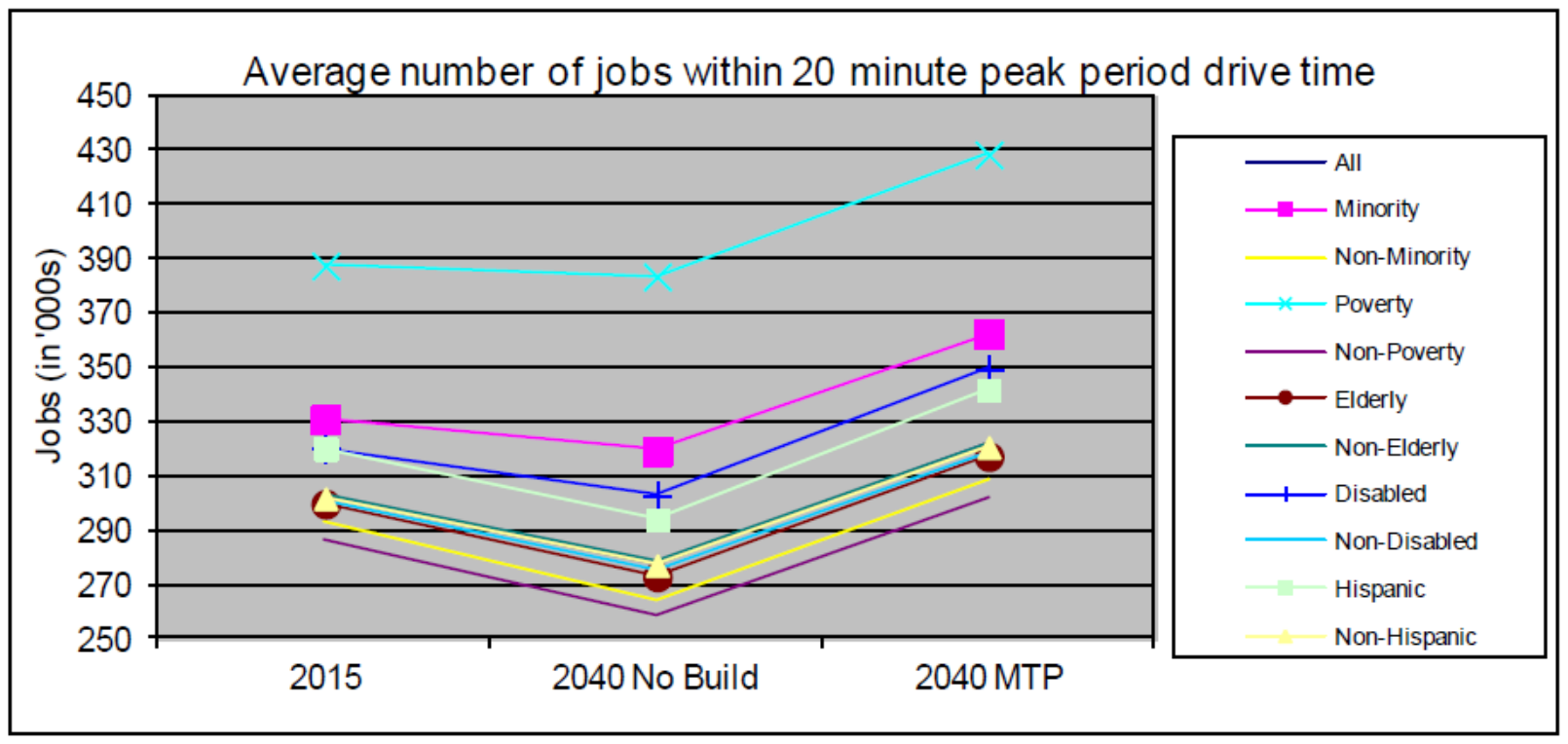

Figure 20. Average number of jobs reachable within 20-minute peak period drive time (CMid-Ohio Regional Planning Commission, 2016). 


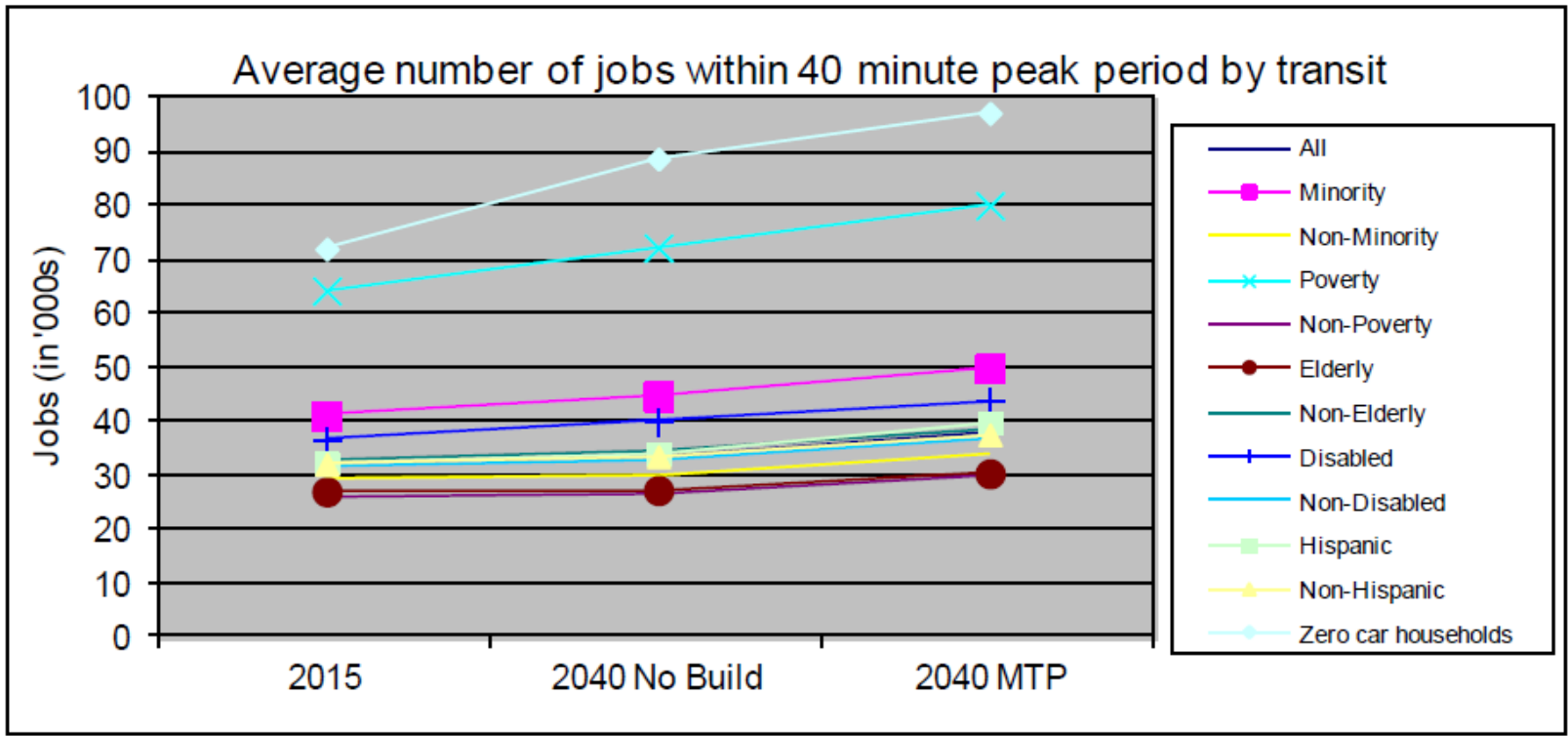

Figure 21. Average number of jobs reachable within 40-minute peak period by public transit (CMid-Ohio Regional Planning Commission, 2016).

Using this approach, the analysis includes many similar comparisons between the plan scenarios for the different target populations for each outcome measure. In the drivetime example (Figure 20), the metropolitan transportation plan clearly improves job accessibility for drivers in the target populations compared to the no build. Similarly, the metropolitan transportation plan improves job accessibility by public transit for the target populations.

\section{KEY TAKEAWAYS}

MORPC's use of this unique population-based method of accounting for the location and quantity of EJ households, makes their equity analysis exemplary. Using this method presents no discernable disadvantages, as it captures the location of EJ population more precisely. This analysis approach offers a more accurate assessment of transportation impacts when EJ households are dispersed. This may be especially true in suburban areas where groups of EJ households are increasingly locating, especially considering the national trends of the suburbanization of poverty (Brookings Institute, 2017). As EJ populations disperse, they might no longer comprise large concentrations in any given TAZ and then could be "lost" in a traditional binary analysis. This approach also helps overcome the difficulties that arise when EJ populations live in TAZs located farther from project impacts (e.g., in suburbs). The population-based method employed by MORPC still counts these impacts, no matter the location of the populations. 


\section{ATLANTA REGIONAL COMMISSION}

\section{INTRODUCTION AND OBJECTIVES}

The Atlanta Regional Commission (ARC) is the metropolitan planning organization for the greater 20-county Atlanta region. ARC carries out population forecasts for the entire 20-county region and has produced county-specific (and smaller) forecasts by population, employment, race and ethnicity, and age. To both maximize the utility and exposure of their forecasting efforts and to update and improve their methods and assumptions based on local feedback, ARC engages in a "small area outreach" process to connect with local jurisdictions on their forecasts. This small area outreach enables ARC to improve their forecasting, while helping local jurisdictions to better prepare for demographic change. This notable practice is the subject of this case study. Through better outreach, local jurisdictions may benefit from improved data and forecasting and ARC can benefit from more up-to-date and accurate data on local jurisdiction plans and developments.

\section{COMMUNITY PROFILE}

The Atlanta metro region has experienced a significant increase in population in the past several decades. Current (2015) population estimates are 5.7 million for the 20-county region (ARC, 2018B). The Atlanta region ranked sixth in the Nation for minority population growth between 1990 and 2010. Population increases among communities of color have outpaced overall growth with increases of 39 percent for black residents, 102 percent for Latino residents, 86 percent for Asian \& Pacific Islanders, 32 percent for Native Americans, and 72 percent for mixed/other. In 2015, the region's aggregate communities of color reached 51.3 percent of the overall 20-county region population (ARC 2018B).

In the city of Atlanta, white and higher-income suburban households began moving back to the dense central areas as investment and development took place in historically black inner neighborhoods. These shifts have correlated with the decline in very high shares of black residents living in central parts of the city. The share of black residents in suburban areas has subsequently increased, particularly suburban counties to the south, west, and east. Census tracts with the highest concentration of the Hispanic/Latino population are predominantly found in tracts in northeastern counties (Gwinnett, Barrow, Hall, and Forsyth), north Fulton, and Cobb counties. The heaviest concentrations of Hispanics/Latinos are found in suburban town centers throughout the region, in places like Canton and Cartersville to the north, and Griffin and Newnan to the south. Figure 22 shows the concentration of racial and ethnic groups throughout the 20-county metro region in 2010.

Metro Atlanta has experienced the highest nationwide increase in suburban poverty rate since 2000 at 15.2 percent. Many areas have not experienced these levels of poverty previously, such as Cherokee, Forsyth, and Fayette Counties. Communities with the highest poverty rates are concentrated in the areas southwest and southeast of the principal city. High-poverty neighborhoods, defined as the region's top 20 percent most densely impoverished, are 88 percent minorities (Atlanta Regional Commission, 2018d). Figure 23 shows the concentration of populations in poverty throughout the 20county metro region. 


\section{Atlanta Distribution of Race}

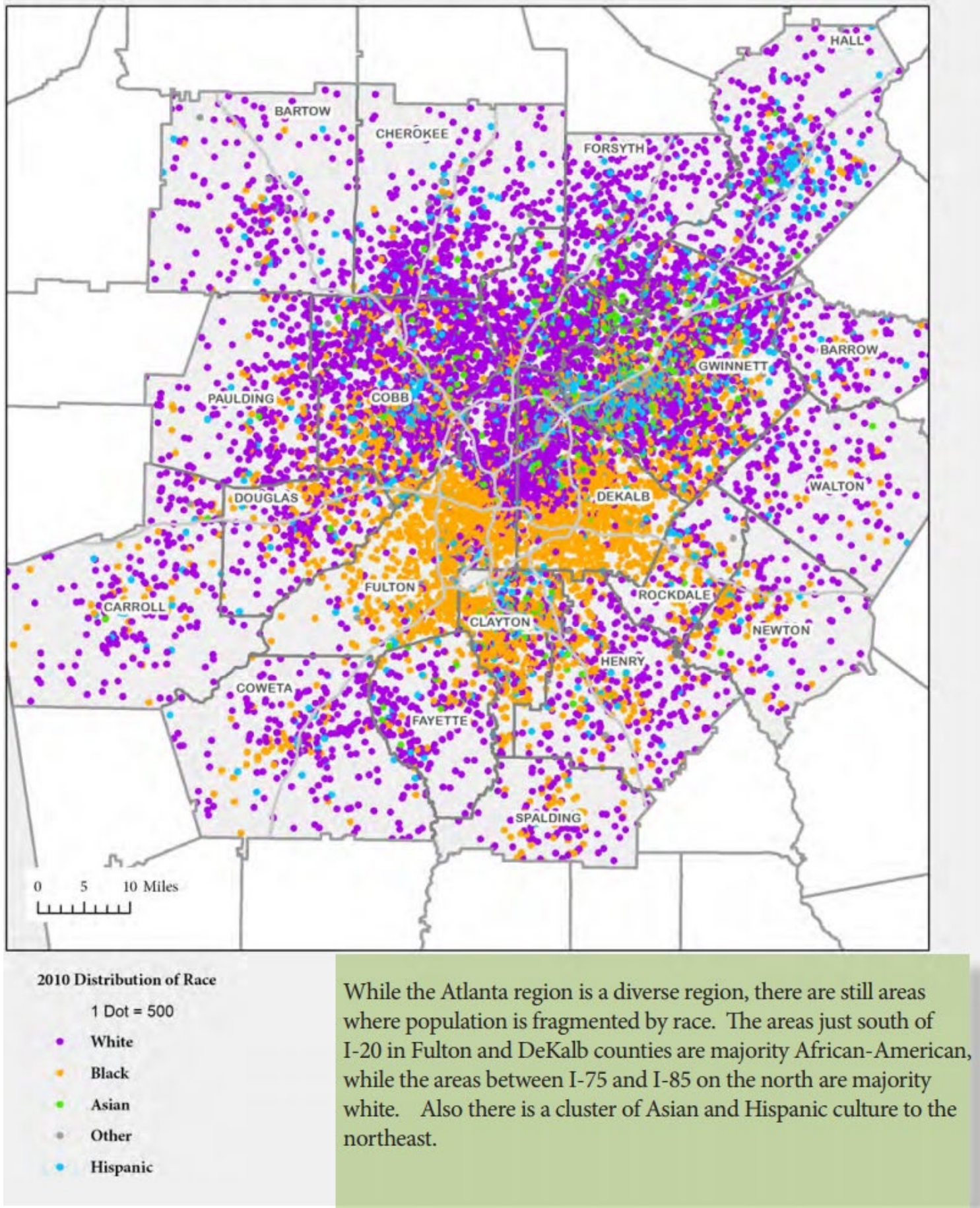

Figure 22. 2010 Distribution of race in Atlanta region (ㄷ) Atlanta Regional Commission, 2018). 


\section{Percentage of the Population in Poverty}

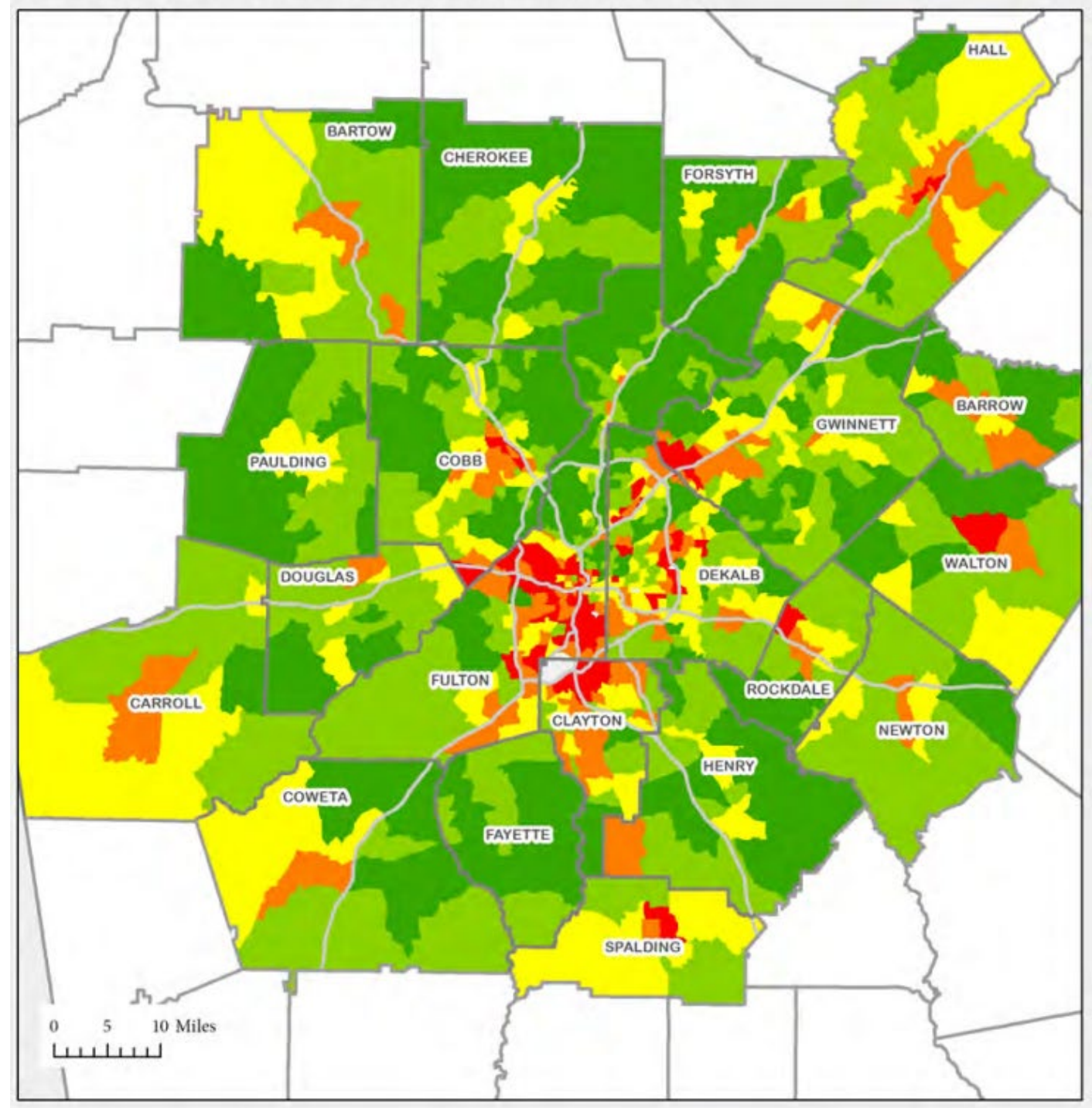

Percent of the Population in Poverty

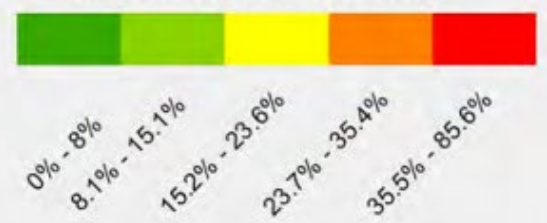

Figure 23. Percentage of the population in poverty in the Atlanta region (@) Atlanta Regional Commission, 2018). 


\section{PROBLEM STATEMENT}

ARC carries out forecasting efforts for all 20 counties and engages local jurisdictions to understand how local changes, plans, and knowledge might influence future trends throughout the diverse and fast growing 20-county Atlanta metro area. ARC engagement with local communities also helps jurisdictions understand regional trends, projections, and potential demographic shifts that can help communities to better plan for, accommodate, and guide change.

ARC's forecasting considers the most currently available estimated demographic distributions from the U.S. Census and American Community Survey and adjusts for trends or changes they observe or expect. In areas of the metro region where populations shift and change quickly, however, ARC might be unaware of local changes as they are happening. Further, plans, policies, and investments made by local jurisdictions can affect how and where change happens. For example, county or local plans to implement new transportation infrastructure or change zoning to higher densities could influence where and how growth occurs. Although ARC might not be aware of certain trends and plans happening at a more local level, local jurisdictions might not always be aware of larger current or forecast trends throughout the region, or how the decisions and policies of their neighboring jurisdictions will affect them (e.g., if one county takes measures to limit development, growth might spill over into a neighboring county). Coordination between ARC and local jurisdictions offers an opportunity to identify such blind spots and react accordingly.

\section{METHOD OF ANALYSIS}

ARC forecast population change for the 20-county Atlanta Region through 2040 for the Atlanta Region's Plan. As part of their forecasting work, ARC forecast 2040 population, employment, race and ethnicity, and age by county (ARC, 2018D). Table 17 provides ARC's demographic projections for the 20-county region to 2040 by racial and ethnic groups. Figure 24 provides a sample snapshot for forecast race and ethnicity distribution for one of the 20 counties (Gwinnett County).

Table 17. Demographic projections to 2040 (Adapted from Atlanta Regional Commission's 20-County Data Dashboard).

\begin{tabular}{|l|c|c|}
\hline & $\mathbf{2 0 1 5}$ & $\mathbf{2 0 4 0}$ Projection \\
\hline 20-County Atlanta Region Population & $5,591,573$ & $8,063,017$ \\
\hline White \% & $48.7 \%$ & $41.8 \%$ \\
\hline Black \% & $31.5 \%$ & $27.1 \%$ \\
\hline Hispanic \% & $12.4 \%$ & $21.6 \%$ \\
\hline Other \% & $7.4 \%$ & $9.5 \%$ \\
\hline
\end{tabular}



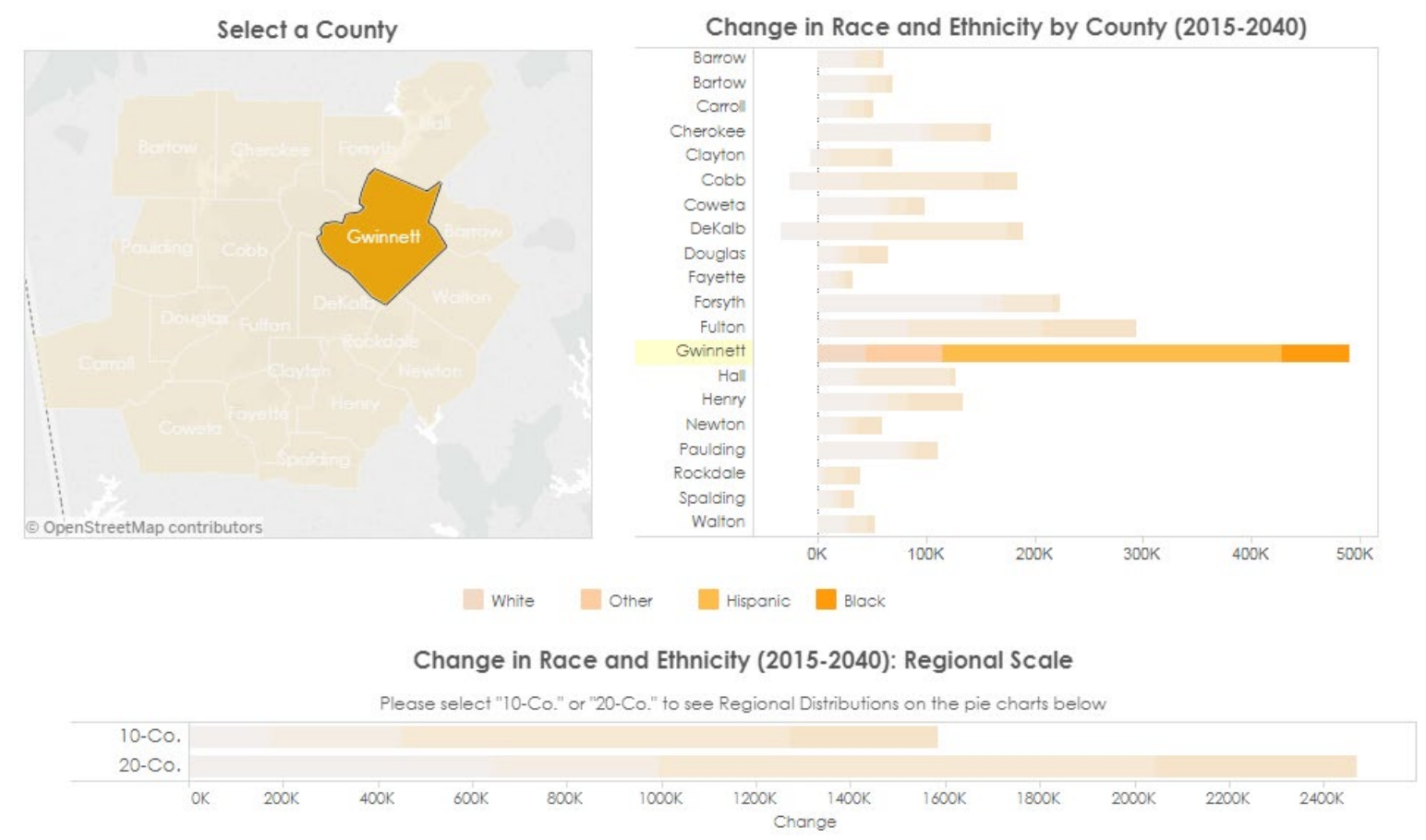

2015 Race and Ethnicity Distribution per County

2040 Race and Ethnicity Distribution per County Gwinnett Gwinnett
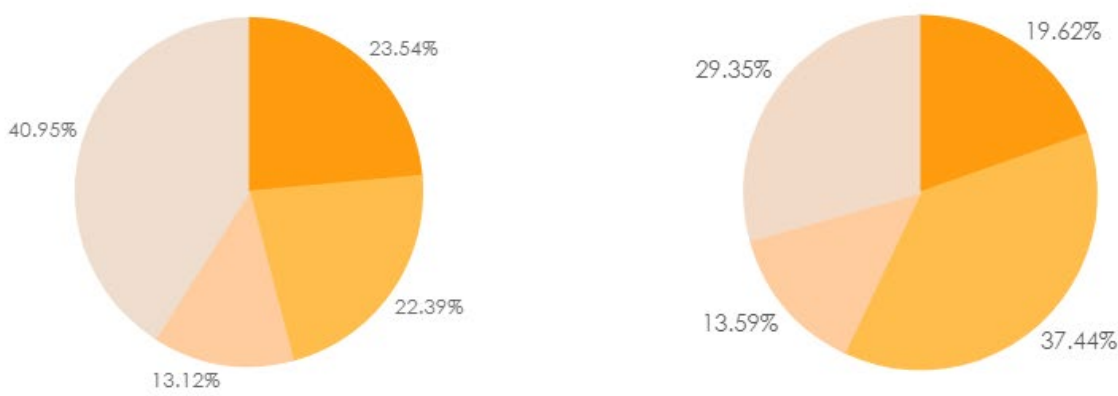

Figure 24. Sample snapshot for Gwinnett County from ARC's 20-County Population and Employment Forecasts (C) Atlanta Regional Commission, n.d.).

Following a review of ARC's planning documents, ARC's lead demographer was interviewed to better understand how ARC planners work directly with stakeholders to augment survey data and census data. Agencies that can better understand and validate demographic change as it is happening might be best able to forecast and plan for coming changes. ARC planners and demographers have developed a process of stakeholder engagement called "Small Area Outreach." In this process, ARC works with local jurisdictions to discuss their current forecasting efforts, obtain feedback on local developments, and determine if the jurisdictions are aware of ARC's forecast changes. Currently, ARC seeks to carry out an outreach process with each jurisdiction every 3 years on a rolling basis. Local governments are contacted about timing and availability at the beginning of the 3-year cycle, and ARC develops a calendar of engagement over the cycle. The jurisdictions also are asked to 
respond to custom information requests. The demographer highlighted this approach, which combines robust quantitative analysis with intensive community engagement, as one of the most important practices ARC has in creating better forecasting and understanding community change. ARC's lead demographer provided the information in ARC's Small Area Outreach process (see box, below), which outlines the step-by-step scope, thinking, and processes behind the Small Area Outreach Process.

\section{Atlanta Regional Commission's Small Area Outreach Process}

\section{Purpose}

- Anticipate economic shifts.

- Convene decision-makers.

- Address future unknowns.

- Conduct healthy dialogue and seize constructive feedback.

\section{Objectives}

- Demonstrate forecasting and modeling process transparency.

- Introduce and integrate modeling tools used to support regional work programs.

- Engage planning partners and elected officials on future development plans.

- Collaborate to promote insightful and innovative planning practices.

\section{Requirements}

- Participation in meetings to assess baseline output from model build and previous forecast.

- Guide regional planners in refining calibrations for new model forecast.

- Critique and sanction expected land use, transportation and economic development conditions, activities and trends.

- Contribute additional information for input into the model for reasonable outcomes.

- Help regional planners understand the activity allocation and space development systems in place.

- Identify major developments of regional impact and planning implications.

\section{Outcomes}

- Provide research and analytic capabilities and technical assistance.

- Support local agencies on policy decision-making methods.

- Answer "what-if" questions.

- Explore regional opportunities.

- Measure sustainable development.

Goals

- Produce a regional socioeconomic forecast through 2050.

- Provide regional outcomes for small-area modeling.

- Ratify a forecast for planning purposes and scenario modeling approaches.

ARC staff engages the community by asking community members how they would like to see future spatial distributions of population and employment based on anticipated population growth rates. ARC asks counties or other jurisdictions in their region where they expect (or plan for) growth to concentrate and if the county has plans in place that could accommodate the transportation and other 
needs expected from the projected growth. ARC staff then evaluates land use policies by comparing ARC's unified growth policy map to existing zoning and land uses in these small areas.

Public engagement and partnerships help ARC perform a reality check to assess if the agency is missing any information at the local level. In situations where ARC's forecasts and the expectations of the county or local community are at odds, ARC reaches out to the jurisdiction to understand if ARC's assumptions need to be updated or if the jurisdiction needs to update their planning to reflect the forecast possibilities. The engagement also provides ARC planners with opportunities to work with local jurisdictions to improve their data collection, which can trickle up into better regional planning. Additionally, the engagement gives ARC an opportunity to incentivize sustainable development directly through their Livable Choices Initiative, which provides matching funds for developers and local jurisdictions for more compact and mixed-use land development.

ARC's interactions with Hall County provides a window into how the small area outreach process helped ARC improve its forecast modeling and Hall County better prepare for coming population changes. At the time of the engagement, Hall County was updating their transportation network to calibrate their transportation model. Hall County was building their network model based on their plans and public engagement with their constituents but had been unable to model the potential impacts of the buildout fully. ARC learned the types of transportation projects Hall County sought to implement and could take the county's planned updates to its transportation network, run it through their modeling process, and then share with Hall County what sociodemographic impacts and shifts the model projected the updated network would have on growth in the county.

In other cases, ARC has encountered jurisdictions that are apprehensive about growth, do not want to grow, or do not understand the type of growth likely to come. In such cases, ARC's growth forecast and small area outreach engagement can be a wakeup call to the jurisdiction about needing to understand that growth will happen whether they prepare for it or not. As an example, Fayette County, through its engagement with ARC, recognized that forecasts suggested that their population makeup would shift such that the elderly population would be a much larger percentage of the overall population by 2040. In response, the county had to consider various factors including how this would affect income and tax revenue. One result was that the county made an effort to bring in jobs or industries to attract a younger demographic and actively worked to develop a television content production industry.

ARC also makes a concerted effort to disseminate their forecast information beyond their member jurisdictions. ARC maintains a "20-County Data Dashboard" that enables users to navigate through county-by-county forecast data. They also maintain the $33^{\circ} \mathrm{N}$ blog , where ARC can regularly post samples of their forecasting findings and other articles about regional growth and demographics. These outlets allow ARC to communicate the type of data they collect and the analysis they produce.

\section{KEY TAKEAWAYS}

ARC's effort to ground-truth their forecasts for jurisdictions within their metro area is notable because it offers the opportunity to improve their modeling of demographic change while helping 
local communities realize and react to coming change. Other forms of outreach, including the $33^{\circ} \mathrm{N}$ blog_provide further avenues for sharing forecast information with the broader community in an attempt to make their work more tangible and useful to the community. If outreach methods such as these can address EJ community changes, they can be used to alert smaller jurisdictions or other agencies (such as transit agencies) about potential EJ issues stemming from changing community composition. For instance, if ARC outreach highlighted an emerging refugee community, this may help agencies working in that area to develop new outreach approaches with that community.

ARC's experience with small area outreach is a reminder that forecast and modeling inputs need to be locally validated and as accurate as possible for the outputs to be on target, and that applying the outputs at various levels by various jurisdictions can make them more useful. Small area outreach offers an opportunity to apply both lessons. Further, the process reveals that accurate forecasting is an iterative process and is often a collaboration between regional planning agencies with technical expertise in demographic analysis and forecasting, and jurisdictions with intimate knowledge of local demographic shifts, trends and plans. 


\section{METROPOLITAN TRANSPORTATION COMMISSION}

\section{INTRODUCTION AND OBJECTIVES}

Metropolitan Transportation Commission is the metropolitan planning organization for the ninecounty San Francisco Bay Area. It is responsible for updating the long-range regional transportation plan. Escalating housing costs over the past decade have displaced low-income and minority communities from desirable locations in San Francisco, the Peninsula, South Bay, and other bayside locations and some suburban locations (herein “central areas”), especially near transit. An innovative performance measure designed to understand the potential for the regional plan investments to create additional displacement pressure was used to evaluate the most recent 2017 long-range transportation plan, the Plan Bay Area 2040. The measure was proposed to help reduce the displacement pressures created by the long-range transportation plan by highlighting neighborhoods potentially experiencing more pressure. The measure serves as a tool for planners and advocates to use in improving planning for affordable housing and protecting current supplies of affordable housing near transit and in other desirable locations. This displacement potential measure is the subject of this case study.

\section{COMMUNITY PROFILE}

The nine-county San Francisco Bay Area transitioned to become "majority-minority” around 2000 and continues to become more diverse every year. Table 18 shows the demographic breakdown and recent trends. While overall population growth surpassed 20 percent in 1990, the number of white and black residents has declined, while the numbers of Asian and Hispanic residents has nearly doubled. Table 19 shows projections for some race and ethnicity characteristics to 2040. The region is expected to continue growing and diversifying.

Table 18. Bay Area population by race and ethnicity (adapted from MTC 2017A, Table 3-2).

\begin{tabular}{|l|c|c|c|c|c|}
\hline & 1990 & 2000 & $\begin{array}{c}\text { 2005-2009 } \\
\text { Average }\end{array}$ & $\begin{array}{c}\text { 2010-2014 } \\
\text { Average }\end{array}$ & $\begin{array}{c}\text { Change } \\
\text { 1990-2014 (\%) }\end{array}$ \\
\hline White Alone & $3,658,309$ & $3,392,204$ & $3,165,395$ & $3,050,293$ & -17 \\
\hline Black Alone & 516,420 & 497,205 & 463,359 & 455,865 & -12 \\
\hline Asian Alone & 884,547 & $1,278,515$ & $1,519,768$ & $1,758,791$ & +99 \\
\hline Latino / & 923,606 & $1,315,175$ & $1,521,456$ & $1,743,954$ & +89 \\
\hline Hispanic & & & & & \\
\hline All & $6,023,577$ & $6,783,760$ & $6,950,764$ & $7,360,487$ & +22 \\
\hline
\end{tabular}


Table 19. Demographic projections to 2040 (Adapted from Association of Bay Area Governments, n.d.).

\begin{tabular}{|l|c|c|}
\hline & Base Year (2010) & Projected Year (2040) \\
\hline Total (Millions) & 7.2 & 9.5 \\
\hline Percent Hispanic & 23 & 35 \\
\hline Percent Black & 6 & 5 \\
\hline Percent Asian & 21 & 24 \\
\hline Percent Non-Hispanic White & 45 & 31 \\
\hline Percent Other & 5 & 5 \\
\hline
\end{tabular}

The number of low-income households (defined as those with incomes below 200 percent of the federal poverty line) and their share of the region have been growing steadily since 1990. In 1990, 1.24 million households in the nine-county area were low income, constituting 21 percent of all households, while in the 2010-2014 American Community Survey, 1.84 million households—26 percent of all households-were considered low income. The number of LEP people increased significantly from around 200,000 to 360,000 between 1990 and the 2010-2014 American Community Survey (Metropolitan Transportation Commission, 2017a)

\section{PROBLEM STATEMENT}

Housing affordability, lack of housing supply, growing congestion and the increased desirability of living in central locations have created significant pressures on centrally located neighborhoods, especially those near good transportation facilities. Regional equity advocates have highlighted this housing crisis and the resulting process of displacement of low income and minority households from centrally located areas as one of the most important challenges for regional planning and investments (Marcantonio \& Karner, 2014). This passage from the equity analysis chapter of MTC’s 2017 regional plan update summarizes these issues well:

The Bay Area faces many challenges related to housing, which have a disproportionate impact on the region's low-income population. These challenges include: rising housing costs and decreasing affordability; lack of supply to meet current and future needs; a spatial mismatch between the location of jobs and housing; lack of adequate public funding to provide new affordable units or preserve existing ones; and rising poverty along with declining economic opportunities...The Bay Area does have some affordable homes, but they are primarily located in inland communities... While these homes may be newer, larger, served by better schools, and/or more affordable, their residents face longer commutes and have access to fewer services and amenities close to where they live. Conditions are even worse for renters. The average rent in the region was $\$ 2,526$ in the second quarter of 2015, which rose another 10 percent in the final quarter.

These increasing prices and rents cause households to have to extend themselves to afford their housing. "Rent burden" is a measure of the share of the household budget that is put towards rent. Rent burden has been increasing dramatically across the Bay Area, and a rent burden of more than 50 percent is considered "severe.” The number and share of households experiencing severe rent burden 
have increased dramatically, from 19 percent of renter households in 2000 to 26 percent of average renter households in 2010-2014. Low-income communities are especially hard hit, with many neighborhoods containing more than 40 percent of their households experiencing severe rent burden.

Figure 25 illustrates the risk of displacement based on analysis of housing market pressures in lowincome communities (purple shades) and pressures forcing low income households from higher income communities (orange shades). Displacement results from a physical process (e.g., divestment) or an economic process (e.g., increasing housing prices) that forces low-income residents to move. This figure also classifies some neighborhoods as undergoing gentrification. Gentrification is defined as the influx of capital and higher-income residents to working class neighborhoods, which might or might not cause or accompany displacement ${ }^{8}$. These two phenomena are interrelated, with gentrification often causing economic displacement of low-income households from formerly affordable areas.

${ }^{8}$ See Urban Displacement Project, p. 2. 


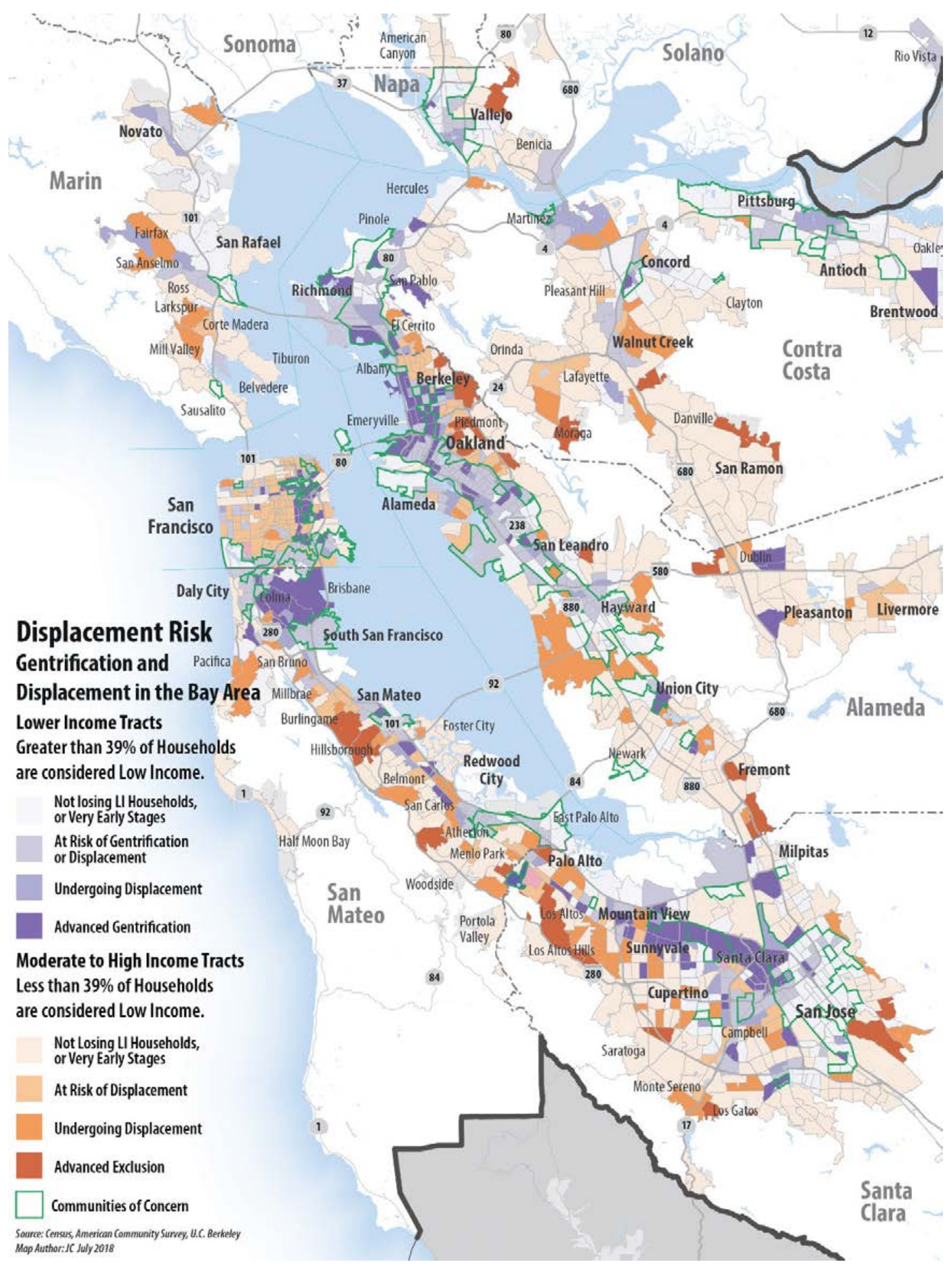

Figure 25. Displacement risk (@ Metropolitan Transportation Council, 2017). 
Figure 26 and Figure 27 illustrate the demographic effects of the displacement pressures: minority and low-income communities have been forced from central areas and experience most of their growth in outlying communities or areas with significantly less locational desirability. This pattern of movement is similar to national trends, as suburbs become more diverse and lower income due to displacement pressures in desirable core neighborhoods (Brookings Institute, 2017). This spatial dispersion in search of affordable housing places additional transportation cost burdens on these households.

According to MTC, "low-income households that are unable to afford to live near transit and job centers commute further from less urbanized areas, thereby increasing the amount of time and household budget they spend on transportation” (Metropolitan Transportation Commission, 2017a). In 2006, low-income families (annual incomes under \$70,000) were estimated to have spent a combined average of 61 percent of their annual earnings on housing (39 percent) and transportation (22 percent). (The national average for combined housing and transportation expenditures in 2006 was 51 percent.) Because of the increased dispersion of low-income households to distant areas of the region, MTC estimated in 2017 that the share spent on housing and transportation will grow to 67 percent by 2040.

While rent burden and the displacement and gentrification they can cause are outcomes of real estate market processes, these factors can be directly affected by transportation investments. Evidence shows that investments in transportation, especially rail transportation, which can improve access and mobility in areas experiencing high levels of traffic congestion, can improve the desirability of neighborhoods near those investments. This causes increases in housing prices and rents that can increase the risk of displacement of low-income households. At a regional scale, this phenomenon can create significant shifts in the location and quantity of EJ populations. In the San Francisco Bay Area and many other metropolitan areas throughout the United States, the movement and increase in EJ populations in suburban and inland areas will create new equity issues for those jurisdictions. To address this issue, MTC's regional planning process added a measure of displacement potential in 2013 to its list of equity measures used to evaluate the regional plan. In developing this measure, planners and advocates cautioned that the measure did not contribute to the risk of displacement by highlighting communities where there was potential for further investment thereby exacerbating the very problem the measure was trying to prevent. This delicate balance between information and the impacts of the information is important to understand for this measure.

\section{METHOD OF ANALYSIS}

Against this backdrop of a widely recognized crisis of housing affordability and availability, Bay Area advocates proposed to include a careful exploration of the impacts of regional plan investments on households with already high housing cost burdens (Marcantonio \& Karner, 2014). A measure of the displacement potential of the regional plan scenarios was included in the equity analysis of the 2013 regional plan (Metropolitan Transportation Commission, 2013). The 2017 update of the plan, which altered the 2013 measure slightly, is the focus of this case study. 


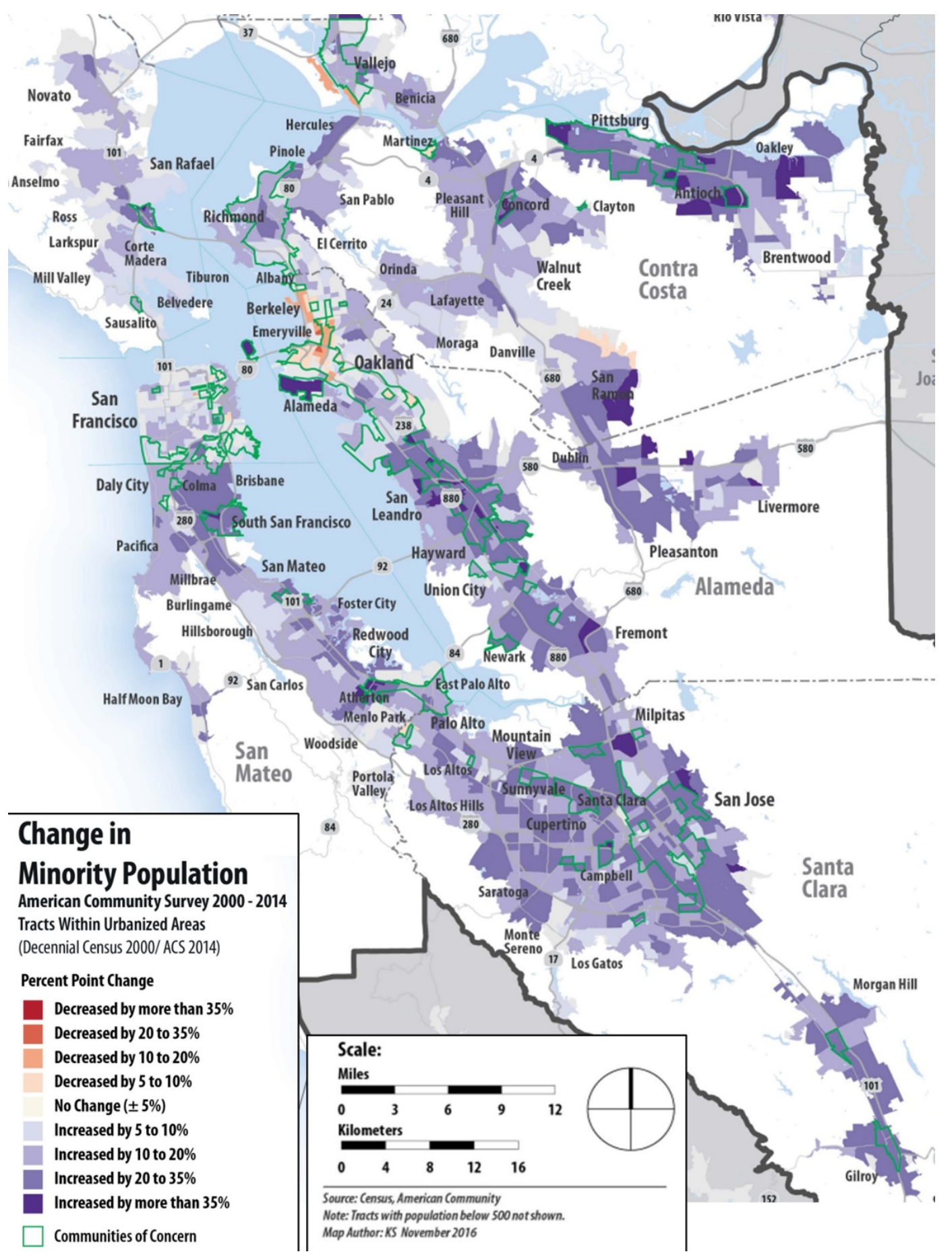

Figure 26. Change in minority population, 2000-2014 (@ Metropolitan Transportation Council, 2017). 


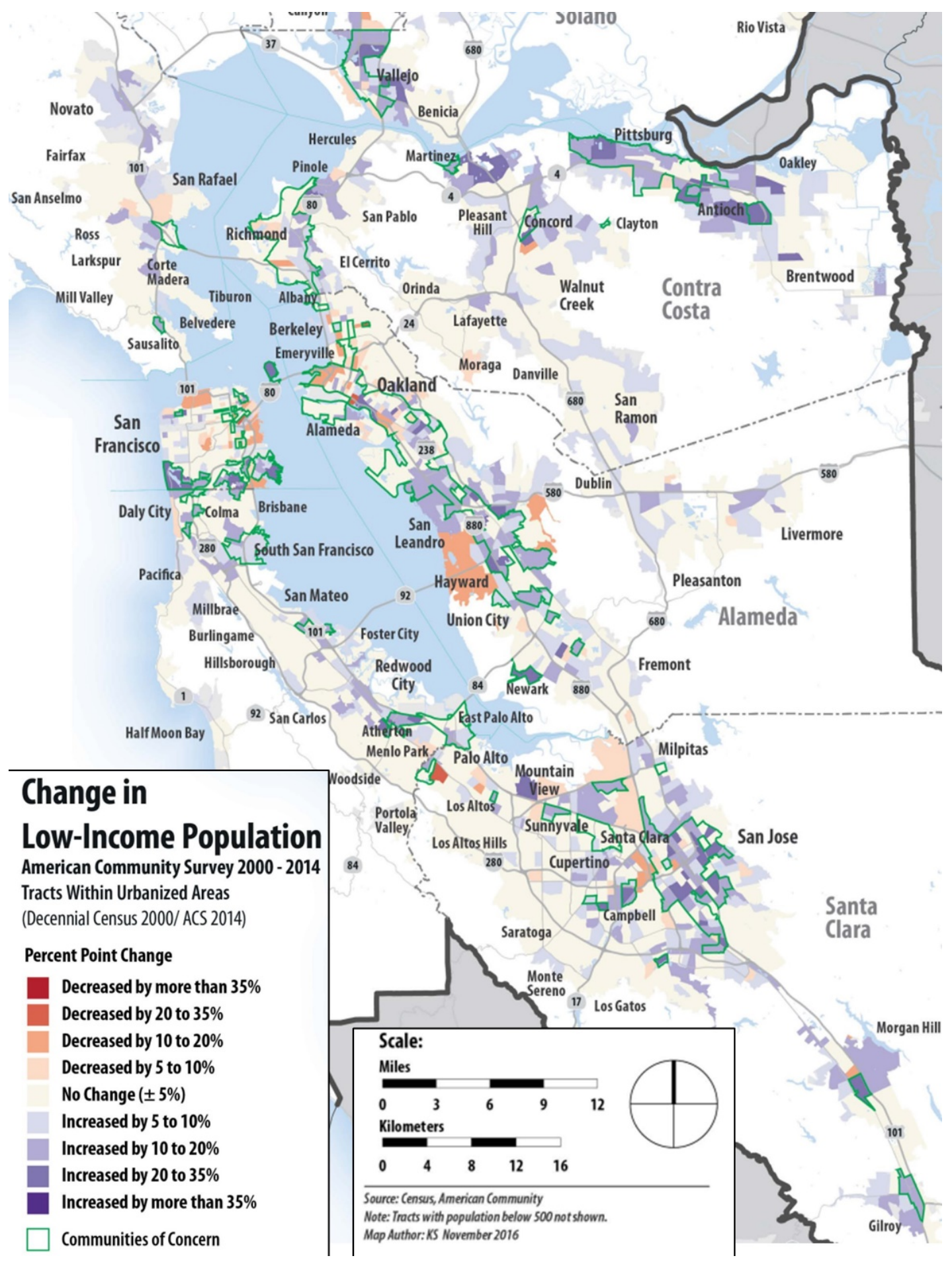

Figure 27. Change in low-income population, 2000-2014 (@ Metropolitan Transportation Council, 2017).

MTC conducts a broad equity analysis for its regional transportation plans. A Regional Equity Working Group (REWG) was formed with representatives of "low-income and minority communities; seniors and persons with disabilities; staff representing local jurisdictions, transit 
agencies and county congestion management agencies (CMAs); public health departments; and community-based organizations and advocacy groups" (Metropolitan Transportation Commission and Association of Bay Area Governments, 2017). MTC gathers feedback and recommendations through the REWG to help design the equity measures and shape the draft regional plan. The group also helps define the potential disadvantaged communities used in the measures in their comparative analyses with the rest of the region.

The equity measures are used to assess project performance and the performance of full regional plan scenarios (Metropolitan Transportation Commission, 2015). Thirteen overall performance measures were used for the regional plan, six of which focus specifically on equity. Measure number seven (of a set called "equitable access" measures) assesses the share of low- and moderate-income renters in three types of areas at increased risk of displacement:

- Priority Development Areas (PDA) are "areas designated by local jurisdictions for higherdensity, walkable and mixed-use communities” and special funding through the One Bay Area Grants program.

- Transit Priority Areas (TPA) are half-mile buffer areas surrounding high-capacity transit stations (bus, rail, or ferry).

- High Opportunity Areas (HOA) are areas with "higher performing schools, strong labor market engagement including low unemployment and higher educational attainment, lower poverty levels, and overall better housing and neighborhood quality” (ABAG, 2015).

While displacements from PDAs and TPAs are more typical processes of displacement, the measure also includes displacement from HOAs, where some low-income households might be located. The measure is not intended to predict displacement, but rather to measure risk or vulnerability to changes in the housing market.

\section{Measure Calculation}

Calculating these measures involves several steps. First, the measures require an estimate of the number of households in each census tract that are potentially rent burdened and therefore at risk of displacement, using income as a proxy. That estimate is based on the Association of Bay Area Government's (ABAG) long-range growth model that MTC uses in its transportation plan analysis (the two agencies have since merged). Low-income households are assumed rent burdened, and so their share of each neighborhood is calculated. Displacement pressures are assumed to come from investments associated with PDA, TPA, or HOA, so the share of low-income households within those specific areas are calculated. That share is considered the displacement risk. The analysis compares displacement risk with the base year, reporting the results as percentage differences with that base year percentage. This change in displacement risk from the base year is compared for each plan scenario. 


\section{Communities of Concern Methodology}

The potential for displacement measure is analyzed for neighborhoods classified as "communities of concern" (CoC), the label used by MTC to refer to EJ communities and compared to neighborhoods in the remainder of the region. MTC used various factors to define CoCs over the past few regional plans and has again updated that definition for the 2017 plan (MTC 2015 p. 4). For the 2017 plan, CoCs are defined as census tracts having a high concentration of both minority (above 70 percent of households) and low-income (above 30 percent) households, or census tracts having high concentrations of low-income households and concentrations above the concentration threshold for three or more other disadvantage factors listed in Table 20.

Table 20. Factors defining communities of concern (adapted from MTC, 2015, p.5).

\begin{tabular}{|c|c|c|}
\hline Disadvantage Factor & \% Regional Populations & Concentration Threshold \\
\hline Minority & $58 \%$ & $70 \%$ \\
\hline $\begin{array}{l}\text { Low Income (<200\% Federal Poverty } \\
\text { Level) }\end{array}$ & $25 \%$ & $30 \%$ \\
\hline Limited English Proficiency & $9 \%$ & $20 \%$ \\
\hline Zero-Vehicle Proficiency & $10 \%$ & $10 \%$ \\
\hline Seniors 75 Years and Over & $6 \%$ & $10 \%$ \\
\hline People with Disability & $9 \%$ & $25 \%$ \\
\hline Single-Parent Family & $14 \%$ & $20 \%$ \\
\hline Severely Rent-Burdened Household & $11 \%$ & $15 \%$ \\
\hline
\end{tabular}

The effect of this definition is that 23 percent of the population lives in census tracts that are designated CoC. Table 21 shows the proportion of the region's populations that live in CoC. The CoC geography overlaps strongly with the location of minority and low-income households, while significantly less strongly with other households experiencing transportation disadvantage, especially seniors and people with disabilities, who are more dispersed throughout the region. Of the 1,588 total census tracts in the region, 365 were designated CoC; the remaining 1,223 tracts are considered "remainder of the region." Figure 28 shows the location of CoC tracts. 
Table 21. Population shares within communities of concern tracts (Adapted from MTC, 2017A, p. 2-3).

\begin{tabular}{|c|c|c|c|c|c|c|c|c|c|}
\hline & ?를 & 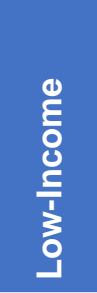 & 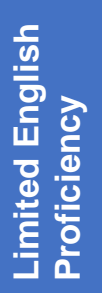 & 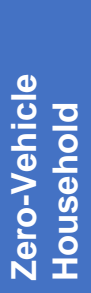 & 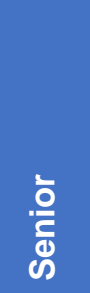 & $\begin{array}{l}\frac{\lambda}{5} \\
\frac{0}{50} \\
\frac{0}{0}\end{array}$ & 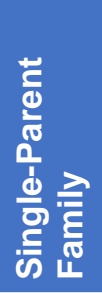 & 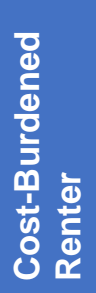 & $\begin{array}{l}\frac{5}{0} \\
\frac{0}{7} \\
\frac{0}{2} \\
\frac{0}{0} \\
\frac{1}{0} \\
\frac{\pi}{0} \\
\end{array}$ \\
\hline $\begin{array}{l}\text { Population Inside CoCs (Total, } \\
\text { thousands) }\end{array}$ & 1,415 & 798 & 289 & 97 & 79 & 187 & 87 & 110 & 1,708 \\
\hline Share of Population Inside CoCs (\%) & $33 \%$ & $43 \%$ & $48 \%$ & $38 \%$ & $18 \%$ & $28 \%$ & $37 \%$ & $38 \%$ & $23 \%$ \\
\hline $\begin{array}{l}\text { Share of Population Inside CoCs (\% } \\
\text { of total CoC population) }\end{array}$ & $83 \%$ & $47 \%$ & $17 \%$ & $18 \%$ & $5 \%$ & $11 \%$ & $25 \%$ & $20 \%$ & $100 \%$ \\
\hline $\begin{array}{l}\text { Population Inside Remainder of } \\
\text { Region (Total, thousands) }\end{array}$ & 2,891 & 1,040 & 319 & 161 & 350 & 487 & 147 & 180 & 5,631 \\
\hline $\begin{array}{l}\text { Share of Population Inside } \\
\text { Remainder of Region (RoR, \%) }\end{array}$ & $67 \%$ & $57 \%$ & $52 \%$ & $62 \%$ & $82 \%$ & $72 \%$ & $63 \%$ & $62 \%$ & $77 \%$ \\
\hline $\begin{array}{l}\text { Share of Population Inside } \\
\text { Remainder of Region (\% of total RoR } \\
\text { Population) }\end{array}$ & $51 \%$ & $18 \%$ & $6 \%$ & $8 \%$ & $6 \%$ & $9 \%$ & $11 \%$ & $9 \%$ & $100 \%$ \\
\hline Region (Total, thousands) & 4,306 & 1,838 & 608 & 257 & 428 & 674 & 234 & 290 & 7,339 \\
\hline Region (\%) & $59 \%$ & $25 \%$ & $9 \%$ & $10 \%$ & $6 \%$ & $9 \%$ & $14 \%$ & $11 \%$ & $100 \%$ \\
\hline
\end{tabular}




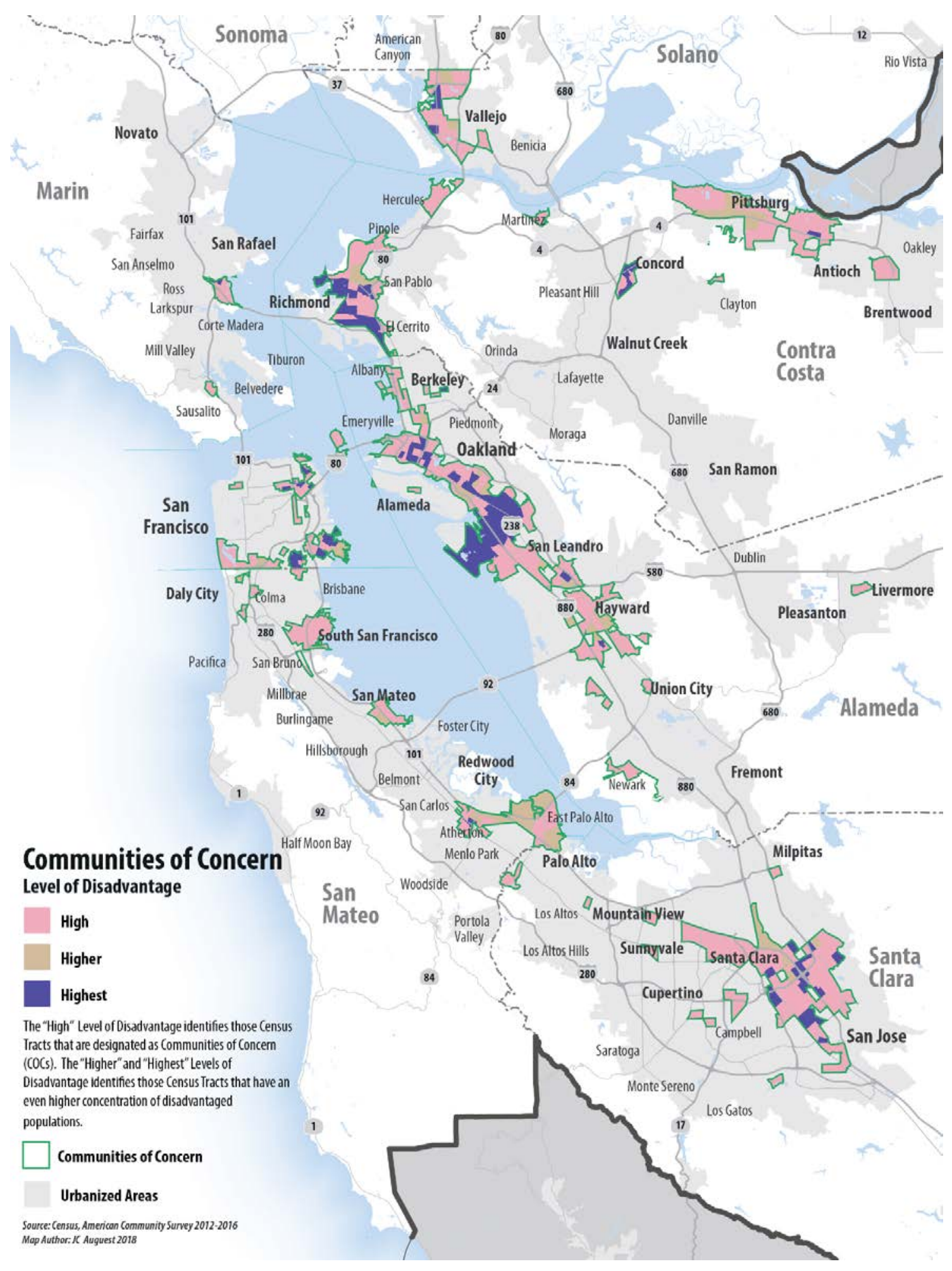

Figure 28. Communities of concern (@ Metropolitan Transportation Council, 2017). 


\section{Regional Plan Scenarios}

MTC analyzed several 2040 regional plan scenarios as part of its process to develop the final plan. The scenarios differ in terms of where they assume population and employment growth occur and where transportation investments are located by the plan. These scenarios were evaluated using the equity measures. The following descriptions of the scenarios are paraphrased from descriptions in MTC documents (Metropolitan Transportation Commission, 2017a):

- No Project Scenario: assumes a more limited set of transportation investments and that no region-wide land-use coordination would be implemented to achieve integrated transportation investments and population and job growth.

- Main Streets Scenario: places future growth in the downtowns in all Bay Area cities. This scenario would expand high-occupancy toll lanes and increase highway widenings and assumes development on land outside the current urban footprint.

- Big Cities Scenario: concentrates future growth within the Bay Area's three largest cities: San Jose, San Francisco, and Oakland. Transportation investments would go to the transit and freeways serving these cities. No development would occur on open spaces outside the urban footprint.

- Environment, Equity, and Jobs (EEJ) Scenario: includes strategies to focus more growth in suburban communities and away from transit-rich areas to reduce risk of displacement in urban areas and improve access to high opportunity areas in suburban locations. This scenario includes more funding for bus operations in suburban areas to serve lower-income residents and reduces funding for highway expansion and efficiency projects. This alternative would encourage intensification of land use beyond PDAs to include jobs-rich, highopportunity TPAs not currently identified as PDAs.

- Draft Plan: represents a “middle scenario” between the more dispersed Main Streets and the more concentrated Big Cities scenarios. The Draft Preferred Scenario focuses 75 percent of new households and 52 percent of new jobs into PDAs (principally in San Jose, San Francisco, and Oakland, and along the east and west bayside corridors) and distributes all remaining growth within established urbanized areas (Metropolitan Transportation Commission, 2018).

Of chief importance is whether the investment plans change the risk already present in the base case. The results for the draft plan do show some increased risk (+7 percent) to low-income households outside CoC areas and a small increase in risk ( +1 percent) to low-income households inside CoC areas. These results lead MTC to conclude that the draft plan does not significantly increase the risk of displacement for low-income households living in communities of concern (compared to doing nothing, "No project"). Furthermore, it concludes that even comparing CoCs with the remainder of the region, because the draft plan increases risk less than doing nothing, the draft plan does not create significant disproportionate burdens (MTC 2017A, 6-4). MTC does recognize existing disparities in risk between CoCs and other communities (primarily because, as was mentioned above, CoCs contain higher numbers of low-income households assumed rent burdened), and that the draft plan does not reduce that existing risk (MTC 2017A, 6-5). 


\section{KEY TAKEAWAYS}

MTC's attempt to rigorously assess the impact of the long-range regional transportation plan on displacement risk is notable. Few regional plans address the interaction between transportation investments and housing prices and potential impacts on neighborhood displacement. This practice attempts, proactively, to forecast potential demographic shifts due to transportation investments. This analysis could be used by later phases of transportation decision-making to reassess community profiles and better understand shifting demographics. For instance, a major rail project that would expand or add to TPAs in the region would be a major force for adding displacement risk, according to the measure described here. Knowing about this risk could lead the project planning and environmental review process to prioritize development strategies to reduce that risk (say, by leveraging land purchasing and development to increase affordable housing near the stations), and to highlight that risk within environmental review documents. This risk might also be recognized as land is acquired and more detailed design and engineering is undertaken. Working with the communities at these stages might reduce risk of displacement in neighborhoods already presumed under stress from development and investment.

The analysis MTC used illustrates that, without the plan or even with different planning scenarios that attempt to address equity, significant pressures remain on low-income households to move from PDAs and TPAs to more affordable areas on the outskirts of the region. To address this inability for the transportation plan to solve housing and displacement challenges, MTC developed an Action Plan to confront housing affordability issues more broadly from both a supply and a demand approach. The Action Plan includes three parts: the resiliency program, economic development focusing on middle-wage jobs, and the housing production preservation and protection program. These programs are quite complex and the reader is encouraged to visit the MTC and ABAG $\underline{\text { Action }}$ Plan website for further documentation. 


\section{METRO}

\section{INTRODUCTION AND OBJECTIVES}

Metro is the metropolitan planning organization for the Portland, Oregon metropolitan area. It is responsible for developing long-range forecasts of population, housing and economic activity, and the long-range Regional Transportation Plan (RTP). Significant shifts and displacement of lowincome and minority communities in parts of the region have heightened concerns over the impacts of plans and investments on those communities. Metro has been attempting to improve its modeling practice as it investigates these processes of displacement to make more accurate assessments of plans and forecasts. Two practices are profiled in this case study. The first is an innovative approach to long-range transportation modeling where Metro produced an interim model to help understand long-range plan impacts on EJ communities. The model was developed because of concern about the accuracy of long-range forecasts of the location of EJ communities and therefore the reliability of long-range plan EJ analyses produced using those forecasts. The second practice is a displacement scenario that was developed by a demographer alongside their other long-range population forecasts. This was done to better understand the dynamics of community displacement within forecasting systems and to try and predict patterns of displacement to assist housing planners in understanding potential housing and neighborhood change.

\section{COMMUNITY PROFILE}

Like most of the Nation, communities in the Portland region are becoming more diverse. By 2045, communities of color are projected to be the majority. Between 1990 and 2010, minority populations increased from 11 percent to 26 percent (Metro, 2018a). However, a long history of exclusionary and discriminatory policies has resulted in most communities of color in the region experiencing worse economic and social outcomes than other demographic groups. According to the American Community Survey, Median household income varies significantly by race in the greater Portland area, with Hispanic households making around \$41,000 and black households making \$35,000 compared to $\$ 62,000$ earned annually by their white counterparts.

In addition to the disparity in income, regional population growth and market pressures due to shifts in housing preferences (smaller, older homes in walkable locations) and increased popularity of central locations in the region, have caused an increase in rental costs for Portland's central neighborhoods, displacing low-income people and people of color eastward. Figure 29 illustrates this displacement process between 1990 and 2010. Rents for one-bedroom apartments have increased by 52 percent since 2010, during which time renter incomes have only increased 19 percent (Metro, 2018a). From 1990 to 2010, North and Northeast Portland's black population decreased from over 35 percent to just under 15 percent.

East Portland has become the most diverse community in the State with significant shares of the regional minority communities (20 percent and 24 percent of the regional black and Hispanic populations, respectively). Between 2000 and 2010, the white population has decreased, while the Hispanic population has increased by 106 percent and the black population by 166 percent (Metro, 
2015). A disproportionate share of households earning below $\$ 39,580$ (200 percent poverty level) are found in east Multnomah County. Figure 30 shows the location of census tracts where historically marginalized communities are now concentrated above the regional average. How the outer regions have higher concentrations while the inner tracks do not have concentrations of these communities is notable.

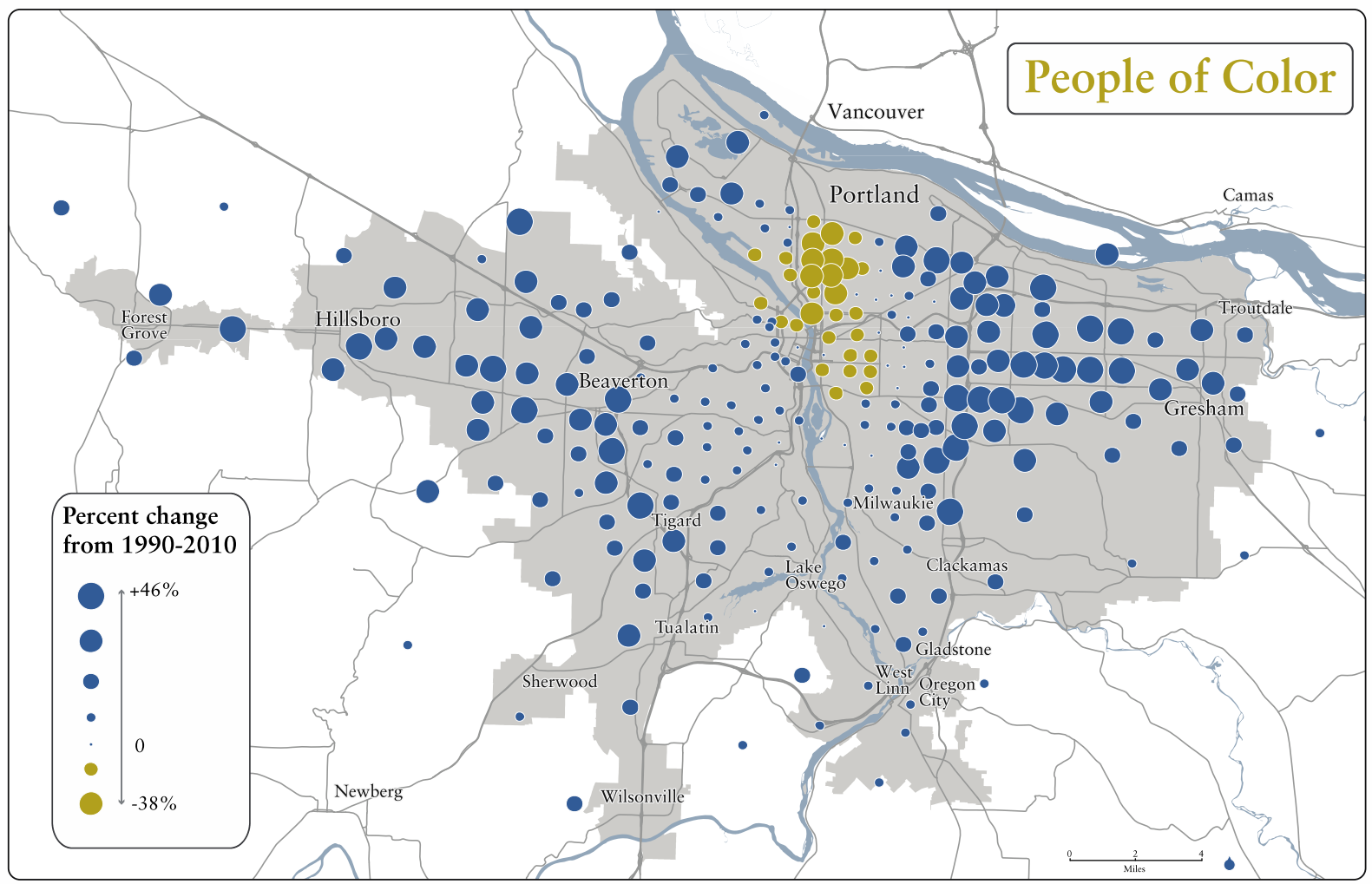

Figure 29. Change in number of people of color (1990-2010) (CCity of Portland, n.d.). 


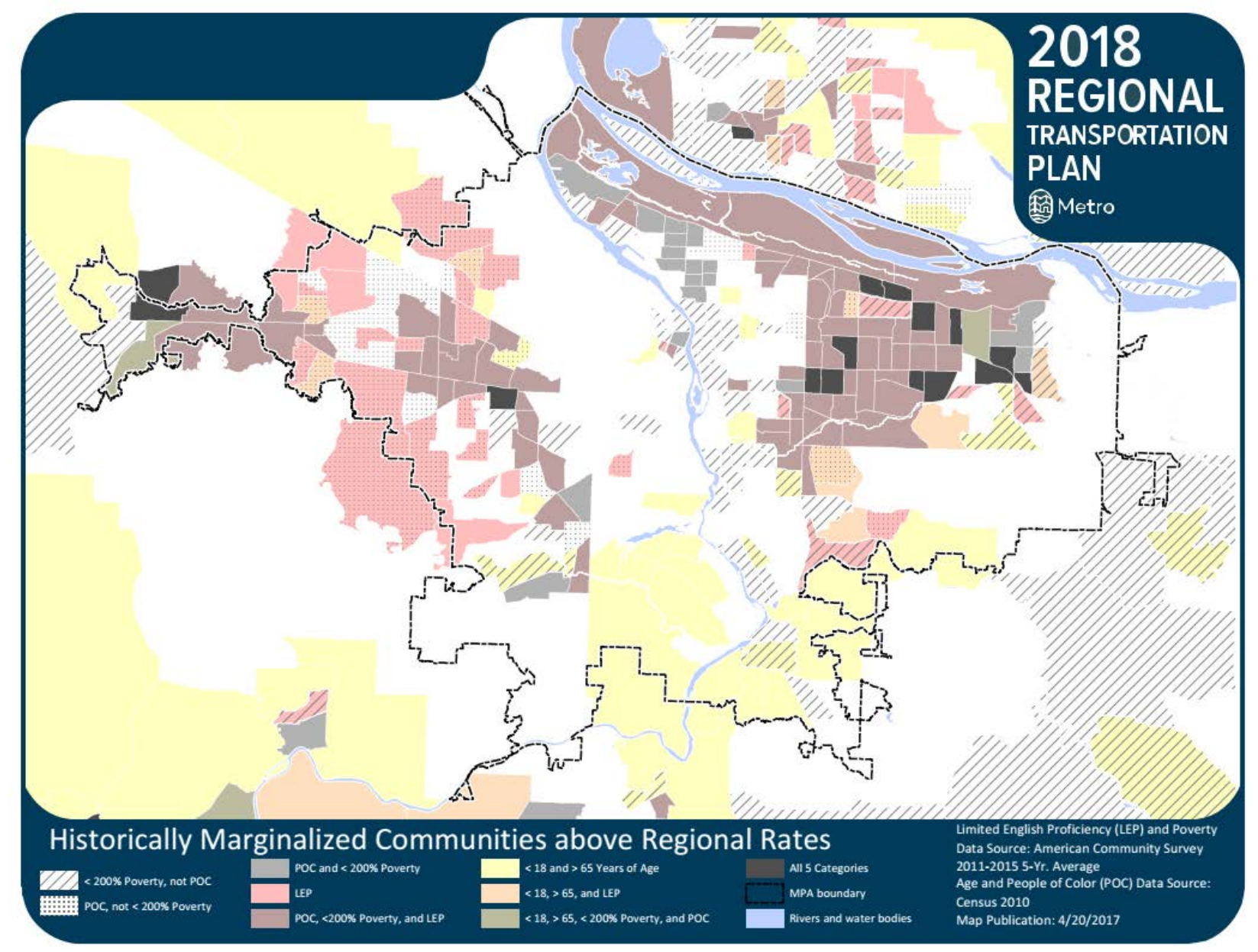

Figure 30. Location of high concentrations of historically marginalized communities (@Metro, 2018).

\section{PROBLEM STATEMENT}

Against this backdrop of displacement, and the shifting location and size of EJ communities, advocates and agency staff have been particularly focused on addressing these issues in planning at all levels. One challenge for long-range planning under these conditions of changing community demographics is the accuracy of long-range forecasts and models and analyses that rely on those forecasts. Metro produces a long-range demographic forecast based on a complex forecasting system combining housing dynamics, economic activity, and core demographic changes (migration, births, and deaths). This forecast is used to define the location of EJ communities for use in EJ analyses as part of the evaluation of the long-range plan. Typical forecasting practice projects race and ethnic profiles using current day profiles, projecting them forward onto future population growth. However, because EJ communities have been changing so quickly, advocates have noted that long-range projections that assume a similar racial profile to the present could be very inaccurate, especially as the forecast extends farther into the future.

Therefore, the issues addressed in this case study are twofold: first, how to address the lack of accuracy in forecasts in long-range transportation models; and second, how to better understand 
long-range dynamics of community displacement to make better forecasts by race and ethnicity. The first issue is partially addressed using an interim year model run wherein the location and quantity of EJ communities can be more confidently modeled; as the forecasting timeframe is shorter (10 years), forecasting errors can be assumed smaller than with a full-term forecast (20+ years). The second issue is addressed through a scenario exercise that Metro forecasters use to understand displacement dynamics.

\section{METHOD OF ANALYSIS}

\section{Interim (10-Year) Model Run for the EJ Analysis}

From 2015 to 2018, Metro developed its 2018 Regional Transportation Plan (RTP). Part of the development process is an effort to evaluate various outcomes and impacts from the regional plan investment. Typical practice for large MPOs is to create models of the regional transportation system and project and compare outcomes for different regional plan scenarios. The models evaluate the full buildout of the regional plan (at the final plan year assuming all projects are built by that time) and compare that to a "no-build" scenario that assumes the same regional growth in population and jobs but no investments in new transportation infrastructure. Sometimes, different versions of the regional plan are developed, based on differing assumptions of revenues; one scenario might be a financially constrained plan in which only known revenues are assumed, while a better funded version would include additional revenues to complete high-priority regional projects.

Metro convened a series of working groups to help define methods for evaluating the RTP, using outputs from the modeling efforts. Through a series of work group meetings over 3 years, the Equity Work Group (EWG) helped define the preliminary ("Round 1") EJ analysis for the RTP. The EWG contained representatives from about 30 local transportation and public transit agencies, county health departments, EJ advocacy organizations, and other community organizations. Results from Round 1 were used to refine the regional plan projects and the equity analysis approach, resulting in a Round 2 analysis. In this section, the Round 1 analysis is presented. See Metro 2018b for a complete presentation of both analyses.

Through a series of discussions, the EWG recommended which communities to include as transportation disadvantaged (called "Historically Marginalized Communities" or HMCs). Three groups were used for the analysis: HMCs, "Focused HMCs," and "People of Color.” Table 22 and Table 23 show the definitions used for HMCs and Focused HMCs. Focused HMCs is a subset of HMCs pertaining more closely to Federal regulations and EJ guidance. The EWG also recommended measures to use as part of the analysis (described in more detail later). 
Table 22. Historically marginalized community definitions and thresholds (Adapted from: Metro, 2018 Regional Transportation Plan - Public Review Draft, Appendix E).

\begin{tabular}{|c|c|c|c|}
\hline Community & Definition & Geography Threshold & Date Source \\
\hline People of Color ${ }^{1}$ & Persons who identify as minorities. & $\begin{array}{l}\text { Census tracts above the } \\
\text { regional rate ( } 26.5 \%) \text { for people } \\
\text { of color. }\end{array}$ & $\begin{array}{l}2010 \\
\text { Decennial } \\
\text { Census } \\
\end{array}$ \\
\hline Low-Income & $\begin{array}{l}\text { Households with incomes equal to or } \\
\text { less than 200\% of the Federal Poverty } \\
\text { Level (2016); adjusted for household } \\
\text { size }\end{array}$ & $\begin{array}{l}\text { Census tracts above the } \\
\text { regional rate ( } 31.1 \%) \text { for } \\
\text { Household with Lower Income }\end{array}$ & $\begin{array}{l}\text { American } \\
\text { Community } \\
\text { Survey, 2011- } \\
2015\end{array}$ \\
\hline $\begin{array}{l}\text { Limited English } \\
\text { Proficiency }\end{array}$ & $\begin{array}{l}\text { Persons who identify as unable "to } \\
\text { speak English very well." }\end{array}$ & $\begin{array}{l}\text { Census tracts above the } \\
\text { regional rate ( } 8.5 \% \text { ) for Limited } \\
\text { English Proficiency (all } \\
\text { languages combined). }\end{array}$ & $\begin{array}{l}\text { American } \\
\text { Community } \\
\text { Survey, 2011- } \\
2015 \text { and } \\
\text { Oregon } \\
\text { Education } \\
\text { Department } \\
\text { School } \\
\text { Enrollment } \\
\text { Data }\end{array}$ \\
\hline Older Adults & Persons 65 years of age and older & $\begin{array}{l}\text { Census tracts above the } \\
\text { regional rate for Older Adults } \\
(11 \%)\end{array}$ & $\begin{array}{l}2010 \\
\text { Decennial } \\
\text { Census } \\
\end{array}$ \\
\hline Young People & Persons 17 years of age and younger & $\begin{array}{l}\text { Census tracts above the } \\
\text { regional rate for Young People } \\
(22.8 \%)\end{array}$ & $\begin{array}{l}2010 \\
\text { Decennial } \\
\text { Census }\end{array}$ \\
\hline People of Color ${ }^{1}$ & Persons who identify as minorities. & $\begin{array}{l}\text { Census tracts above the } \\
\text { regional rate ( } 26.5 \%) \text { for people } \\
\text { of color. }\end{array}$ & $\begin{array}{l}2010 \\
\text { Decennial } \\
\text { Census } \\
\end{array}$ \\
\hline Low-Income & $\begin{array}{l}\text { Households with incomes equal to or } \\
\text { less than 200\% of the Federal Poverty } \\
\text { Level (2016); adjusted for household } \\
\text { size }\end{array}$ & $\begin{array}{l}\text { Census tracts above the } \\
\text { regional rate ( } 31.1 \%) \text { for } \\
\text { Household with Lower Income }\end{array}$ & $\begin{array}{l}\text { American } \\
\text { Community } \\
\text { Survey, 2011- } \\
2015\end{array}$ \\
\hline $\begin{array}{l}\text { Limited English } \\
\text { Proficiency }\end{array}$ & $\begin{array}{l}\text { Persons who identify as unable "to } \\
\text { speak English very well." }\end{array}$ & $\begin{array}{l}\text { Census tracts above the } \\
\text { regional rate ( } 8.5 \% \text { ) for Limited } \\
\text { English Proficiency (all } \\
\text { languages combined). }\end{array}$ & $\begin{array}{l}\text { American } \\
\text { Community } \\
\text { Survey, 2011- } \\
2015 \text { and } \\
\text { Oregon } \\
\text { Education } \\
\text { Department } \\
\text { School } \\
\text { Enrollment } \\
\text { Data }\end{array}$ \\
\hline Older Adults & Persons 65 years of age and older & $\begin{array}{l}\text { Census tracts above the } \\
\text { regional rate for Older Adults } \\
(11 \%)\end{array}$ & \begin{tabular}{|l}
2010 \\
Decennial \\
Census
\end{tabular} \\
\hline
\end{tabular}

${ }^{1}$ The term "People of Color" and its associated definition were adopted by the 2018 RTP Equity Work Group (Oregon Metro, 2017, Appendix 1, p. 1). 
Table 23. Focused HMC definitions and thresholds (Adapted from: Metro, 2018 Regional Transportation Plan Public Review Draft, Appendix E).

Community

People of Color

Low-Income
Geographic Threshold

The census tracts that are above the regional rate for people of color AND the census tract has twice $(2 \times)$ the population density of the regional average (regional average is 0.48 person per acre)

The census tracts that are above the regional rate for low income households AND the census tract has twice $(2 \times)$ the population density of the regional average (regional average is 0.58 person per acre).

Limited English The census tracts that are above the regional rate for low income households AND Proficiency (regional average is 0.15 person per acre) OR those census tracts that have been identified as "safe harbor" tracts for language isolation. ${ }^{9}$

Central to understanding how the plan affects EJ communities is understanding the size and location of those communities, in the near term and in the outer years of the plan, in this case 2040. This information is necessary because the evaluation will attempt to compare plan benefits and burdens for EJ communities with the rest of the region. (The plan is considered fair if benefits and burdens are similarly shared.)

Discussion at work group meetings and among staff indicated long-range forecasts of the quantity and location of HMCs were not dependable because of the speed at which these communities are changing and because Metro forecasts do not explicitly model race when they locate households. Instead, they assume the same spatial distribution of race and ethnicity from the current year and project that forward.

In response, the working group and staff added a shorter-term evaluation to improve the projection quality (fewer years over which errors can grow) and thus the EJ analysis results. Agency staff and stakeholders agreed that demographic projections were more certain over 10 years than for 2040, especially regarding the location of HMCs. According to Metro, "the emphasis on the near-term analysis years are to: 1 ) recognize that over the long-term, it is unrealistic to assume a community will not have turn over and change; [and] 2) emphasize the existing transportation needs and current disparities experienced by these communities” (Metro, 2016a).

\section{Interim Scenario Development}

Metro therefore developed an "interim" evaluation point for 2027 that would include 10 years of investments, starting from the 2017 modeling date. The 10-year time point included almost 50

\footnotetext{
${ }^{9}$ Safe Harbor is noted in Federal guidance on LEP which addresses how agencies provide language assistance to limited English proficiency persons to ensure access to all public resources (https://www.govinfo.gov/content/pkg/FR-2005-12-14/html/05-23972.htm). "The safe harbor provision mainly addresses translation of documents and language assistance, however for analysis purposes; it may help to identify areas where additional attention is warranted because of a concentration of language isolation. Safe harbor applies when a language isolated group constitutes 5\% or 1,000 persons of the total population in the given area." (Metro, 2018b).
} 
percent of the total regional plan investments (Table 24). The interim model produces the same kind of information the full long-term model produces, which is needed to evaluate transportation impacts, such as a VMT, traffic delay, travel speeds, and mode choice for each neighborhood.

Table 24. Summary of 2018 RTP investments in each of the scenarios for Round 1 evaluation (Adapted from: Metro, 2018 Regional Transportation Plan - Equity Work Group, November 30, 2017 meeting).

\begin{tabular}{|l|c|c|}
\hline & $\begin{array}{c}2027 \text { Constrained Investment } \\
\text { Strategy (2018-2027) }\end{array}$ & $\begin{array}{c}\text { 2040 Constrained Investment } \\
\text { Strategy (2018-2040) }\end{array}$ \\
\hline Amount of investment & $\$ 6.2 \mathrm{~B}$ & $\$ 14.7 \mathrm{~B}$ \\
\hline Number of projects & 374 & 762 \\
\hline
\end{tabular}

\section{Analysis Measures}

Table 24 list some of the numerous measures used as part of the equity analysis framework for the 2018 RTP. Not all of measures are described in detail here.

\section{Example Results}

Each measure in Table 25 was subject to multiple analyses (presenting all results of these analyses is beyond the scope of this case study).

Table 26 shows the analysis results for the "access to community places” measure (as the share of regional community places accessible within 30 minutes by transit, during the peak and off-peak periods). Community places include schools, libraries, grocery stores, pharmacies, medical facilities, etc. The results in Table 26 represent how much access is improved compared to doing nothing (i.e., access by transit during the peak hour to community places is 16 percent higher with the 10 -year regional investment compared to making no investments). The key comparisons are between the performance outcomes for HMC and FHMC neighborhoods and the regional measures. Differences for HMC communities are slightly worse than for the region overall, although those differences are small, while differences for FHMC communities are significantly higher than for the region, meaning the investment has a bigger positive impact on those communities' access to community places.

Table 25. Equity analysis measures used in the 2018 RTP (Adapted from: Metro, 2018 Regional Transportation Plan - Public Review Draft, Appendix E).

\begin{tabular}{|l|l|}
\hline \multicolumn{1}{|c|}{ Measure } & \multicolumn{1}{c|}{ Description } \\
\hline Access to Jobs & $\begin{array}{l}\text { The sum of the total number of family wage jobs that are accessible to } \\
\text { historically underrepresented communities by automobile, transit, bicycle, } \\
\text { and walking in a given commute time window. Assess the change in } \\
\text { historically underrepresented communities with added transportation } \\
\text { investments. }\end{array}$ \\
\hline $\begin{array}{l}\text { Access to Community } \\
\text { Places }\end{array}$ & $\begin{array}{l}\text { The sum of the total number of existing essential destinations or existing } \\
\text { daily needs that are accessible to historically underrepresented } \\
\text { communities by automobile, transit, and bicycle in a given travel time } \\
\text { window. Depending on whether essential destinations or daily needs are } \\
\text { selected, the travel times will change. Assess the change in historically } \\
\text { underrepresented communities with added transportation investments. }\end{array}$ \\
\hline
\end{tabular}


Access to Travel Options How many miles (and ultimately the amount of gaps) and connectivity of - System Connectivity and Completeness the region's active transportation infrastructure (sidewalks, bicycle routes) are getting completed region wide, around transit, and in historically marginalized communities (in aggregate), and understand if the 2018 RTP investment strategies are further increasing the completeness and connectivity of the regional active transportation network for historically marginalized communities. Additionally, look further at the timing of the active transportation investments in the 2018 RTP investment strategies.

Share of Safety Projects

Identified transportation safety investments are mapped to illustrate which overlap with the high injury network and in historically underrepresented communities. Assess whether investments are being made evenly in certain communities with evident transportation safety issues (as indicated by the categorization as a high injury corridor).

Exposure to Crash Risk

The sum of all non-interstate vehicle miles traveled (VMT) would be totaled for historically underrepresented communities and based on the transportation investment program, examine how VMT changes in historically underrepresented communities, and correlate traffic safety exposure.

Table 26. Improvements in access to community places by transit created by the 2018-2027 constrained investment compared to the 2027 no-build scenario (Adapted from Metro, 2018 Regional Transportation Plan - Public Review Draft, Appendix E).

\begin{tabular}{|l|c|c|}
\hline \multicolumn{1}{|c|}{ Peak-Hour } & Off-Peak \\
\hline Region & $+16.0 \%$ & $+22.0 \%$ \\
\hline HMC & $+15.7 \%$ & $+20.7 \%$ \\
\hline
\end{tabular}

\section{Displacement Forecasting Scenario: Exploring New Approaches}

Metro's 2060 Growth Forecast includes an informational document describing an examination of differences in how the regional growth and racial composition might be distributed between each county based on a series of different development and growth patterns or scenarios (Metro, 2016c). Following a review of this document, the Metro demographer who prepared the analysis was interviewed. Metro had not previously carried out projection scenarios by race and ethnicity at levels smaller than the Metro area as a whole and was interested in initiating such an analysis. The project was made possible by a small amount of funding the demographer had available for innovative analysis, and it was carried out in part to understand what would go into such an analysis. Metro used a "matrix scaling approach," sometimes called "bi-proportional fitting or iterative proportional fitting (IBF) procedure" to estimate the county level projections ${ }^{10}$.

Starting with 2010 Census data for race, age, and county, Metro applied the IBF procedure to project to 2060. Although they could limit the number of strong assumptions made by starting with this

${ }^{10}$ see "FAQ: Metro 2060 Population Forecast” pages 23-25 for an overview (Metro, 2016c). 
baseline data, they had to make some assumptions. Three scenario series were considered about racial concentrations and growth flows, including one in which the minority share of residents remains constant by county, another in which minority populations shift to suburban and exurban counties, and a third in which the shift of minority populations to suburban and exurban counties is accompanied by a "white flight" returning to the city of Portland. A fourth series assumes the area within the Metro Urban Growth Boundary, a boundary around the urbanized area designed to control expansion, will accommodate a disproportionate share of overall growth. The FAQ document notes these sets of assumptions should not be interpreted as low- and high-growth scenarios, which Metro employs separately for its overall population forecast and regions often employ when forecasting growth. Metro's four county-level population growth scenario series by future racial and ethnic dispersion are as follows:

1. "Status quo county trend:" assumes steady increase in minority share between counties by race while adjusting for the rising percentage of minorities in the MSA.

2. Faster share of minorities shifting outward to live in suburban and exurban counties (i.e., urban area fringes).

3. Minority shift to urban fringe and white "flight" into central city (same as \#2 and at the same time increasing the share of whites into living in Portland city).

4. Metro [urban growth boundary] “captures” proportionally higher share of minority population growth of the MSA (Metro, 2016c)

This scenario series did not affect the overall 2060 forecast, but rather is meant to examine differences in how the forecast population might be allocated by county based on the different concentrations of minority and white populations. The process was a first step by Metro to explore alternatives or scenarios for growth and demographic change on a smaller than regional scale, with the intent of catalyzing conversation around these topics, and bringing considerations of demographic changes on a smaller scale into Metro planning and forecasting.

Not surprisingly, the series suggested that under the second scenario, the central county of the metropolitan statistical area (Multnomah County), would experience limited growth, with more in suburban counties. Under the fourth scenario, Multnomah and the inner suburban counties of Washington and Clackamas County saw concentrated growth. Metro's informational document notes that series four "most closely aligns with the Metro TAZ [transportation analysis zone] growth distribution forecast” (p. 24). In addition to this early take on county-level demographic forecasting, Metro is continuing to look at other agencies and resources to improve their methodology for including race and ethnicity in smaller-scale forecasting, with a goal of eventually being able to conduct them at the TAZ level.

\section{KEY TAKEAWAYS}

Metro's innovations in equity analysis and forecasting are notable in improving practice to understand and address fast-changing communities. Advocates' concerns about the accuracy of demographic forecasts as pertains to race and ethnicity were addressed by Metro's use of an interim modeling analysis. Although one might note that in an area with fast changing demographics, a 10-year interim model might still be inaccurate, the model would likely be an improvement over a 
full 25 or 30-year projection that typically assumes race and ethnic profiles remain the same as the base year. Barring other innovations in forecasting for race and ethnicity, this interim year model is the best option available. Furthermore, Metro's willingness to explore demographic forecasting scenarios that explicitly include displacement dynamics is important, even though the scenarios were not used in the official projection. This might represent a first step toward developing more accurate long-range forecasts where race and ethnicity play an important role in community change, especially the noticeable trend of increased diversity in suburban areas. At this point, whether Metro will actually use its displacement scenario in any official forecasts is unclear. However, it may be useful for predicting dynamics in other parts of their modeling work. 


\section{RESEARCH SUMMARY AND CONCLUSIONS}

Demographics are changing rapidly in communities across the United States, especially with respect to minority populations and low-income populations. In some places these communities are growing, while in others they are shrinking. Given this rapid pace of change, community demographics may shift to the extent that a neighborhood that was not EJ during a planning phase of a transportation activity may become so during subsequent transportation decision-making phases (or vice versa). Further, understanding whether a transportation action has a disproportionately high and adverse effect on low-income and minority groups suggests a need for accurate and up-to-date demographic profiles of affected neighborhoods. However, many Federal resource data sets such as the decennial census and the American Community Survey (ACS), which works by grouping survey responses from successive annual surveys, may not be updated frequently enough or be sufficiently granular to capture this change. These factors influence how practitioners come to understand the needs of EJ populations and potential EJ impacts across the lifespan of a transportation project.

It is FHWA's policy to identify and prevent discriminatory effects by actively administering its programs, policies, and activities to ensure that social impacts to communities and people are recognized early and continually throughout the transportation decision-making process from early planning through implementation and operations. Implementation of these principles are supported by the U.S. DOT Environmental Justice Order 5610.2(a); U.S. DOT Environmental Justice Strategy; FHWA Order 6640.23A: Actions to Address on Environmental Justice in Minority Populations and Low-Income Populations; and FHWA's Guidance on Environmental Justice and NEPA Memorandum.

This report helps further FHWA's efforts to advance non-discrimination in transportation by addressing considerations of changing demographics in EJ analysis and by providing information to improve understanding of how Federal EJ requirements are being implemented in this environment. Additionally, the report assesses national demographic trends and the current state of practice for considering demographic change in EJ analysis. The report also identifies strategies for addressing community change and environmental justice impacts across planning and project development lifecycles. High level takeaways of this research, potential areas for further study, and questions for transportation agencies to consider when implementing EJ in the context of rapid demographic change are highlighted below (see Table 27).

\section{Growing minority and immigrant populations and continued growth of lower income populations mean that the number and share of $E J$ populations are projected to continue rising, especially in metro areas.}

The U.S. population is projected to continue growing and diversifying, with substantial growth in the total number and share of minority populations. In 2018, the country is 63 percent white, and by 2060, it is projected to be less than 44 percent. Immigration is expected to continue to be a major component of population growth in the U.S.; the number of foreign-born residents, currently 13 percent of the population, is projected to grow to nearly 19 percent of the population in 2060. 
Overall, the nation's poverty rate has fluctuated between 10 and 15 percent for the past several decades, with a significant number sitting just above the poverty line. This means that as the nation's total population rises, the absolute number of households and residents in poverty is likely to rise accordingly, even assuming the national share of population in poverty continues to fluctuate. Relative increases in poverty were greatest in the Southeast, West, and Midwest with the highest increases seen in the state of Nevada, which doubled its share of population in poverty, and in the major metro areas of these regions (e.g., Miami, Los Angeles and Detroit). Significant increases in the share of impoverished suburban residents of major metro areas occurred in regions like Washington, DC, New York Atlanta, Las Vegas and Denver. Such increases in suburban poverty merit special concern for transportation providers, as these households often need improved public transportation services.

Absolute growth of EJ populations has been concentrated in the Nation's largest metro areas. However, small metro areas with historically low shares of EJ populations have seen the greatest relative change. In both respects, these population change dynamics are nuanced and complex.

Minority populations are growing fastest in the largest metros in the West, South and across the eastern seaboard, though fastest relative changes are happening across the center of the country where shares of minority populations were historically smaller. The nature of this change is dynamic and complex. For example, in 1970, about 80 percent of South Los Angeles was African American. By 2010, the area had become nearly 65 percent Latino. Meanwhile, many African Americans are leaving urban centers in the West and Midwest and returning to the South in reverse of their outmigration made decades ago. A similar range of trends are seen in the shares of population in poverty. While some metro regions such as New Orleans and Houston have lost low-income populations in the wake of devasting hurricanes many others metro areas such as the San Francisco Bay Area have gained low-income populations despite skyrocketing housing prices.

Some of the fastest demographic changes have occurred in small metro areas across the country. The Fayetteville, Arkansas region, for example, saw its minority shares increase ten-fold over the past two decades. Addressing rapid demographic change in small metro areas that may face resource and capacity constraints requires careful consideration and further study. The complexity of these demographic change trends suggests that transportation decision makers may wish to continually monitor demographic change in communities to help inform transportation investments.

EJ populations living in central city or inner suburban areas are increasingly being displaced by real estate market pressures, causing rapid shifts in their locations. Transportation improvements that create accessible and attractive locations may contribute to these real estate market pressures.

Shifts in housing and location preferences toward central, accessible locations in urban areas has resulted in gentrification and displacement of EJ populations in urban neighborhoods. This trend has been especially pronounced in urban centers of the Northeast and has displaced some EJ populations to outer, less accessible areas with fewer transit options, making it more challenging for displaced individuals to access economic opportunities and needed goods and services. In some instances, 
housing market pressures like these have led to interregional migrations. These rapid demographic shifts affect considerations of the EJ impacts of transportation plans and projects.

Transportation planners are increasingly recognizing the interaction between transportation investments that create accessible and attractive locations and their impacts on real estate market pressures and subsequent displacement of EJ populations. This report highlights agencies such as Metropolitan Transportation Council (MTC) in the San Francisco Bay Area, Metro in the Portland, Oregon region, and the Puget Sound Regional Council in the Seattle area who are making efforts to prevent further displacement of EJ communities by monitoring and predicting the potential impacts of their transportation investments. MTC has taken this one step further by developing a housing action plan to reduce housing costs, improve job access and prevent displacement.

Despite the growth of minority populations in states and metro areas, and within existing majorityminority regions across the country, this study found a lack of EJ analysis approaches designed to explicitly address demographic change.

None of the State DOTs, metropolitan planning organizations (MPOs), or other agencies reviewed in this study explicitly address the issue of changing demographics within their EJ analyses. Even in majority-minority areas, for which EJ populations make up a numerical majority of the population, environmental justice analyses are carried out in similar ways to places where EJ populations are much smaller shares. In these cases, regional averages established for considering communities for EJ impacts are typically adjusted proportionally to reflect higher overall concentrations of EJ populations.

Generally, this study found that considerations of changing demographics are most likely to be explored during the forecasting stages of the long-range transportation planning process and less often during programming, project development and environmental review phases. Still, forecast changes to EJ populations did not trigger a specific type of impact analysis resulting from that change; typical analysis techniques are used whether or not significant changes are forecast to occur.

\section{Despite the limited consideration of demographic change, this study highlighted important practices used to understand the current composition of communities and how they are changing.}

Agencies across the country and at all scales are using a variety of techniques to engage with and understand EJ community change dynamics and needs. New approaches to public engagement, datagathering and surveying, online engagement, stakeholder advisory committees and other efforts to "know your community" can improve agency awareness of community change by reaching beyond traditional boundaries of transportation decision-making to gather a wider array of data and feedback. By taking these extra steps, transportation agencies can better understand driving forces and ensure those changes are recognized throughout the progression of transportation decision-making and between decennial census releases.

For example, Atlanta Regional Commission (ARC) initiates conversations with local jurisdictions to understand their plans and projects and to gather feedback to improve the data and assumptions that 
inform the agency's demographic forecasting practices. This process benefits both ARC and the local jurisdictions by improving coordination, data quality and forecasting performance. Additionally, the State of Florida's analysis of migration to the State following Hurricane Maria provides an effective example of data gathering beyond traditional sources to better understand rapid demographic change. Florida's estimate of 50,000 arrivals was based on triangulating various kinds of data, including numbers of people seeking migration assistance at airports, flight arrival, and school enrollment data, among other factors.

Besides their use in population forecasting, these alternative data sources are potentially useful to understand how environmental justice communities are changing. School enrollment, refugee resettlement program information or other similar data could yield valuable information about EJ communities in terms of English proficiency or household income and these data, which are often updated on shorter time frames than census data These steps can help to improve transportation decision making and understanding of EJ impacts in areas undergoing rapid change, especially where these changes have been triggered by unforeseen events like natural disasters or rapid changes to local housing markets.

\section{This study also highlighted practices that can improve an agency's ability to predict community change and EJ impacts that may accompany this change in affected areas.}

Generally, this study found that long-range forecasts of race and ethnicity are not conducted at neighborhood scales because of inaccuracies and because some agencies expressed a wish to avoid the impression that they are trying to affect community change. Where neighborhood-level forecasts have been conducted, forecasts typically assume the same racial and ethnic composition as present day. There are numerous historic examples of inaccurate predictions of race and ethnicity composition at neighborhood scales using approaches such as these. A host of exogenous factors can impact natality rates, migration and job and housing markets and affect the accuracy of long-range demographic forecasts.

Portland Metro was the only agency reviewed that attempted to develop a model of intrametropolitan shifts in the location of racial and ethnic minorities. While the model was not used for its official population projection, such a model could be helpful in improving EJ analysis for longrange plans, project development or long-range operational programs. Instead of explicitly forecasting change, some agencies attempt to flag the risk of undesired community change with the goal of being able to shape or prevent it. MTC, Metro and Puget Sound Regional Council include measures of displacement risk as part of their regional planning efforts in order to predict and prevent further displacement of EJ communities due to transportation investments.

Recognizing the risk of displacement along with the uncertainty in forecasting the location of EJ communities, Metro also performs an “interim year” (10-years) analysis of their regional plan's EJ impacts. This allows Metro to be more certain of their analysis results even though the full extent of their plan is not considered in the analysis. Mid-Ohio Regional Planning Commission (MORPC) uses a unique "population-based" approach to its EJ analysis of transportation impacts from its long-range plan. This approach uses travel demand model outputs to analyze aggregate impacts of transportation 
actions on different demographic groups, whether they live in a neighborhood designated as EJ or not and is a more precise accounting of impacts. This technique could improve the data analysis in areas where EJ populations are growing but may still be a small share of the population within a neighborhood - an increasingly common occurrence in suburban and exurban areas.

\section{An integrated approach to demographic analysis within a unified planning tool or data repository may help systematize the understanding of community change across the spectrum of transportation decision-making.}

The transportation decision-making process occurs over many phases - from initial planning and programming, project development and environmental review, design, and construction through to operations and maintenance. When decisions and EJ analyses are spread across multiple agencies over prolonged periods of time, changes in the size and location of EJ populations may be overlooked. This has important implications for understanding disproportionately high and adverse impacts of a transportation action. A unified approach to understanding community composition would improve sensitivity to environmental justice impacts when communities undergo change from stage to stage. Florida Department of Transportation's Environmental Screening Tool (EST) shows great potential to make different decision making teams aware of community changes and prepare them to make necessary adjustments to EJ analyses. By creating a single data and analysis repository that is regularly updated at project milestones, the screening tool serves as a universal broker of community information and ensures that different teams located in disparate jurisdictions across the state or performing analyses separated by years are aware of how communities have changed since prior decision-making phases.

Such awareness is best achieved by having a tool to bridge the gaps in time between decision-making phases. Such a tool can be cross-tabulated with updated on-the-ground stakeholder and community engagement and be used to alter outreach planning and techniques. Similarly, a national scale screening tool could be developed to flag fast-changing communities and allow practitioners to further investigate how demographic change may affect transportation decision-making in their jurisdictions. This could be done through national planning tools such as the Census Transportation Planning Package or environmental justice screening tools such as EJSCREEN. Adding tables or layers to these tools that highlight the pace and extent of community change would ensure that decision makers are aware of changes and can adjust their EJ analyses practices accordingly. 
Table 27. A few questions to consider when implementing EJ in the context of demographic change.

\section{A FEW QUESTIONS TO CONSIDER WHEN IMPLEMENTING ENVIRONMENTAL JUSTICE}

\section{Local Trends}

- Is your community addressing the issue of demographic change when engaging the public in transportation decisionmaking?

- Is your community aware of demographic changes to date that may have already shifted the community such that an EJ assessment is or will be necessary?

- Do recent demographic trends suggest the community is likely to shift and include more low-income and/or minority individuals over the lifecycle of a transportation action?

\section{Impacts of Planned Investments}

- Is your community considering how planned investments could potentially result in local demographic change?

- Has your community developed a process to evaluate the impact of investments on neighborhood change or to evaluate the effectiveness of countermeasures?

- Do transportation investments address the needs of EJ populations and are there scenarios considering a potential shift in community demographics? 


\section{REFERENCES}

AASHTO. (2016). Practitioners Peer Exchange: Environmental Justice Roadmap. AASHTO. Retrieved from https://environment.transportation.org/pdf/2016_environmental_justice_peer_exchange/ejrm _1_v6.pdf

ABAG. (2015). Toward opportunity - Fair Housing and Equity Assessment of the San Francisco Bay Area. Association of Bay Area Governments (ABAG). Retrieved from https://abag.ca.gov/files/1_FHEAFinalReport_3.13.15.pdf

Aimen, D., \& Morris, A. (2016). NCHRP Report 710: Practical Approaches for Involving Traditionally Underserved Populations in Transportation Decisionmaking. Washington, D.C.: Transportation Research Board of the National Academies. Retrieved from http://www.trb.org/Publications/Blurbs/166872.aspx

Atlanta Regional Commission. (2016a). Outreach Evaluation. Atlanta, GA: Atlanta Regional Commission (ARC). Retrieved from https://documents.atlantaregional.com/The-AtlantaRegion-s-Plan/TARP-Community-Engagement-Evaluation.pdf

Atlanta Regional Commission. (2016b). Stakeholder Engagement Plan. Retrieved from ARC: https://documents.atlantaregional.com/The-Atlanta-Region-s-Plan/Stakeholder-EngagementPlan.pdf

Atlanta Regional Commission. (2016c). The Atlanta Region's Plan. Appendix J: Equitable Target Areas Methodology. ARC. Retrieved from http://documents.atlantaregional.com/TheAtlanta-Region-s-Plan/rtp/eta.pdf

Atlanta Regional Commission. (2018a). 20-County Dashboard. Retrieved from https://atlantaregional.org/atlanta-region/regional-data-resources/atlanta-region-20-countydata-dashboard/

Atlanta Regional Commission. (2018b). About ARC. Retrieved from ARC: https://atlantaregional.org/about-arc/

Atlanta Regional Commission. (2018c). New Voices Initiative. Retrieved from ARC: https://newvoices.atlantaregional.com/

Atlanta Regional Commission. (2018d). Population and Employment Forecasts. Retrieved from ARC: https://atlantaregional.org/atlanta-region/population-forecasts-estimates/populationemployment-forecasts/

Atlanta Regional Commission. (2018e). The Atlanta Region's Plan . Retrieved from ARC: https://atlantaregionsplan.org/ 
Atlanta Regional Commission. (n.d.). 33 n Blog: Atlanta Regional Commission. Retrieved May 29, 2018, from $33^{\circ} \mathrm{n}$ : https://33n.atlantaregional.com

Atlanta Regional Commission. (n.d.). Comparative Analysis of PLAN 2040 Investments in Equitable Target Areas (ETA) [Presentation Slides]. Retrieved from

http://www.atlantaregional.com/File\%20Library/Transportation/Plan\%202040/tp_PLAN_20 40_ETA_Web.pdf

Author Team. (2018a). Telephone interview with ARC demographer, January 3, 2018.

Author Team. (2018b). Telephone interview with Anne Morris, Principal of Anne Morris and Associates, April 21, 2018.

Author Team. (2018c). Telephone interview with Metro demographer, Thursday, May 17th, 2018. .

Author Team. (2018d). Telephone interview with Colby Lancelin, Atlanta Regional Commission, January 3, 2018, and May 22, 2018.

Author Team. (2018e). Personal Correspondence with Colby Lancelin, Atlanta Regional Commission, May 4, 2018.

Bend Metropolitan Planning Organization. (2014). Title VI and EJ Plan. Retrieved from BMPO: http://www.bendoregon.gov/home/showdocument?id=1653

Brookings Institute. (2017, February 5). Testimony by Elizabeth Kneebone: The changing geography of US poverty. Retrieved from Brookings Institute.

Bureau of Economic and Business Research. (2018a). Growth af The Puerto Rican Population In Florida And On The U.S. Mainland. Retrieved from BEBR: https://www.bebr.ufl.edu/population/website-article/growth-puerto-rican-population-floridaand-us-mainland

Bureau of Economic and Business Research. (2018b). Projects of Florida Population by County, 2020- 2045, with Estimates for 2017. Retrieved from https://www.bebr.ufl.edu/sites/default/files/Research\%20Reports/projections_2018.pdf

Cambridge Systematics. (2002). NCHRP Project 8-36 (11): Technical Methods to Support Analysis of Environmental Justice Issues. Washington, D.C.: National Academy Press.

Campbell, P. (1994). Population Projections for States, by Age, Sex, Race, and Hispanic Origin: 1993 to 2020. US Department of Commerce, Bureau of the Census. Retrieved from https://www.census.gov/prod/1/pop/p25-1111.pdf

Center for American Progress. (2015). States of Change: The Demographic Evolution of the American Electorate, 1974 - 2060. Center for American Progress. Retrieved from http://apps.trb.org/cmsfeed/TRBNetProjectDisplay.asp?ProjectID=3642 
Center for Business and Policy Research. (2016). Stanislaus County Forecast Summary. Eberhardt School of Business. Retrieved from http://www.stancog.org/pdf/2016ForecastSummary.pdf

Chatman, D. (2014). Explaining the "Immigrant Effect" on Auto Use: the Influences of Neighborhoods and Preferences. Retrieved from https://www.researchgate.net/publication/257640468_Explaining_the_immigrant_effect_on_ auto_use_The_influences_of_neighborhoods_and_preferences

Clewlow, R., \& Mishra, G. (2017). Disruptive transportation: The adoption, utilization, and impacts of ride-hailing in the United States. University of California, Davis.

Coughlin, J. (2017). Transportation in a World that is Gray, Delayed, Small, and Female. Webinar through the Volpe Center, US DOT. USDOT.

Delaware Valley Regional Planning Commission. (2010). Environmental Justice at DVRPC. Retrieved from DVRPC: https://www.dvrpc.org/GetInvolved/TitleVI/

Delaware Valley Regional Planning Commission. (2013). Transportation Improvement Program (TIP). Retrieved from DVRPC: https://www.dvrpc.org/TIP/

EHI Consultants. (2003). Southend Park Urban Village Plan. Retrieved from http://previous.lexingtonky.gov/Modules/ShowDocument.aspx@documentid=1904

Federal Highway Administration. (2012a). Applications of Geographic Information Systems for Highway Traffic Noise Analysis. Retrieved from FHWA: https://www.gis.fhwa.dot.gov/documents/GIS_for_Highway_Traffic_Noise_Analysis.htm\#fl 0

Federal Highway Administration. (2012b). FHWA Environmental Justice Order 6640.23A. Retrieved from https://www.fhwa.dot.gov/legsregs/directives/orders/664023a.cfm

Federal Highway Administration. (2012c). The Role of Transportation Systems Management and Operations in Supporting Livability and Sustainability. Retrieved from https://ops.fhwa.dot.gov/publications/fhwahop12004/fhwahop12004.pdf

Federal Highway Administration. (2013). Developing Environmental Justice in NEPA: Project Highlights. Retrieved from FHWA: https://www.fhwa.dot.gov/environment/environmental_justice/resources/ej_and_nepa/highlig hts/ejandnepa.pdf

Federal Highway Administration. (2015). Environmental Justice Reference Guide, FHWA-HEP-15035. Retrieved from FHWA: https://www.fhwa.dot.gov/environment/environmental_justice/publications/reference_guide_ 2015/section00.cfm 
Federal Highway Administration. (2017a). Bagley Pedestrian Bridge - "Connecting Neighbors" [Case Study]. Retrieved from FHWA Environmental Justice: https://www.fhwa.dot.gov/environment/environmental_justice/resources/ej_and_nepa/case_st udies/case03.cfm

Federal Highway Administration. (2017b). Context Sensitive Solutions. Retrieved from FHWA Office of Planning, Environment, \& Realty (HEP): https:/www.fhwa.dot.gov/planning/css/

Federal Highway Administration and Kentucky Transportation Cabinet . (2007a). Final Environmental Impact Statement - Record of decision - Newtown Pike extension project. Retrieved from http://newtownextension.com/wpcontent/uploads/2015/06/CompleteEISNewtownPikeExtension.pdf

Federal Highway Administration and Kentucky Transportation Cabinet. (2007b). Record of decision - Newtown Pike extension project. Retrieved from http://newtownextension.com/wpcontent/uploads/2015/06/Final_NPE_ROD_Oct07.pdf

Federal Highway Administration. (n.d.). FHWA Initiatives to Accelerate Project Delivery. Retrieved from FHWA Environmental Review Toolkit: https://www.environment.fhwa.dot.gov/env_initiatives/pel/case_florida.aspx

Federal Highway Administration. (n.d.b.). Context Sensitive Solutions. Retrieved from https://www.fhwa.dot.gov/planning/css/

Federal Highway Administraton. (n.d.a.). Bagley Predestrian Bridge Case Study. https://www.fhwa.dot.gov/environment/environmental_justice/resources/ej_and_nepa/case_st udies/case03.cfm.

Federal Register. (1994). Executive Order 12898. Retrieved from https://www.archives.gov/files/federal-register/executive-orders/pdf/12898.pdf

Federal Transit Administration. (2012). Circular 4703.1 - Environmental Justice Policy Guidance for Federal Transit Administration Recipients. Retrieved from FTA: http://www.fta.dot.gov/documents/FTA_EJ_Circular_7.14-12_FINAL.pdf

Florida Bureau of Economic and Business Research. (2018). Growth of The Puerto Rican Population In Florida And On The U.S. Mainland. Retrieved from BEBR: https://www.bebr.ufl.edu/population/website-article/growth-puerto-rican-population-floridaand-us-mainland

Florida Department of Transportation. (2012). Sociocultural Effects (SCE) Considerations. Retrieved from http://www.fdot.gov/environment/pubs/sce/SCEConsiderations2012.pdf

Florida Department of Transportation. (2013). Sociocultural Effects Evaluation. Retrieved from http://www.fdot.gov/environment/pubs/sce/EST_Project\%20InformationSheet-20131010.pdf 
Florida Department of Transportation. (2014). Stepping Beyond Census Data for Community Impact Assessments. Retrieved from http://www.fdot.gov/environment/pubs/sce/TRB-PosterSlides.pdf

Florida Department of Transportation. (2015). Chapter 9-Title VI and Nondiscrimination Program Guidance for Metropolitan Planning Organization. Retrieved from FDOT: http://www.fdot.gov/planning/Policy/To\%20Delete/mpohandbook/Ch9.pdf

Florida Department of Transportation. (2016). Environmental Screening Tool. Retrieved from https://etdmpub.fla-etat.org/est/

Florida Department of Transportation. (2017a). EDTM Manual. Retrieved from http://www.fdot.gov/environment/pubs/etdm/archive/12-1-2015/650-000002_ETDM_Manual_Ch6_Approved-2015-1201-2017-0518.pdf

Florida Department of Transportation. (2017b). NEPA Quality Assurance / Quality Control Plan [Web training]. Retrieved from http://wbt.dot.state.fl.us/ois/NEPA/QAQCCBT/QAQC.htm

Florida Department of Transportation. (2017c). Project Development and Environmental Manual. Retrieved from http://www.fdot.gov/environment/pubs/pdeman/archive/2016/Pt2Ch9_082516-current.pdf

Florida Department of Transportation. (2017d). Title VI Implementation Plan. Retrieved from http://www.fdot.gov/equalopportunity/TitleVI/2018\%20FDOT\%20T6\%20Implementation\% 20Plan\%20Final\%20-\%20Final.pdf

Florida Department of Transportation. (n.d.a.). FDOT Efficient Transportation Decision Making (ETDM) Process Overview. Retrieved from FDOT Office of Environmental Management: http://www.fdot.gov/environment/etdm.shtm

Florida Department of Transportation. (n.d.b.). Environmental Screening Tool Overview. Retrieved from http://www.fdot.gov/environment/EST-Overview.shtm

Florida Legislature Office of Economics and Demographic Research. (2011). Florida: Demographics. Retrieved from http://edr.state.fl.us/Content/presentations/populationdemographics/DemographicOverview_4-20-11.pdf

Georgia Department of Transportation. (2015). Environmental Justice Identification and Proposed Outreach Report.

Georgia Department of Transportation. (2018). Impact of Environmental Justice Analysis of Transportation Planning.

Global Insight. (2018). Economics and Country Risk. Retrieved from https://ihsmarkit.com/industry/economics-country-risk.html 
Golub, A., \& Martens. (2014). Using principles of justice to assess the modal equity of regional transportation plans. Journal of Transport Geography, 10-20.

Golub, A., \& Martens, K. (2014). Using principles of justice to assess the modal equity of regional transportation plans. Journal of Transport Geography, 41(0), 10-20. Retrieved from https://trid.trb.org/view.aspx?id=1330557

Golub, A., Serritella, M., \& Satterfield, V. S. (2018). Community-Based Assessment of Smart Transportation Needs in the City of Portland. Retrieved from https://trec.pdx.edu/research/project/1163/Communitybased_Assessment_of_Transportation_Needs_to_inform_City_of_Portland_Smart_Cities_Pl an

Greater Dalton Metropolitan Planning Organization. (2015). Non-Discrimination / Title VI Program . Retrieved from GDMPO: https://www.whitfieldcountyga.com/eng/mpo/GDMPOTitleVIPlan.pdf

Hampton Roads Transportation Planning Organization. (2014). Public Involvement: Environmental Justice Methodology Tool. Retrieved from HRTPO: http://hrtpo.org/page/ej-methodologytool/

Houston-Galveston Area Council. (2011). The 2035 Houston-Galveston Regional Transportation Plan Update. Retrieved from https://www.h-gac.com/taq/plan/2035_rtp.aspx

Houston-Galveston Area Council. (2013). An Equity Profile of the Houston-Galveston Region. Retrieved from http://www.ourregion.org/download/Regional_Equity_Profile.pdf

Houston-Galveston Area Council. (2016). 2040 RTP, Appendix B: Environmental Justice Analysis. Retrieved from H-GAC: http://www.hgac.com/taq/plan/2040/docs/Appendix\%20B\%20Environmental\%20Justice.pdf

IHS Markit. (2018). Economics \& Country Risk. Retrieved from https://ihsmarkit.com/industry/economics-country-risk.html

Karner, A. (2016). Planning for Transportation Equity in Small Regions: Towards Meaningful Performance Assessment. Transport Policy, 52.

Manson, S., Schroeder, J., Van Riper, D., \& Ruggles, S. (2017). IPUMS National Historical Geographic Information System: Version 12.0 [Database]. Minneapolis: University of Minnesota. Retrieved from http://doi.org/10.18128/D050.V12.0

Marcantonio, R., \& Karner, A. (2014). Disadvantaged communities teach regional planners a lesson in equitable and sustainable development. Poverty and Race, 23(1), 5-8. Retrieved from http://www.prrac.org/pdf/JanFeb2014PRRAC_Marcantonio-Karner.pdf 
Maricopa Association of Governments. (2017). 2040 RTP. Maricopa Association of Governments (MAG). Retrieved from http://www.azmag.gov/Portals/0/DocumentsExt/Transportation/2040-RTP-Final2017-09-17.pdf

Mejia, B. (2017). How Houston has become the most diverse place in America. Retrieved from Los Angeles Times: http://www.latimes.com/nation/la-na-houston-diversity-2017-htmlstory.html

Memphis MPO. (2014). Public Participan Plan of the Memphis Urban Area Metropolitan Planning Organization. Retrieved from http://memphismpo.org/sites/default/files/public/2014\%20PPP\%20Final.pdf

Memphis MPO. (n.d.a). LIBABILITY 2040 Regional Transportation Plan. Retrieved from http://memphismpo.org/sites/default/files/public/livability-2040-all-chapters.pdf

Metro. (2014). 2015-2018 Metropolitan Transportation Improvement Program Environmental Justice and Title VI Adoption Draft Report.

Metro. (2015). 2015 trip-based based travel demand model methodology report - draft version. Retrieved from Metro: https://www.oregonmetro.gov/sites/default/files/2015/04/16/tripbased_travel_demand_model_methodology.pdf

Metro. (2016a). Transportation equity working group meeting packet, June 30, 2016.

Metro. (2016b). Transportation equity working group meeting packet. September 29, 2016.

Metro. (2016c). 2060 growth forecast. Retrieved from https://www.oregonmetro.gov/2060-growthforecast

Metro. (2017a). Transportation equity working group meeting packet April 6, 2017. Retrieved from Metro: https://www.oregonmetro.gov/event/2018-regional-transportation-plan-transportationequity-analysis-work-group-meeting-1/2017-04

Metro. (2017b). Transportation equity working group meeting packet, November 30, 2017. Retrieved from https://www.oregonmetro.gov/event/2018-regional-transportation-plan-transportationequity-work-group-meeting-0/2017-11-30

Metro. (2018a). Regional Snapshot. Retrieved from https://www.oregonmetro.gov/regionalsnapshots

Metro. (2018b). 2018 regional transportation plan - Public Review Draft, Appendix E Transportation Equity Evaluation. Retrieved from Metro: https://www.oregonmetro.gov/sites/default/files/2018/06/29/RTPAppendix_E_2018_RTP_Transportation_Equity_Evaluation_with_attachments.pdf

Metropolitan Area Planning Agency. (2017). 2040 Long-Range Transportation Plan. Retrieved from MAPA: http://mapacog.org/projects/lrtp/ 
Metropolitan Transportation Commission . (2017b). Plan Bay Area 2040 - Equity analysis website. Retrieved from https://www.planbayarea.org/2040-plan/plan-details/equity-analysis

Metropolitan Transportation Commission. (2013). Plan Bay Area Equity Analysis Report. Retrieved from MTC: https://mtc.ca.gov/sites/default/files/A04_FINAL_PBA_Equity_Analysis_Report.pdf

Metropolitan Transportation Commission. (2015). MTC Resolution No. 4217: Equity Framework for Plan Bay Area 2040. Retrieved from MTC: https://mtc.legistar.com/LegislationDetail.aspx?ID=2555452\&GUID=575A6D3F-B8B844CF-9F2D-ABEF8B3C9F06\&Options=ID

Metropolitan Transportation Commission. (2017a). Plan Bay Area 2040 - Equity Analysis Report. Retrieved from MTC: https://mtc.ca.gov/sites/default/files/meetings/packets/Reasearch\%20Papers\%20for\%20REW G\%20Review.pdf

Metropolitan Transportation Commission. (2018). Plan Bay Area 2040 Draft Preferred Land Use Scenario. Retrieved from Plan Bay Area 2040: https://www.planbayarea.org/2040-plan/finalpreferred-scenario/plan-bay-area-2040-draft-preferred-land-use-scenario

Metropolitan Transportation Commission and Association of Bay Area Governments. (2017). Plan Bay Area 2040 - Action Plan. Retrieved from http://2040.planbayarea.org/action-plan

Metropolitan Washington Council of Governments. (2017). Equity Emphasis Areas for TPB's Enhanced Environmental Justice Analysis. Retrieved from MWCOG: https://www.mwcog.org/transportation/planning-areas/fairness-andaccessibility/environmental-justice/equity-emphasis-areas/

Michigan Department of Transportation. (2011). Environmental Justice for Michigan Transportation Plans, Programs and Activities. Retrieved from https://www.michigan.gov/documents/mdot/mdot_EJ_Guidance_Document_345493_7.pdf

Mid-Ohio Regional Planning Commission. (2016a). 2016 - 2040 Columbus Area Metropolitan Transportation Plan. Retrieved from MORPC: http://www.morpc.org/programservice/metropolitan-transportation-plan/

Mid-Ohio Regional Planning Commission. (2016b). 2016 - 2040 Columbus Area Metropolitan Transportation Plan, Appendix D: Environmental Justice Technical Analysis. Retrieved from MORPC: https://www.morpc.org/Assets/MORPC/files/000MTPAppendix\%20D\%20EJ\%20merged.pd f 
Nelson, A. (2014). Columbus, Ohio: Metropolitan Area Trends, Preferences, and Opportunities: 2010 to 2030 and to 2040. Retrieved from NRDC:

https://www.nrdc.org/sites/default/files/columbus-metro-area-trends-report.pdf

Nevada Department of Transportation. (2009). Statewide Transportation Planning Public Participation Process. Retrieved from NDOT:

https://www.nevadadot.com/home/showdocument?id=4504

Nevada Department of Transportation. (2018). One Nevada Transportation Plan: Focus Group Summary \& Key Strategies. Retrieved from NDOT: http://onenvplan.com/wpcontent/uploads/2018/03/One-NV-Plan-Focus-Group-Summary-and-Key-Strategies.pdf

Nevada Department of Transportation. (2018b). One Nevada Transportation Plan: Phase 1 Public Outreach Summary. Retrieved from http://onenvplan.com/wpcontent/uploads/2018/03/PublicOutreachSummary.pdf

New Hampshire Department of Transportation . (2017). Title VI Program: 2017 Implementation Plan. Retrieved from NHDOT: https://www.nh.gov/dot/org/administration/ofc/documents/2018-title-VI-implementationplan.pdf

New Jersey Transportation Planning Authority. (2013). Regional Transportation Plan 2040.

Retrieved from NJTPA: https://www.njtpa.org/archive/planning-archive/plan-update-to-2040

New York Metropolitan Transportation Council. (2017). RTP Plan 2045, Appendix 4: Environmental Justice and Title VI. Retrieved from NYMTC:

https://www.nymtc.org/Portals/0/Pdf/RTP/Plan\%202045\%20Final\%20Documents/Plan\%202 045\%20Individual\%20Appendices/Appendix\%204_EJ\%20Assessment\%20of\%20the\%20Pla nning\%20Process.pdf

North Central Texas Council of Governments. (2016). Mobility 2040, Appendix B: Social Considerations. Retrieved from NCTCOG: http://www.nctcog.org/trans/mtp/2040/documents/BSocialConsiderations.pdf

North Jersey Transportation Planning Authority. (2005). Environmental Justice Regional Analysis Proportional Distribution of Benefits of Transportation Projects in the NJTPA Region. Retrieved from NJTPA: https://www.njtpa.org/planning/regionalstudies/environment/environmental-justice.aspx

Ohio Department of Transportation. (2015). Public Involvement Manual (website). Retrieved from ODOT:

https://www.dot.state.oh.us/Divisions/Planning/Environment/NEPA_policy_issues/PUBLIC_ INVOLVEMENT/Pages/default.aspx 
Ohio DOT. (2016). Office of Environmental Services' Environmental Justice (EJ) Guidance Revised June 2016. Retrieved from ODOT:

https://www.dot.state.oh.us/Divisions/Planning/Environment/NEPA_policy_issues/ENVIRO NMENTAL_JUSTICE/Documents/EJGuidanceJune2016a.pdf

Omaha-Council Bluffs Metropolitan Area Planning Agency. (2015). 2040 Long-range Transportation Plan. Retrieved from MAPACOG: http://mapacog.org/projects/lrtp/

PolicyLink. (2017). National Equity Atlas - Beyond a People-of-Color Majority: US Demographic Projections to 2050. Retrieved from https://racialequitybuffalo.org/news/article:02-23-201712-00am-beyond-a-people-of-color-majority-u-s-demographic-projections-to-2050/

Polk County Transportation Planning Organization. (2015). Neighborhood Mobility Audit. Retrieved from http://polktpo.com/what-we-do/our-planning-documents/neighborhood-mobility-audits

Proctor, B. D., Semega, J., \& Kollar, M. (2016). Income and poverty in the United States: 2015. Retrieved from United States Census Bureau: https://www.census.gov/data/tables/2016/demo/income-poverty/p60-256.html

Puget Sound Regional Council. (2018). HIP Tool: Displacement Resources. Retrieved from https://www.psrc.org/displacement-resources

Purvis, C. (2001). Data and analysis methods for metropolitan-level environmental justice assessment. Transportation Research Record: Journal of the Transportation Research Board(1756), 15-21. Retrieved from https://trid.trb.org/view/695866

Rayer, S., \& Wang, Y. (2017). Methodology for Constructing Population Projections by Age, Sex, Race, and Hispanic Origin for Florida and Its Counties, 2020-2045, With Estimates for 2016. Bureau of Economic and Business Research. University of Florida. Retrieved from http://edr.state.fl.us/Content/populationdemographics/data/Methodology_Projections_ARSH.pdf

Rhode Island Department of Administration. (2017). Transportation 2037: State Guide Plan Element 611, Report \#116 (Interim). Retrieved from State of Rhode Island, Department of Administration, Statewide Planning Program: http:/www.planning.ri.gov/documents/trans/2017/LRTP-37.pdf

Romero, D. (2017). 5 Ways South L.A. Has Changed Since the Riots. Retrieved from https://www.laweekly.com/news/5-ways-south-los-angeles-has-changed-since-1992-8154680

San Diego Association of Governments. (2010). 2050 Regional Growth Forecast: Process and Model Documentation. Retrieved from SANDAG: https://www.sandag.org/uploads/publicationid/publicationid_1490_11298.pdf 
San Diego Association of Governments. (2012). Healthy Communities Atlas. Retrieved from SANDAG:

https://www.sandag.org/index.asp?classid=12\&projectid=482\&fuseaction=projects.detail

Smith, S., Tayman, J., \& Swanson, D. A. (2001). State and Local Population Projections: Methodology and Analysis. Acdemic/Plenum Publishers. doi:10.1007/0-306-47372-0

Southern California Association of Governments. (2012). Regional Transportation Plan 2012-2035, Environmental Justice Appendix. Retrieved from SCAG: http://rtpscs.scag.ca.gov/Documents/2012/final/SR/2012fRTP_EnvironmentalJustice.pdf

Southern California Association of Governments. (n.d.). Local Sustainability Planning Tool. Retrieved from SCAG: http://rtpscs.scag.ca.gov/Pages/Local-Sustainability-PlanningTool.aspx

St. Cloud Area Planning Organization. (2015). Long-Range Transportation Plan. Retrieved from http://www.stcloudapo.org/uploads/1/2/8/7/12874227/apo_long_range_plan_june2015amendment.pdf

State of Oregon, Office of Economic Analysis . (2010). The Oregon Economic Model: Annual Review of Methodology, 2010. Retrieved from Department of Administrative Services : https://www.oregon.gov/das/OEA/Documents/economic_methodology_dec2010.pdf

Stein, J., \& Van Dam, A. (2018, February 6). Trump immigration plan could keep whites in U.S. majority for up to five more years. Retrieved from Washington Post: https://www.washingtonpost.com/news/wonk/wp/2018/02/06/trump-immigration-plan-couldkeep-whites-in-u-s-majority-for-up-to-five-more-years/?utm_term=.1c4b3cbbf001

Struglia, R., Winter, P., \& Meyer, A. (2003). Southern California Socioeconomic Assessment: Sociodemographic Conditions, Projections, and Quality of Life Indices. USDA Forest Service, Pacific Southwest Research. Albany, CA: U.S. Department of Agriculture. Retrieved from https://www.fs.fed.us/psw/publications/documents/psw_gtr187/psw_gtr187_01.pdf

Texas Demographic Center. (2018). Projections of the Population of Texas and Counties in Texas by Age, Sex and Race/Ethnicity for 2010-2050. Retrieved 2018, from Georgia Governor's Office of Planning and Budget.

Together North Jersey. (2013). Regional Fair Housing and Equity Assessment. Retrieved from TNJ: http://togethernorthjersey.com/wp-content/uploads/2013/07/FHEA_Maps_Intro_fixed.pdf

United States Census Bureau. (2014). Projections of the Size and Composition of the U.S. Population: 2014 to 2060, Current Population Reports, P25-1143. Washington, D.C.: U.S. Census Bureau.

United States Department of Transportation. (2012). Department of Transportation Order 5610.2(a): Final DOT Environmental Justice Order. Retrieved from USDOT: 
http://www.fhwa.dot.gov/environment/environmental_justice/ej_at_dot/orders/order_56102a/ index.cfm

United States Department of Transportation. (2015). A guide to transportation decisionmaking. Retrieved from USDOT:

https://www.planning.dot.gov/documents/GuidetoTransportationDecisionmaking.pdf

University of California at Berkeley. (2015, December). Urban Displacement Project: Executive Summary. Retrieved from https://urbandisplacement.org/sites/default/files/images/urban_displacement_project__executive_summary.pdf

USDA Forest Service. (2003). Southern California Socioeconomic Assessment: Sociodemographic Conditions, Projections, and Quality of Life Indices. . 


\section{APPENDIX A: NATIONAL DEMOGRAPHIC CHANGE MAPS}

Minority Population Absolute Change: 2000-2010

Counties

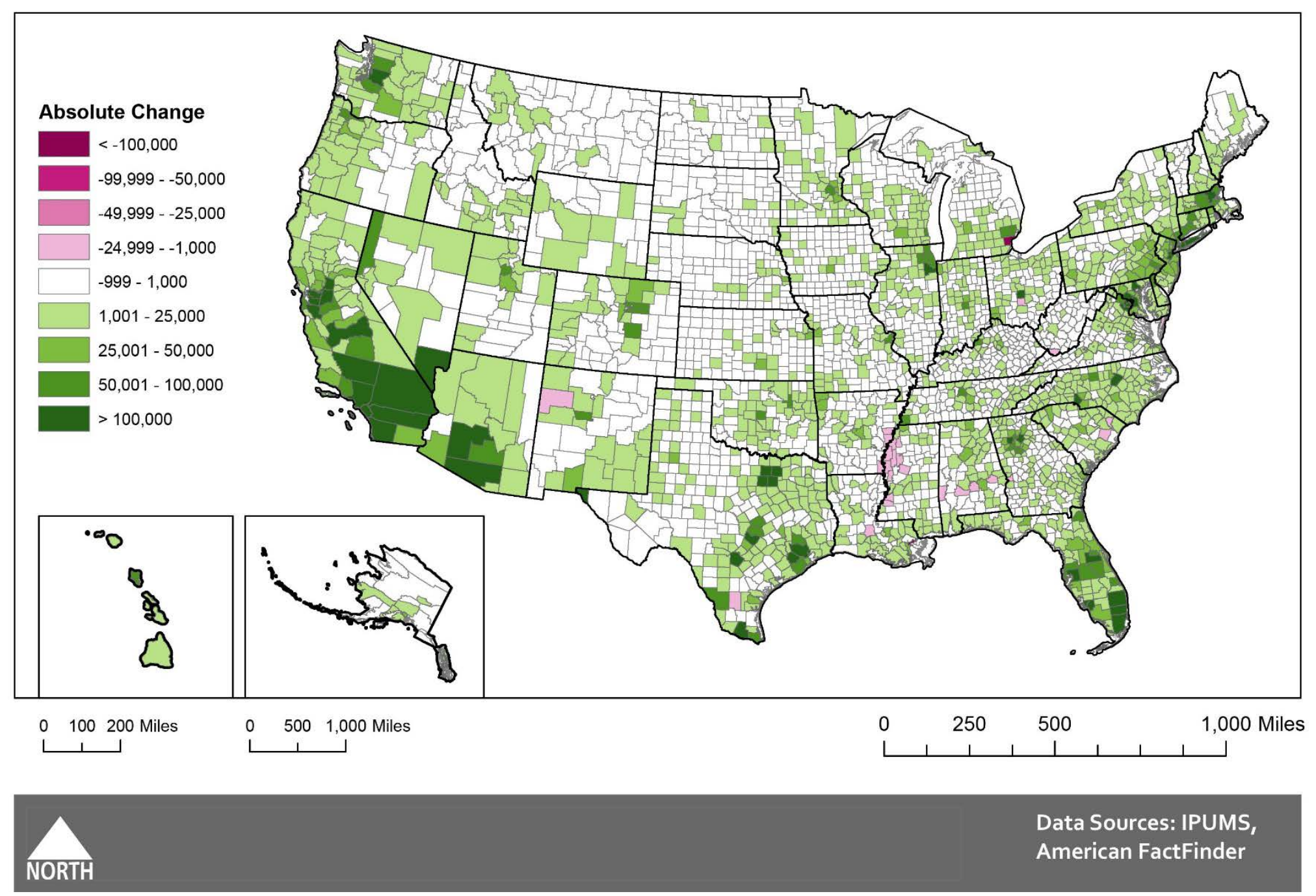

Figure A-1. Minority Population Absolute Change: 2000-2010, Counties. 


\section{Minority Population Percent Change: 2000-2010}

Counties

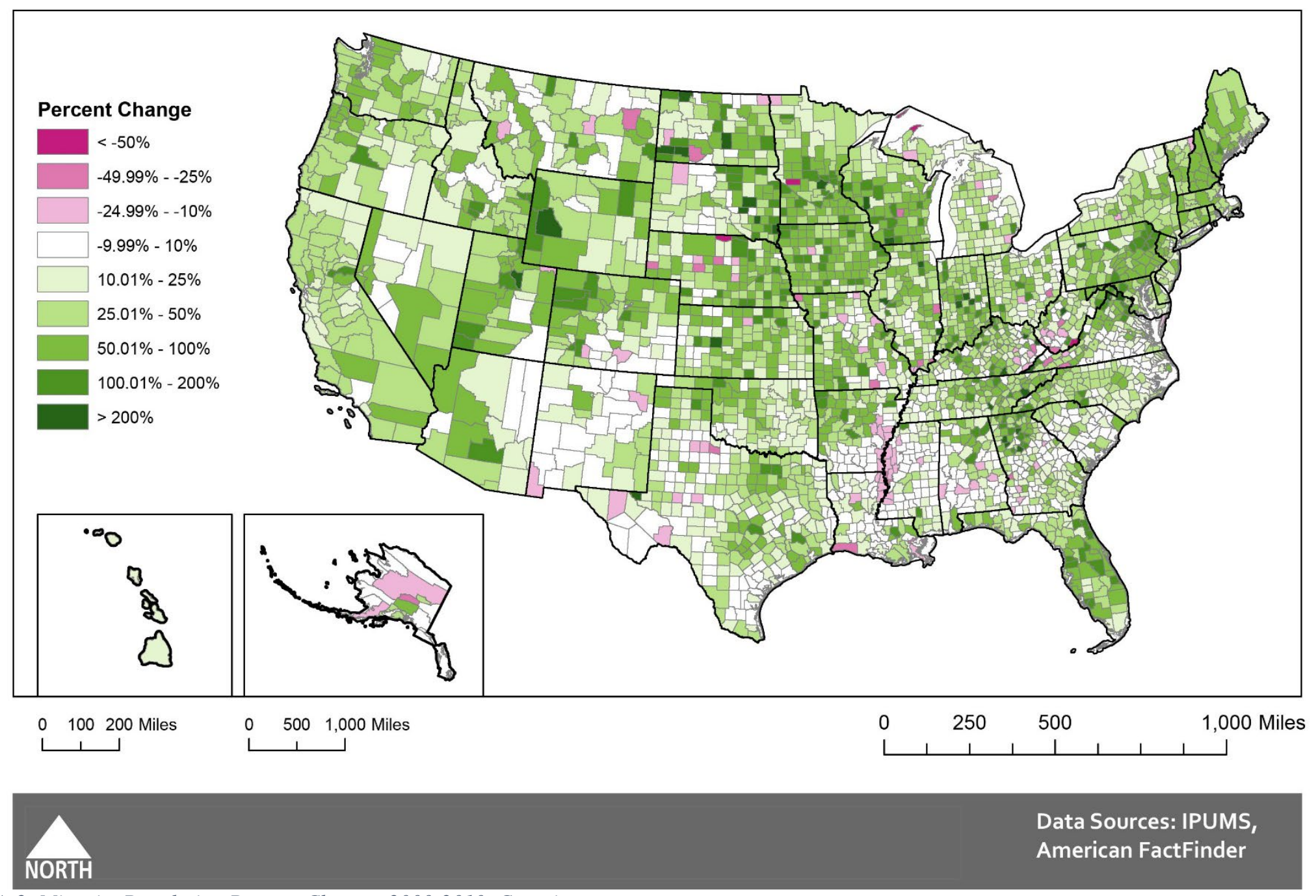

Figure A-2. Minority Population Percent Change: 2000-2010, Counties. 
Population in Poverty Absolute Change: 1990 - 2010

Counties
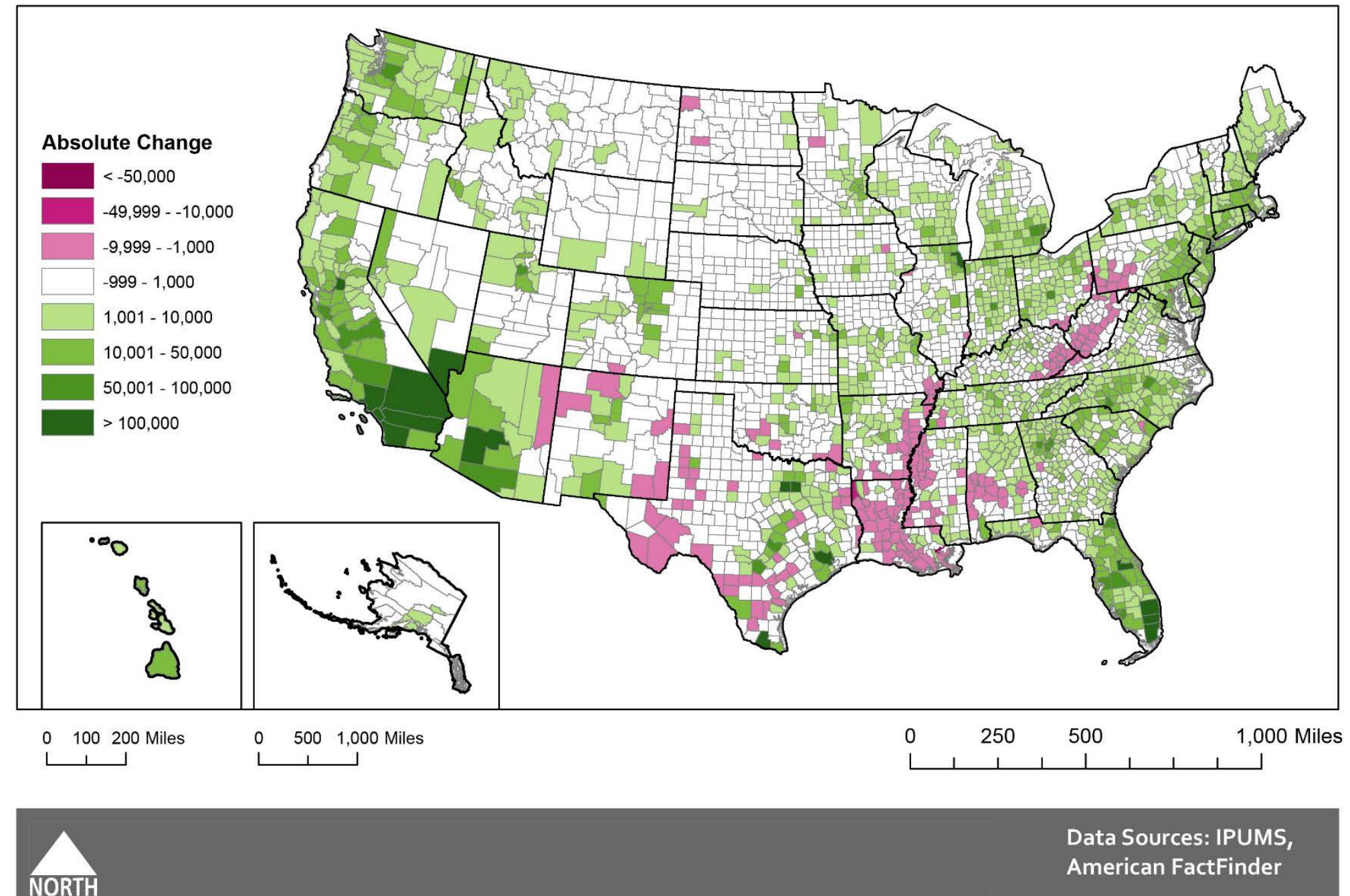

Data Sources: IPUMS, American FactFinder

Figure A-3. Population in Poverty Absolute Change: 1990-2010, Counties. 


\section{Population in Poverty Percent Change: 1990 - 2010}

Counties

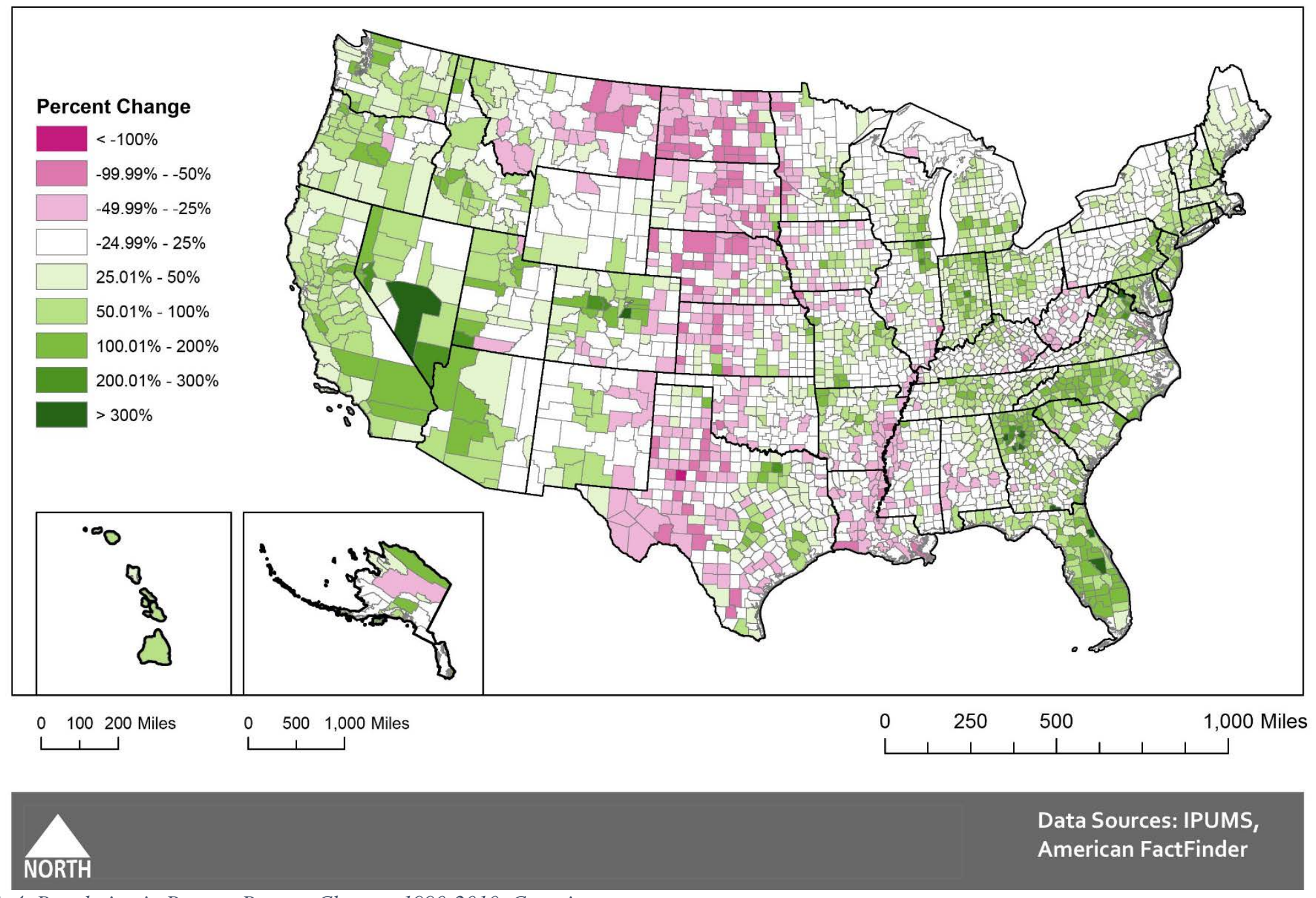

Figure A-4. Population in Poverty Percent Change: 1990-2010, Counties. 


\section{Population with Limited English Proficiency Absolute Change: 1990 - 2010}

Counties
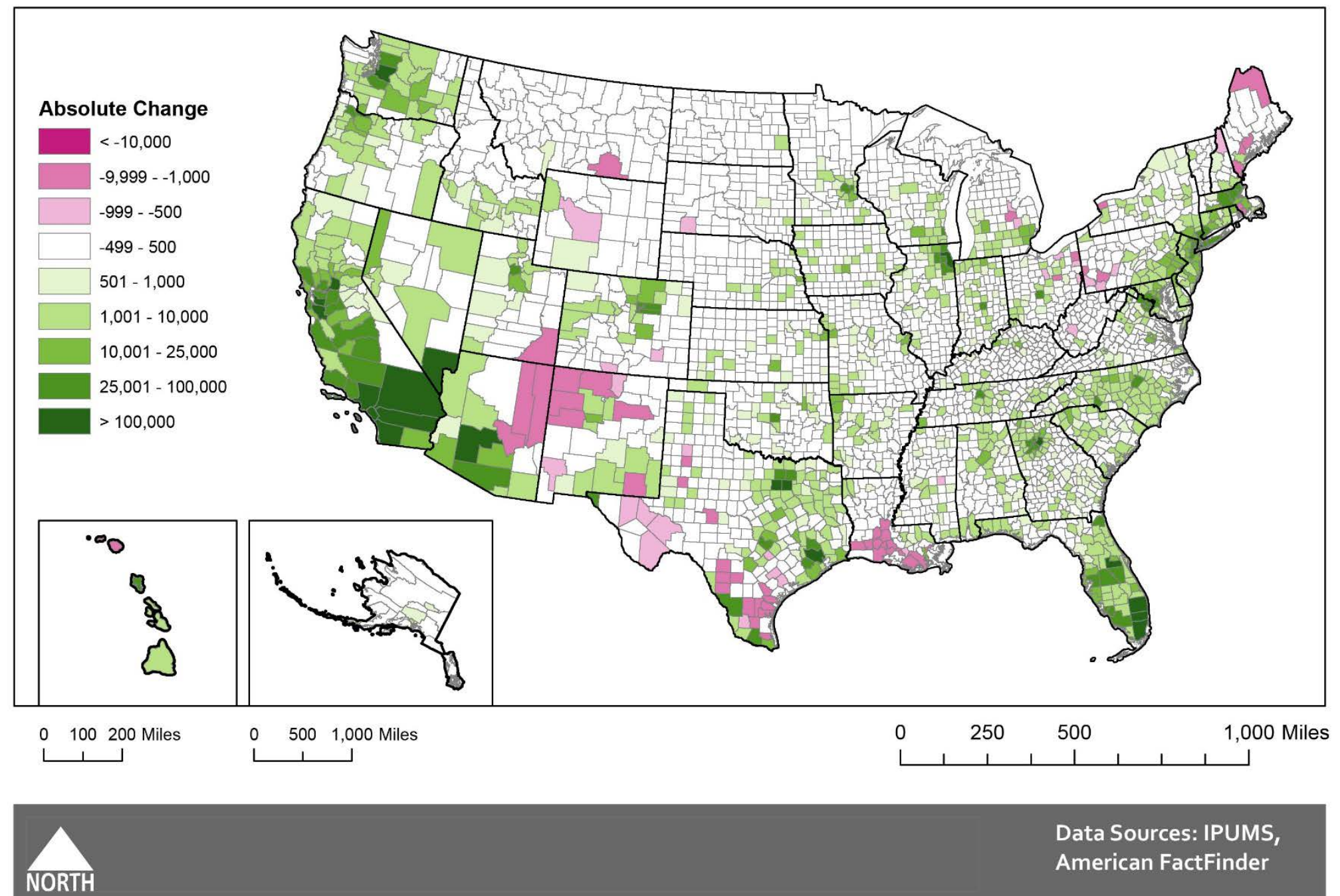

Data Sources: IPUMS, American FactFinder

Figure A-5. Population with Limited English Proficiency Absolute Change: 1990-2010, Counties. 
Population with Limited English Proficiency Percent Change: 1990 - 2010

Counties
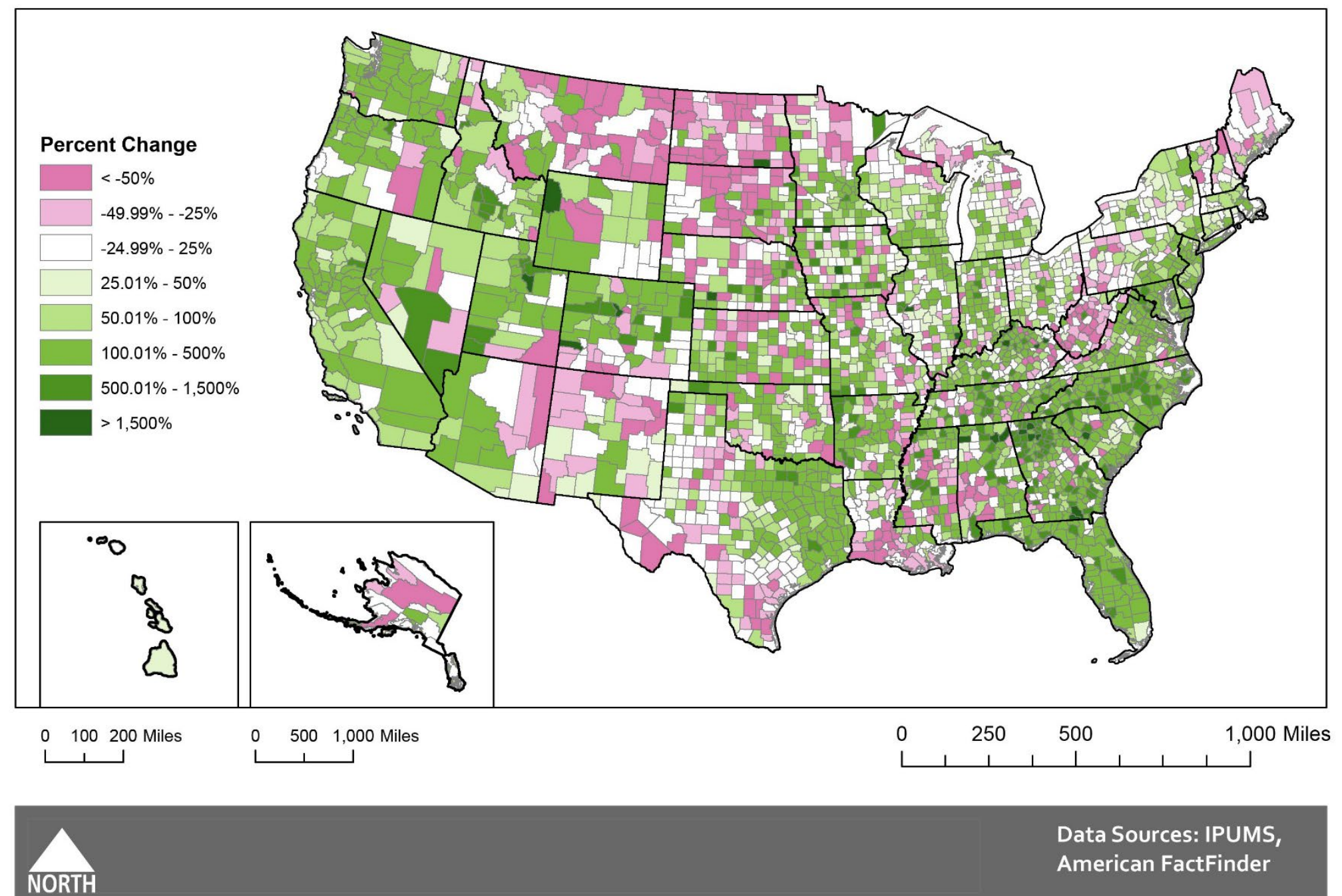

Data Sources: IPUMS, American FactFinder

Figure A- 6. Population with Limited English Proficiency Percent Change: 1990-2010, Counties. 


\section{APPENDIX B: CASE STUDY MSA DEMOGRAPHIC CHANGE MAPS}

\section{Minority Population Absolute Change: 2000-2010}

MTC

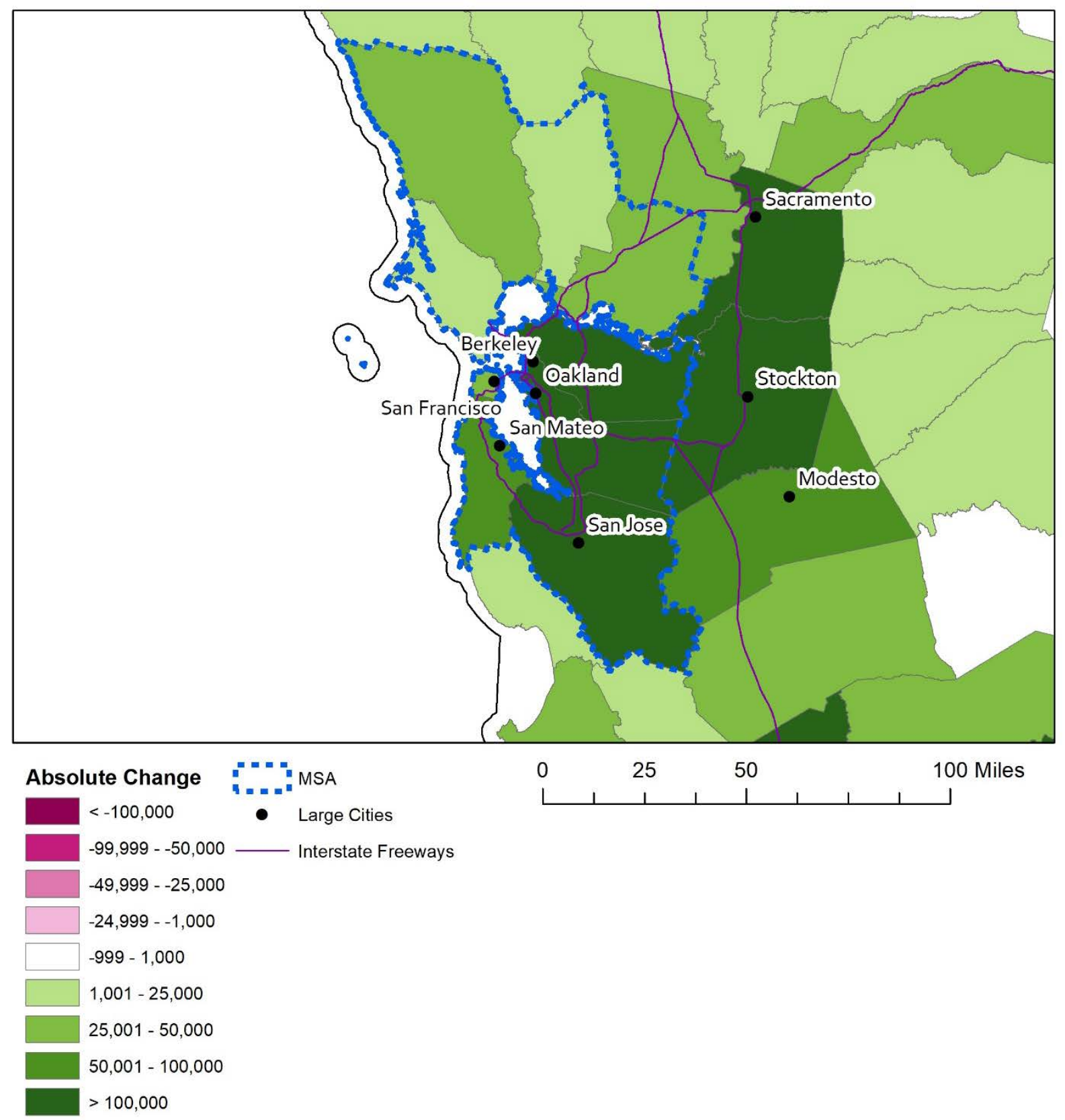

Data Sources: IPUMS, American FactFinder

Figure B-1. Minority Population Absolute Change: 2000-2010, Metropolitan Transportation Commission. 


\section{Minority Population Percent Change: 2000-2010}

MTC

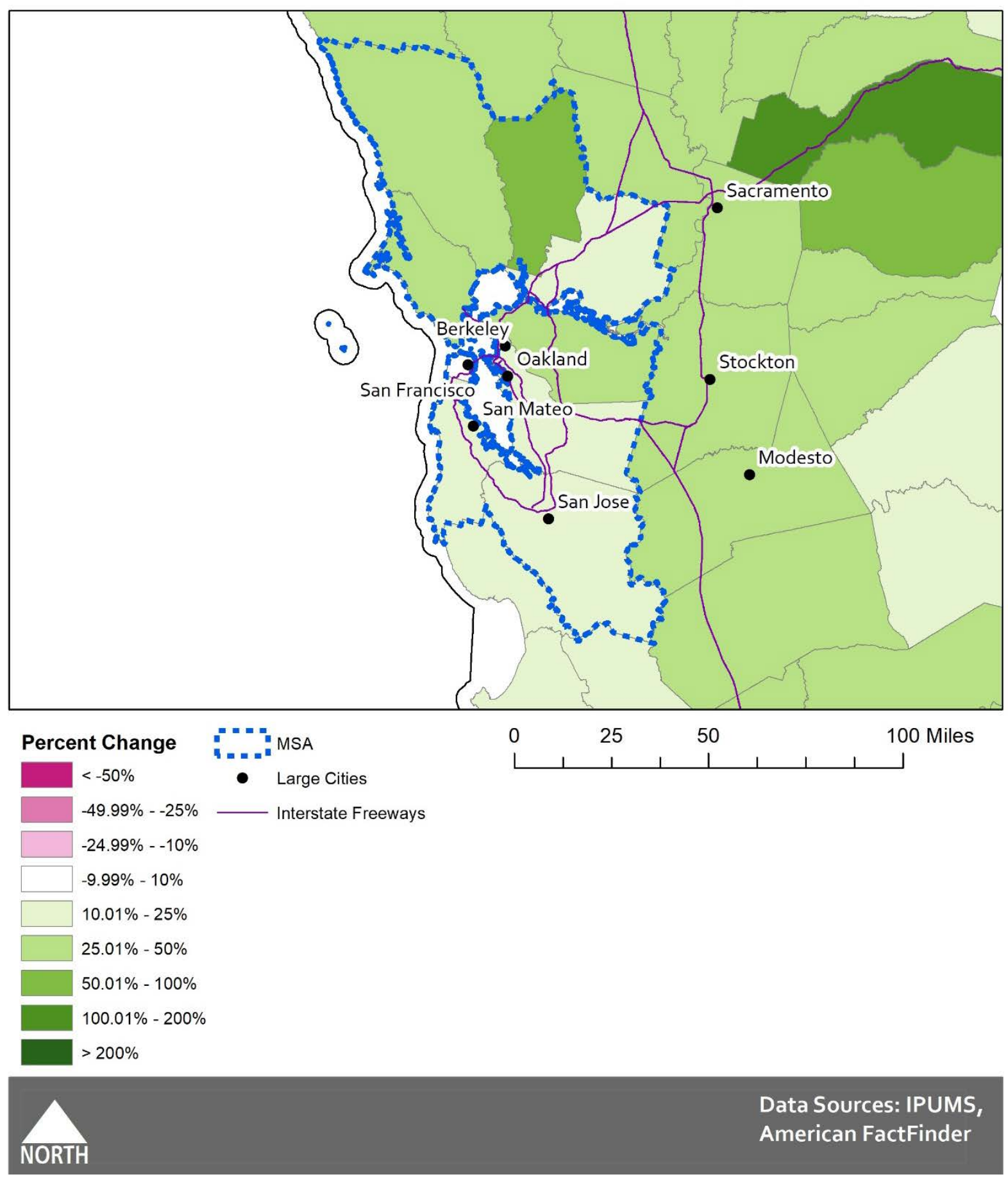

Figure B-2. Minority Population Percent Change: 2000-2010, Metropolitan Transportation Commission. 


\section{Population in Poverty Absolute Change: 1990 - 2010

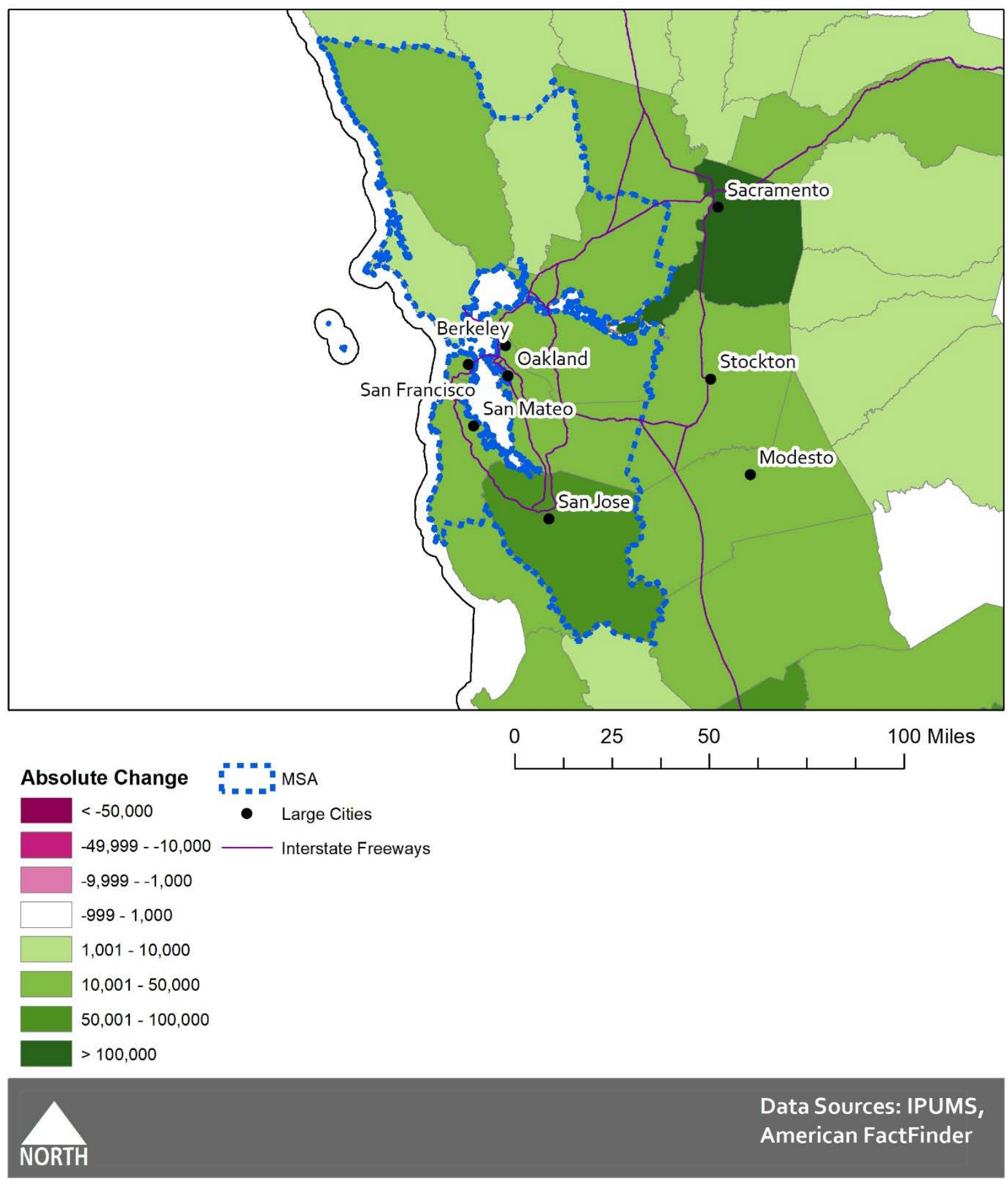

Figure B-3. Population in Poverty Absolute Change: 1990-2010, Metropolitan Transportation Commission. 


\section{Population in Poverty Percent Change: 1990 - 2010}

MTC

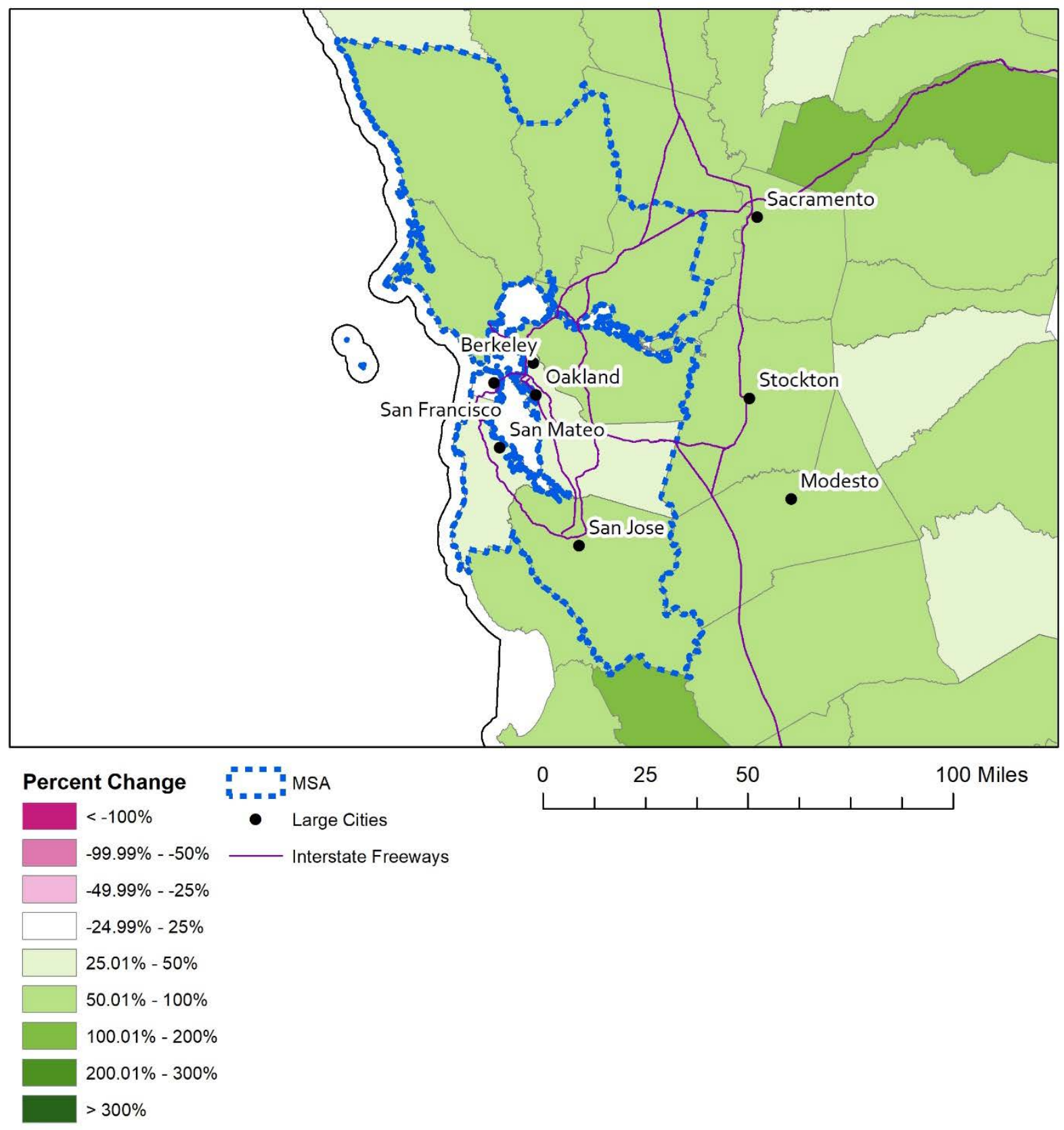

Data Sources: IPUMS,

American FactFinder

Figure B-4. Population in Poverty Percent Change: 1990-2010, Metropolitan Transportation Commission. 


\section{Population with Limited English Proficiency Absolute Change:}

$1990-2010$

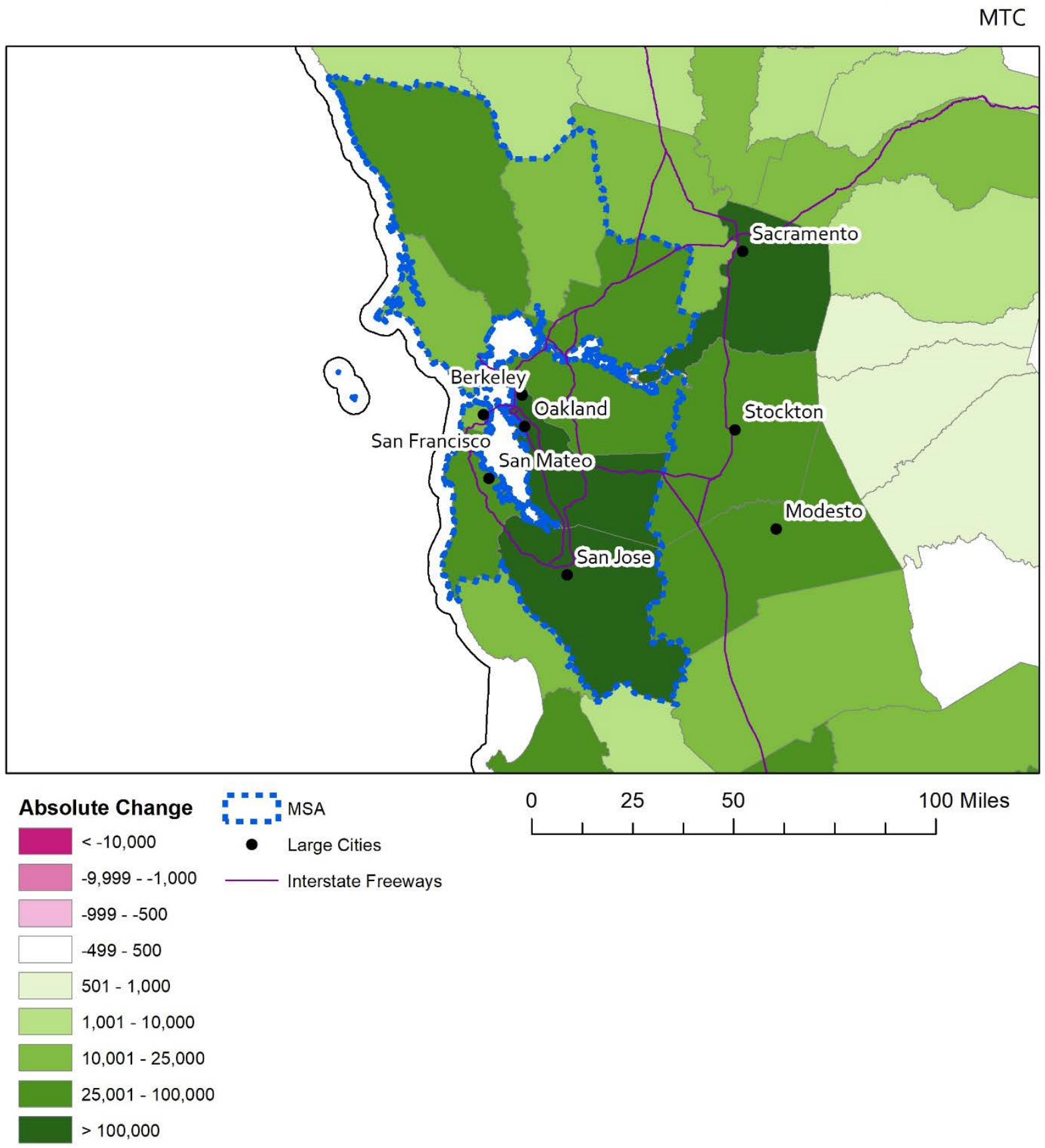

NORTH

Data Sources: IPUMS,

American FactFinder

Figure B-5. Population with Limited English Proficiency Absolute Change: 1990-2010, Metropolitan Transportation Commission. 


\section{Population with Limited English Proficiency Percent Change:}

$1990-2010$

MTC

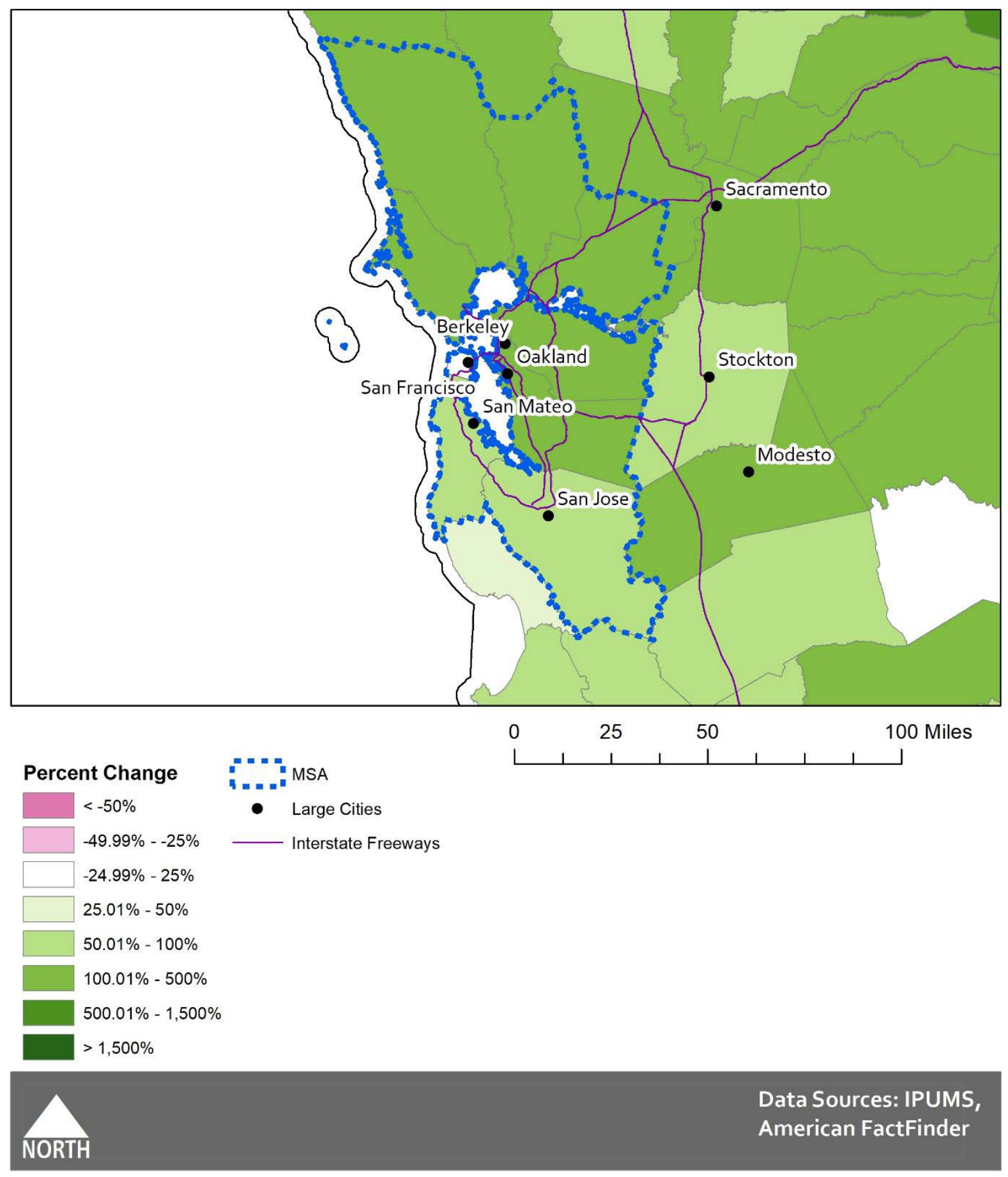

Figure B-6. Population with Limited English Proficiency Percent Change: 1990-2010, Metropolitan Transportation Commission. 


\section{Minority Population Absolute Change: 2000-2010}

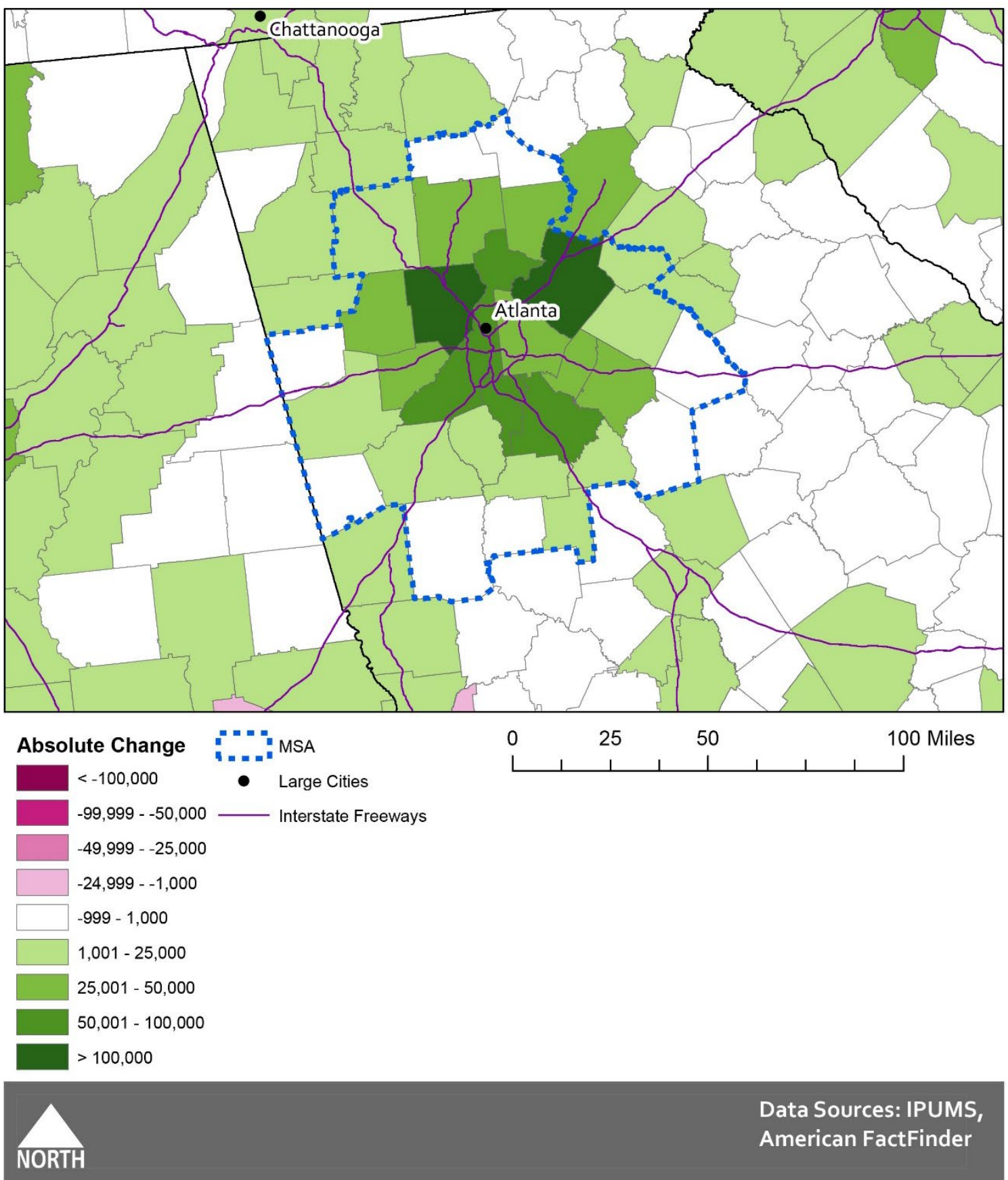

Figure B-7. Minority Population Absolute Change: 2000-2010, Atlanta Regional Commission. 


\section{Minority Population Percent Change: 2000-2010}

ARC

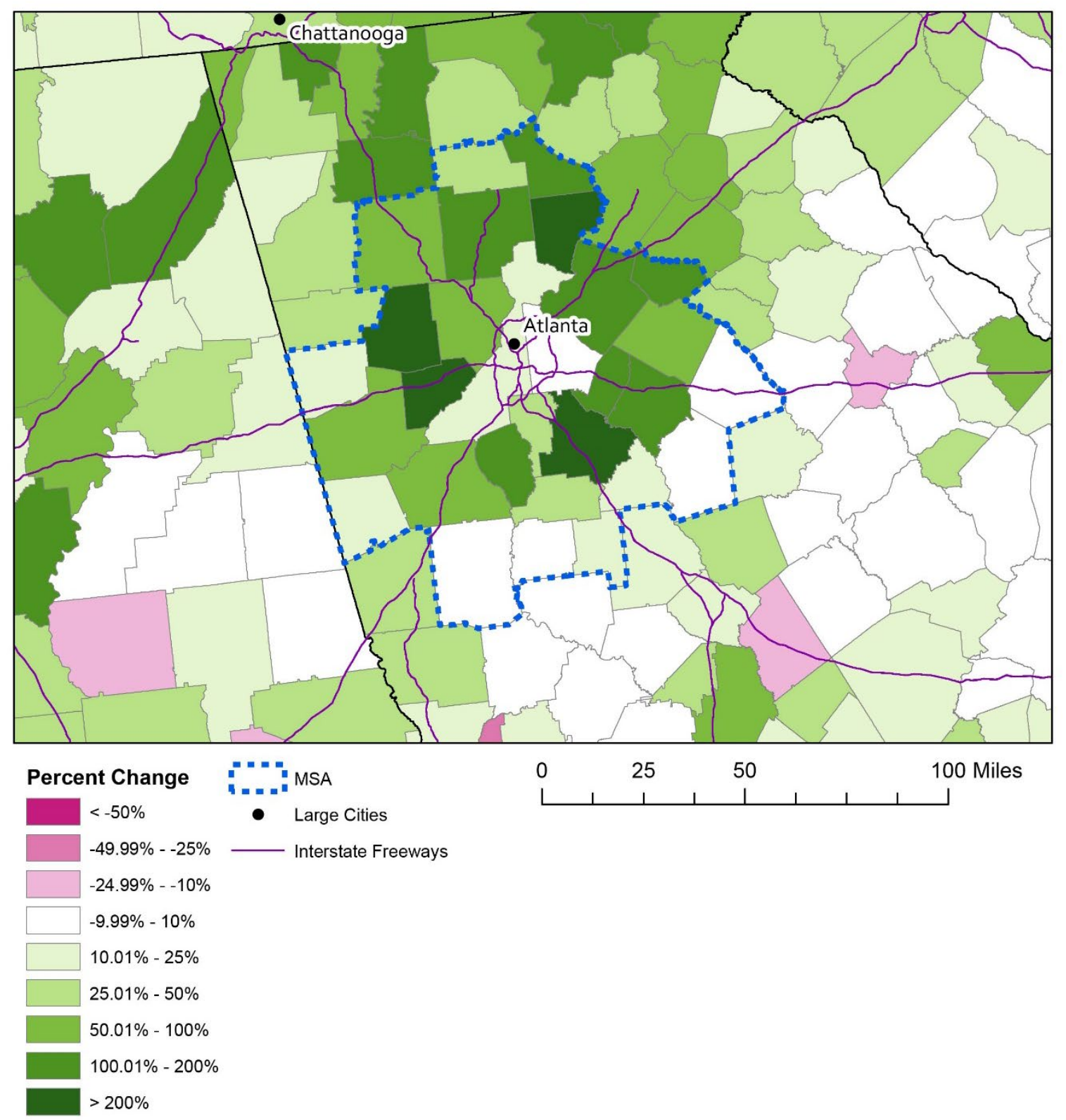

Figure B-8. Minority Population Percent Change: 2000-2010, Atlanta Regional Commission. 


\section{Population in Poverty Absolute Change: 1990 - 2010}

ARC

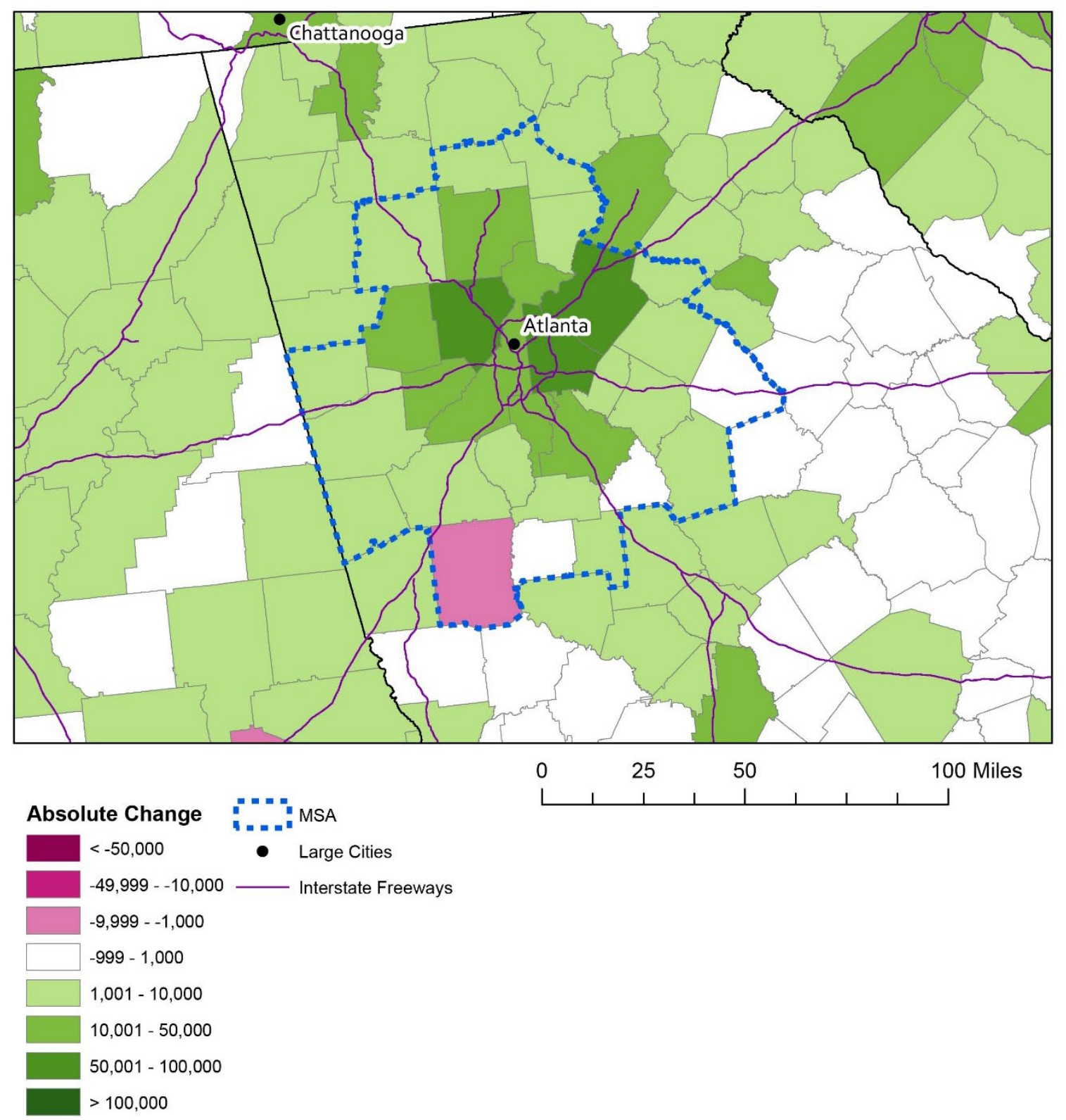

NORTH

Figure B-9. Population in Poverty Absolute Change: 2000-2010, Atlanta Regional Commission. 


\section{Population in Poverty Percent Change: 1990 - 2010}

ARC

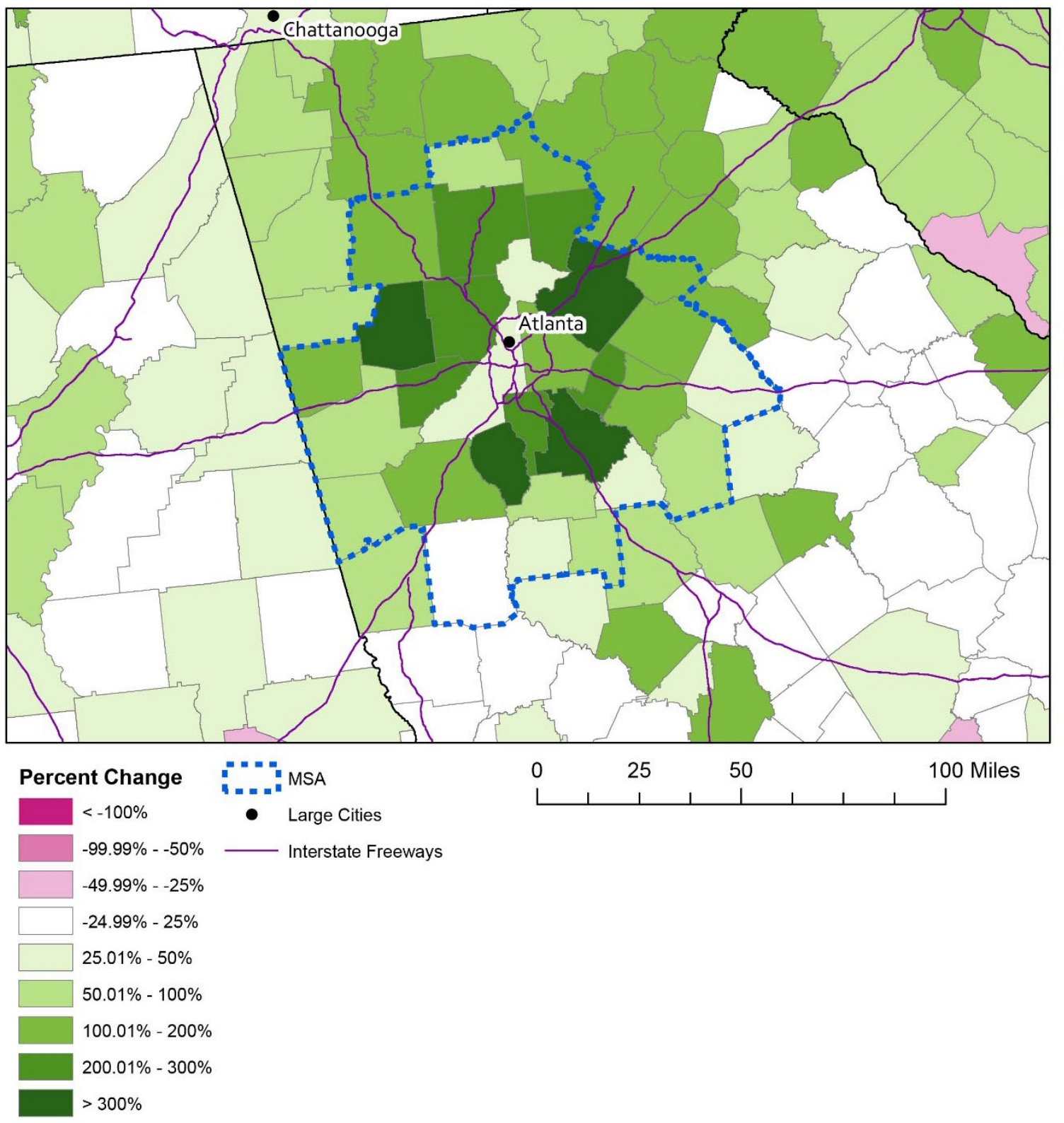

NORTH

Data Sources: IPUMS,

American FactFinder

Figure B-10. Population in Poverty Percent Change: 1990-2010, Atlanta Regional Commission. 


\section{Population with Limited English Proficiency Absolute Change:}

$1990-2010$

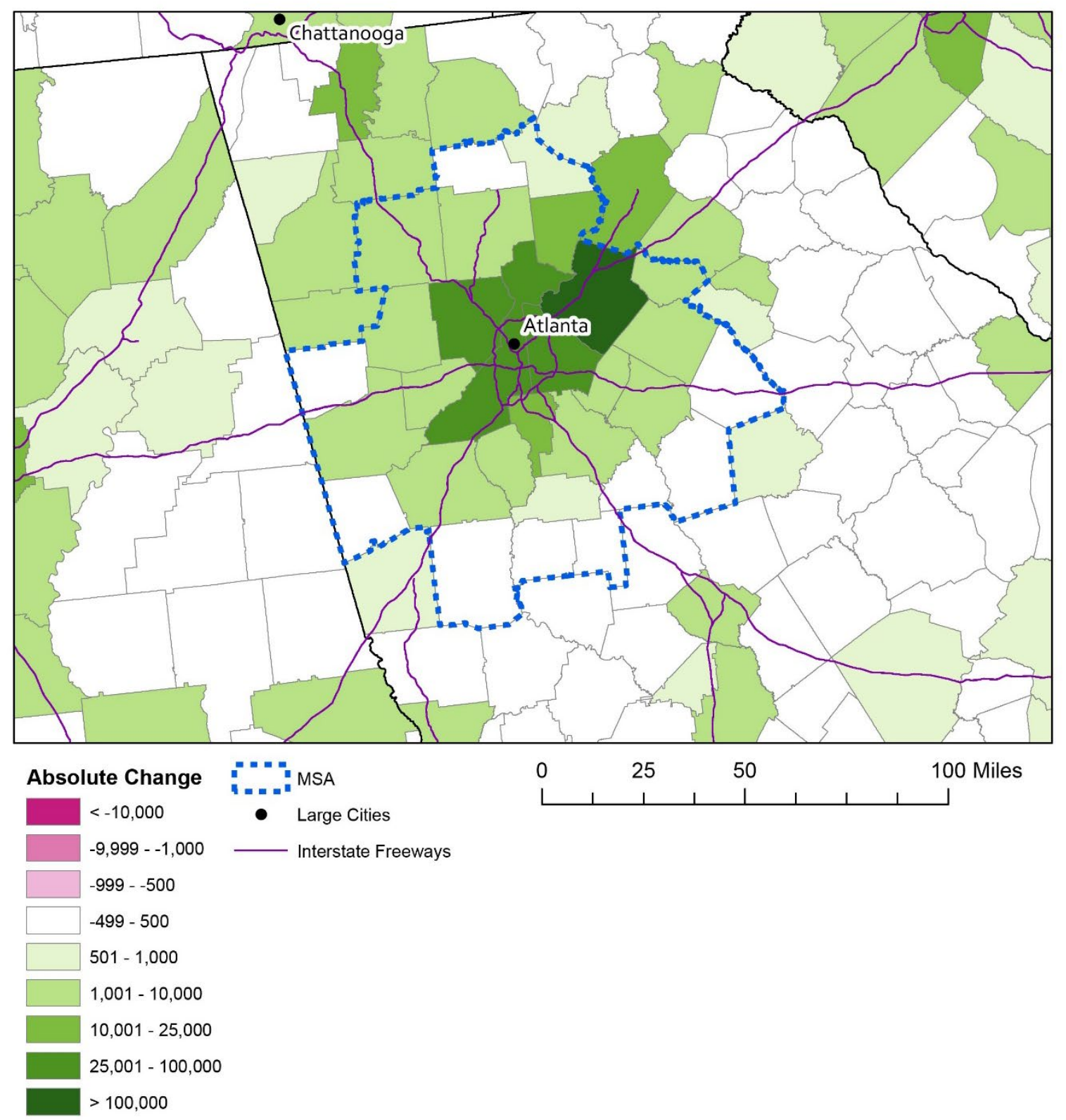

Figure B-11. Population with Limited English Proficiency Absolute Change: 1990-2010, Atlanta Regional Commission. 


\section{Population with Limited English Proficiency Percent Change: $1990-2010$}

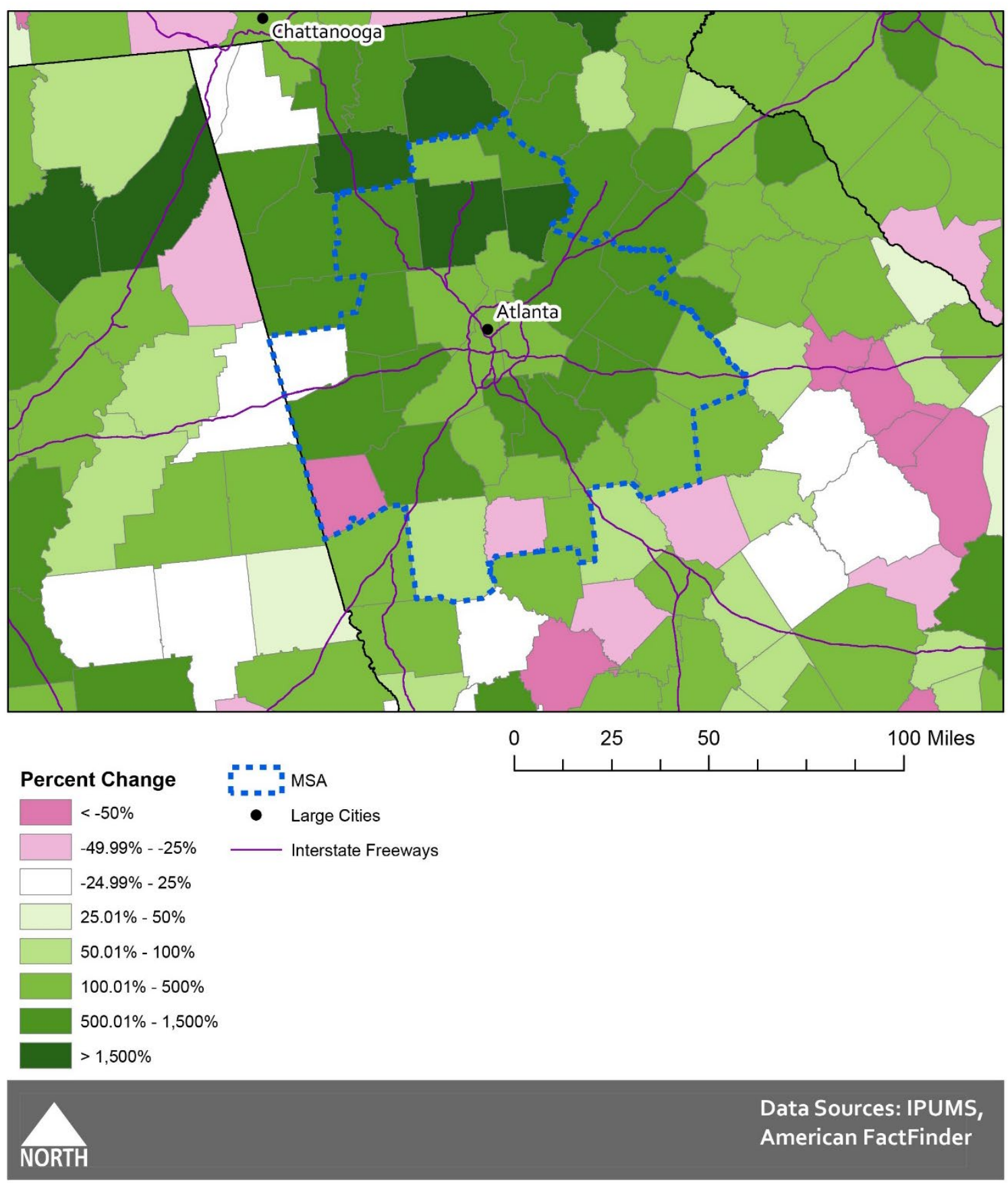

Figure B-12. Population with Limited English Proficiency Percent Change: 1990-2010, Atlanta Regional Commission. 


\section{Minority Population Absolute Change: 2000-2010}

Metro

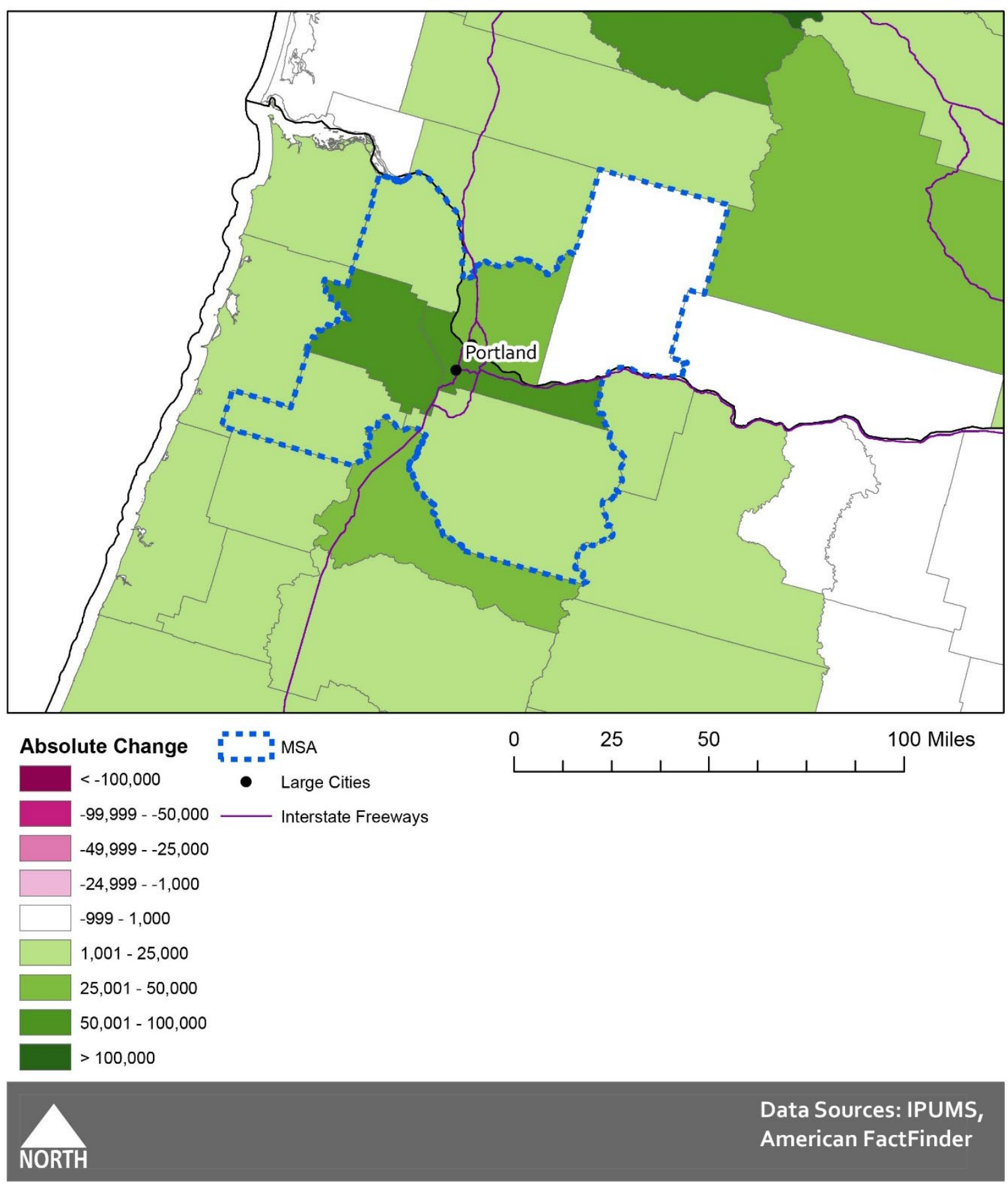

Figure B-13. Minority Population Absolute Change: 2000-2010, Metro. 


\section{Minority Population Percent Change: 2000-2010}

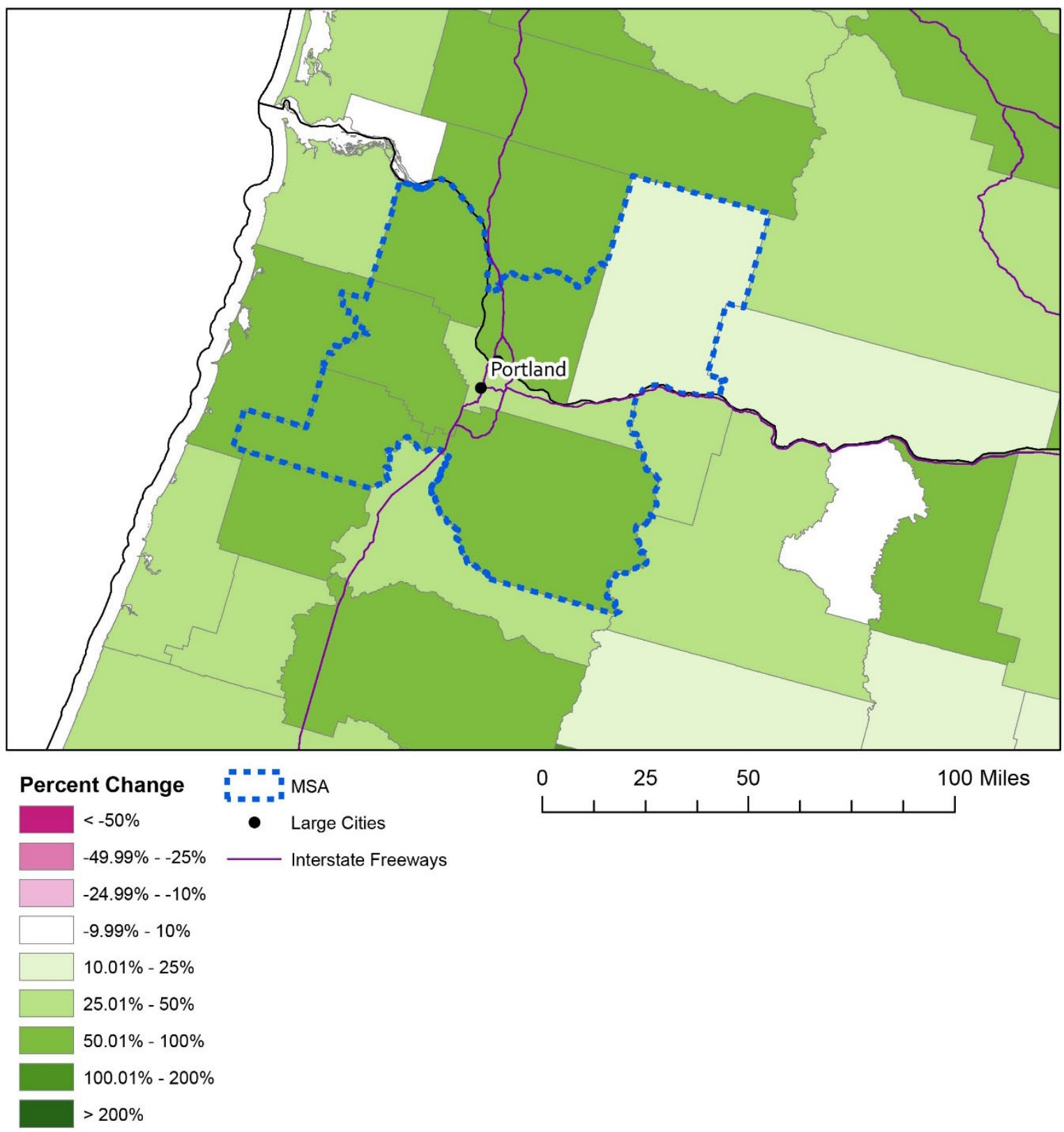

NORTH

Figure B-14. Minority Population Percent Change: 2000-2010, Metro. 


\section{Population in Poverty Absolute Change: 1990 - 2010}

Metro

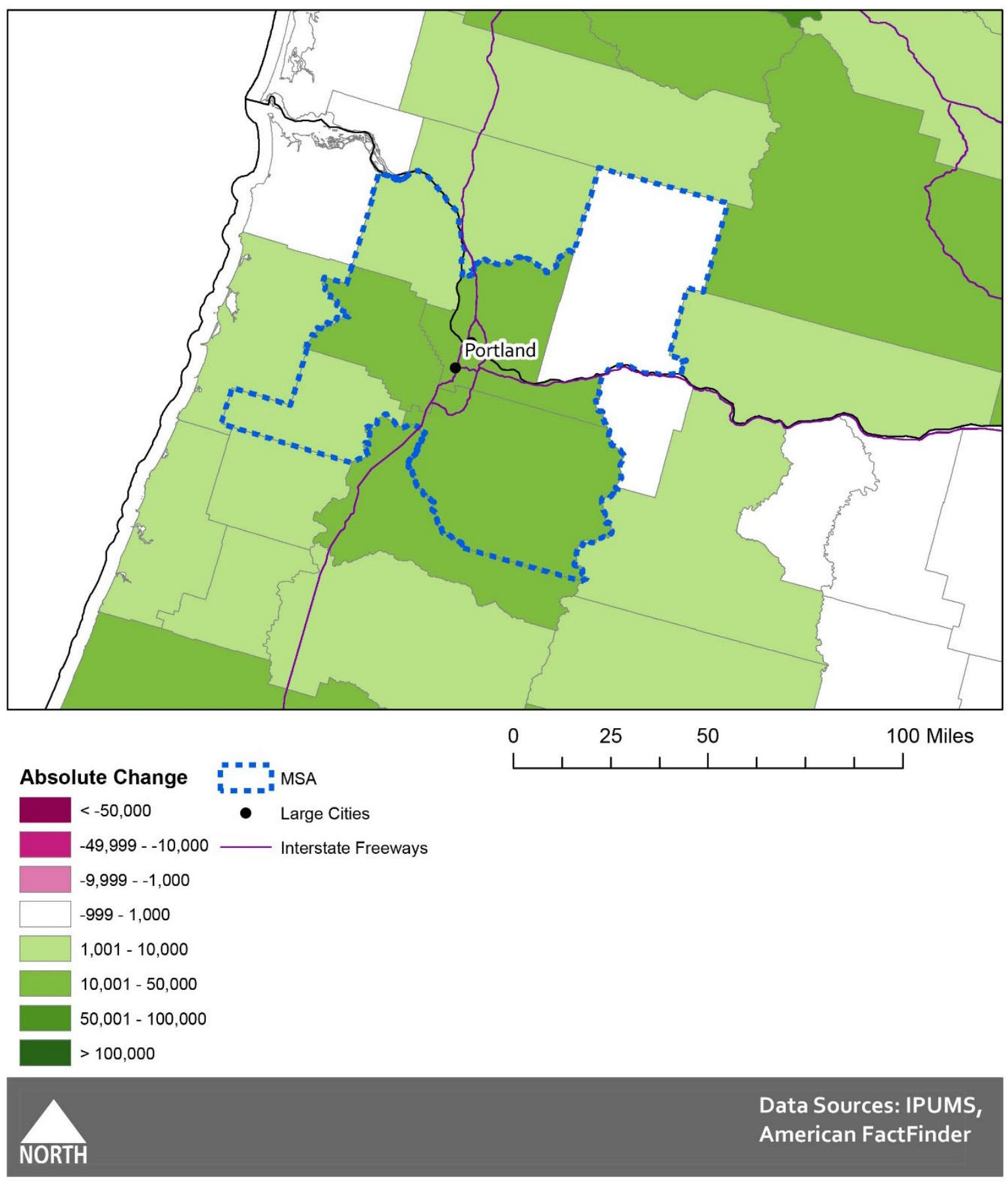

Figure B-15. Population in Poverty Absolute Change: 1990-2010, Metro. 


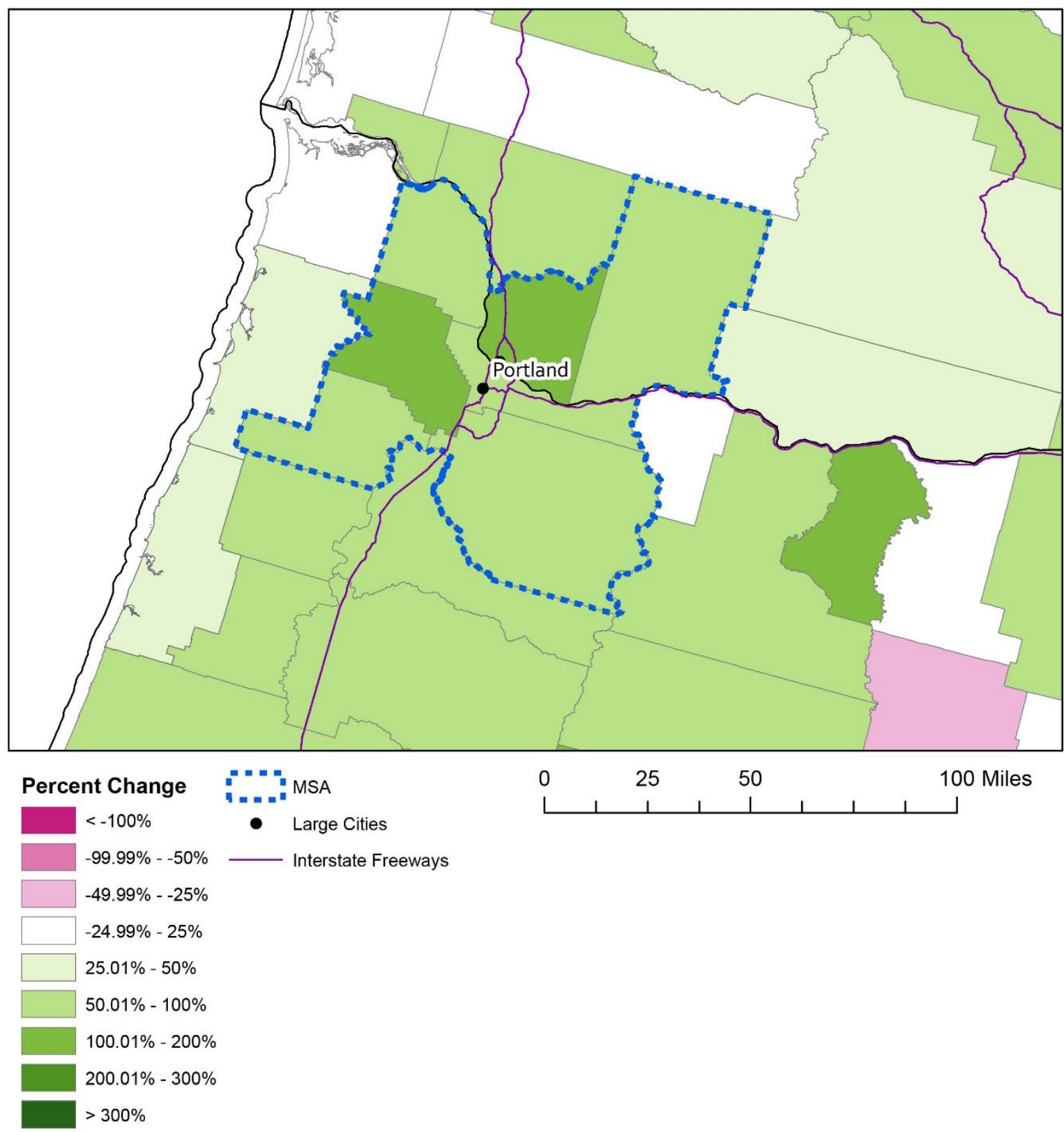

NORTH

Figure B-16. Population in Poverty Percent Change: 1990-2010, Metro. 


\section{Population with Limited English Proficiency Absolute Change:}

$1990-2010$

Metro

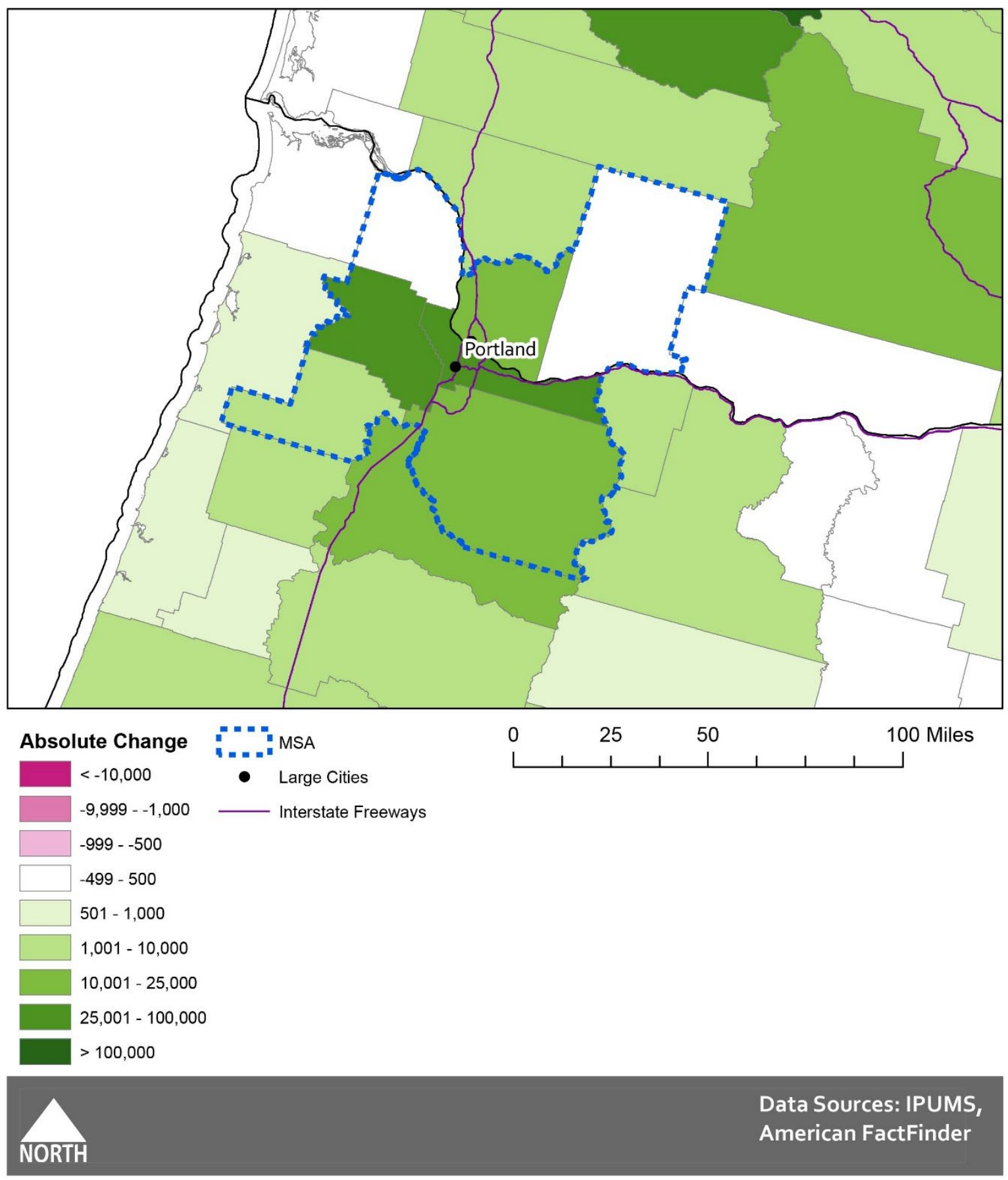

Figure B-17. Population with Limited English Proficiency Absolute Change: 1990-2010, Metro. 


\section{Population with Limited English Proficiency Percent Change:}

$1990-2010$

Metro

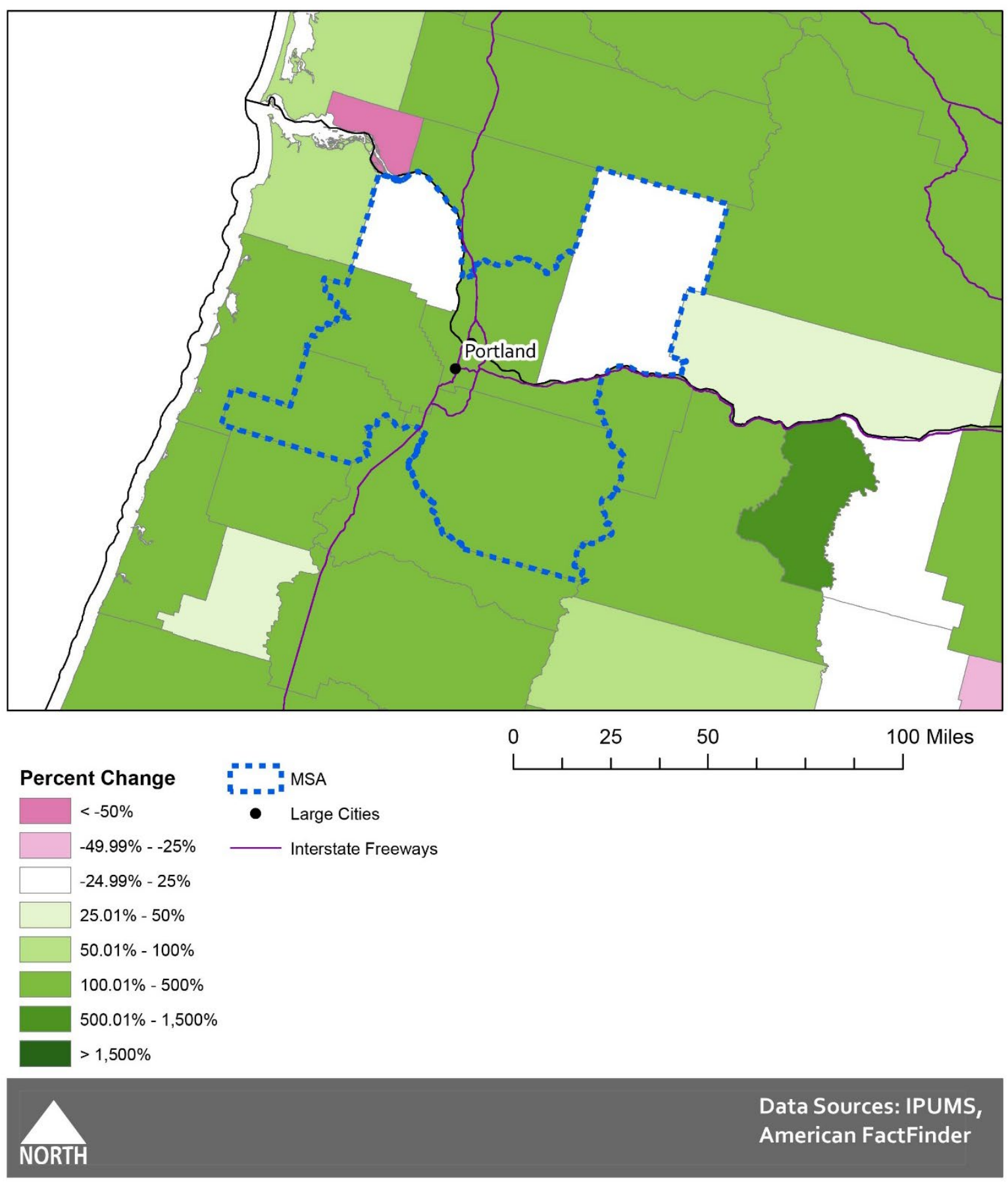

Figure B-18. Population with Limited English Proficiency Percent Change: 1990-2010, Metro. 


\section{Minority Population Absolute Change: 2000-2010}

MORPC
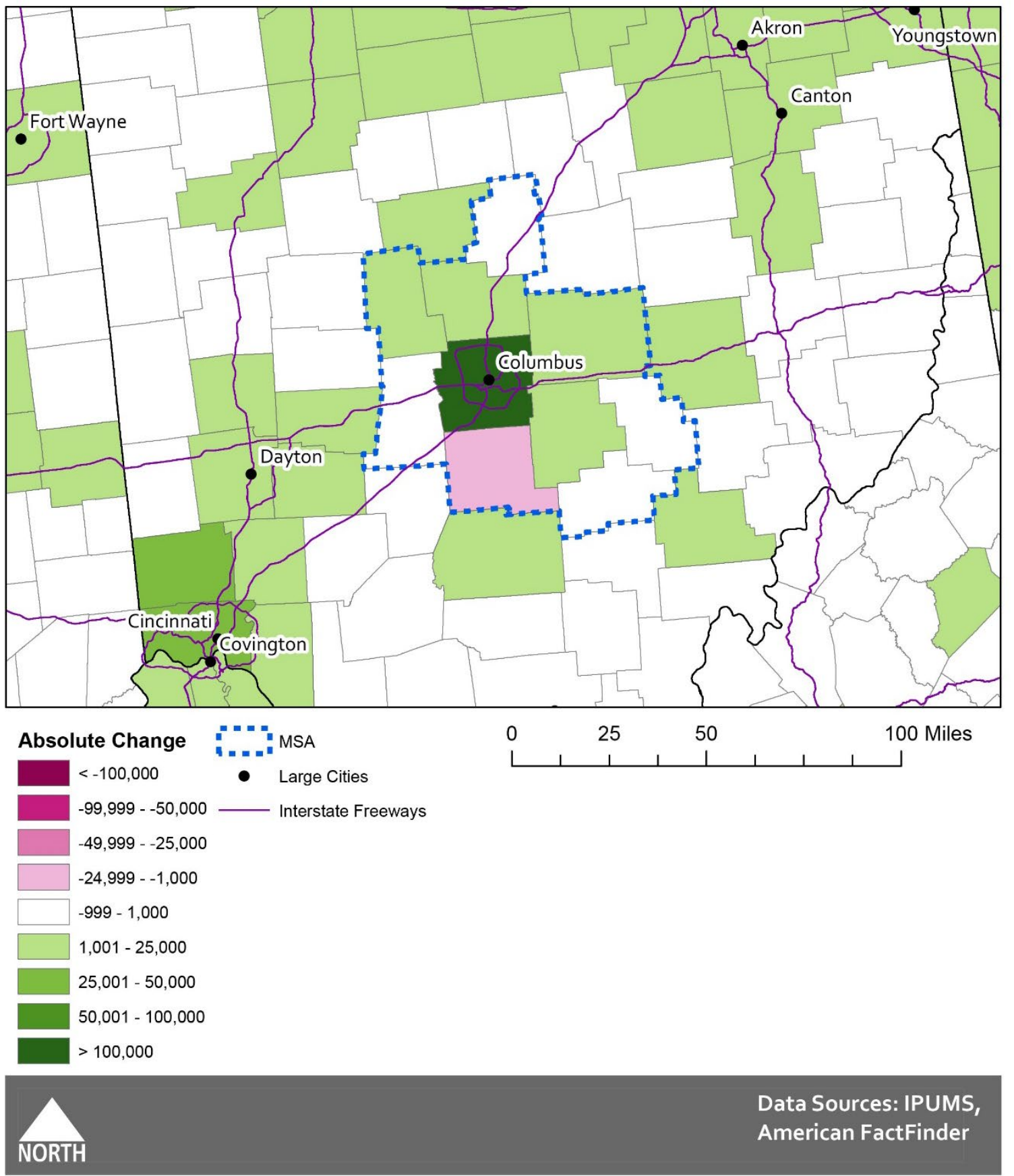

Figure B-19. Minority Population Absolute Change: 2000-2010, Mid-Ohio Regional Planning Commission. 


\section{Minority Population Percent Change: 2000-2010}

MORPC

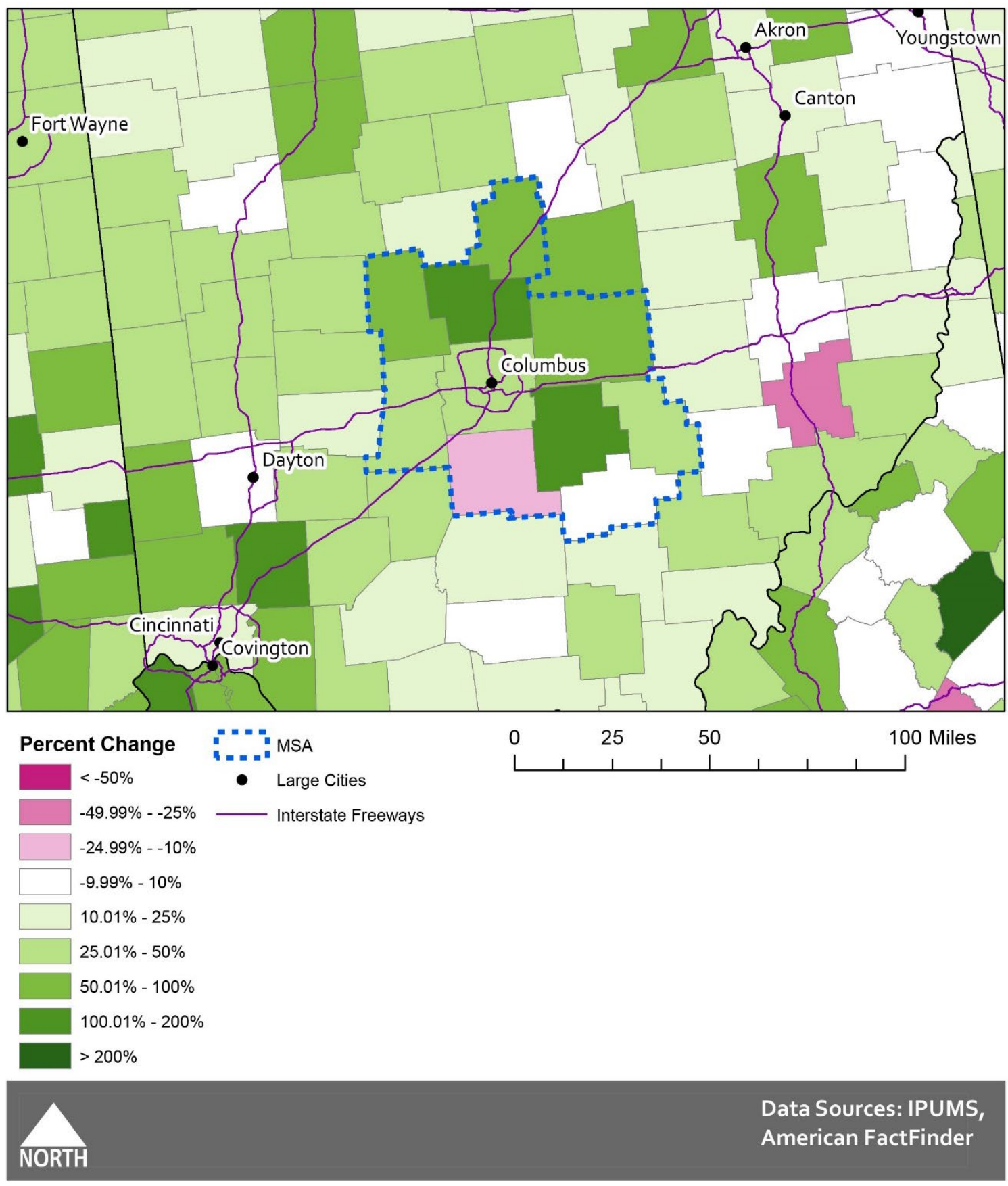

Figure B-20. Minority Population Percent Change: 2000-2010, Mid-Ohio Regional Planning Commission. 


\section{Population in Poverty Absolute Change: 1990 - 2010}

MORPC
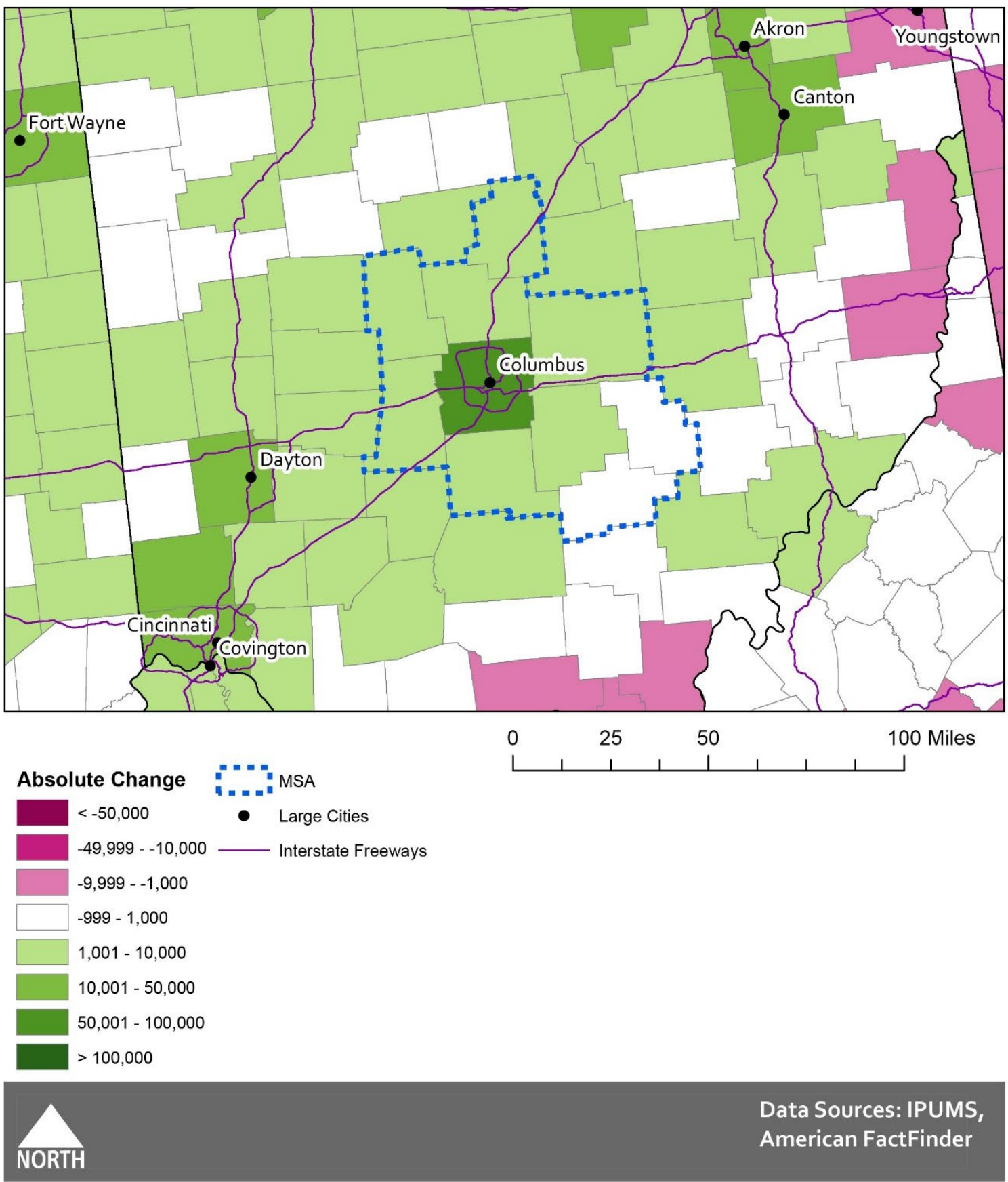

Figure B-21. Population in Poverty Absolute Change: 1990-2010, Mid-Ohio Regional Planning Commission. 


\section{Population in Poverty Percent Change: 1990 - 2010}

MORPC
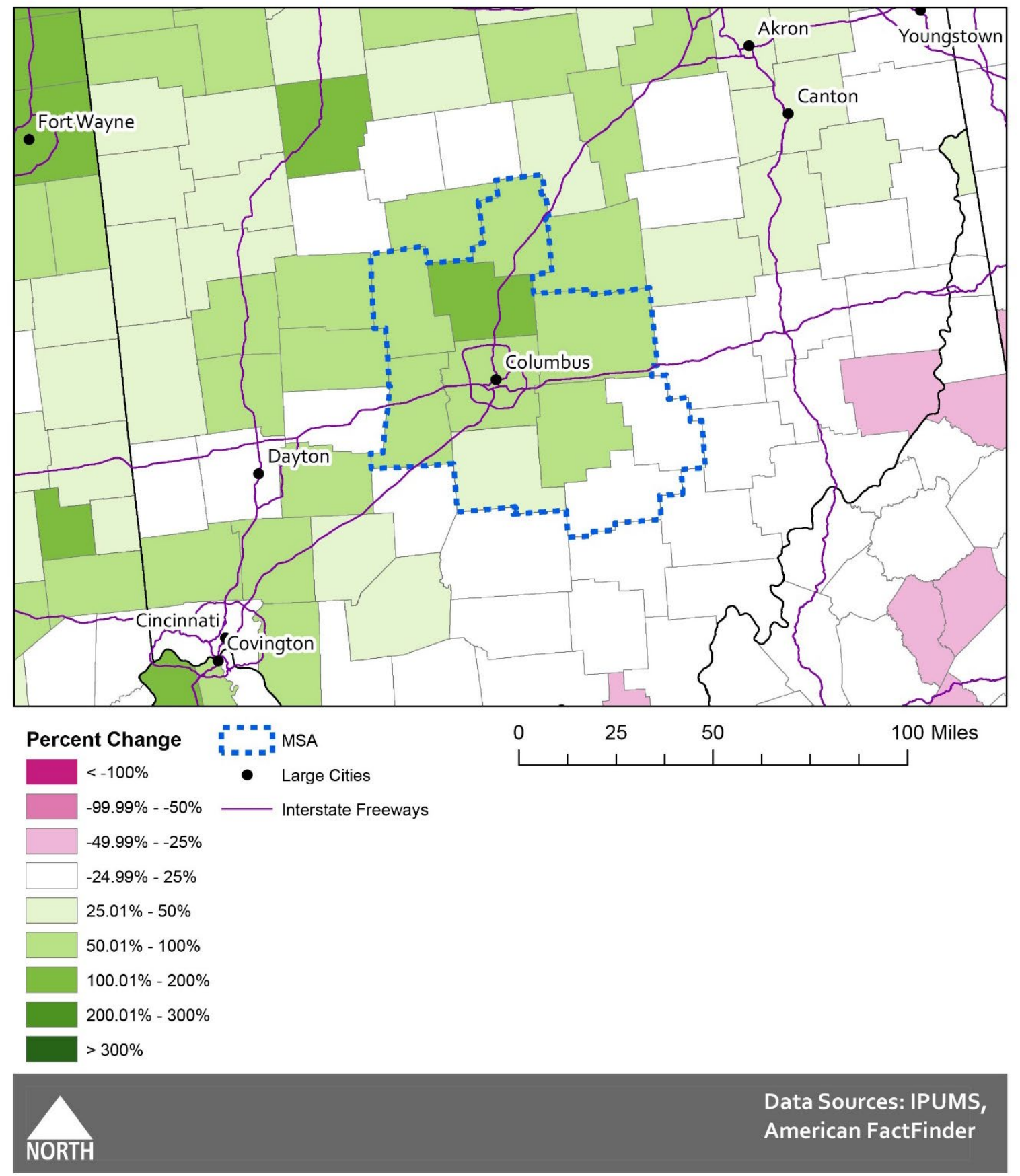

Figure B-22. Population in Poverty Percent Change: 1990-2010, Mid-Ohio Regional Planning Commission. 
Population with Limited English Proficiency Absolute Change: $1990-2010$ MORPC
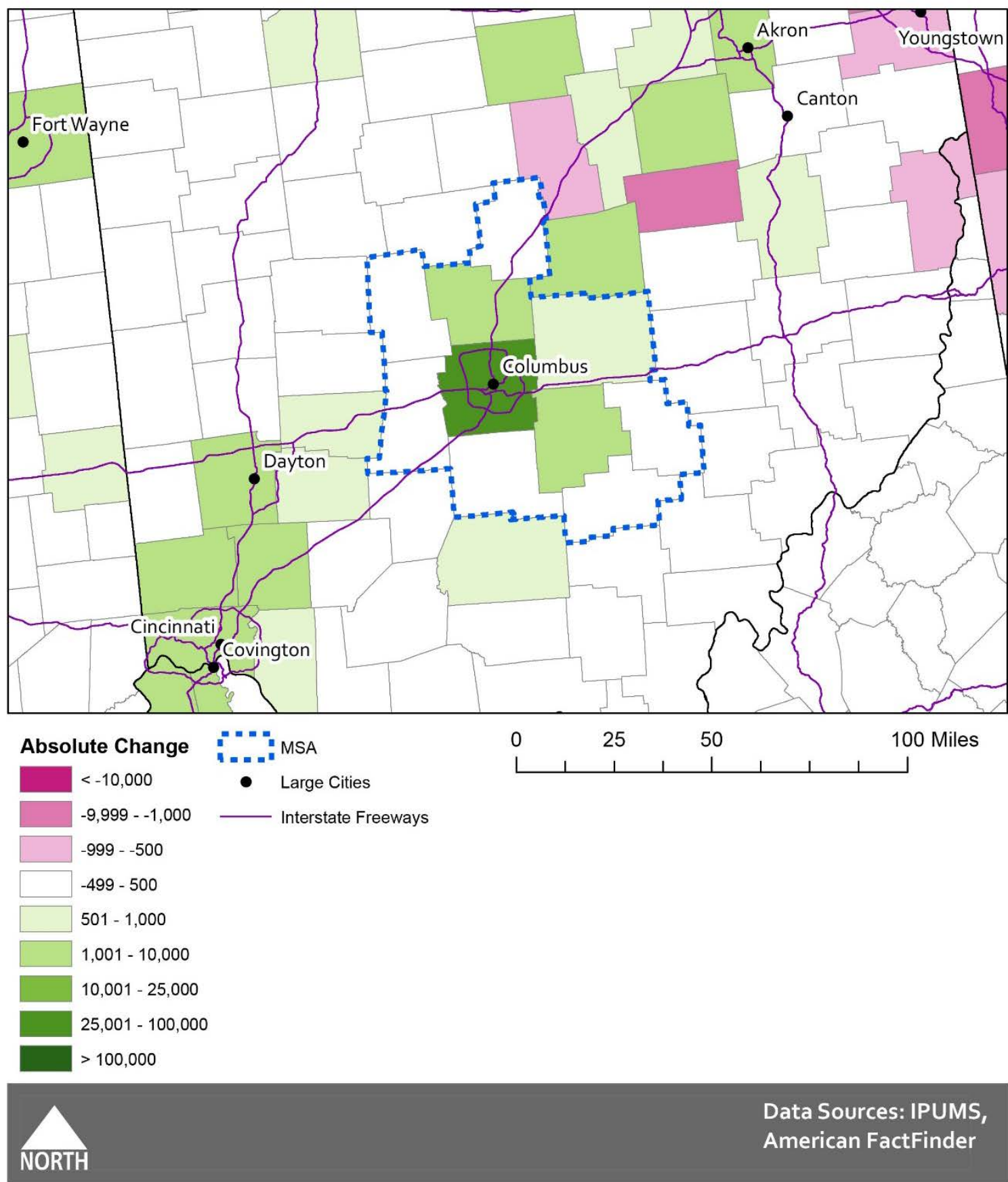

Figure B-23. Population with Limited English Proficiency Absolute Change: 1990-2010, Mid-Ohio Regional Planning Commission. 


\section{Population with Limited English Proficiency Percent Change:}

$1990-2010$ MORPC

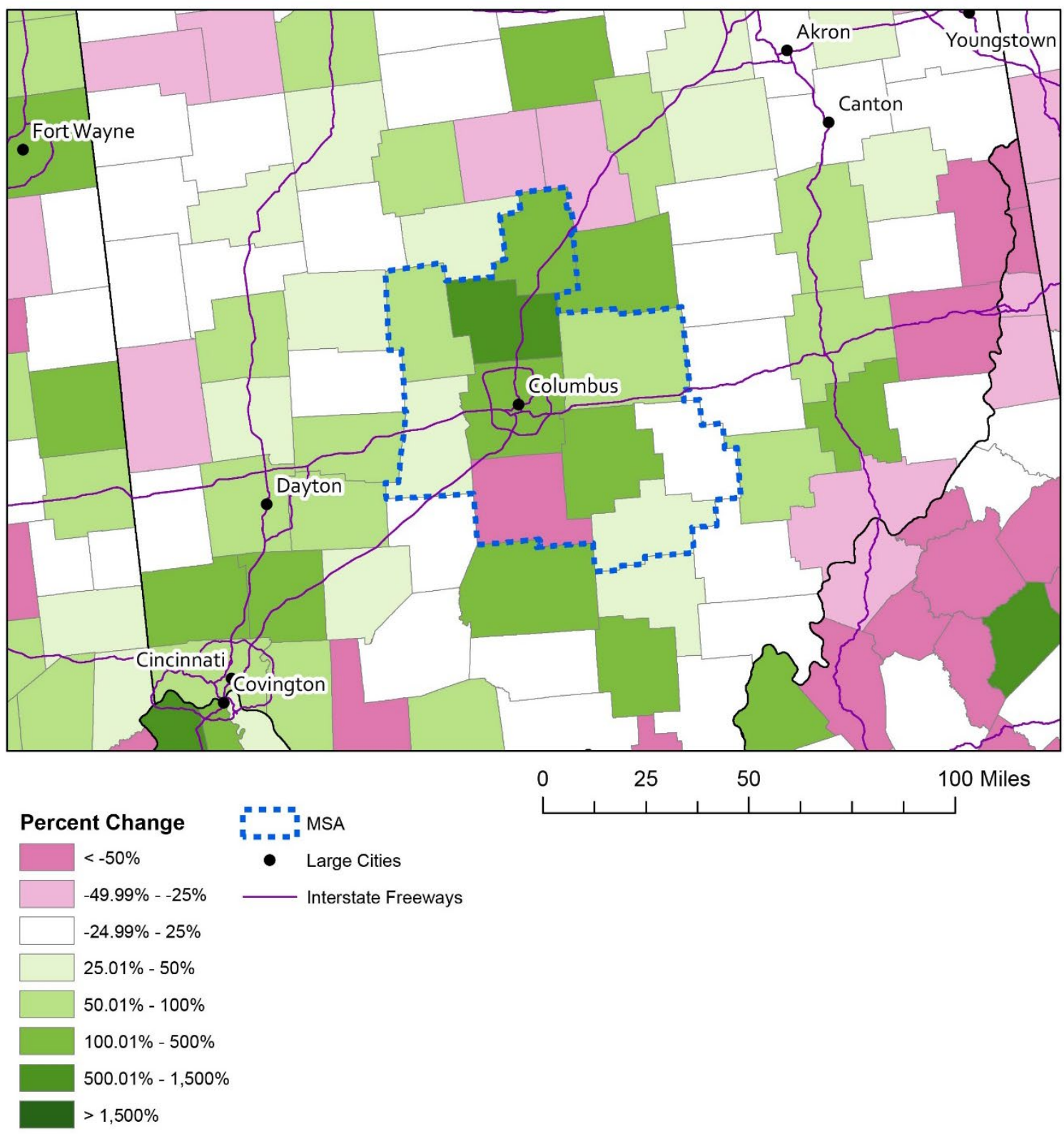

Figure B-24. Population with Limited English Proficiency Percent Change: 1990-2010, Mid-Ohio Regional Planning Commission. 


\section{Minority Population Absolute Change: 2000-2010}

Florida
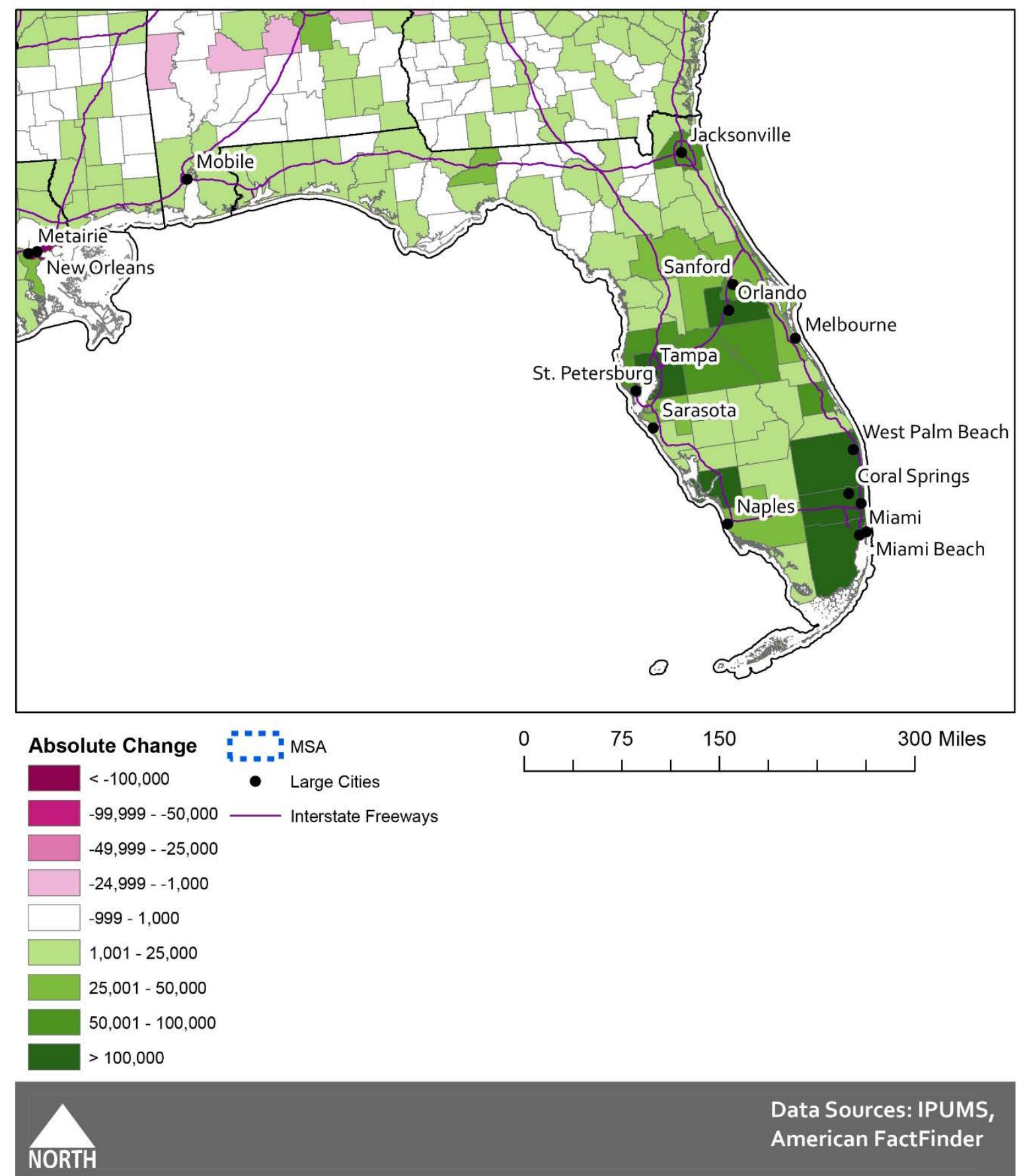

Figure B-25. Minority Population Absolute Change: 2000-2010, Florida. 


\section{Minority Population Percent Change: 2000-2010}

Florida
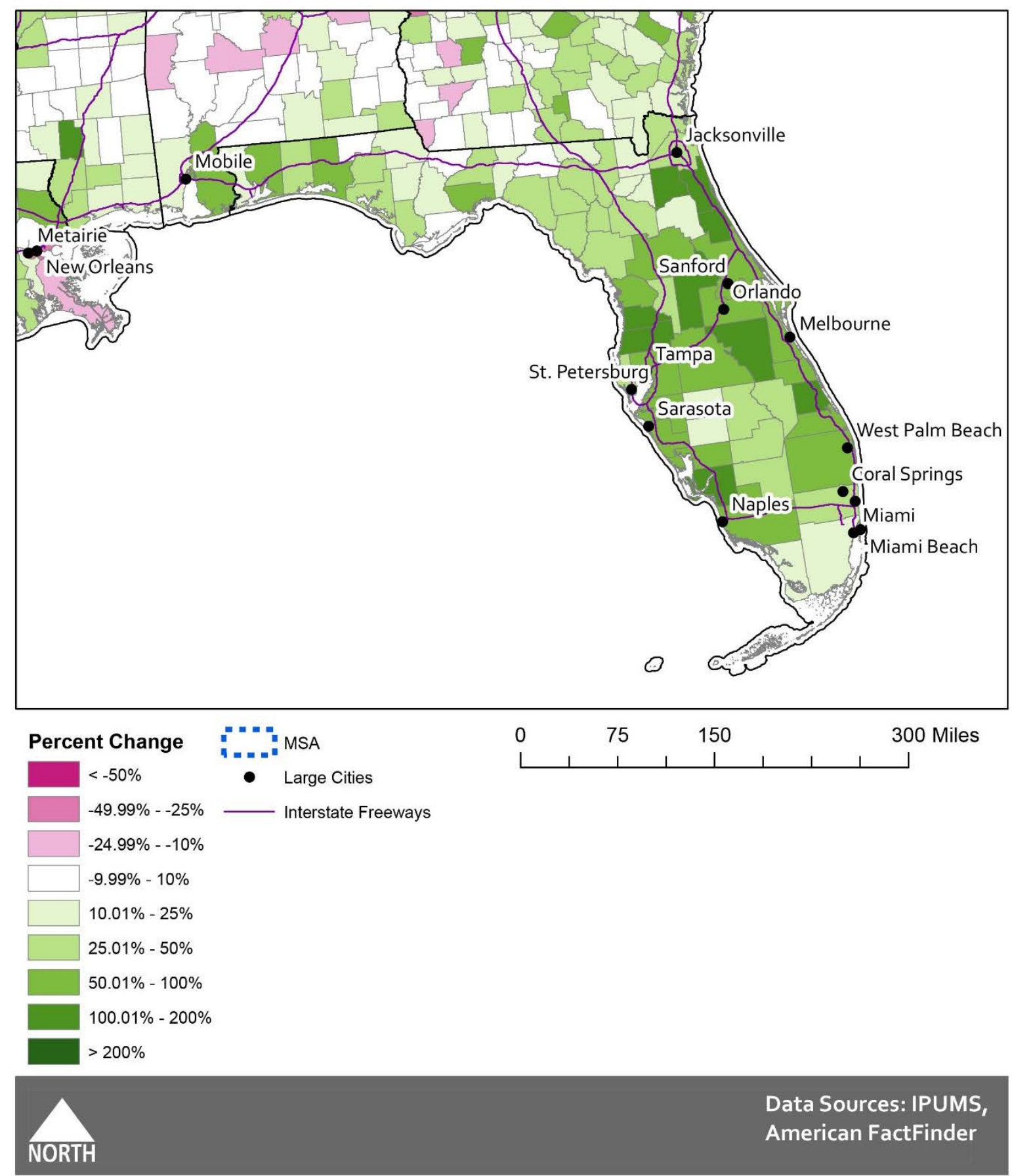

Figure B-26. Minority Population Percent Change: 2000-2010, Florida. 


\section{Population in Poverty Absolute Change: 1990 - 2010}

Florida

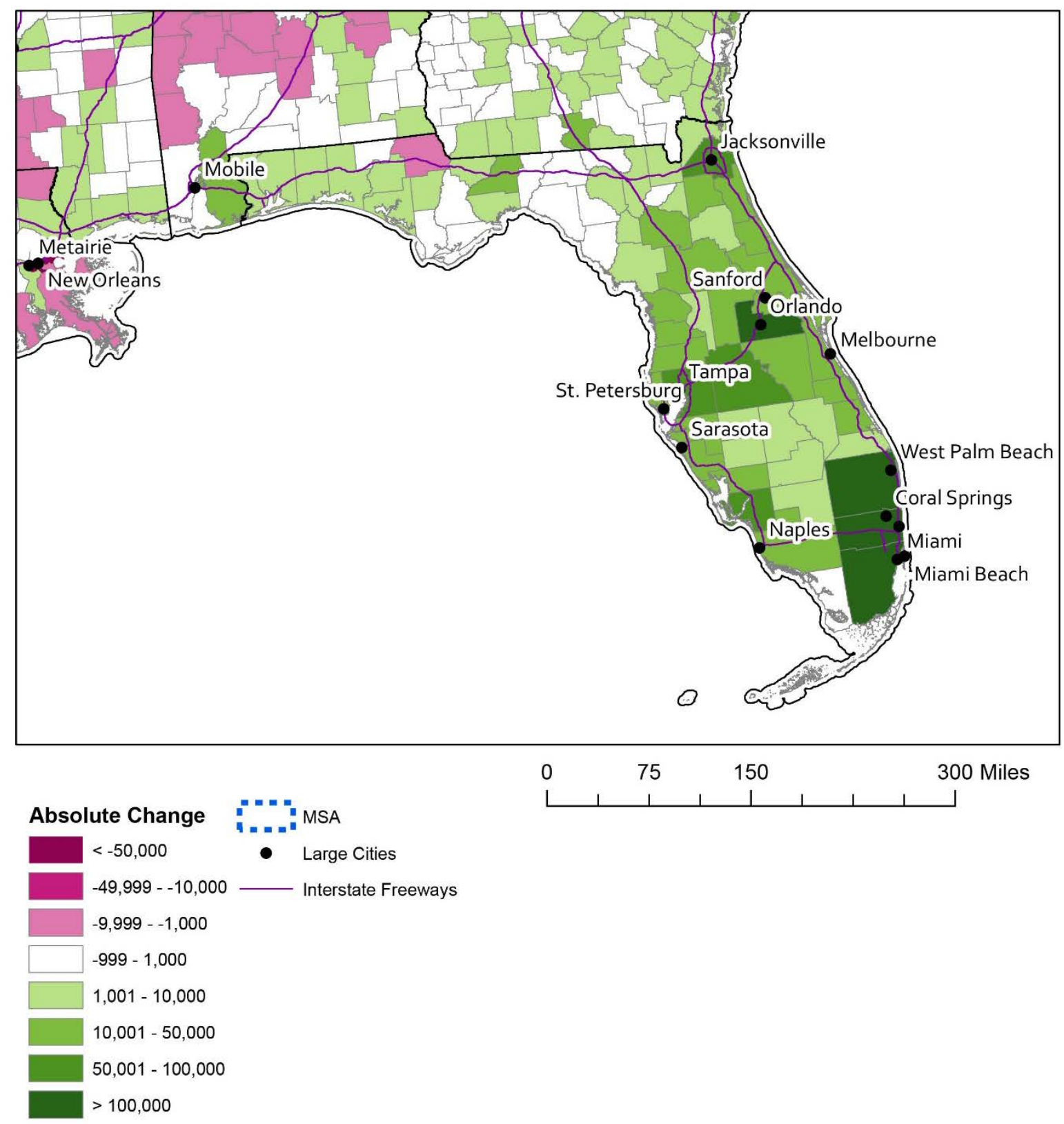

\section{NORTH}

Figure B-27. Population in Poverty Absolute Change: 1990-2010, Florida. 


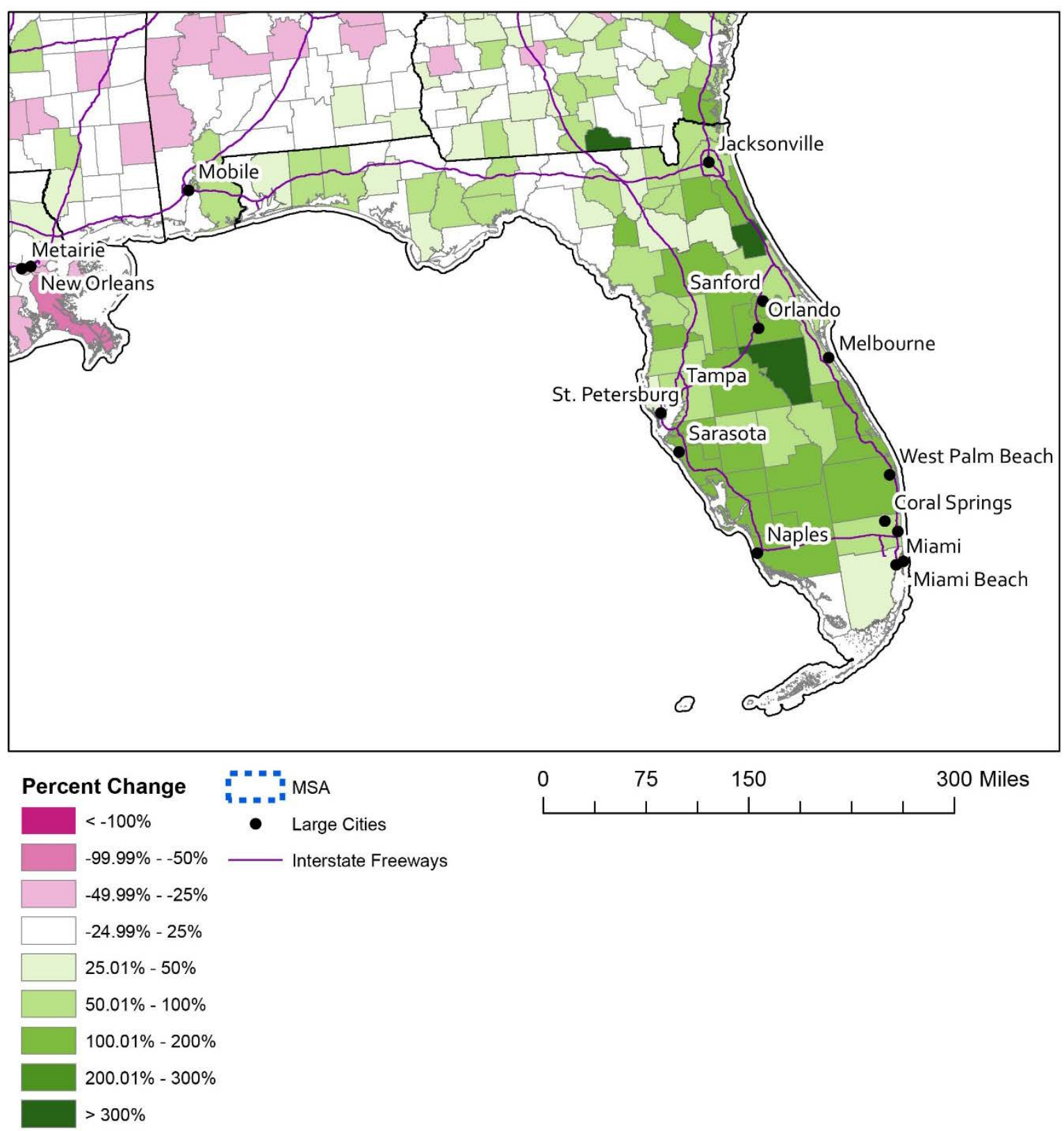

Figure B-28. Population in Poverty Percent Change: 1990-2010, Florida. 


\section{Population with Limited English Proficiency Absolute Change: $1990-2010$}

Florida
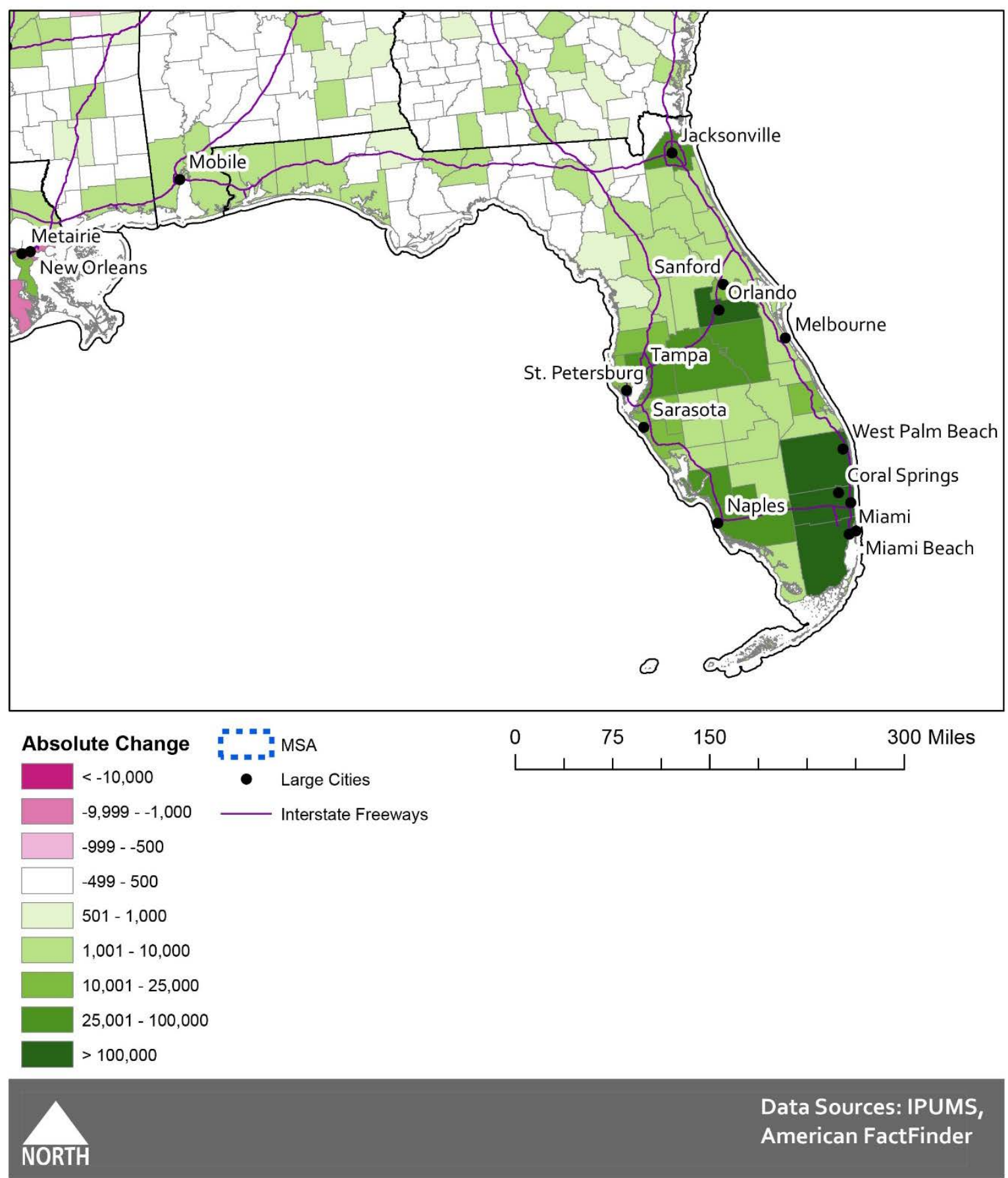

Figure B- 29. Population with Limited English Proficiency Absolute Change: 1990-2010, Florida. 


\section{Population with Limited English Proficiency Percent Change:}

$1990-2010$

Florida

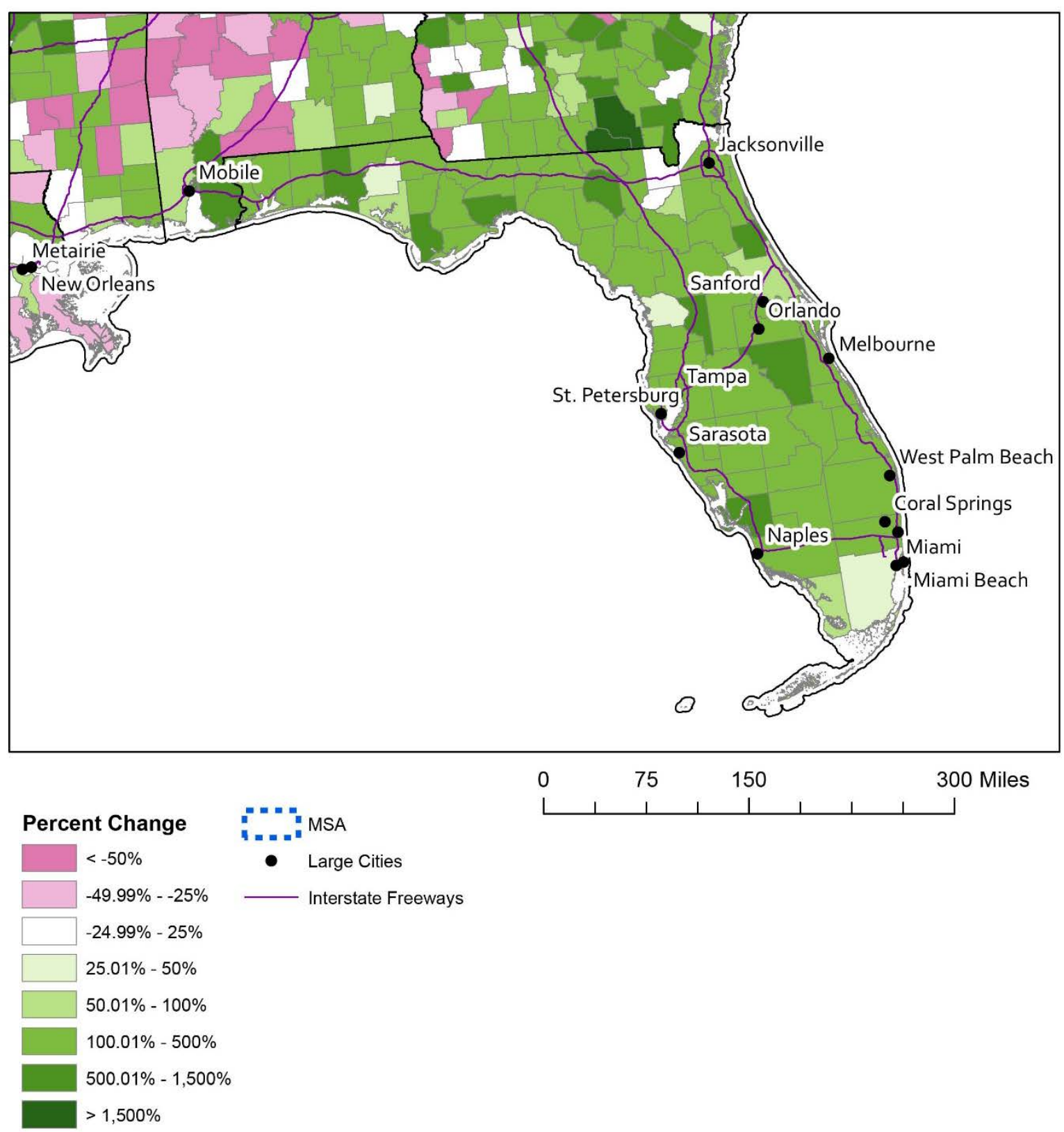

NORTH

Data Sources: IPUMS,

American FactFinder

Figure B-30. Population with Limited English Proficiency Percent Change: 1990-2010, Florida. 
Office of Planning, Environment \& Realty

Federal Highway Administration

1200 New Jersey Ave, SE

Washington, DC 25090

https://www.fhwa.dot.gov/hep

2

U.S.Department of Transportation

Federal Highway Administration 